\title{
Segmentação de vasos sangüíneos em imagens de retina usando wavelets e classificadores estatísticos
}

\section{João Vitor Baldini Soares}

\author{
DisSERTAÇÃo APRESENTADA \\ $\mathrm{AO}$ \\ Instituto De Matemática E EstatísticA \\ DA \\ UNIVERSIDADE DE SÃO PAULO \\ PARA \\ obtenção Do Grau De Mestre \\ EM \\ CIÊNCIAS \\ Área de Concentração: Ciência da Computação \\ Orientador: Prof. Dr. Roberto Marcondes Cesar Junior
}

São Paulo, julho de 2007

O autor recebeu apoio do CNPq, processo 131403/2004-4, durante a elaboração deste trabalho 



\section{Segmentação de vasos sangüíneos em imagens de retina usando wavelets e classificadores estatísticos}

Este exemplar corresponde à redação final da dissertação devidamente corrigida e defendida por João Vitor Baldini Soares e aprovada pela Comissão Julgadora.

São Paulo, 20 de julho de 2007.

Banca Examinadora:

Prof. Dr. Roberto Marcondes Cesar Junior (orientador) - IME-USP

Prof. Dr. Marcel Parolin Jackowski - IME-USP

Prof. Dr. Alexandre Xavier Falcão - IC-UNICAMP 



\section{Resumo}

Esta dissertação apresenta o desenvolvimento e avaliação de um método para a segmentação de vasos sangüíneos em imagens de retina, em que se usa a transformada wavelet contínua bidimensional combinada com classificação supervisionada. A segmentação dos vasos é a etapa inicial para a análise automática das imagens, cujo objetivo é auxiliar a comunidade médica na detecção de doenças. Entre outras doenças, as imagens podem revelar sinais da retinopatia diabética, uma das principais causas de cegueira em adultos, que pode ser prevenida se detectada em um diagnóstico precoce. A abordagem apresentada consiste na geração de segmentações pela classificação supervisionada de pixels nas classes vaso e não vaso. As características usadas para classificação são obtidas através da transformada wavelet contínua bidimensional usando a wavelet de Gabor. Resultados são avaliados nos bancos públicos DRIVE e STARE de imagens coloridas através da análise ROC (receiver operating characteristic, ou característica de operação do receptor). O método atinge áreas sob curvas ROC de 0.9614 e 0.9671 nos bancos DRIVE e STARE, respectivamente, ligeiramente superiores àquelas apresentadas por outros métodos do estado da arte. Apesar de bons resultados ROC, a análise visual revela algumas dificuldades do método, como falsos positivos ao redor do disco óptico e de patologias. A wavelet de Gabor mostra-se eficiente na detecção dos vasos, superando outros filtros lineares. Bons resultados e uma classificação rápida são obtidos usando o classificador bayesiano em que as funções de densidade de probabilidade

condicionais às classes são descritas por misturas de gaussianas. A implementação do método está disponível na forma de scripts código aberto em MATLAB para pesquisadores interessados em detalhes de implementação, avaliação ou desenvolvimento de métodos. 


\section{Abstract}

This dissertation presents the development and evaluation of a method for blood vessel segmentation in retinal images which combines the use of the two-dimensional continuous wavelet transform with supervised classification. Segmentation of the retinal vasculature is the first step towards automatic analysis of the images, aiming at helping the medical community in detecting diseases. Among other diseases, the images may reveal signs of diabetic retinopathy, a leading cause of adult blindness, which can be prevented if identified early enough. The presented approach produces segmentations by supervised classification of each image pixel as vessel or nonvessel, with pixel features derived using the two-dimensional continuous Gabor wavelet transform. Results are evaluated on publicly available DRIVE and STARE color image databases using ROC (receiver operating characteristic) analysis. The method achieves areas under ROC curves of 0.9614 and 0.9671 on the DRIVE and STARE databases, respectively, being slightly superior than that presented by state-of-the-art approaches. Though good ROC results are presented, visual inspection shows some typical difficulties of the method, such as false positives on the borders of the optic disc and pathologies. The Gabor wavelet shows itself efficient for vessel enhancement, outperforming other linear filters. Good segmentation results and a fast classification phase are obtained using the Bayesian classifier with class-conditional probability density functions described as Gaussian mixtures. The method's implementation is available as open source MATLAB scripts for researchers interested in implementation details, evaluation, or development of methods. 


\section{Sumário}

\begin{tabular}{lll}
\hline 1 & Introdução & 1
\end{tabular}

1.1 Comentários preliminares $\ldots \ldots \ldots \ldots \ldots \ldots \ldots \ldots \ldots$

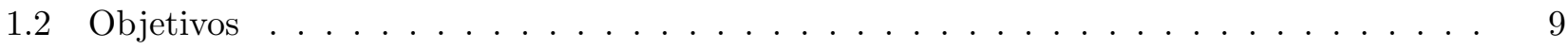

1.3 Contribuições $\ldots \ldots \ldots \ldots \ldots \ldots \ldots \ldots \ldots \ldots \ldots$

1.4 Organização do texto $\ldots \ldots \ldots \ldots \ldots \ldots \ldots \ldots$

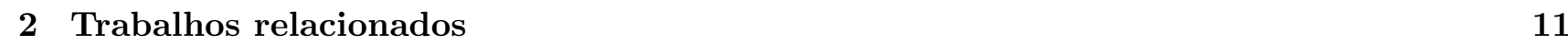

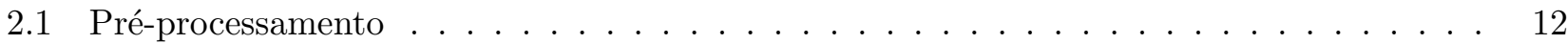

2.2 Detecção local dos vasos $\ldots \ldots \ldots \ldots \ldots \ldots \ldots \ldots$

2.2 .1 Modelos de vaso $\ldots \ldots \ldots \ldots \ldots \ldots \ldots$

2.2 .2 Limiarização $\ldots \ldots \ldots \ldots \ldots \ldots \ldots \ldots \ldots$

2.2 .3 Filtros casados $\ldots \ldots \ldots \ldots \ldots \ldots \ldots \ldots \ldots$

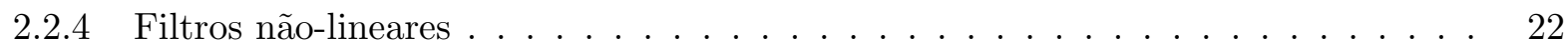

$2.2 .5 \quad$ Avaliação de curvatura $\ldots \ldots \ldots \ldots \ldots \ldots$. . . . . . . . . . . . . . . 24

2.2 .6 Avaliação de bordas $\ldots \ldots \ldots \ldots \ldots \ldots \ldots$

2.2 .7 Classificação supervisionada $\ldots \ldots \ldots \ldots \ldots$. . . . . . . . . . . . . . 27

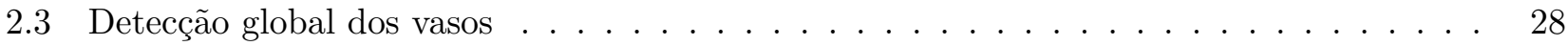

2.3 .1 Rastreamento . . . . . . . . . . . . . . . . . . . . . . . 29

$2.3 .2 \quad$ Crescimento de regiões $\ldots \ldots \ldots \ldots \ldots$

2.3 .3 Modelos deformáveis . . . . . . . . . . . . . . . . . . . . . . . . . 31 
2.3 .4 Inferência bayesiana de árvores $\ldots \ldots \ldots \ldots \ldots$. . . . . . . . . . 32

2.4 Contextualização da abordagem proposta $\ldots \ldots \ldots \ldots \ldots \ldots$. . . . . . . . . . 32

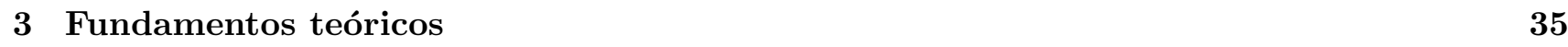

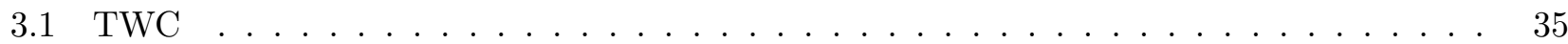

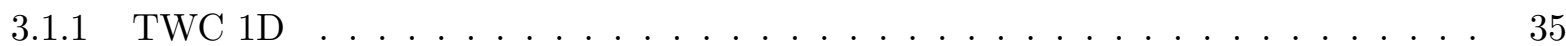

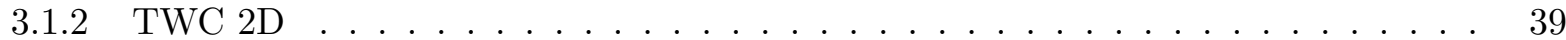

3.1 .3 Wavelet $2 \mathrm{D}$ de Gabor $\ldots \ldots \ldots \ldots \ldots$

3.1 .4 Outras wavelets $2 \mathrm{D} \ldots \ldots \ldots \ldots \ldots \ldots$

3.2 Classificação supervisionada $\ldots \ldots \ldots \ldots \ldots$

$3.2 .1 \quad$ Teoria de decisão bayesiana $\ldots \ldots \ldots \ldots$. . . . . . . . . . . . 5 50

$3.2 .2 \quad$ Classificador bayesiano usando modelos de mistura gaussiana . . . . . . . . . . 53

$3.2 .3 \quad$ Classificador dos $k$ vizinhos mais próximos $\ldots \ldots \ldots \ldots$. . . . . . . . . 60

3.2.4 Classificador linear de erro quadrático mínimo . . . . . . . . . . . . . . . 61

4 Segmentação usando wavelets e classificadores estatísticos 63

4.1 Pré-processamento $\ldots \ldots \ldots \ldots \ldots \ldots \ldots \ldots$

4.2 Detecção usando a wavelet $2 \mathrm{D}$ de Gabor $\ldots \ldots \ldots \ldots$. . . . . . . . . . . 66

4.3 Normalização de características . . . . . . . . . . . . . . . . . . . . . . 70

4.4 Classificação supervisionada de pixels $\ldots \ldots \ldots \ldots$. . . . . . . . . . . . . . 70

$4.5 \quad$ Avaliação experimental . . . . . . . . . . . . . . . . . . . . . . . . . 72

4.5 .1 Bancos de imagens . . . . . . . . . . . . . . . . . . . . 72

$4.5 .2 \quad$ Experimentos e configurações $\ldots \ldots \ldots \ldots$. . . . . . . . . . . . 73

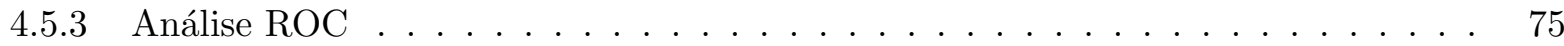

4.6 Implementação e protótipo de interface gráfica $\quad \ldots \ldots \ldots$. . . . . . . . . . . . . . . 79

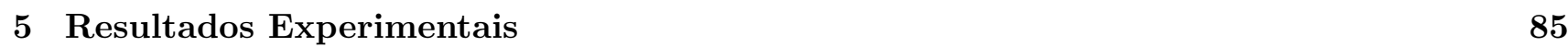


\begin{tabular}{llr}
\hline 6 & Conclusão & 95
\end{tabular}

6.1 Comentários finais $\ldots \ldots \ldots \ldots \ldots \ldots \ldots \ldots \ldots$

6.2 Trabalhos futuros $\ldots \ldots \ldots \ldots \ldots \ldots \ldots \ldots$

\begin{tabular}{|lr}
\hline A Publicações & 103
\end{tabular}

A.1 Comparison of various methods to delineate blood vessels in retinal images . . . . . . . . 103

A.2 Development of retinal blood vessel segmentation methodology using wavelet transforms for assessment of diabetic retinopathy. . . . . . . . . . . . . . . . . . . . . . . . . . 109

A.3 Using the 2-D Morlet wavelet with supervised classification for retinal vessel segmentation 123

A.4 Retinal vessel segmentation using the 2-D Gabor wavelet and supervised classification . . 135

\begin{tabular}{lr}
\hline Referências Bibliográficas & 146
\end{tabular} 


\section{Lista de Figuras}

1.1 Imagens de retina obtidas de diferentes formas $\ldots \ldots \ldots \ldots$

$1.2 \quad$ Diagramas apresentando as principais estruturas do fundo do olho . . . . . . . . . . . . 4

1.3 Imagens de retinas apresentando anomalias $\ldots \ldots \ldots \ldots \ldots$

$2.1 \quad$ Detalhes e cortes de imagens apresentando perfis de vasos $\ldots \ldots \ldots$. . . . . . . . . 17

2.2 Esquema apresentando as medidas usadas na sondagem de limiarizações para segmentação

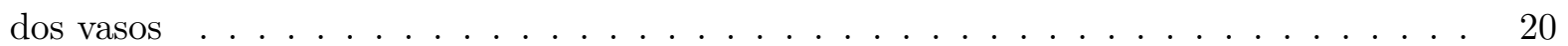

$2.3 \quad$ Representação em superfícies de dois filtros casados $2 \mathrm{D} \ldots \ldots \ldots$. . . . . . . . . . . . . 22

3.1 A wavelet 2D de Gabor no domínio espacial e de freqüências espaciais . . . . . . . . . . 45

3.2 O chapéu mexicano no domínio espacial e de freqüências espaciais . . . . . . . . . . . . 49

3.3 Exemplo de execução do algoritmo EM. . . . . . . . . . . . . . . . . . . . . . . 58

4.1 Esquema geral da abordagem adotada . . . . . . . . . . . . . . . . . . . . 64

4.2 Canais vermelho, verde e azul de uma imagem colorida . . . . . . . . . . . . . . . 66

4.3 Pré-processamento para remoção de efeitos de borda ～. . . . . . . . . . . . . . . . . . 67

4.4 A wavelet 2D de Gabor em diferentes representações $\ldots \ldots \ldots$. . . . . . . . . . . . . 68

4.5 Ilustração do módulo máximo da transformada wavelet de Gabor sobre todos os ângulos 69

4.6 Espaço de características com amostras rotuladas . . . . . . . . . . . . . . . . . . 71

4.7 Imagens dos bancos DRIVE e STARE acompanhadas de suas respectivas segmentações

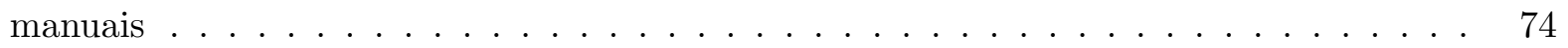


4.8 Exemplos de gráficos ROC ilustrando propriedades $\ldots \ldots \ldots$. . . . . . . . . . . 78

4.9 Resultados ilustrativos de segmentação em HTML gerados pelo software . . . . . . . . . 81

4.10 Tabela ilustrativa em HTML gerada pelo software, contendo estatísticas . . . . . . . . . 82

4.11 Exemplo de uso da interface gráfica $\ldots \ldots \ldots \ldots$. . . . . . . . . . . 83

5.1 Resultados ilustrativos no banco DRIVE . . . . . . . . . . . . . . . . . 86

5.2 Resultados ilustrativos no banco STARE . . . . . . . . . . . . . . . . . . . . 87

5.3 Resultados ilustrativos produzidos treinando o classificador MMG em cada uma dos bancos DRIVE e STARE e testando no outro . . . . . . . . . . . . . . . . . . . . . 88

5.4 Curvas ROC para resultados no banco DRIVE $\ldots \ldots \ldots \ldots$. . . . . . . . . . . . . 90

5.5 Curvas ROC para resultados no banco STARE $\ldots \ldots \ldots \ldots$. . . . . . . . . . 91 


\section{Lista de Tabelas}

2.1 Relação de métodos de segmentação de vasos de trabalhos relacionados . . . . . . . . . . 13

4.1 Matriz de confusão para avaliação de métodos $\ldots \ldots \ldots \ldots$. . . . . . . . . 76

$5.1 \quad A_{z}$ e acurácia para os diferentes classificadores testados $\ldots \ldots \ldots$. . . . . . . 89

$5.2 \quad A_{z}$ e acurácia para diferentes métodos de segmentação . . . . . . . . . . . . . . . 90 


\section{Lista de Siglas}

$1 \mathrm{D}$

$2 \mathrm{D}$

$\mathrm{DM}$

DRIVE

EM

HSI

$k \mathrm{NN}$

LEQM

MMG

$\mathrm{RD}$
Unidimensional

Bidimensional

Diabete melito

Digital retinal images for vessel extraction

Expectation-Maximization

Do inglês hue, saturation e intensity: matiz, saturação e intensidade

Do inglês $k$ nearest neighbors, ou $k$ vizinhos mais próximos

Linear de erro quadrático mínimo (em referência ao classificador)

Modelo de mistura gaussiana (também usado em referência ao classificador bayesiano que usa o modelo)

Retinopatia diabética 
RDNP

RDP

RGB

ROC

STARE

$\mathrm{TF}$

TWC

TWD
Retinopatia diabética não proliferativa

Retinopatia diabética proliferativa

Do inglês red, green e blue: vermelho, verde e azul

Do inglês receiver operating characteristic: característica de operação do receptor

Structured analysis of the retina

Transformada de Fourier

Transformada wavelet contínua

Transformada wavelet discreta 


\title{
Lista de Símbolos
}

\author{
$\mathbb{R}^{2}$ \\ O plano real $\mathbb{R} \times \mathbb{R}$ \\ $\mathbf{x}, \mathbf{b}$ \\ Vetores em $\mathbb{R}^{2}$ representando posições espaci- \\ ais \\ $L^{2}\left(\mathbb{R}^{2}\right)$ \\ Espaço das funções de energia finita (quadra- \\ ticamente integráveis) sobre $\mathbb{R}^{2}$ \\ $f$ \\ Sinal unidimensional $f \in L^{2}(\mathbb{R})$ ou bidimensi- \\ onal $f \in L^{2}\left(\mathbb{R}^{2}\right)$, representando uma imagem \\ $\psi$ \\ Função em $L^{2}(\mathbb{R})$ ou $L^{2}\left(\mathbb{R}^{2}\right)$ representando \\ a wavelet protótipo (também chamada de \\ wavelet mãe ou analisadora) \\ $\hat{f}, \hat{\psi}$ \\ Transformadas de Fourier de $f$ e $\psi$ \\ $i$ \\ $\sqrt{-1}$ \\ $\mathbf{k}$ \\ Vetor em $\mathbb{R}^{2}$ representando uma freqüência \\ espacial \\ Ângulo de rotação de uma wavelet
}


$a$

$\psi_{\mathbf{b}, a, \theta}$

$r_{\theta}$

$G$

$L^{2}(G)$

$T_{\psi}$

$c_{\psi}$

$K$

$\psi_{G}$

$\mathbf{k}_{\mathbf{0}}$

A
Escala de uma wavelet, ou, equivalentemente, o parâmetro de dilatação

Wavelet protótipo transladada de $\mathbf{b}$, dilatada por $a$ e rotacionada em $\theta$

Rotação por $\theta$

Grupo euclidiano 2D com dilatações atuando sobre $L^{2}\left(\mathbb{R}^{2}\right)$, definido pelas operações de translação, rotação e dilatação

Espaço de funções de energia finita sobre $G$, contendo as transformadas wavelet contínuas bidimensionais

Transformada wavelet contínua usando a wavelet protótipo $\psi$

Constante de normalização para a wavelet $\psi$

Núcleo reprodutor da transformada wavelet contínua

A wavelet bidimensional de Gabor

Freqüência da wavelet protótipo de Gabor

Matriz definindo o alongamento das wavelets de Gabor e chapéu mexicano 
$B$

$\psi^{*}$

$M_{\psi}$

$C_{1}$

$C_{2}$

$\mathbf{v}$

$d$

$P\left(C_{i} \mid \mathbf{v}\right)$

$p\left(\mathbf{v} \mid C_{i}\right)$

$P\left(C_{i}\right)$

$p(\mathbf{v})$
$B=A^{-1}$, matriz definindo o alongamento das wavelets de Gabor e chapéu mexicano no domínio de freqüências espaciais

Coeficiente que define as matrizes de alongamento $A$ e $B$ das wavelets

Conjugado complexo de $\psi$

Módulo máximo da transformada wavelet contínua sobre todos os ângulos em função da posição b e escala $a$, usando a wavelet mãe $\psi$ Classe de pixels pertencentes a vasos

Classe de pixels não pertencentes a vasos

Vetor em $\mathbb{R}^{d}$, representando as características de um pixel

Dimensão do espaço de características

Probabilidade posterior da classe $C_{i}$, dado o vetor de características $\mathbf{v}$

Função de densidade de probabilidade de $\mathbf{v}$ condicional à classe $C_{i}$, também chamada de verossimilhança

Probabilidade a priori da classe $C_{i}$

Função de densidade de probabilidade de $\mathbf{v}$, também chamada de evidência 
$\alpha_{i}$

$\lambda\left(\alpha_{i} \mid C_{j}\right)$

$c$

$N$

$N_{i}$

$\boldsymbol{\mu}_{j}$

$\Sigma_{j}$

$P_{j}$

$\phi_{j}$

$\phi$

$\mathcal{D}$

$M$
A decisão de escolher a classe $C_{i}$ para dada amostra

A perda decorrente de tomar a decisão $\alpha_{i}$ para uma amostra da classe $C_{j}$

Número de gaussianas modelando a verossimilhança de uma classe

Número total de amostras de treinamento

Número de amostras de treinamento com o rótulo da classe $C_{i}$

Média da gaussiana $j$ no MMG

Matriz de covariância da gaussiana $j$ no MMG

Peso da gaussiana $j$ no MMG

$\phi_{j}=\left\{\boldsymbol{\mu}_{j}, \Sigma_{j}\right\}$, os parâmetros que descrevem a gaussiana $j$ no MMG

$\phi=\left\{\phi_{1}, \ldots, \phi_{c}, P_{1}, \ldots, P_{c}\right\}$, o conjunto de parâmetros que descreve completamente um MMG

Conjunto de dados observados de uma classe, usado no EM para estimação de um MMG

O tamanho do conjunto $\mathcal{D}$, isto é, o número de amostras usadas no EM para estimação de um MMG 
$\mathcal{J}$

$\mathcal{C}$

$Q$

$k$

$k_{i}$

$g(\mathbf{v})$

w

$w_{0}$

$p$

$n$

$v p$

$f p$

$v n$

fn
Conjunto de rótulos dos dados observados $\mathcal{D}$, indicando a gaussiana de cada amostra no MMG

$\mathcal{C}=\{\mathcal{D}, \mathcal{J}\}$, o conjunto de dados completos usados no EM para estimação de um MMG

Esperança da log-verossimilhança dos dados usada no EM

Número de vizinhos analisados pelo classificador $k \mathrm{NN}$

Número de vizinhos de uma amostra que pertencem à classe $C_{i}$

Função linear de decisão do classificador LEQM

Vetor de pesos da função linear de decisão

Limiar da função linear de decisão

Número de amostras positivas na referência

Número de amostras negativas na referência

Número de verdadeiros positivos

Número de falsos positivos

Número de verdadeiros negativos

Número de falsos negativos 
Taxa de verdadeiros positivos

Taxa de falsos positivos

$A_{z}$

Área sob a curva ROC

Número de pixels de uma imagem 


\section{Capítulo 1}

\section{Introdução}

\subsection{Comentários preliminares}

A análise de imagens de fundo de olho (Figura 1.1) é muito usada pela comunidade médica para diagnóstico de doenças oculares ou doenças que tenham efeitos globais sobre a vasculatura do corpo. A inspeção dos vasos do fundo do olho pode revelar sinais de hipertensão, diabetes, arteriosclerose e doenças cardiovasculares Kanski, 1989. A segmentação dos vasos serve como etapa inicial para a análise automática da vasculatura e também para o registro de imagens. A análise automática da morfologia dos vasos poderá ser aplicada em uma ferramenta de triagem para a detecção da retinopatia diabética, como explicado a seguir. Por sua vez, o registro de imagens pode ser usado em detecção de mudanças, construção de mosaicos de fundo e localização espacial (ou rastreamento) em tempo real para auxílio em cirurgias.

Existem diferentes formas de obter imagens de fundo de olho. Os tipos comuns de câmeras (também chamadas de microscópios ou retinógrafos) são midriáticas ou não midriáticas. Instrumentos midriáticos são projetados assumindo que os olhos foram dilatados pelo uso de colírios, ao contrário dos não midriáticos, que não requerem dilatação. Os midriáticos produzem imagens de melhor qualidade devido ao maior campo de vista proporcionado pela dilatação, enquanto os não midriáticos são mais adequados a programas de triagem ou quando a dilatação é problemática ou impossível. A aquisição das imagens pode ser por fotografia colorida (Figuras 1.1(c) e 1.1(d) , monocromática ou por técnicas de angiografia 
usando corantes fluorescentes. Na fotografia monocromática, filtros de cor são usados para realçar determinadas estruturas do fundo. A fotografia monocromática mais utilizada é a aneritra (red-free), pois deixa vasos da retina, hemorragias e exsudatos mais aparentes (Figura 1.1(b)). As angiografias, por sua vez, requerem a injeção de uma pequena quantidade de corante no paciente, iluminação e câmeras específicas. Fluoresceína sódica e verde indocianina são os corantes mais usados. As angiografias de fluoresceína evidenciam os vasos e fluxo sangüíneo e possíveis vazamentos (Figura 1.1(a)], mas não são adequadas a programas de triagem, uma vez que exigem a presença de um oftalmologista e um fotógrafo e são invasivas, apresentando um certo risco de efeitos colaterais ao paciente.

Dados os diferentes modos de aquisição, é desejável que os métodos de segmentação sejam aplicáveis às diferentes modalidades de imagens. Além disso, tem-se a dificuldade adicional de que mesmo imagens de mesma modalidade apresentam variabilidade de acordo com o paciente, presença de patologias, modelo de câmera utilizado, ajustes de foco, campo de vista e iluminação. Imagens com fortes variações ou deficiência de iluminação, reflexos luminosos sob a córnea ou foco inadequado são comuns e, dependendo da aplicação, devem ser tratadas, o que apresenta uma dificuldade adicional ao desenvolvimento dos métodos Fritzsche et al., 2003.

Os vasos sangüíneos do fundo do olho estão dispostos em várias camadas e têm como funções o fornecimento de nutrientes e oxigênio ao fundo e a ajuda na eliminação de resíduos metabólicos. A camada superior dos vasos (aqui chamada de vasculatura da retina, ou retínica) pode ser vista com facilidade. Ela está disposta na forma de duas redes complexas - uma de veias e outra de artérias - que surgem da região do disco óptico e bifurcam sucessivamente ao ocuparem as demais regiões da retina, como ilustrado nas Figuras 1.1 e 1.2. É possível distinguir a rede de artérias da de veias nas imagens: na Figura 1.1(a), as artérias aparecem como completamente iluminadas (mais claras), enquanto apenas as bordas das veias mais grossas estão aparentes, devido ao momento em que foi registrado o angiograma; na Figura 1.1(b), as artérias mostram-se mais claras e com um reflexo central mais acentuado. O disco óptico, que pode ser visto como a estrutura mais clara nas Figuras 1.1(b), 1.1(c) e 1.1(d), corresponde à região em que fibras nervosas se reúnem para formar parte do nervo óptico. A região mais escura, localizada no centro das imagens da Figura 1.1, é a mácula, que contém a fóvea (região de maior 


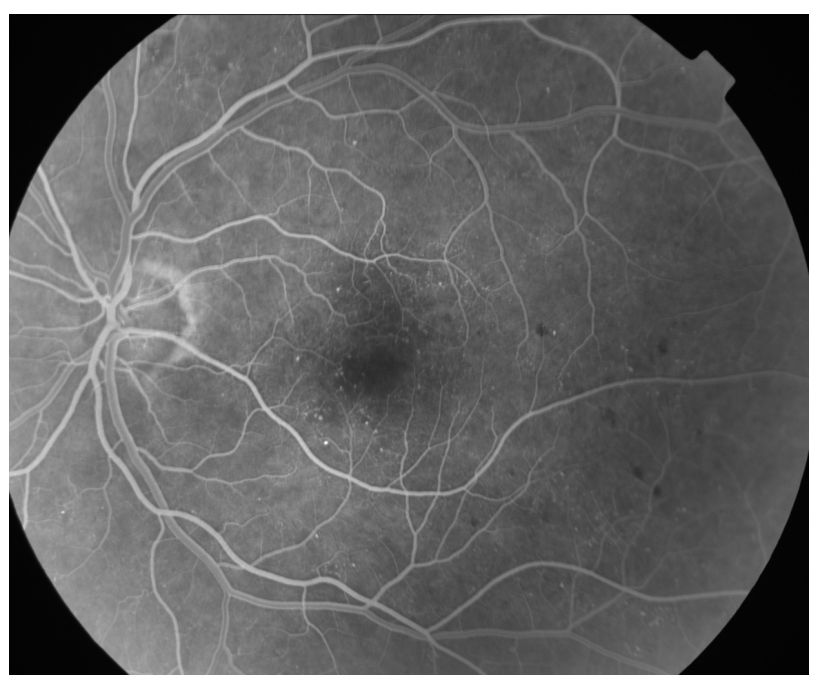

(a) Imagem de angiografia fluoresceínica.

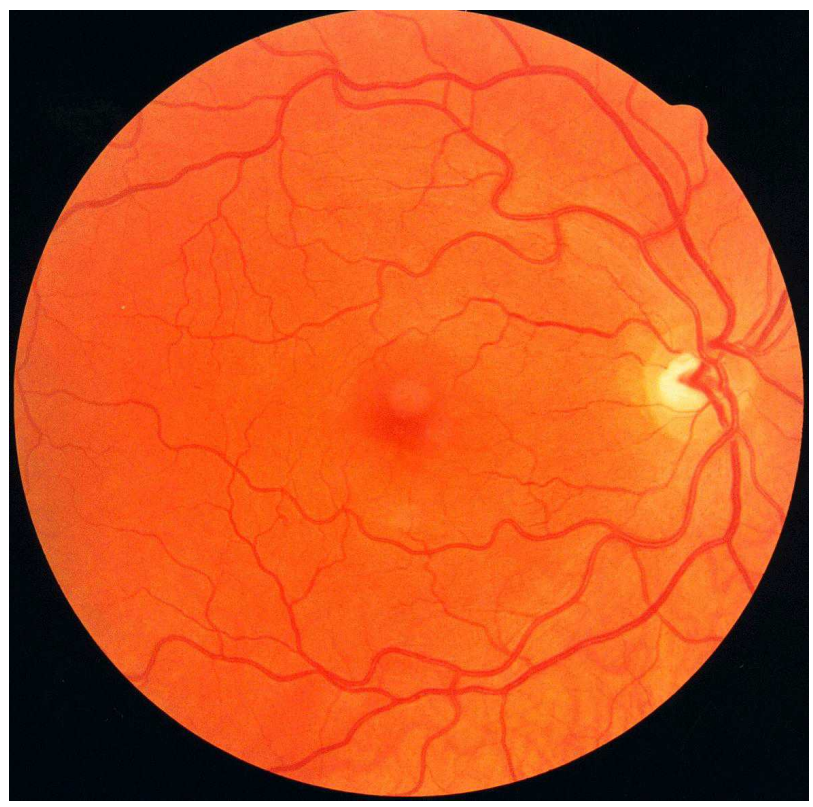

(c) Fotografia colorida de um olho direito.

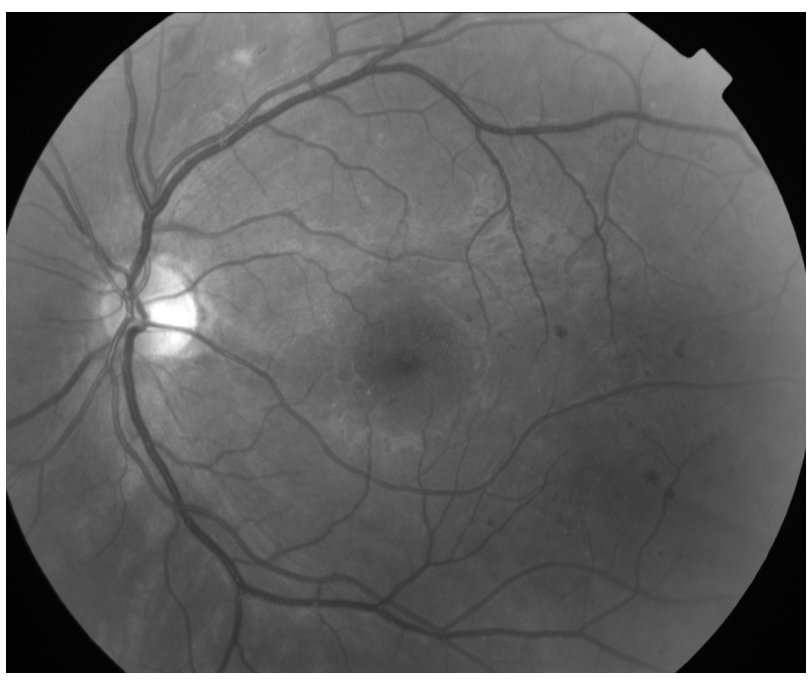

(b) Fotografia aneritra do mesmo olho que em 1.1(a)

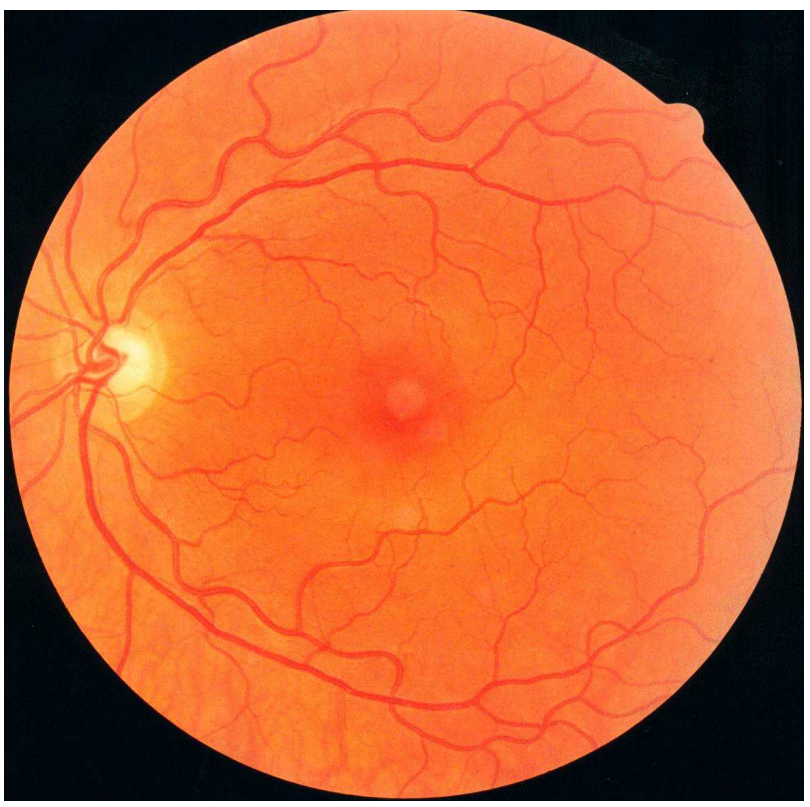

(d) Fotografia colorida de um olho esquerdo.

Figura 1.1: Exemplos de imagens de retina obtidas de diferentes formas: através de angiografia fluoresceínica, fotografia aneritra e fotografia colorida. 


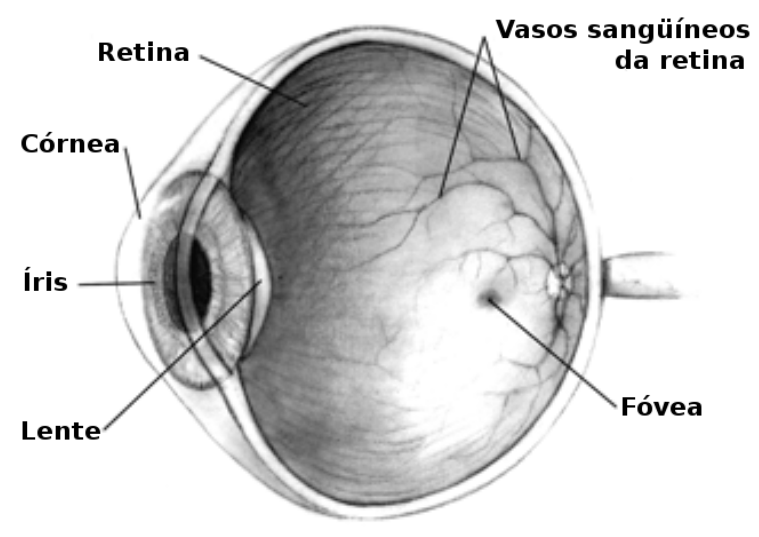

(a) Diagrama apresentando as principais estruturas do olho. Imagem adaptada de U.S. National Eye Institute, 2006.

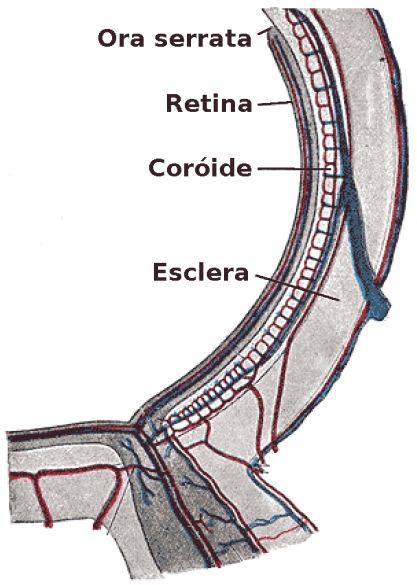

(b) Diagrama de seção horizontal do olho destacando veias e artérias. Imagem adaptada de Gray, 1918.

Figura 1.2: Diagramas apresentando as principais estruturas e vasos sangüíneos do fundo do olho.

acuidade visual) e é livre de vasos sangüíneos.

O diabetes e complicações associadas foram identificados como um problema de saúde pública mundial significante e crescente [Taylor e Keeffe, 2001]. Estima-se que 2,8\% da população mundial tinha diabetes no ano 2000, projetado para 4,4\% em 2030 [Wild et al., 2004]. Uma das complicações mais importantes do diabetes é a retinopatia diabética (RD), a principal causa de novos casos de cegueira entre norte-americanos nas idades de 20 a 64 anos, causando mais de 10.000 novos casos de cegueira a cada ano American Diabetes Association, 2006]. No Brasil, estima-se que 7,6\% da população urbana entre 30 e 69 anos apresente diabete melito (DM), dos quais 46\% dos casos não se sabem portadores Malerbi e Franco, 1992]. Dos brasileiros portadores de DM, metade é afetada pela RD, responsável por 7,5\% das causas de incapacidade de adultos para o trabalho Ministério da Saúde, 2000 e por 4,58\% das deficiências visuais Schellini et al., 1994]. Além disso, após 20 anos de duração de DM, a RD ocorre em 99\% dos pacientes com DM tipo 1 (insulino-dependente) e em $60 \%$ dos pacientes com DM tipo 2 (não insulino-dependente), sendo $20 \%$ do tipo proliferativo Boelter et al., 2003.

Retinopatia diabética $(\mathrm{RD})$ denomina o conjunto de alterações retínicas e vítreas causadas pelo 
diabetes. A RD causa alterações aos vasos retínicos como aumento de permeabilidade, dilatação/estreitamento e surgimento de novos vasos, alterando também a estrutura e distribuição vascular, como ilustrado na Figura 1.3. As alterações da retina decorrentes da RD apresentam estágios evolutivos característicos American Academy of Ophthalmology, 2000, Corrêa e Eagle, 2005]:

1. RD não proliferativa (RDNP) mínima e leve: no estágio inicial, observam-se microaneurismas capilares (pequenas áreas de inchaço) e podem ocorrer algumas hemorragias dispersas (Figura 1.3(b)).

2. RDNP moderada: com o decorrer da doença, aparecem hemorragias moderadas e podem surgir exsudatos duros (fluidos normalmente acompanhados de lipídios, que vazam dos capilares e acumulam-se na retina) ou manchas algodonosas (lesões de aspecto algodonoso causadas pelo infarto de fibras nervosas, também conhecidas como exsudatos moles).

3. RDNP grave e muito grave: podem ocorrer hemorragias severas, veias em rosário (apresentando dilatações segmentadas) e anormalidades microvasculares. Também podem aparecer áreas de infarto retínico com isquemia progressiva, possivelmente acompanhadas de manchas algodonosas.

4. RD proliferativa (RDP) de baixo risco: nesse estágio avançado, ocorre neovascularização (formação de novos vasos) na retina (Figura 1.3(c) ou na íris. Os neovasos são frágeis e sujeitos a hemorragias. Sua formação é provavelmente estimulada pela liberação de um fator angiogênico produzido pela retina isquêmica. Manchas algodonosas tornam-se proeminentes.

5. RDP de alto risco: ocorrem neovasos intensos ao redor do disco óptico e/ou hemorragia pré-retínica ou vítrea acompanhada de neovasos.

Em qualquer estágio da RD pode ocorrer edema macular, caracterizado pelo acúmulo de fluidos e espessamento da retina nas regiões periféricas da mácula devido a vazamentos dos vasos e que pode resultar na diminuição da acuidade visual. A cegueira está associada à RDP devido a complicações como hemorragia pré-retínica ou vítrea e descolamento tracional de retina.

Até em estágios avançados, a RD pode não apresentar perda da acuidade visual, fazendo com que muitos pacientes permaneçam sem diagnóstico. Tão logo tenha sido diagnosticado o diabetes, o paciente 


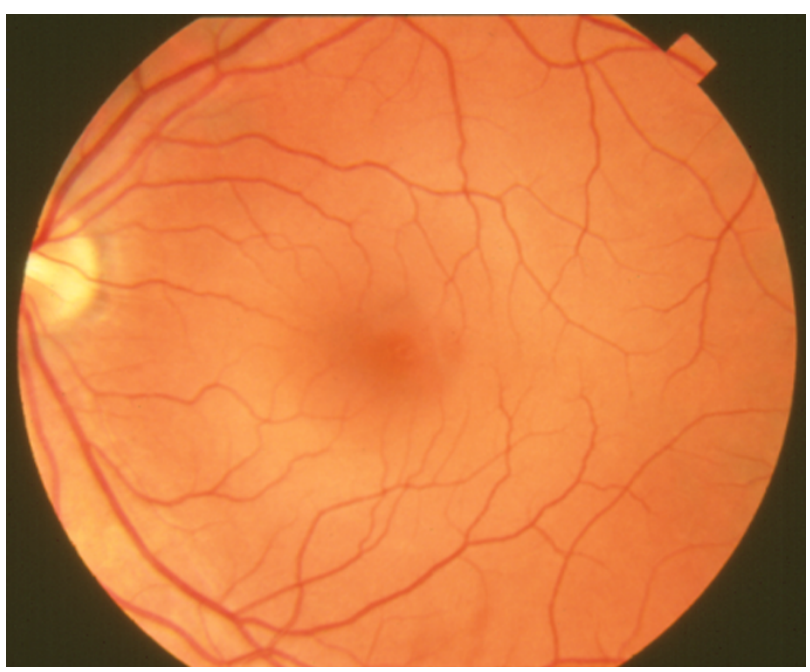

(a) Retina normal. Imagem cortesia de U.S. National Eye Institute, 2006.

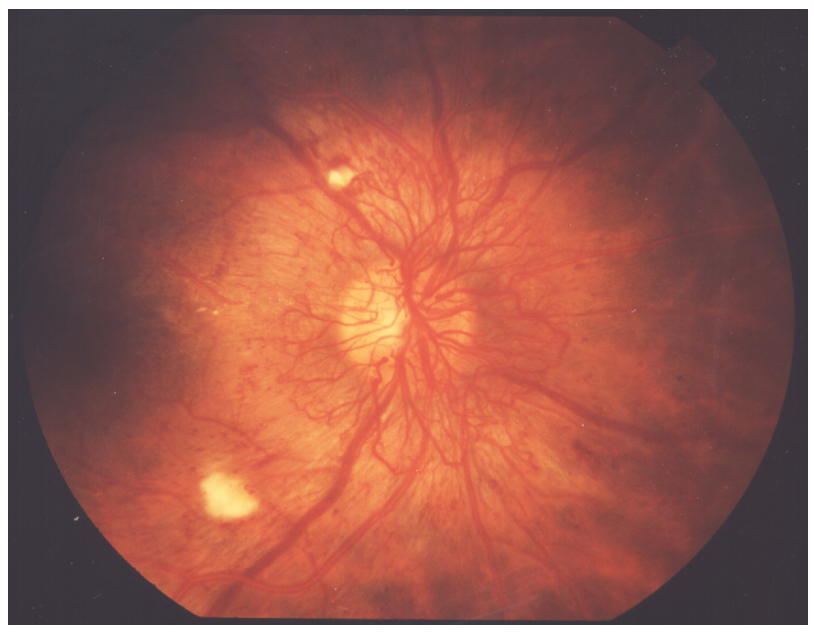

(c) Retina apresentando neovascularização no disco óptico, causada pela RDP. Imagem cortesia de U.S. National Eye Institute, 2006.

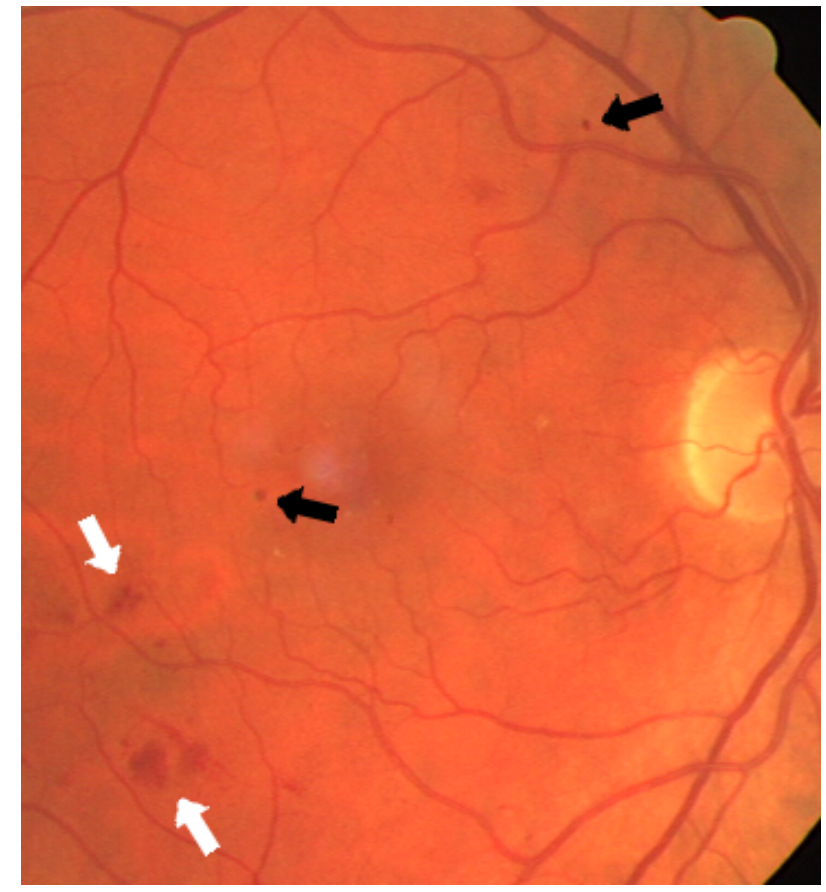

(b) Detalhe ilustrando microaneurismas (setas pretas) e hemorragias (setas brancas).

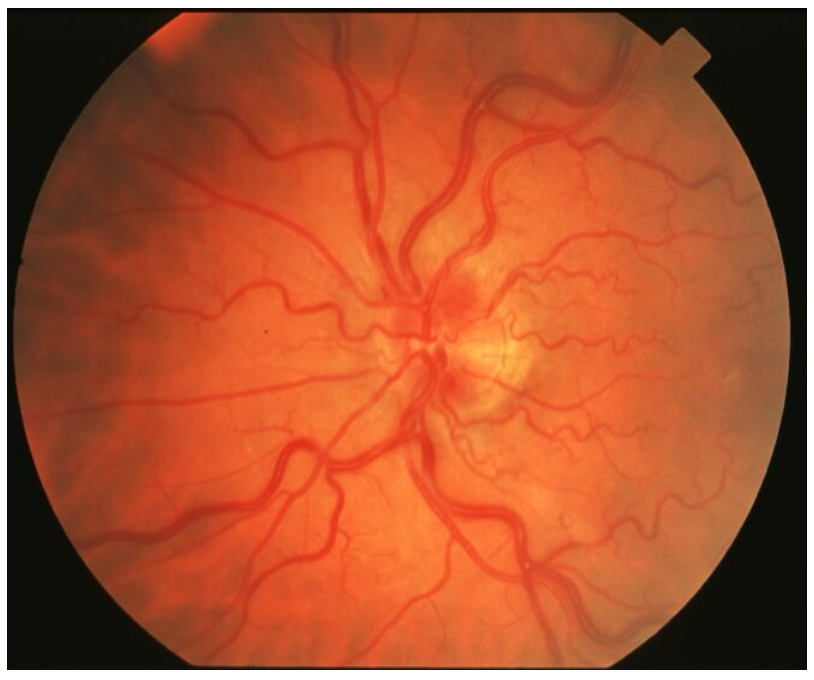

(d) Retina apresentando vasos tortuosos.

Figura 1.3: Imagens de retinas apresentando anomalias. 
deverá ser examinado para RD e reexaminado anualmente caso não apresente sinais da doença. Caso a RD seja diagnosticada, a freqüência de exames aumenta de acordo com o estágio da doença American Academy of Ophthalmology, 2000]. A detecção precoce de alterações na estrutura vascular pode evitar perdas visuais ao permitir intervenções médicas [Taylor e Keeffe, 2001]. Assim, esforços para reduzir o número de pessoas seriamente afetadas pela RD envolvem a obtenção e análise de um grande número de imagens de fundo de olho de pacientes diabéticos. A identificação de anomalias requer uma trabalhosa inspeção por especialistas e as imagens normalmente não apresentam anomalias nas primeiras inspeções. Estudos que acompanharam trabalhadores da saúde mostraram que a taxa de detecção (sensibilidade) da RDP por não especialistas da retina (incluindo especialistas em medicina interna, em diabetes e médicos residentes) era de aproximadamente 50\%. Essa sensibilidade diminuiu na presença de obstruções ou para a detecção de estágios iniciais de proliferação [Sussman et al., 1982].

Tendo em vista essas dificuldades, um passo importante para a redução do número de pessoas seriamente afetadas pela RD é simplificar o procedimento de diagnóstico da doença, garantindo que exames se tornem rotina para diabéticos. A triagem de pacientes, especialmente em comunidades rurais ou remotas, pode ser difícil devido ao isolamento geográfico e econômico aliado ao custo de visitas a especialistas e à falta de oftalmologistas disponíveis [Lee et al., 2001]. A introdução de uma forma simples e econômica de avaliar quantitativamente a saúde da retina que alcance regiões rurais e remotas proveria suporte a trabalhadores de saúde não especializados. Assim, métodos computacionais para a análise das imagens vêm sendo desenvolvidos para que, após uma triagem preliminar, apenas os pacientes que apresentassem indicativos de RD fossem encaminhados para a análise por um oftalmologista.

A triagem para detecção da RD envolve a avaliação da retina com atenção em uma variedade de características. Alguns estudos anteriores concentraram-se na detecção de microaneurismas, associados aos estágios iniciais da doença Sinthanayothin et al., 1999; Streeter e Cree, 2003]. Também existem esforços para a detecção de exsudatos duros Osareh et al., 2003, hemorragias Niemeijer et al., 2005 e edemas. A análise de alterações na circulação sangüínea e distribuição dos vasos, devidas a dilatação/estreitamento dos vasos, oclusões, ou neovascularização é de grande importância CesarJr. e Jelinek, 2003, McQuellin et al., 2002; Wong et al., 2005. Na RDP, a neovascularização forma 
vasos surgindo da região do disco óptico e crescendo em direção à mácula ou surgindo dos vasos periféricos Kanski, 1989]. Antes da formação dos novos vasos, é comum observar-se dilatação e aumento da tortuosidade dos vasos (Figura 1.3(d) . Essas mudanças podem ser avaliadas por técnicas de análise morfológica. Medidas de interesse incluem comprimento e largura dos vasos [Pedersen et al., 2000], tortuosidade Hart et al., 1999 e dimensão fractal [Jelinek et al., 2005].

Outro uso importante da segmentação dos vasos é o registro entre imagens obtidas em diferentes ângulos, modalidades ou instantes de tempo. Pontos de bifurcação e cruzamento ou os próprios esqueletos das segmentações são usados como referências espaciais, permitindo assim o registro até entre imagens de diferentes modalidades Yang e Stewart, 2004: Zana e Klein, 1999]. O registro temporal de imagens do mesmo olho auxilia no acompanhamento e detecção de doenças e averiguação dos efeitos de tratamentos. Também pode ser usado na análise da circulação em seqüências de vídeo de angiografia à medida que o corante ocupa os vasos e fundo de olho. O registro entre imagens de diferentes modalidades permite que seja feita a correspondência e sobreposição de elementos que somente apareciam separadamente. Finalmente, pode-se construir mosaicos de imagens a partir de diferentes ângulos. Os mosaicos então são usados para extração de medidas ou planejamento e auxílio em cirurgias a laser, através de localização e rastreamento em tempo real [Fritzsche et al., 2003.

As estruturas dos vasos da retina e da coróide são igualmente usadas em biometria para identificação e verificação de pessoas em sistemas de segurança. Entre as características biométricas utilizadas, a retina/coróide possui possivelmente a taxa de erro mais baixa, além de ser bastante estável com o passar do tempo e praticamente impossível de falsificar. Por outro lado, seu uso tem um alcance limitado pelo alto custo e desconforto do usuário na aquisição da imagem. É possível que essas desvantagens sejam superadas, mas com a variedade de métodos de identificação biométrica existentes, é difícil prever o futuro dessa aplicação Hill, 1998.

Uma avaliação automática de anomalias da retina requer uma segmentação precisa dos vasos sangüíneos, para que haja posteriormente uma correta extração de características desses vasos. Muitos métodos têm sido desenvolvidos para a segmentação dos vasos retínicos, porém inspeção visual e análise ROC (do inglês receiver operating characteristic, ou característica de operação do receptor) mostram 
que há espaço para melhorias: observadores humanos são mais precisos que os métodos, que apresentam falhas ao redor do disco óptico e não detectam os vasos mais finos Cree et al., 2005b; Niemeijer et al., 2004. Além disso, para que trabalhadores comunitários não especializados possam obter resultados a respeito de imagens coletadas, é importante que não haja necessidade de intervenção humana ou configuração de parâmetros.

\subsection{Objetivos}

Os objetivos deste trabalho foram:

- Desenvolvimento de um método de segmentação dos vasos retínicos com as seguintes características: robustez na presença de ruídos, patologias e variações na aquisição das imagens; independência de intervenção de usuário ou configuração de parâmetros; capacidade de segmentar a vasculatura completa; alta precisão, permitindo a detecção da maioria dos vasos e medição de suas larguras; rapidez suficiente para uso em um software de auxílio diagnóstico.

- Avaliação exaustiva dos resultados, permitindo comparação com métodos da literatura e identificação das qualidades e limitações do método desenvolvido.

- Implementação de um software protótipo, facilitando o desenvolvimento e avaliação de métodos e levantamento de requisitos junto a oftalmologistas e pesquisadores.

\subsection{Contribuições}

As principais contribuições deste trabalho são:

- Levantamento bibliográfico de métodos de segmentação de vasos sangüíneos em imagens de retina.

- Aprimoramento do método de segmentação que utiliza a wavelet bidimensional de Gabor CesarJr. e Jelinek, 2003; Leandro et al., 2001, introduzindo o uso de diversas escalas da wavelet para a detecção de vasos de diferentes larguras e do classificador bayesiano com modelos de misturas 
gaussianas para as verossimilhanças das classes, permitindo uma classificação rápida com bom desempenho.

- Testes e análise ROC dos métodos desenvolvidos em duas bases públicas de imagens de retina, confirmando o desempenho do método. A obtenção de material, análise qualitativa dos resultados e identificação de atributos desejáveis para os métodos foi feita em colaboração com o Dr. Herbert F. Jelinek, da Charles Sturt University.

- Desenvolvimento de um pacote código aberto de scripts do MATLAB MATLAB, 2006 para a segmentação dos vasos retínicos, incluindo uma interface gráfica 1 .

- Publicação de artigos Cornforth et al., 2005, Leandro et al., 2003, Soares et al., 2005; Soares et al., 2006 descrevendo os avanços obtidos.

\subsection{Organização do texto}

O restante deste texto é organizado como segue. O Capítulo 2 apresenta uma visão geral sobre métodos de segmentação de vasos sangüíneos em imagens de retina, incluindo a contextualização da abordagem proposta nesta dissertação. Em seguida, o Capítulo 3 revisa os fundamentos teóricos usados no desenvolvimento dos métodos, incluindo propriedades da transformada wavelet contínua bidimensional (Seção 3.1), a wavelet bidimensional de Gabor e os classificadores supervisionados testados (Seção 3.2). O Capítulo 4 apresenta a abordagem adotada para obtenção da segmentação através da classificação supervisionada de pixels (Seção 4.4) e o processo de geração de características (Seção 4.2). No capítulo também está descrita a avaliação experimental realizada - que inclui a descrição dos conjuntos de imagens usados da análise ROC (Seção 4.5) - e uma visão geral da implementação (Seção 4.6). Os resultados experimentais são apresentados no Capítulo 5 , enquanto a conclusão, com os comentários finais e possíveis passos para trabalhos futuros, está no Capítulo 6 .

\footnotetext{
${ }^{1}$ Disponível em http://retina.iv.fapesp.br
} 


\section{Capítulo 2}

\section{Trabalhos relacionados}

Muitas abordagens diferentes para a segmentação de vasos sangüíneos em imagens de diversos domínios têm sido desenvolvidas [Kirbas e Quek, 2004]. Mesmo restritos a imagens de retina, existe uma variedade de métodos publicados. Assim, os trabalhos de segmentação dos vasos retínicos aqui relacionados estarão limitados aos mais recentes ou de maior destaque. Alguns métodos elaborados para imagens de outros domínios também serão discutidos por terem relação direta com a abordagem que será apresentada, isto é, que envolvam wavelets, filtragem multiescala ou classificação supervisionada.

Recentemente, algoritmos de segmentação dos vasos da retina vêm sendo testados em bancos públicos de imagens e avaliados quantitativamente através da comparação com segmentações manuais usando análise ROC. Contudo, apenas algumas abordagens foram avaliadas dessa forma e mesmo a análise quantitativa adotada mostra-se limitada Hoover et al., 2000; Staal et al., 2004]. Além disso, métodos muitas vezes são apresentados sem uma discussão mais aprofundada da relação com outros semelhantes. Neste capítulo, para fins de organização, a discussão será dividida entre detecção local e global dos vasos, mesmo que alguns métodos aliem as duas formas de detecção ou não possam ser perfeitamente categorizadas. Os trabalhos discutidos estão listados para comparação na Tabela 2.1, que relaciona cada método aos tipos de deteç̧ão local e global empregados, bem como a necessidade de interação e capacidade de segmentar as redes vasculares completas. Muitos métodos dependem de parâmetros ajustáveis para cada imagem. A necessidade de interação anotada na tabela indica se dado método 
requer interação do usuário para inicialização ou correções, uma vez que o ajuste parâmetros não costuma ser determinante. Finalmente, existem métodos que não foram desenvolvidos para detectar as redes vasculares completas, podendo ser sensíveis à inicialização ou incapazes de seguir bifurcações e cruzamentos. Vale ressaltar que em algumas imagens as redes não aparecem como totalmente conexas, possuindo ramos que saem e retornam ao campo de vista ou vasos que não são visíveis em alguma parte da imagem, mas que reaparecerem em outras, o que dificulta a detecção.

\subsection{Pré-processamento}

Alguns dos métodos de segmentação possuem uma fase de pré-processamento, em que são compensadas variações como iluminação desigual ou removidos artefatos como ruídos e patologias. Para alguns algoritmos, é desejável que haja também uma normalização de cores entre diferentes imagens, o que pode entrar na fase de pré-processamento. Apesar disso, a maior parte dos métodos que serão apresentados não possui pré-processamento, levando em conta variações de iluminação e presença de artefatos indesejados durante sua formulação.

Um método simples para corrigir variações na intensidade do fundo das imagens foi apresentado em Mendonça e Campilho, 2006; Wood et al., 1995: o valor médio calculado em uma janela centrada em cada pixel é subtraído do seu valor. Um problema desse método é que o contraste apresentado pelos vasos em regiões com pouca iluminação é bem menor do que em regiões bem iluminadas Lowell et al., 2004, o que não é corrigido pelo método.

Técnicas de correção de iluminação e restauração de imagens para a detecção de patologias são analisadas em Cree et al., 2005a; Goatman et al., 2003; Osareh et al., 2002; Sinthanayothin et al., 1999. Em Osareh et al., 2002, a variação entre imagens é reduzida através de especificação de histogramas Gonzalez e Woods, 2002, em que o histograma de cada canal RGB (do inglês red, green e blue, ou vermelho, verde e azul) é transformado separadamente de modo a assemelhar um histograma ideal, proveniente de uma imagem bem comportada. O resultado produzido é uma imagem mais natural, que não exagera a participação do canal azul em imagens coloridas, ao contrário daquele obtido por equalização de histogramas Goatman et al., 2003. Após a especificação de histogramas, aplica-se um realce local 
Tabela 2.1: Relação de métodos de segmentação de vasos apresentados, organizados por abordagens de detecção global e local.

\begin{tabular}{|c|c|c|c|c|}
\hline Método de segmentação & Detecção global & Detecção local & $\begin{array}{c}\text { Requer } \\
\text { interação* }\end{array}$ & $\begin{array}{c}\text { Redes } \\
\text { completas }\end{array}$ \\
\hline Jiang e Mojon, 2003 & Não há & Sondagem de limiarizações & Não & Sim \\
\hline Chaudhuri et al., 1989 & Não há & Filtro casado & Não & Sim \\
\hline Lowell et al., 2004 & Não há & Filtro não-linear & Não & Sim \\
\hline Zana e Klein, 2001 & Não há & $\begin{array}{l}\text { Morfologia matemática } \\
\text { e avaliação de curvatura }\end{array}$ & Não & Sim \\
\hline Fang et al., 2003 & Não há & $\begin{array}{l}\text { Morfologia matemática } \\
\text { e avaliação de curvatura }\end{array}$ & Não & Sim \\
\hline Pinz et al., 1998 & Não há & Avaliação de bordas & Não & $\operatorname{Sim}$ \\
\hline Nekovei e Sun, 1995 & Não há & Classificação superv. & Não & Sim \\
\hline Sinthanayothin et al., 1999 & Não há & Classificação superv. & Não & Sim \\
\hline Staal et al., 2004 & Não há & Classificação superv. & Não & Sim \\
\hline Chutatape et al., 1998 & Rastreamento & Filtro casado & Não & Sim \\
\hline Gang et al., 2002 & Rastreamento & Filtro casado & Não disponível & Não disponível \\
\hline Liu e Sun, 1993 & Rastreamento & Filtro casado & Sim & Sim \\
\hline Zhou et al., 1994 & Rastreamento & Filtro casado & Sim & Não \\
\hline Gao et al., 2001 & Rastreamento & Filtro não-linear (ajuste) & $\operatorname{Sim}$ & Não \\
\hline Can et al., 1999 & Rastreamento & Avaliação de bordas & Não & Sim \\
\hline Lalonde et al., 2000 & Rastreamento & Avaliação de bordas & $\operatorname{Sim}$ & Sim \\
\hline Tolias e Panas, 1998 & Rastreamento & Agrupamento fuzzy & Não & Sim \\
\hline Hoover et al., 2000. & Cresc. de regiões & Filtro casado & Não & Sim \\
\hline Martínez-Pérez et al., 1999 & Cresc. de regiões & $\begin{array}{c}\text { Avaliação de } \\
\text { curvatura e bordas }\end{array}$ & Não & Sim \\
\hline Mendonça e Campilho, 2006 & Cresc. de regiões & Avaliação de bordas & Não & Sim \\
\hline Wang e Lee, 1997 & Cresc. de regiões & Avaliação de bordas & Não & Sim \\
\hline Nain et al., 2004 & Modelos deformáveis & Limiarização adaptativa & Sim & Não disponível \\
\hline Malladi et al., 1995 & Modelos deformáveis & Avaliação de bordas & Sim & Não disponível \\
\hline McInerney e Terzopoulos, 2000 & Modelos deformáveis & Avaliação de bordas & Sim & Não disponível \\
\hline Vasilevskiy e Siddiqi, 2002 & Modelos deformáveis & Avaliação de bordas & $\operatorname{Sim}$ & Não disponível \\
\hline Toledo et al., 2000 & Modelos deformáveis & Classificação superv. & Sim & Não \\
\hline Thönnes et al., 2002 & $\begin{array}{c}\text { Inferência bayesiana } \\
\text { de árvores }\end{array}$ & Filtro não-linear (ajuste) & Não & Sim \\
\hline Wang e Bhalerao, 2003 & $\begin{array}{l}\text { Árvore geradora de } \\
\text { custo máximo }\end{array}$ & Filtro não-linear (ajuste) & Não & Sim \\
\hline
\end{tabular}

* A coluna da tabela indica se dado método requer interação do usuário para inicialização ou correções, sem considerar o ajuste de parâmetros. 
de contraste para compensar variações de iluminação, da mesma forma que em Sinthanayothin et al., 1999. O realce de contraste definido em Sinthanayothin et al., 1999 é aplicado sobre a intensidade das cores no espaço HSI (do inglês hue, saturation e intensity, ou matiz, saturação e intensidade) Gonzalez e Woods, 2002 e clareia regiões escuras, porém pode também magnificar ruídos. Em [Staal et al., 2004], uma forma similar de realce de contraste é aplicada, em que os canais RGB das imagens são localmente normalizados de forma a ficarem com média nula e desvio padrão unitário.

Um problema da equalização e especificação de histogramas é que ao alterar o formato do histograma, a presença de algumas lesões (como exsudatos) pode ficar ficar suprimida. Tendo em vista esse problema, em Cree et al., 2005a propõe-se correção de iluminação (shade-correction) divisória seguida da normalização dos histogramas Gonzalez e Woods, 2002 dos canais RGB. A correção de iluminação divisória é aplicada separadamente aos canais e consiste em dividir o valor de cada pixel por um valor estimado do fundo, dado pela mediana numa subimagem centrada no pixel em questão. Em Spencer et al., 1996], utiliza-se correção de iluminação subtrativa, em que o valor estimado do fundo é subtraído dos pixels ao invés de dividido. Da mesma forma que a subtração da média local em Wood et al., 1995], a correção de iluminação subtrativa não compensa variações locais de contraste.

Em [Cree et al., 1999], argumenta-se que ambas as abordagens apresentadas de correção de iluminação (divisória e subtrativa) não são ideais por não distinguirem variações naturais do fundo daquelas devidas a iluminação desigual. Propõe-se então um modelo da formação das imagens de angiografia fluoresceínica descrito por funções que representam separadamente variações devidas à câmera, ao fundo e às outras estruturas presentes. A estimação das funções depende da determinação de pontos que pertencem ao fundo. Isso é feito eliminando de antemão estruturas como patologias, rede vascular, disco óptico e mácula. Determina-se a função da câmera, que descreve variações na iluminação, através de um polinômio bidimensional de terceiro grau adaptado aos pontos escolhidos como pertencentes ao fundo.

Não existe uma comparação dos métodos de correção de iluminação em termos de desempenho da detecção de vasos. Dependendo das características do algoritmo de segmentação a ser usado, determinada correção pode tornar-se mais adequada.

Em Zana e Klein, 2001, operações morfológicas e avaliação de curvatura são usadas para a detecção 
dos vasos. Algumas estruturas pequenas e claras (menores que a largura dos vasos) e ruído branco podem aparecer como falsos positivos após a operação de realce. Assim, aplica-se um pré-processamento para removê-los, que consiste na reconstrução geodésica da imagem original a partir de uma imagem de aberturas por elementos estruturantes lineares. A imagem de aberturas deve preservar a maior parte dos vasos e eliminar as estruturas indesejadas. Sendo $I_{0}$ a imagem original (no caso, uma angiografia fluoresceínica, em que os vasos são mais claros que o fundo), a reconstrução $I_{o p}$ é dada por

$$
I_{o p}=\gamma_{I_{0}}^{r e c}\left(\max _{i}\left\{\gamma_{L_{i}}\left(I_{0}\right)\right\}\right)
$$

em que $\gamma_{L_{i}}$ denota a abertura pelo elemento estruturante $L_{i}$ e $\gamma_{I_{0}}^{r e c}(I)$ denota a reconstrução geodésica de $I_{0}$ a partir de $I$. Os elementos estruturantes $L_{i}(i \in\{1, \ldots, 12\})$ são rotações de uma linha de 15 pixels, orientados a cada $15^{\circ}$.

A operação é também conhecida como abertura linear por reconstrução de tamanho 15, que é aproximadamente o diâmetro dos maiores vasos presentes nas imagens testadas. Após sua aplicação, estruturas claras de diâmetro menor que 15 pixels são eliminadas, enquanto os vasos são preservados. A operação foi formulada para contornar problemas específicos do método descrito em Zana e Klein, 2001, mas poderia ser aplicada como pré-processamento em outros métodos.

\subsection{Detecção local dos vasos}

A detecção local dos vasos pode fornecer uma classificação (vaso ou não vaso) ou então um indicador da chance de um pixel ou grupo de pixels fazer parte de um vaso. Alguns algoritmos são baseados apenas na detecção local, o que talvez seja insuficiente para a detecção das árvores vasculares completas. Assim, muitos dos algoritmos possuem uma fase adicional de detecção global, em que são usadas técnicas como rastreamento e crescimento de regiões, discutidas na Seção 2.3 . 


\subsubsection{Modelos de vaso}

A detecção local é feita com base em um modelo de vaso sangüíneo ou pela definição de características que distinguem os vasos dos outros elementos das imagens. Por exemplo, a simples observação de que os vasos são mais escuros que o fundo da retina leva às abordagens por limiarização (Seção 2.2.2).

Em Zana e Klein, 2001] os pixels dos vasos são detectados a partir de três características importantes:

1. O formato de uma seção de vaso é aproximadamente gaussiano.

2. Vasos são aproximadamente lineares por partes e conectados em uma estrutura de árvore.

3. Vasos possuem uma determinada largura e não podem estar muito próximos entre si.

Além dessas, em Can et al., 1999: Chaudhuri et al., 1989; Chutatape et al., 1998] observa-se que que a largura dos vasos diminui gradualmente com a distância ao disco óptico, o que é essencial na formulação de algoritmos de rastreamento. Em Can et al., 1999, Chutatape et al., 1998; Zhou et al., 1994 ressalta-se também a continuidade de posição, curvatura e largura dos vasos. Em Can et al., 1999: Lalonde et al., 2000; Pinz et al., 1998; Wang e Lee, 1997], destaca-se que os vasos possuem duas bordas paralelas bem definidas em que a derivada da imagem possui sinais opostos (ver Seção 2.2.6). A maioria das suposições a respeito dos vasos vale tanto para imagens aneritras e coloridas como também para angiografias, sendo que nas angiografias os vasos são mais claros que o fundo, enquanto o contrário vale para as aneritras e coloridas. A Figura 2.1 ilustra cortes contendo perfis de alguns vasos extraídos do canal verde de uma imagem colorida e de uma angiografia fluoresceínica.

Em Chaudhuri et al., 1989, Chutatape et al., 1998; Gang et al., 2002; Hoover et al., 2000; Liu e Sun, 1993 Zhou et al., 1994, filtros casados (matched filters) são usados para a detecção dos vasos sangüíneos. Os filtros casados são desenvolvidos a partir de um modelo gaussiano da intensidade dos perfis dos vasos. Para imagens coloridas ou aneritras, em que os vasos aparecem com intensidade menor que o fundo, o modelo do perfil de um vaso pode ser escrito como Fritzsche et al., 2003

$$
g(x)=b-c \exp \left(-\frac{(x-a)^{2}}{2 \sigma^{2}}\right)
$$




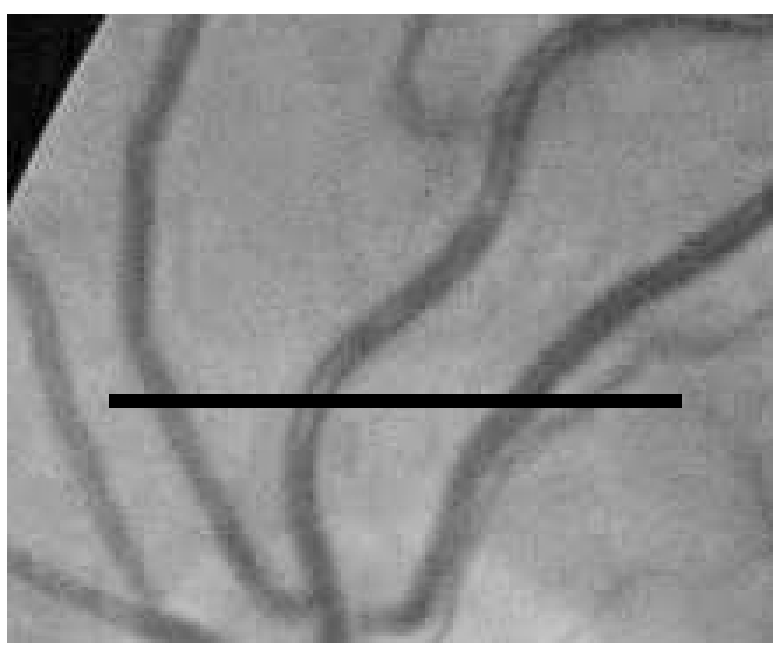

(a) Detalhe do canal verde de uma imagem colorida, indicando o corte analisado na Figura 2.1(b)

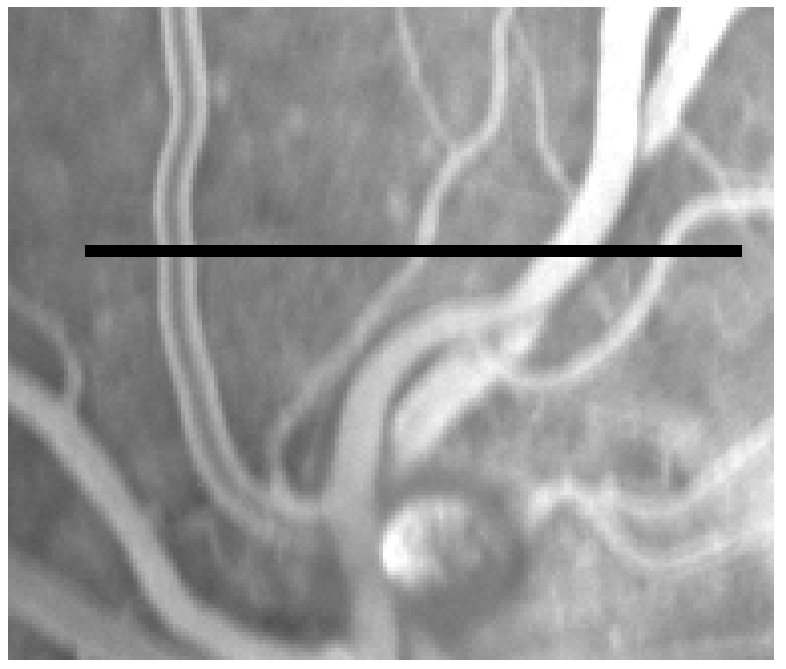

(c) Detalhe do uma angiografia fluoresceínica, indicando o corte analisado na Figura 2.1(d)

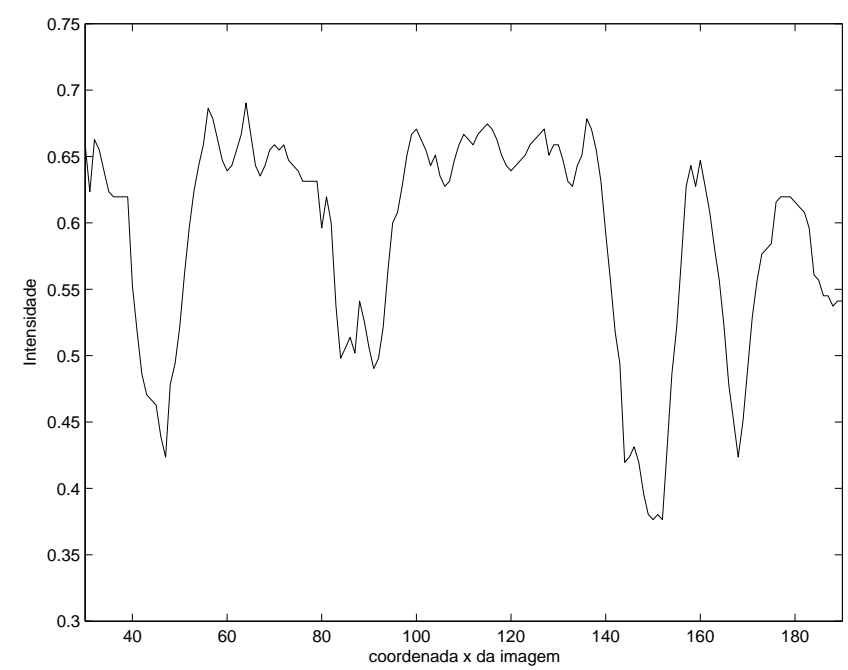

(b) Corte extraído do canal verde da imagem colorida, indicado na Figura 2.1(a) ilustrando perfis dos vasos.

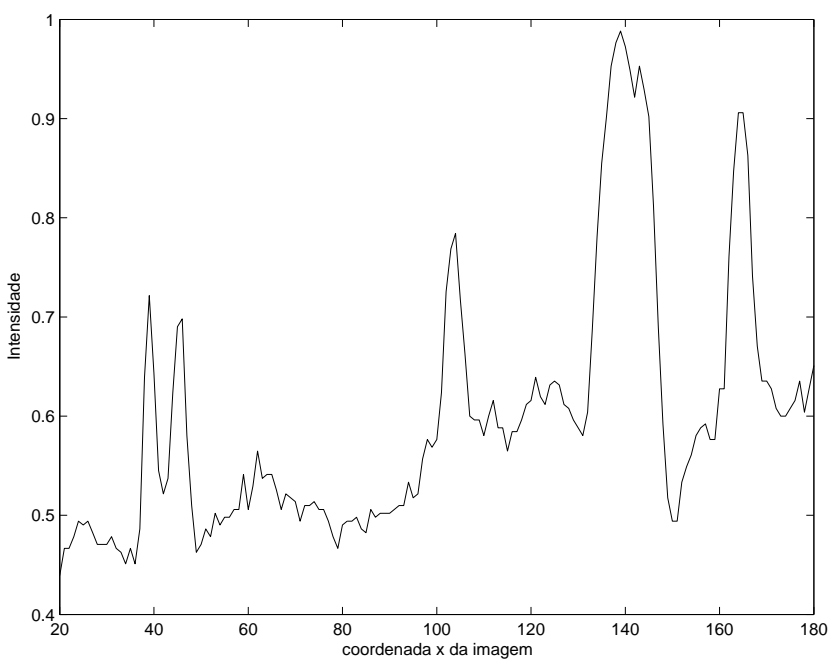

(d) Corte extraído da angiografia fluoresceínica, indicado na Figura 2.1(c) ilustrando perfis dos vasos.

Figura 2.1: Detalhes e cortes de imagens apresentando alguns perfis de vasos. 
em que $a$ é o ponto central do vaso, $\sigma$ representa sua largura, $b$ é uma aproximação do valor do fundo ao seu redor e $c$ quantifica a força do contraste entre o vaso e o fundo.

Em geral, as seções dos vasos podem ser aproximadas localmente pelo modelo gaussiano descrito, como ilustrado na Figura 2.1. Contudo, no canal verde da imagem colorida (Figura 2.1(b)], um dos vasos apresenta uma região central mais clara. Isso ocorre freqüentemente devido à presença dos reflexos centrais, fazendo com que as laterais do vaso sejam mais escuras que o seu centro. Esse fenômeno foi modelado em Gao et al., 2001 para rastreamento dos vasos ao somar uma gaussiana que representa o reflexo ao modelo anteriormente descrito:

$$
g_{2}(x)=b-c \exp \left(-\frac{(x-a)^{2}}{2 \sigma^{2}}\right)+c_{2} \exp \left(-\frac{\left(x-a_{2}\right)^{2}}{2 \sigma_{2}^{2}}\right)
$$

em que os parâmetros $a_{2}, \sigma_{2}$ e $c_{2}$ da nova gaussiana estão relacionados à posição central, largura e contraste do reflexo central.

A medição das larguras dos vasos é uma tarefa importante em que são necessários modelos precisos. Em Pedersen et al., 2000, splines modelam os perfis dos vasos, enquanto que em Li et al., 2003 Lowell et al., 2004 vasos com reflexos centrais são modelados por duas gaussianas, de modo similar ao apresentado acima. Nas imagens de angiografia fluoresceínica não se observa o reflexo central, porém um outro fenômeno pode distanciar o modelo gaussiano (Equação 2.2 dos perfis dos vasos: dependendo do momento em que as imagens são registradas, as bordas das veias podem aparecer como mais claras que seu centro, como ilustrado na Figura 2.1(c).

\subsubsection{Limiarização}

Dado o conjunto de características observadas que definem os vasos sangüíneos, é possível formular uma série de abordagens para a detecção local, apresentadas a seguir. Em imagens aneritras ou no canal verde de imagens coloridas observa-se que os vasos são mais escuros que o fundo da retina (Figura 2.1). Assim, uma abordagem simples para a segmentação é limiarizar a imagem, isto é, classificar todos os pixels com valores abaixo de um limiar $T$ como vaso. Dadas as variações de iluminação, presença de patologias, ruídos e outros fatores, a simples aplicação de um limiar apresenta resultados 
insatisfatórios Jiang e Mojon, 2003.

Sondagem sobre múltiplas limiarizações é aplicada às imagens em [Jiang e Mojon, 2003]. Para cada limiar $T$ escolhido, uma imagem binária $B_{T}$ é gerada pela limiarização do canal verde, em que pixels da imagem original com intensidade menor ou igual a $T$ são candidatos a vaso e os demais pixels são considerados como pertencentes ao fundo. Cada agrupamento de pixels candidatos passa por uma série de verificações e apenas aqueles que possuem características de vaso são armazenados. A segmentação final é dada pela união das regiões armazenados em todas as limiarizações.

Dada uma limiarização $B_{T}$, as regiões que serão preservadas são construídas da seguinte forma:

1. A transformada da distância euclidiana é aplicada a $B_{T}$, gerando um mapa de distâncias.

2. As regiões candidatas a vaso são restringidas com base no mapa de distâncias, fazendo com que permaneçam apenas os pixels centrais de regiões alongadas.

3. Regiões alongadas que permaneceram são reconstruídas a partir de seus pixels centrais.

A etapa 2 de restrição das regiões candidatas é a que define a detecção do método. Ela é feita com base em duas medidas: $\phi$ e $d$, que quantificam a chance de um pixel candidato ser um pixel central de uma região alongada. As medidas são definidas por:

$$
\begin{aligned}
\phi & =\max _{n \in N_{p}} \operatorname{angulo}\left(\overline{p e_{p}}, \overline{p e_{n}}\right)=\max _{n \in N_{p}} \frac{180}{\pi} \cdot \arccos \frac{\overline{p e_{p}} \cdot \overline{p e_{n}}}{\left\|\overline{p e_{p}}\right\| \cdot\left\|\overline{p e_{n}}\right\|}, \\
d & =\max _{n \in N_{p}}\left\|\overline{e_{p} e_{n}}\right\|,
\end{aligned}
$$

em que $p$ é um pixel candidato a vaso e $n$ um dos pixels de sua 8-vizinhança $N_{p}$. $e_{p}$ e $e_{n}$ são os pixels pertencentes ao fundo que estão mais próximos aos pixels $n$ e $p$, respectivamente (Figura 2.2).

Os pixels das linhas centrais de regiões alongadas em geral possuem alto valor de $\phi$. Portanto, a primeira operação de restrição é feita através de um limite $P_{\phi}$ em $\phi$. Além disso, como os vasos possuem larguras limitadas, que é aproximada por $d$, coloca-se um limite $P_{d}$ em $d$ para apenas preservar regiões alongadas. 


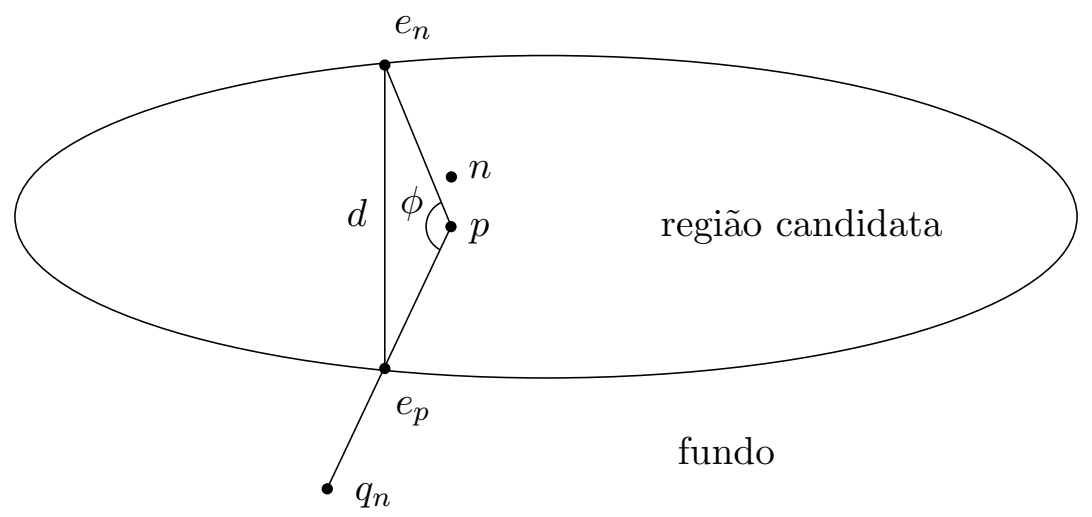

Figura 2.2: Esquema apresentando as medidas usadas para restrição das regiões candidatas após limiarização.

Os autores notam que a aplicação dessas operações de restrição pode produzir regiões finas que apresentam pouco contraste em relação ao fundo e não são vasos. Assim, um terceiro teste é realizado, exigindo um contraste suficientemente forte. A medida de contraste é definida por

$$
c=\max _{n \in N_{p}} \frac{\operatorname{intensidade}\left(q_{n}\right)}{\operatorname{intensidade}(p)}
$$

em que $q_{n}$ representa um pixel do fundo na direção de $\overline{p e_{n}}$ e é tal que $\overline{p q_{n}}=P_{f a c} \cdot \overline{p e_{n}}$, com $P_{f a c}>1$, como ilustrado na Figura 2.2. A restrição correspondente baseia-se em um limite $P_{c}$ aplicado a $c$.

Após a aplicação das três restrições descritas, algumas estruturas muito curtas, que têm pouca chance de serem regiões de vaso, ainda aparecem no resultado. Assim, uma restrição de tamanho mínimo é imposta, de modo que componentes conexas de tamanho menor que $P_{\text {size }}$ são excluídas.

A segmentação é obtida através da união, para todos os valores de limiar $T$ usados, das imagens reconstruídas a partir das restrições sobre cada $B_{T}$. Finalmente, para aumentar a precisão da detecção, um pós-processamento é aplicado. O passo principal do pós-processamento é a eliminação de pixels nas bordas das regiões detectadas que não sejam pontos de máximo local do gradiente da imagem, ou seja, que se encontram externos à borda verdadeira do vaso.

Em Hoover et al., 2000, sondagens são aplicadas sobre limiarizações da resposta do filtro casado de Chaudhuri et al., 1989 em conjunto com um algoritmo similar ao crescimento de regiões (ver Seção 2.3.2. 
Uma característica importante de ambos os métodos citados é a necessidade de uma série de parâmetros e a definição de uma conjunto de regras específicas usadas durante a verificação. Foi realizada a avaliação dos métodos em bases públicas, que demonstram um bom desempenho em comparação com outros recentes [Hoover et al., 2000; Jiang e Mojon, 2003; Niemeijer et al., 2004].

\subsubsection{Filtros casados}

Filtros casados (matched filters) são usados em métodos de rastreamento Chutatape et al., 1998 Gang et al., 2002, Zhou et al., 1994 para determinar, em cada ponto, a direção que o rastreamento deve seguir para acompanhar o vaso. Os modelos gaussianos apresentados na Seção 2.2.1 são a base para a construção de filtros bidimensionais (2D), que detectam segmentos lineares de vasos. Em Chaudhuri et al., 1989, tal filtro é definido como

$$
K(x, y)=-\exp \left(-\frac{x^{2}}{2 \sigma^{2}}\right), \quad \text { para }|y| \leq L / 2
$$

em que $L$ é o comprimento do filtro, associado ao comprimento dos vasos detectados.

O filtro está ilustrado como superfície na Figura 2.3(a). Para a detecção de vasos em todas as orientações, ele é rotacionado em passos de $15^{\circ}$, gerando um total de 12 filtros. Em cada pixel da imagem, toma-se a resposta máxima da convolução desses 12 filtros. Na implementação descrita Chaudhuri et al., 1989, o filtro é truncado em $x= \pm 3 \sigma$ e modificado para ter média zero. Isso é feito para que gere respostas nulas em regiões planas da imagem. O filtro final é dado por

$$
K^{\prime}(x, y)=K(x, y)-\sum_{(x, y) \in N} K(x, y) / A, \quad \forall(x, y) \in N
$$

em que $N=\{(x, y):|x| \leq 3 \sigma,|y| \leq L / 2\}$ e $A=|N|$.

Em Chutatape et al., 1998; Gang et al., 2002, um filtro similar é definido a partir da derivada de segunda ordem da gaussiana:

$$
F(x, y)=\frac{1}{\sqrt{2 \pi} \sigma^{3}}\left(x^{2}-\sigma^{2}\right) \exp \left(-\frac{x^{2}}{2 \sigma^{2}}\right), \quad \text { para }|y| \leq L / 2 .
$$




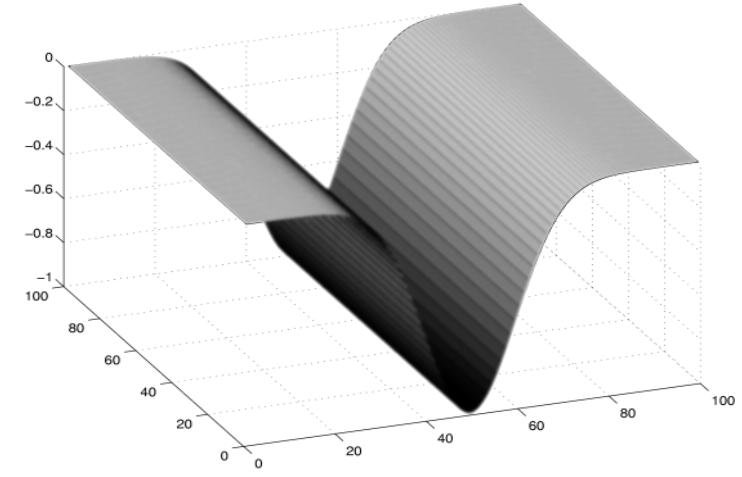

(a) Superfície representando o filtro casado gaussiano 2D (Equação 2.7.).

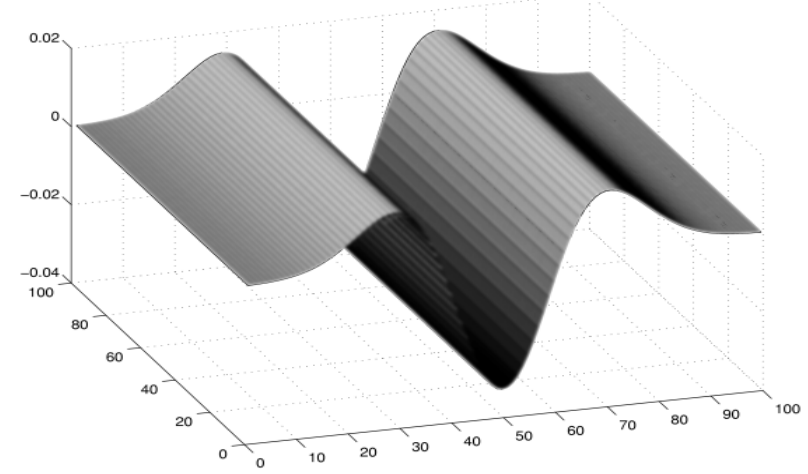

(b) Superfície representando o filtro casado $2 \mathrm{D}$ definido a partir da segunda derivada da gaussiana (Equação 2.9p.

Figura 2.3: Representação em superfícies dos dois filtros casados 2D apresentados nas Equações 2.7 e 2.9.

O filtro está ilustrado como superfície na Figura 2.3(b). Usando este filtro, observa-se uma relação linear entre o parâmetro $\sigma$ e o diâmetro do vaso. Essa propriedade é explorada em Gang et al., 2002 para estimar, de forma adaptável, os diâmetros dos vasos sendo rastreados, aumentando assim a precisão da detecção.

Os filtros casados geram resultados rapidamente e são relativamente simples. Contudo, sua aplicação enfrenta alguns problemas, como a dificuldade de detecção de vasos de pouco contraste (encontrados em regiões com pouca iluminação) e a presença de falsos positivos em bordas de regiões claras, como o disco óptico e exsudatos Chaudhuri et al., 1989; Lowell et al., 2004.

\subsubsection{Filtros não-lineares}

Os problemas apresentados pelos filtros casados motivaram a criação do filtro não-linear apresentado em Lowell et al., 2004. O filtro é construído usando dois elementos estruturantes: o primeiro é uma linha que deverá ter a orientação do vaso sendo detectado e passar pelo seu centro; o segundo é composto de duas linhas paralelas à primeira, que devem acompanhar as regiões laterais ao vaso. Na configuração descrita para as imagens da base STARE [Hoover et al., 2000], as linhas possuem 9 pixels de comprimento e as linhas laterais são colocadas a 5 pixels de distância da linha central. A idéia inicial era a de que 
o resultado da filtragem fosse a diferença entre o maior valor sob o primeiro elemento e o menor sob o segundo. Como essa opção mostrou-se sensível a ruídos, optou-se por tomar a diferença entre o terceiro maior valor sob o primeiro elemento e o terceiro menor valor sob o segundo. A operação é semelhante a tomar a diferença entre uma dilatação e erosão, estando relacionada com a operação morfológica do top-hat. O filtro é rotacionado em passos de $15^{\circ}$ e a resposta máxima é selecionada. Os autores afirmam que o filtro raramente responde fortemente em regiões que não possuam vasos, não apresentando falsos positivos em bordas de regiões claras. Apesar disso, algumas regiões de bifurcações e cruzamentos não são detectadas e necessita-se de um pós-processamento para a remoção de pequenos falsos positivos isolados.

Operações da morfologia matemática para realce dos vasos são apresentadas em Zana e Klein, 2001. A operação de realce é uma soma de top-hats com elementos estruturante lineares rotacionados em todas as orientações. Para que os vasos mais grossos sejam detectados, é necessário que a abertura dos top-hats remova esses vasos. Assim, o elemento estruturante não pode ser muito curto, o que faz com que ruídos também sejam realçados. Para remover esses ruídos, um pré-processamento é aplicado, como explicado na Seção 2.1. Sendo $I_{0}$ a imagem original (no caso, uma angiografia fluoresceínica, em que os vasos são mais claros que o fundo) e $I_{o p}$ o resultado do pré-processamento, a operação de realce é definida como:

$$
I_{\text {sum }}=\sum_{i=1}^{12}\left(I_{o p}-\gamma_{L_{i}}\left(I_{0}\right)\right),
$$

em que $\gamma_{L_{i}}$ denota a abertura pelo elemento estruturante $L_{i}$. Os elementos estruturantes $L_{i}(i \in$ $\{1, \ldots, 12\})$ são rotações de uma linha de 15 pixels, orientados a cada $15^{\circ}$.

Após a soma de top-hats, assume-se que as estruturas detectadas possuam uma direção preferencial, apresentando formas alongadas. Alguns elementos indesejáveis ainda estão presentes: estruturas lineares muito finas ou muito próximas entre si e algumas regiões finas irregulares muito claras ou escuras, que são eliminadas usando avaliação de curvatura (Seção 2.2.5).

Uma limitação comum às abordagens não-lineares anteriores é a incapacidade de realçar pontos de cruzamento e bifurcação, em que os perfis dos vasos são maiores que os elementos estruturantes 
adotados. Além disso, o reflexo central presente em imagens aneritras e coloridas muitas vezes não é detectado Fang et al., 2003. Assim, em Fang et al., 2003 propõe-se uma fase adicional de processamento em relação ao descrito em Zana e Klein, 2001, em que os reflexos e pontos de cruzamento são preenchidos através de um processo de reconstrução morfológica. Além disso, existem algumas situações como imagens com patologias, má iluminação ou pouco contraste, que apresentam problemas nos resultados [Zana e Klein, 2001].

Funções gaussianas bidimensionais são localmente ajustadas às imagens em Thönnes et al., 2002 Wang e Bhalerao, 2003], usando uma decomposição multirresolução da imagem blocos de diferentes tamanhos. Escolhem-se as gaussianas de forma a melhor descrever cada bloco, fornecendo uma representação da imagem que inclui escala e orientação locais fornecidas pelas gaussianas. Outra abordagem não-linear é apresentada em Gao et al., 2001, em que o rastreamento é feito ajustando duas gaussianas (Equação 2.3) a cortes unidimensionais para acompanhar o ponto central dos vasos. A abordagem apresenta bons resultados na detecção de segmentos de vasos, porém não foi desenvolvida para a segmentação das árvores completas.

\subsubsection{Avaliação de curvatura}

A avaliação de curvatura tem sido usada para detectar os vasos sangüíneos de diferentes formas em diferentes modalidades de imagens Frangi et al., 1998; Martínez-Pérez et al., 1999; Sato et al., 1998]. Dado que os vasos mudam de direção lentamente e possuem perfis aproximadamente gaussianos (ver Seção 2.2.1), deverão ter curvatura alta na direção do perfil e baixa paralela ao vaso. Pontos de saliência são máximos (ou mínimos) locais da intensidade na direção em que o gradiente da imagem passa por maior mudança (maior concavidade). Assim, pode-se analisar as curvaturas em um dado ponto para detectar saliências ou formular medidas que indiquem sua chance de pertencer a uma estrutura alongada.

As curvaturas de uma imagem discreta podem ser calculadas a partir de suas derivadas parciais tomadas em determinada escala. Uma imagem $I(x, y)$ gera uma família de imagens $I(x, y ; \sigma)$ através 
da convolução com uma função gaussiana $G(x, y ; \sigma)$ de variância $\sigma^{2}$ :

$$
I(x, y ; \sigma)=I(x, y) \otimes G(x, y ; \sigma)
$$

em que $\sigma$ é o fator de escala que controla a dispersão da gaussiana. À medida que $\sigma$ aumenta, a imagem $I(x, y ; \sigma)$ fica mais borrada e difusa, perdendo detalhes. As derivadas da imagem podem ser definidas em diferentes escalas como sua convolução com derivadas da gaussiana normalizadas:

$$
\begin{aligned}
I_{x}=I(x, y) \otimes \sigma G_{x}(x, y ; \sigma) ; & I_{x x}=I(x, y) \otimes \sigma^{2} G_{x x}(x, y ; \sigma) ; \\
I_{y}=I(x, y) \otimes \sigma G_{y}(x, y ; \sigma) ; & I_{x y}=I(x, y) \otimes \sigma^{2} G_{x y}(x, y ; \sigma) ; \\
& I_{y y}=I(x, y) \otimes \sigma^{2} G_{y y}(x, y ; \sigma),
\end{aligned}
$$

em que os subscritos indicam derivadas parciais e a função $G(x, y ; \sigma)$ é uma gaussiana 2D:

$$
G(x, y ; \sigma)=\frac{1}{2 \pi \sigma^{2}} \exp \left(-\frac{x^{2}+y^{2}}{2 \sigma^{2}}\right)
$$

A informação sobre as segundas derivadas da imagem estão contidas no hessiano:

$$
H=\left(\begin{array}{cc}
I_{x x} & I_{x y} \\
I_{y x} & I_{y y}
\end{array}\right) .
$$

Como $I_{x y}=I_{y x}$, a matriz anterior é simétrica com auto-valores e auto-vetores reais e ortogonais. Os auto-valores do hessiano, $\lambda_{1}$ e $\lambda_{2}\left(\operatorname{com}\left|\lambda_{1}\right| \leq\left|\lambda_{2}\right|\right)$ medem convexidade e concavidade nas direções de seus auto-vetores correspondentes. O maior auto-valor $\left(\lambda_{2}\right)$ corresponde à curvatura principal máxima. Pontos de saliência são máximos (ou mínimos) locais da intensidade na direção em que o gradiente da imagem passa por maior mudança (maior concavidade). Assim, um pixel de uma região de vaso pode ser considerado como pertencendo a uma saliência se possuir alto valor de $\left|\lambda_{2}\right|$.

Em [Martínez-Pérez et al., 1999], a análise multiescala de curvatura e bordas é usada para guiar um algoritmo de crescimento de regiões (ver Seção 2.3.2). Um intervalo de escalas abrangendo a largura 
dos vasos é escolhido e tomam-se os maiores valores da força de saliência e bordas nesse intervalo para guiar o crescimento de regiões.

Em [Staal et al., 2004], os valores da curvatura principal máxima em diferentes escalas $\left(\lambda_{2}(\sigma)\right)$ são usados como características fundamentais na classificação de regiões das imagens . Além disso, os pontos de saliência são usados como referência para particionar as imagens, gerando uma representação em regiões que auxilia a classificação dos pixels (ver Seção 2.2.7).

Em Zana e Klein, 2001, a curvatura é usada para diferenciar alguns elementos direcionais indesejáveis de verdadeiros vasos. Após a estimação da curvatura, espera-se que as estruturas indesejáveis tenham o seguinte tipo de resposta: para o caso de estruturas lineares muito finas, a curvatura tenha valores positivos de largura menor que a largura esperada dos vasos; no caso de regiões finas irregulares, a curvatura alterne valores positivos e negativos de forma desorganizada. Assim, é possível remover os elementos indesejáveis através de uma seqüência de operações morfológicas sobre a imagem da curvatura Zana e Klein, 2001.

\subsubsection{Avaliação de bordas}

Uma maneira de segmentar os vasos é localizando suas bordas, dado que eles possuem duas bordas paralelas bem definidas em que a derivada da imagem apresenta sinais opostos, como observado em diversos trabalhos [Can et al., 1999; Lalonde et al., 2000; Pinz et al., 1998; Wang e Lee, 1997].

Existem diferentes modos de detectar bordas em imagens discretas. Em [Wang e Lee, 1997], a resposta de operadores Sobel é limiarizada e afinada, gerando um mapa das bordas. Para detectar apenas bordas alongadas, o mapa de bordas é processado por filtros casados binários ajustados à detecção de linhas. Em Lalonde et al., 2000; Sinthanayothin et al., 1999 as bordas são detectadas com o operador de Canny, capaz de explorar sua continuidade.

Pode-se também medir a força de borda pelo módulo do gradiente da imagem:

$$
|\nabla I|=\sqrt{I_{x}^{2}+I_{y}^{2}}
$$

em que os subscritos indicam derivadas parciais, calculadas em uma dada escala $\sigma$, como na Seção 2.2.5. 
O gradiente é um campo vetorial que representa a mudança de intensidade em cada região, possuindo valores altos em regiões de bordas. O cálculo do gradiente da forma apresentada na Equação 2.15 também pode ser visto como uma transformada wavelet que detecta bordas Chwialkowski et al., 1996. O filtro de Gabor 2D, que possui estreita relação com as wavelets, foi utilizado para detecção de bordas dos vasos em [Klein et al., 1997], sendo especialmente adequada para transições direcionais.

Além da magnitude do gradiente, pode ser importante observar sua direção, uma vez que para constituir um vaso são necessárias bordas com gradientes em direções opostas. Em Mendonça e Campilho, 2006; Pinz et al., 1998], perfis de vasos são detectados pela formação de pares de bordas que possuam gradientes em direções aproximadamente opostas e distâncias condizentes com a largura dos vasos na imagem. Em [Can et al., 1999], os vasos são rastreados usando filtros casados adaptados à detecção de cada uma das duas bordas alongadas dos vasos.

Uma vantagem da detecção de bordas sobre outros filtros é a de poder diferenciar, através de verificações posteriores, contrastes fortes devidos a patologias ou outros elementos daqueles produzidos pelas bordas dos vasos. Por outro lado, bordas de pouco contraste ou pertencentes a vasos muito finos são de difícil detecção. Pontos de bifurcação e cruzamento podem apresentar uma dificuldade adicional por não se encaixarem nos modelos adotados Can et al., 1999; Lalonde et al., 2000; Pinz et al., 1998]. Da mesma forma, a presença do reflexo central ou preenchimento desigual de corantes angiográficos (ver Seção 2.2.1 necessitam de verificações específicas Pinz et al., 1998.

\subsubsection{Classificação supervisionada}

Métodos supervisionados para classificação de pixels foram apresentados em Nekovei e Sun, 1995. Sinthanayothin et al., 1999; Toledo et al., 2000, Staal et al., 2004. Em Nekovei e Sun, 1995, vetores de características são compostos pelos valores dos níveis de cinza em uma janela centrada no pixel sendo classificado. Utiliza-se uma rede neural treinada por retropropoagação de erros (backpropagation) para classificação. Uma janela de valores também é utilizada em [Sinthanayothin et al., 1999], porém as características são uma transformação de componentes principais dos canais RGB da imagem e medidas de força de borda da imagem formada por essa transformação. Novamente, uma rede neural é usada 
para classificar os pixels. É interessante notar que as redes neurais podem ser vistas como generalizações de filtros casados: os neurônios da primeira camada são filtros casados cuja saída passa para uma árvore de decisão não-linear, gerando a classificação final Nekovei e Sun, 1995.

Em Staal et al., 2004], a detecção de saliências alongadas é usada para criar elementos lineares e particionar a imagem em regiões pertencentes a cada um desses elementos. Características dos pixels são então geradas com base nessa representação. A característica mais importante para a classificação dos pixels é a probabilidade de que o elemento linear de sua partição seja parte de um vaso, calculada através da classificação prévia de cada elemento. Além dessa, muitas outras características são apresentadas e um esquema para seleção de características é usado para escolher apenas aquelas que fornecem boa separação entre as classes. Utiliza-se o classificador dos $k$ vizinhos mais próximos para a classificação dos elementos lineares e dos pixels. O método apresenta um desempenho bom nas bases testadas [Staal et al., 2004, mas alguns erros comuns, como falsa detecção de patologias, bordas do disco óptico e bordas da abertura da câmera.

Em Toledo et al., 2000, primeiramente calcula-se uma direção preferencial para cada pixel baseado na variância da intensidade em cada direção. Em seguida, obtém-se a verossimilhança do corte perpendicular a essa direção com um modelo estatístico do perfil dos vasos. As verossimilhanças são então usadas para guiar um modelo deformável (Seção 2.3.3).

Um aspecto positivo da segmentação por classificação de pixels é que ela não depende da formulação de regras ou ajuste de parâmetros. Por outro lado, são necessárias segmentações manuais para formar o conjunto de treinamento. As abordagens de classificação, assim como outras de detecção local apresentadas, apenas usam informação local, não levando em consideração informações globais ou de contexto, que podem ser importantes. Assim, podem ser usadas como fase inicial de algoritmos de detecção global.

\subsection{Detecção global dos vasos}

Nesta seção são apresentadas abordagens globais para a extração da vasculatura, incluindo rastreamento, crescimento de regiões e modelos deformáveis. Muitos métodos de segmentação usam algoritmos 
globais que incorporam alguma forma de detecção local, que foi apresentada na seção anterior. Por outro lado, existem métodos que não possuem uma fase de detecção global, utilizando técnicas como varredura, em que cada pixel da imagem é processado separadamente.

\subsubsection{Rastreamento}

Foram apresentados diversos métodos para o rastreamento dos vasos Can et al., 1999; Chutatape et al., 1998; Gang et al., 2002; Gao et al., 2001; Lalonde et al., 2000; Liu e Sun, 1993; Tolias e Panas, 1998: Zhou et al., 1994. Os algoritmos em geral são capazes de fornecer a estrutura vascular, incluindo informações como direção, largura e a localização de pontos de bifurcação e cruzamento. O rastreamento consiste em acompanhar as linhas centrais dos vasos, normalmente procurando o caminho que mais se assemelha a um modelo local do vaso. Em Can et al., 1999 Chutatape et al., 1998, Zhou et al., 1994 ressalta-se a continuidade de posição, curvatura e largura dos vasos, propriedades essenciais na formulação dos métodos.

Um aspecto importante dos algoritmos de rastreamento é a geração dos pontos iniciais do rastreamento, chamados de sementes. Alguns métodos dependem de um usuário para fornecer as sementes Gao et al., 2001; Lalonde et al., 2000. A circunferência do disco óptico pode ser detectada e usada para a geração automática das sementes [Chutatape et al., 1998; Tolias e Panas, 1998]. Uma desvantagem dessa abordagem é que nem sempre o disco óptico está presente nas imagens e quando está ele pode não estar diretamente conectado a toda a rede vascular. Para contornar esse problema, em Can et al., 1999 sementes são geradas por toda a imagem: uma grade regular de linhas é analisada e apenas os pontos que se assemelham a pontos centrais de vasos são armazenados como sementes.

Os algoritmos de rastreamento devem lidar de forma apropriada com pontos de bifurcação e cruzamento. Bifurcações/cruzamentos são detectados de diferentes formas e freqüentemente são considerados como sementes para processamento posterior. Podem ser detectados pela ausência de uma das bordas laterais dos vasos durante o rastreamento Can et al., 1999; Lalonde et al., 2000 ou pela detecção de duas formas similares a vasos nos perfis sendo analisados Chutatape et al., 1998; Tolias e Panas, 1998.

Uma vantagem que os algoritmos de rastreamento apresentam sobre algoritmos baseados em var- 
redura (em que todos os pixels da imagem são analisados) é a eficiência computacional, uma vez que apenas os pixels de interesse precisam ser processados. Além disso, normalmente é gerada uma descrição dos vasos que inclui sua direção e largura e pontos de cruzamento ou bifurcação. Por outro lado, os algoritmos de rastreamento devem lidar com dificuldades adicionais, como geração de sementes que permitam a detecção de todos os vasos e tratamento de pontos de bifurcação, cruzamento e terminação, o que pode acarretar na formulação de uma série de regras e dependência de parâmetros Chutatape et al., 1998. Para contornar o problema do ajuste de parâmetros por usuários, em Abdul-Karim et al., 2005 propõe-se um método automático para determinar os parâmetros dos algoritmos de segmentação, que é testado sobre o algoritmo de Can et al., 1999.

\subsubsection{Crescimento de regiões}

Em Martínez-Pérez et al., 1999, a análise multiescala de curvatura e bordas é usada para guiar um algoritmo de crescimento de regiões. O método inicialmente combina a informação de derivadas de primeira e segunda ordem em diferentes escalas para o cômputo de forças de saliência e borda. O algoritmo de crescimento de regiões possui duas classes que crescem simultaneamente: vaso e não vaso. As sementes das duas classes são geradas com base no histograma da força de saliência. Em seguida, ambas as classes crescem, com a força de saliência favorecendo os pixels da classe vasos e desfavorecendo os da classe não vaso, enquanto ambas as classes são impedidas por altos valores de força de borda. As restrições são sucessivamente relaxadas utilizando estatísticas dos histogramas das forças até que todos os pixels pertençam a uma das duas classes.

Em Hoover et al., 2000, sondagens são aplicadas sobre limiarizações da resposta do filtro casado de Chaudhuri et al., 1989 em conjunção com um algoritmo similar ao crescimento de regiões. Regiões contendo sementes são limiarizadas com o valor mais baixo que permita que a região seja aprovada por um conjunto de regras de verificação. Regiões aceitas como vaso geram sementes em suas extremidades para sondagens posteriores. A sondagem é baseada em características da região incluindo tamanho, bifurcações e conectividade com regiões já classificadas. Em [Mendonça e Campilho, 2006], após a detecção das linhas centrais dos vasos pela avaliação de bordas, o crescimento de regiões é usado para 
completar a segmentação com o auxílio de morfologia matemática, preenchendo vasos de larguras sucessivas a partir das linhas centrais. Também em Wang e Lee, 1997 um algoritmo simples de crescimento de regiões é aplicado após a detecção local dos vasos usando informações de borda.

Nos exemplos de crescimento de regiões citados, os resultados apresentam melhorias em relação à simples detecção local, porém alguns problemas apresentados pela detecção local ainda estão presentes, como a presença de falsos positivos em patologias e na região da borda do disco óptico.

\subsubsection{Modelos deformáveis}

O uso de modelos deformáveis tem mostrado resultados promissores em Malladi et al., 1995; McInerney e Terzopoulos, 2000; Nain et al., 2004; Toledo et al., 2000; Vasilevskiy e Siddiqi, 2002. Modelos deformáveis em duas dimensões são curvas que definem contornos de objetos e são deformadas por forças internas e externas. Forças internas definem características como tensão e rigidez dos contornos, enquanto as externas são definidas a partir de alguma propriedade das imagens, como intensidade ou força de borda. As forças podem ser formuladas empiricamente ou de modo a minimizar alguma energia. Para a tarefa da segmentação de vasos, as energias são formuladas de modo que sejam mínimas quando os contornos definirem as regiões dos vasos. De forma equivalente, forças são definidas para que os contornos encontrem um equilíbrio e estacionem nas condições desejadas. A inicialização consiste na definição dos contornos iniciais e pode ser determinante no resultado final.

Forças internas bastante usadas são a de inflação ou deflação (dependendo da inicialização dos contornos) normalmente constantes, bem como alguma força de resistência para garantir a suavidade do contorno. Em [Nain et al., 2004], uma força que penaliza regiões acima de uma certa largura é incluída, evitando vazamentos indesejados freqüentemente encontrados em resultados. As forças externas são derivadas das características locais das imagens, incluindo limiarizações adaptativas da intensidade dos pixels Nain et al., 2004, transformações inversas do gradiente (ver Seção 2.2.6 Malladi et al., 1995: McInerney e Terzopoulos, 2000], o divergente do gradiente [Vasilevskiy e Siddiqi, 2002] e as verossimilhanças dos pixels obtidas por modelos estatísticos de vasos (ver Seção 2.2.7] Toledo et al., 2000 . 
Snakes são modelos deformáveis parametrizados que apresentam alguma dificuldade em suportar mudanças topológicas e geometrias complexas. Para a segmentação dos vasos sangüíneos, mudanças topológicas são necessárias para lidar com cruzamentos. Além disso, as formas alongadas dos vasos apresentam uma dificuldade para a evolução adequada da parametrização. A reparametrização das snakes usando uma decomposição das imagens em células mostrou-se uma maneira eficiente de resolver esses problemas McInerney e Terzopoulos, 2000]. Por sua vez, os level-sets representam os contornos dos modelos deformáveis bidimensionais pelo conjunto de nível zero de uma superfície em três dimensões Malladi et al., 1995. Os contornos evoluem implicitamente através das mudanças da superfície e são capazes de acomodar mudanças topológicas de maneira natural. Uma desvantagem dos level-sets em relação às snakes é que a incorporação de restrições a priori e inclusão de diferentes forças é bastante difícil devido à formulação implícita [McInerney e Terzopoulos, 2000].

Os trabalhos que usam modelos deformáveis para a segmentação dos vasos retínicos mostram resultados promissores, porém ainda não há um método que forneça a segmentação completa das imagens sem a interação de um usuário nem uma avaliação objetiva de resultados.

\subsubsection{Inferência bayesiana de árvores}

Em [Thönnes et al., 2002], adota-se uma abordagem probabilística bayesiana para incorporar conhecimentos a priori sobre estruturas globais e inferir florestas (conjuntos de árvores) de vasos a partir das

imagens. As florestas são inferidas usando o algoritmo de Markov Chain Monte Carlo para amostragem da distribuição posterior condicionada nos dados. O algoritmo tem alta demanda computacional, mas a formulação bayesiana é interessante, permitindo incorporar conhecimentos a priori sobre as árvores e quantificar incertezas sobre o resultado produzido.

\subsection{Contextualização da abordagem proposta}

Uma característica marcante de muitos métodos é uso de um número grande de regras para lidar com situações específicas, resultando em algoritmos complexos e muitas vezes dependentes de parâmetros (como exemplos, tem-se Hoover et al., 2000; Jiang e Mojon, 2003; Mendonça e Campilho, 2006; Zana 
e Klein, 2001). Mesmo com a grande quantidade de regras, algumas situações como reflexos centrais e pontos de bifurcação/cruzamento podem não ser tratadas. Comparativamente, a abordagem de classificação de pixels é conceitualmente simples e permite que o classificador trate situações mais específicas, evitando a necessidade de regras e ajuste explícito de parâmetros. A abordagem que será apresentada nesta dissertação (Capítulo 4) utiliza classificação supervisionada de pixels, evitando a formulação de regras. Para tanto, leva em consideração apenas informação local, deixando espaço para melhorias ao acresentar uma fase de detecção global. Mesmo assim, é capaz de segmentar as redes vasculares completas e não necessita de interação de usuário, mas depende de imagens manualmente segmentadas.

A detecção usando wavelets $2 \mathrm{D}$ segue a linha dos filtros casados, incorporando a representação no espaço de ângulos e escalas, especialmente adequada para a detecção dos vasos sangüíneos. Uma questão importante discutida em alguns trabalhos é a escolha da escala dos filtros na detecção local. Em Martínez-Pérez et al., 1999], filtros de diferentes escalas são combinados de forma empírica, enquanto muitos algoritmos atuam sobre apenas uma escala Chaudhuri et al., 1989; Hoover et al., 2000 Zana e Klein, 2001]. Na abordagem de classificação usando wavelets, a combinação de diferentes escalas é fundamentada no treinamento estatístico usando imagens manualmente segmentadas.

A velocidade dos algoritmos pode ser importante em aplicações práticas ou em tempo real, levando a diferentes considerações no desenvolvimento dos métodos Can et al., 1999]. A classificação de todos os pixels das imagens pode ser um processo demorado [Staal et al., 2004], dependendo da escolha do classificador. Na abordagem descrita nessa dissertação, utilizou-se o classificador bayesiano com modelos de misturas gaussianas para as verossimilhanças das classes, permitindo uma classificação rápida com bom desempenho. 


\section{Capítulo 3}

\section{Fundamentos teóricos}

Este capítulo apresenta os fundamentos teóricos usados no desenvolvimento da abordagem proposta para a segmentação dos vasos retínicos, que será apresentada no Capítulo 4 A Seção 3.1 introduz as wavelets, apresentando a transformada wavelet contínua (TWC), de modo breve na versão unidimensional (1D) e com um pouco mais de detalhe na versão bidimensional (2D), que foi explorada nesta dissertação. A Seção 3.2 contém os fundamentos dos classificadores testados nos experimentos, incluindo as qualidades mais importantes de cada.

\subsection{TWC}

\subsubsection{TWC 1D}

A análise de sinais pode ser feita por meio de transformações capazes de evidenciar determinadas características, permitindo o processamento (como estimação de parâmetros, remoção de ruído ou detecção de estruturas) do sinal no domínio da transformada, em que essas características estão mais evidentes. Aqui serão introduzidas brevemente a transformada de Fourier (TF), a TF janelada e finalmente a transformada wavelet contínua (TWC), seguindo a motivação em Daubechies, 1992; Rioul e Vetterli, 1991]. A evolução dessas transformadas tem raízes na análise de Fourier, sendo todas lineares e também inversíveis, quer dizer, capazes de representar completamente o sinal original.

A TF é mais apropriada à análise de sinais estacionários - sinais cujas propriedades não evoluem 
com o tempo - o que decorre de sua própria definição. Dado um sinal $f(x)$, sua TF $\hat{f}(k)$ pode ser definida por

$$
\hat{f}(k)=\int \exp (-i k x) f(x) d x
$$

com $i=\sqrt{-1}$ e $x, k \in \mathbb{R}$ representando, respectivamente, tempo e freqüência. No restante desta subseção, a variável $x$ é interpretada como tempo, porém também pode representar o espaço, como na análise de imagens, preservando as mesmas propriedades. Os coeficientes $\hat{f}(k)$ definem a presença de freqüências globais no sinal através da operação de correlação, que pode também ser vista como um produto escalar que projeta o sinal nas funções base da exponencial complexa.

Não é difícil ver que a TF não é adequada para localizar um fenômeno ou freqüência de curta duração no tempo, mas sim para a análise de sinais estacionários. Por exemplo, uma mudança abrupta no sinal no domínio do tempo acaba se refletindo sobre todo o espectro de freqüências, complicando muito a tarefa de localizá-la. A TF foi primeiramente estendida no contexto de síntese de sinais para representar freqüências locais no tempo Gabor, 1946]. A localização é possível com a restrição do sinal pela multiplicação por uma janela $g(x-b)$ que se desloca no tempo. A partir dela, define-se a TF janelada (também chamada de TF a curto-termo)

$$
U(b, k)=\int g^{*}(x-b) \exp (-i k x) f(x) d x
$$

em que o asterisco denota o conjugado complexo. A TF janelada preserva as propriedades de inversão e linearidade, porém adiciona a posição da janela $b \in \mathbb{R}$ como uma nova dimensão na análise. O domínio de $U(b, k)$ é chamado de plano tempo-freqüência e representa o o desdobramento de $f$ nas duas dimensões. Gabor mostrou que, tomando $g$ como uma gaussiana, a incerteza conjunta da análise no tempo e freqüência é minimizada, propriedade relacionada com o princípio da incerteza de Heisenberg. A TF janelada que utiliza uma janela gaussiana ficou então conhecida como transformada de Gabor. Além de interpretar a transformada como uma análise das freqüências do sinal restrito no tempo pela janela, é também possível enxergar a transformada como a decomposição de $f$ através de sua projeção 
em funções base locais $g_{b, k}(x)=g(x-b) \exp (-i k x)$. Essa interpretação é muito similar à feita na formulação das wavelets que segue. Agora, uma dificuldade que pode surgir com o uso da TF janelada é que o tamanho fixo da janela implica que o sinal é observado sob apenas uma resolução. Isso impede a análise simultânea de freqüências de longa e curta duração, impossibilitando, por exemplo, a localização de singularidades temporais.

Para solucionar a dificuldade da resolução fixa, pode-se variar o tamanho da janela durante a análise, resultando na análise multirresolução. Como observado por Gabor, existe um limite inferior para o produto das resoluções da análise no tempo e freqüência. Isso significa que, quando no limite, o aumento de precisão temporal exige uma compensação na forma de uma diminuição da precisão de freqüência e vice-versa. A transformada wavelet é definida de forma que a razão entre a resolução de freqüência (também conhecida como largura de banda) e a freqüência central sendo observada seja constante. Com isso, freqüências baixas são analisadas com escala temporal grande (baixa precisão temporal, alta precisão de freqüência) e freqüências altas com escala temporal pequena (alta precisão temporal, baixa precisão de freqüência). Portanto, ela é especialmente adequada a sinais com componentes de freqüência baixa de longa duração e de freqüências altas de curta duração, sendo capaz de detectar singularidades Grossmann, 1988; Mallat e Hwang, 1992 e de extrair freqüências instantâneas. Ocorre que essa relação de duração dos componentes de baixa e alta freqüência aparece repetidamente em problemas de diferentes áreas, determinando o sucesso da transformada wavelet. Inclusive, foi a observação desse comportamento em dados sísmicos na prospecção de petróleo que motivou a utilização dessa análise multirresolução, resultando na formalização da teoria da TWC Goupillaud et al., 1984; Grossmann e Morlet, 1984.

A TWC é definida pela introdução do parâmetro de dilatação (escala) $a \in \mathbb{R}$ que atrela o tamanho da janela de observação à freqüência, gerando sempre wavelets de mesmo formato,

$$
U(b, a)=|a|^{-1 / 2} \int \psi^{*}\left(a^{-1}(x-b)\right) f(x) d x,
$$

em que a função $\psi$ é a wavelet protótipo (ou wavelet mãe, ou ainda, analisadora). A definição da wavelet de Morlet esclarece a relação da TWC com a TF janelada, sendo simplesmente a função de Gabor com 
dada freqüência base $k_{0}$

$$
\psi(x)=g(x) \exp \left(-i k_{0} x\right)+\text { correção, }
$$

em que o termo de correção é necessário para garantir a condição de admissibilidade da wavelet (média nula). Assim como a transformada de Gabor, a wavelet de Morlet minimiza a incerteza conjunta nos domínios do tempo e da freqüência, característica desejável na análise wavelet. A transformada $U(b, a)$ tem como domínio o chamado plano tempo-escala, em oposição ao plano tempo-freqüência da TF janelada. Novamente, a transformada pode ser vista como uma decomposição linear do sinal através de sua projeção em funções base $\psi_{b, a}(x)=\psi\left(a^{-1}(x-b)\right)$. Assim, a análise wavelet provê uma decomposição do sinal no plano tempo-escala em diferentes escalas e localizações temporais.

As transformadas wavelet contínua e discreta possuem características distintas que determinam suas aplicações práticas. A transformada wavelet discreta (TWD) se restringe a conjuntos discretos de valores na amostragem de posição e escala e formula wavelets capazes de eliminar ou minimizar a redundância da representação Daubechies, 1992. Inclusive, a TWD é capaz de formar bases ortogonais, que são rápidas e eficientes para a representação de dados discretos, tendo êxito na codificação e reconstrução de sinais. Por outro lado, a TWC não forma bases ortogonais, mas permite que sejam considerados todos os valores de posição e escala, sendo preferida para a análise de sinais em busca de determinadas características.

A teoria de wavelets provê uma visão unificada de várias técnicas desenvolvidas independentemente para processamento de sinais, tendo precursores em Matemática Pura, Física e Engenharia. A transformada wavelet é uma ferramenta bastante versátil. Para citar apenas algumas de suas áreas de aplicação, ela é utilizada em problemas de diversas áreas da física [Daubechies, 1992], codificação de áudio e imagens Rioul e Vetterli, 1991, análise fractal, análise de formas [Costa e Cesar-Jr., 2001] e dados biológicos [Unser e Aldroubi, 1996] (por exemplo detecção de atividade cerebral em ressonância magnética funcional Van De Ville et al., 2004). 


\subsubsection{TWC 2D}

A TWC pode ser estendida para maiores dimensões, permitindo analisar imagens (vistas como funções 2D) e sinais evoluindo no espaço e no tempo, entre outros fenômenos. A generalização para mais dimensões preserva as propriedades fundamentais da transformada 1D, sendo baseada na teoria dos grupos e estados coerentes, que define operações sobre as wavelets no espaço de sinais em questão de modo a preservar noções de simetria. Em 1D, as operações naturais são translação e dilatação, que podem ser estendidas para 2D como translação, dilatação e rotação Antoine et al., 1993; Murenzi, 1990 .

A introdução da operação de rotação na TWC 2D permite a análise de estruturas orientadas se adotadas wavelets direcionais. A TWC é bastante usada para análise e detecção em sinais, em oposição à TWD 2D, que é preferida para síntese ou compressão de dados, por ser bastante rápida e econômica. Como no caso 1D, a TWD 2D é capaz de formar bases ortogonais ou biortogonais, levando a representações eficientes, ao contrário da TWC, que gera bases redundantes. Contudo, a TWD 2D é formulada pelo produto tensorial das análises discretas unidimensionais em cada direção, o que a restringe à geometria cartesiana e dificulta a análise de transições direcionais. Assim, na detecção dos vasos sangüíneos, foi utilizada a TWC 2D com a wavelet de Gabor, apresentada na Seção 3.1.3.

Existem diversas aplicações da TWC 2D em visão computacional e processamento de imagens, como análise de imagens astronômicas, médicas Ferrari et al., 2001], identificação de texturas Manjunath e Ma, 1996, detecção de bordas Mallat e Hwang, 1992; Mallat e Zhong, 1992; Marr e Hildreth, 1980 e análise fractal [Argoul et al., 1990; Arnéodo et al., 2000]. A transformada também possui aplicações em problemas físicos envolvendo imagens, como análise de falhas geológicas, turbulência em fluidos Farge, 1992 e detecção de simetrias de dilatação e rotação Antoine et al., 1999]. A seguir são introduzidas as definições necessárias para entender a TWC 2D, assim como suas propriedades mais importantes.

O plano real $\mathbb{R} \times \mathbb{R}$ é denotado por $\mathbb{R}^{2}$ e seus vetores por letras em negrito, como $\mathbf{x}, \mathbf{b}, \mathbf{k} \in \mathbb{R}^{2}$. As imagens são representadas por funções de energia finita (quadraticamente integráveis) $f \in L^{2}\left(\mathbb{R}^{2}\right)$. O vetor $\mathbf{x}$ representa uma posição espacial nas imagens e $\mathbf{k}$, uma freqüência espacial. O domínio das 
freqüências espaciais é definido pela TF $2 \mathrm{D} \hat{f}$ de uma imagem $f$,

$$
\hat{f}(\mathbf{k})=(2 \pi)^{-1} \int \exp (-i \mathbf{k x}) f(\mathbf{x}) d^{2} \mathbf{x}
$$

A wavelet protótipo, denotada $\psi \in L^{2}\left(\mathbb{R}^{2}\right)$, pode assumir valores complexos e deve satisfazer a condição de admissibilidade, descrita mais adiante. Uma família de wavelets $\left\{\psi_{\mathbf{b}, a, \theta}\right\}$ de mesmo formato é definida por translações, dilatações e rotações (por b, $a$ e $\theta$, respectivamente) da wavelet protótipo, isto é,

$$
\begin{aligned}
\psi_{\mathbf{b}, a, \theta}(\mathbf{x}) & =a^{-1} \psi\left(a^{-1} r_{-\theta}(\mathbf{x}-\mathbf{b})\right) \\
\hat{\psi}_{\mathbf{b}, a, \theta}(\mathbf{k}) & =a \exp (-i \mathbf{b k}) \hat{\psi}\left(a r_{-\theta}(\mathbf{k})\right),
\end{aligned}
$$

em que $a>0$ e $r_{\theta}$ denota a rotação $2 \mathrm{D}$ usual

$$
r_{\theta}(\mathbf{x})=(x \cos \theta-y \sin \theta, x \sin \theta+y \cos \theta), 0 \leq \theta<2 \pi
$$

As operações de translação, dilatação e rotação geram o grupo euclidiano 2D com dilatações atuando sobre $L^{2}\left(\mathbb{R}^{2}\right)$, que será denotado $G$ Antoine et al., 1993.

A TWC $T_{\psi} \in L^{2}(G)$ é definida pelo produto escalar de $f$ com cada wavelet $\psi_{\mathbf{b}, a, \theta}$, como uma função $\operatorname{de}(\mathbf{b}, a, \theta) \in G$ :

$$
\begin{aligned}
T_{\psi}(\mathbf{b}, a, \theta) & =\left\langle\psi_{\mathbf{b}, a, \theta} \mid f\right\rangle \\
& =a^{-1} \int \psi^{*}\left(a^{-1} r_{-\theta}(\mathbf{x}-\mathbf{b})\right) f(\mathbf{x}) d^{2} \mathbf{x} \\
& =a \int \exp (i \mathbf{b k}) \hat{\psi}^{*}\left(a r_{-\theta}(\mathbf{k})\right) \hat{f}(\mathbf{k}) d^{2} \mathbf{k}
\end{aligned}
$$

A transformada é uma representação local nas quatro dimensões de $G$, sendo capaz de evidenciar simetrias de dilatação e rotação [Antoine et al., 1999, Ferrari et al., 2001]. Sendo definida através de uma correlação, ela gera respostas fortes quando a wavelet casar com o sinal, ou seja, quando estiver 
na mesma posição, escala e orientação que o sinal. Uma característica importante é a covariância sob translação, dilatação e rotação. Sendo $T_{\psi}(\mathbf{b}, a, \theta)$ a transformada de $f(\mathbf{x})$, tem-se

$$
\begin{aligned}
f\left(\mathbf{x}-\mathbf{x}_{0}\right) & \mapsto T_{\psi}\left(\mathbf{b}-\mathbf{x}_{0}, a, \theta\right) \\
a_{0}^{-1} f\left(a_{0}^{-1} \mathbf{x}\right) & \mapsto T_{\psi}\left(a_{0}^{-1} \mathbf{b}, a_{0}^{-1} a, \theta\right) \\
f\left(r_{\theta_{0}}(\mathbf{x})\right) & \mapsto T_{\psi}\left(r_{-\theta_{0}}(\mathbf{b}), a, \theta-\theta_{0}\right)
\end{aligned}
$$

A visualização da transformada é importante para entender suas propriedades. Ela pode ser visualizada de duas formas naturais: fixando $a$ e $\theta$, resultando numa função de b (representação de posição) ou, de forma contrária, fixando b, o que resulta numa função de $a$ e $\theta$ (representação escala-ângulo). A representação de posição costuma ser mais apropriada para processamento de imagens, permitindo localizar formas ou características específicas. A representação escala-ângulo permite visualizar todas as escalas ao mesmo tempo, sendo adequada para análise fractal Argoul et al., 1990, Arnéodo et al., 2000 ou da regularidade da transformada na posição fixada. O par $\left(a^{-1}, \theta\right)$ pode também ser interpretado como freqüências espaciais em coordenadas polares.

Se $\psi$ e $\hat{\psi}$ forem bem localizadas, não é difícil ver que a transformada fornece uma filtragem com largura de banda proporcional à freqüência sendo analisada. Assim, da mesma forma que no caso 1D, a análise tem baixa precisão espacial em baixas freqüências e alta precisão espacial em altas freqüências, o que a permite analisar e detectar singularidades, como as bordas presentes em imagens Mallat e Hwang, 1992; Mallat e Zhong, 1992]. A transformada wavelet conserva energia e fornece uma decomposição linear de $f$ em função da família de wavelets $\left\{\psi_{\mathbf{b}, \theta, a}\right\}$, com coeficientes $T_{\psi}(\mathbf{b}, \theta, a)$. Ela pode ser invertida pela fórmula de reconstrução do sinal

$$
f(\mathbf{x})=c_{\psi}^{-1} \iiint_{G} T(\mathbf{b}, a, \theta) \psi_{\mathbf{b}, a, \theta}(\mathbf{x}) a^{-3} d^{2} \mathbf{b} d a d \theta
$$

em que $c_{\psi}$ é uma constante de normalização. A condição de admissibilidade da wavelet, necessária para 
garantir a reconstrução, é

$$
c_{\psi}=(2 \pi)^{2} \int|\hat{\psi}(\mathbf{k})|^{2}|\mathbf{k}|^{-2} d^{2} \mathbf{k}<\infty
$$

No caso de $\psi$ suficientemente regular $\left(\psi \in L^{1}\left(\mathbb{R}^{2}\right) \cap L^{2}\left(\mathbb{R}^{2}\right)\right.$ é suficiente), a condição simplesmente exige que a wavelet tenha média nula,

$$
\hat{\psi}(\mathbf{0})=0 \Longleftrightarrow \int \psi(\mathbf{x}) d^{2} \mathbf{x}=0
$$

Além da condição de admissibilidade, é possível definir algumas condições desejáveis, como a de que $\psi$ e $\hat{\psi}$ sejam bem localizadas e que $\psi$ possua alguns momentos nulos, sendo insensível a polinômios de certos graus.

A informação contida na TWC é bastante redundante, o que pode ser quantificado pelo seu núcleo reprodutor. A projeção de $L^{2}(G)$ sobre a imagem de $W_{\psi}$ (o espaço das transformadas wavelet) é um operador integral cujo núcleo pode ser definido pela TWC de $\psi_{\mathbf{b}, a, \theta}$ por ela mesma,

$$
K\left(\mathbf{b}^{\prime}, a^{\prime}, \theta^{\prime} \mid \mathbf{b}, a, \theta\right)=c_{\psi}^{-1}\left\langle\psi_{\mathbf{b}^{\prime}, a^{\prime}, \theta^{\prime}} \mid \psi_{\mathbf{b}, a, \theta}\right\rangle
$$

O núcleo caracteriza a correlação entre os coeficientes da transformada, permitindo analisar sua redundância e precisão em posição, escala e ângulo. Ele é chamado de reprodutor porque uma função $S_{\psi} \in L^{2}(G)$ será a transformada wavelet de algum sinal $f \in L^{2}\left(\mathbb{R}^{2}\right)$ se e somente se satisfizer a propriedade de reprodução

$$
S_{\psi}\left(\mathbf{b}^{\prime}, a^{\prime}, \theta^{\prime}\right)=\iiint_{G} K\left(\mathbf{b}^{\prime}, a^{\prime}, \theta^{\prime} \mid \mathbf{b}, a, \theta\right) S_{\psi}(\mathbf{b}, a, \theta) a^{-3} d^{2} \mathbf{b} d a d \theta
$$

A transformada wavelet pode ser implementada eficientemente usando a transformada rápida de Fourier Gonzalez e Woods, 2002 e a definição da transformada wavelet no domínio de freqüências espaciais (Equação 3.11). Ela também pode ser implementada diretamente através de correlações espaciais das wavelets filha com a imagem sendo analisada. Para tanto, a wavelet pode ser truncada nas regiões que estão fora de seu suporte espacial. No caso em que a wavelet é bem localizada espacialmente, 
a implementação usando a correlação espacial poderá ficar mais eficiente do que a implementação no domínio de freqüências espaciais.

Como observado anteriormente, a informação contida na TWC é bastante redundante. Na prática, ela é calculada sobre uma família discreta de wavelets $\left\{\psi_{\mathbf{b}_{i}, a_{j}, \theta_{k}}\right\}$. Uma fórmula de reconstrução aproximada é então dada pela soma

$$
\tilde{f}(\mathbf{x})=\sum_{i j k} \psi_{\mathbf{b}_{i}, a_{j}, \theta_{k}} T_{\psi}\left(\mathbf{b}_{i}, a_{j}, \theta_{k}\right)
$$

em que $\tilde{f}$ é a reconstrução aproximada de $f$. Os parâmetros $\mathbf{b}_{i}, a_{j}, \theta_{k}$ devem ser escolhidos de forma a prover uma reconstrução numericamente estável e definem o chamado frame. O estudo das propriedades do núcleo $K$ em relação à precisão da wavelet protótipo em escala e ângulo fornece diretrizes para uma amostragem eficiente, permitindo definir frames que formem coberturas dos domínios do espaço e de freqüências espaciais Antoine et al., 1993; Antoine e Murenzi, 1996. Ainda assim, a representação decorrente será redundante, ao contrário do que ocorre na TWD.

\subsubsection{Wavelet 2D de Gabor}

A wavelet 2D de Gabor vem sendo muito utilizada pela comunidade de visão computacional em diferentes contextos, com ênfase na sua relação com o sistema visual humano. Uma das características mais importantes da wavelet é sua capacidade de detectar estruturas direcionais, ao mesmo tempo que minimiza a incerteza conjunta nos domínios espacial e de freqüências espaciais. A versão 2D do filtro de Gabor provavelmente foi primeiramente apresentada em Daugman, 1980], que, junto com Marčelja, 1980, mostrou a semelhança do filtro com as respostas de células simples do córtex visual. Em [Daugman, 1988, sugeriu-se a generalização do filtro para uma transformada wavelet, o que foi chamado de wavelet de Gabor. Por outro lado, em Antoine et al., 1993, Murenzi, 1990], com base em teoria dos grupos e estados coerentes, apresentou-se a generalização da TWC para duas ou mais dimensões, em que a mesma wavelet foi chamada de wavelet de Morlet, por ser uma generalização natural da wavelet $1 \mathrm{D}$ de Morlet. Na comunidade de visão computacional, usa-se muito o nome wavelet de Gabor, adotado nesta dissertação. A wavelet é explorada em diversas áreas da visão computacional, como 
representação de objetos Krueger e Sommer, 2002; Lee, 1996] (em especial faces [Feris et al., 2004]), detecção e segmentação de texturas Manjunath e Ma, 1996; Sagiv et al., 2002] e análise de estruturas orientadas Chen et al., 2000; Ferrari et al., 2001], tendo mostrado desempenho superior ao de outros filtros lineares Ayres e Rangayyan, 2005].

A wavelet 2D de Gabor é definida como

$$
\begin{aligned}
& \psi_{G}(\mathbf{x})=\exp \left(i \mathbf{k}_{\mathbf{0}} \mathbf{x}\right) \exp \left(-\frac{1}{2}(\mathbf{x} A \mathbf{x})\right)+\text { correção, } \\
& \hat{\psi}_{G}(\mathbf{k})=(\operatorname{det} B)^{1 / 2} \exp \left(-\frac{1}{2}\left(\left(\mathbf{k}-\mathbf{k}_{0}\right) B\left(\mathbf{k}-\mathbf{k}_{0}\right)\right)\right)+\text { correção, }
\end{aligned}
$$

em que $A$ é uma matriz definida positiva $2 \times 2$ (que define a anisotropia da wavelet), $B=A^{-1}$ e $\mathbf{k}_{\mathbf{0}} \in \mathbb{R}^{2}$ define a freqüência da exponencial complexa. Para definir a matriz da anisotropia, toma-se

$$
A=\left[\begin{array}{cc}
\epsilon^{-1} & 0 \\
0 & 1
\end{array}\right],
$$

$\operatorname{com} \epsilon \geq 1$.

A wavelet de Gabor é portanto simplesmente uma gaussiana alongada modulada por uma exponencial complexa, o que deixa clara sua relação com o filtro de Gabor e wavelet de Morlet unidimensionais. Ela difunde o sinal em todas as direções, mas detecta as transições bruscas na direção de $\mathbf{k}_{0}$. No domínio de freqüências espaciais, a wavelet é uma gaussiana centrada em $\mathbf{k}_{0}$ e alongada na direção de $k_{y}$ com o aumento de $\epsilon$. Assim, ela é bem localizada tanto no espaço (ao redor da origem) quanto em freqüências espaciais (ao redor de $\mathbf{k}_{0}$ ). A seletividade angular aumenta com $\left|\mathbf{k}_{0}\right|$ e $\epsilon$. Pode-se combinar os efeitos dos dois parâmetros para obter maior seletividade angular, escolhendo $\mathbf{k}_{0}=\left[0, k_{y}\right]$ e $\epsilon \gg 1$. A Figura 3.1 mostra o efeito da mudança dos parâmetros da wavelet de Gabor nos domínios espacial e de freqüências espaciais.

Para garantir a condição de admissibilidade $\left(\hat{\psi}_{G}(\mathbf{0})=0\right)$, é necessário adicionar os termos de correção à wavelet Antoine et al., 1993. Vale notar que os termos são numericamente desprezíveis para $\left|\mathbf{k}_{0}\right| \geq 5.6$, 


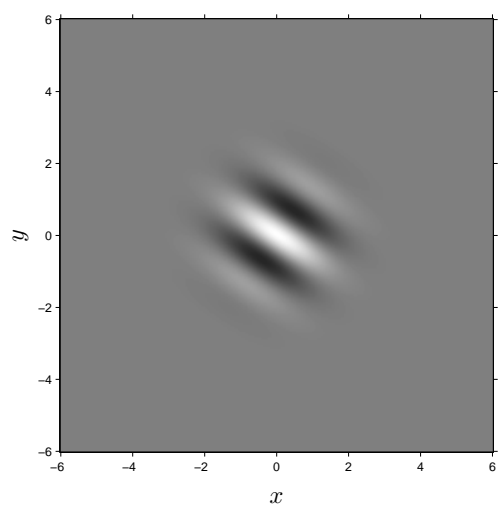

(a) $\Re\left(\psi_{G}\right), \mathbf{k}_{0}=[2,3], \epsilon=1$.

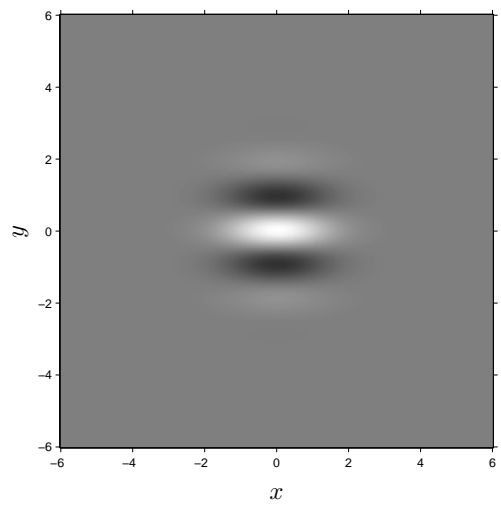

(c) $\Re\left(\psi_{G}\right), \mathbf{k}_{0}=[0,3], \epsilon=1$.

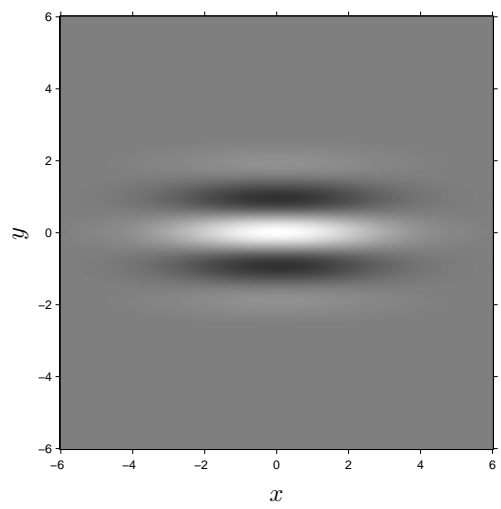

(e) $\Re\left(\psi_{G}\right), \mathbf{k}_{0}=[0,3], \epsilon=4$.

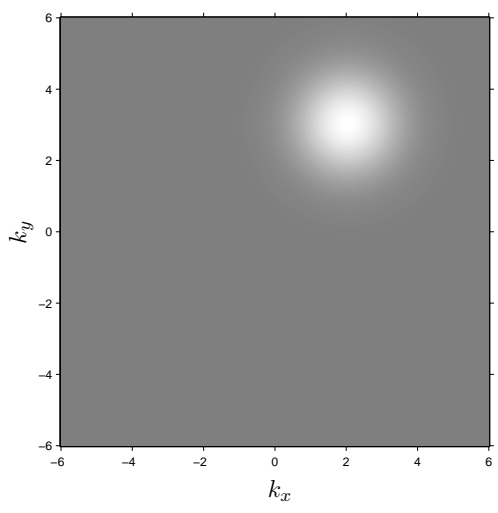

(b) $\hat{\psi}_{G}, \mathbf{k}_{0}=[2,3], \epsilon=1$.

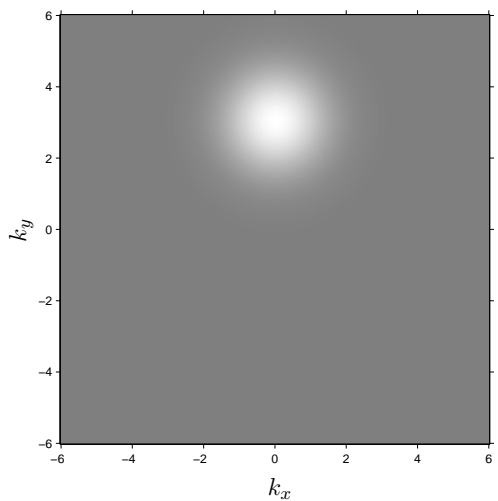

(d) $\hat{\psi}_{G}, \mathbf{k}_{0}=[0,3], \epsilon=1$.

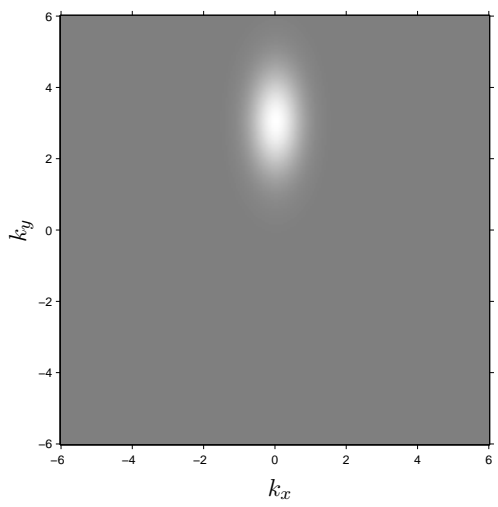

(f) $\hat{\psi}_{G}, \mathbf{k}_{0}=[0,3], \epsilon=4$.

Figura 3.1: A wavelet de Gabor no domínio espacial $\left(\psi_{G}\right)$ e de freqüências espaciais $\left(\hat{\psi}_{G}\right)$ para diferentes valores dos parâmetros $\mathbf{k}_{0}$ e $\epsilon$. As wavelets no domínio espacial estão ilustradas apenas por suas partes reais, $\Re\left(\psi_{G}\right)$. Tons claros e escuros representam, respectivamente, valores positivos e negativos. 
sendo muitas vezes desnecessários. Eles não foram utilizados na implementação realizada, uma vez que a correção implica na perda de localização espacial de wavelet, com $\left|\psi_{G}\right|^{2}$ tornando-se bimodal Harrop et al., 2002. Esse problema deverá ser tratado em trabalhos futuros, como discutido na Seção 6.2 .

Em Antoine e Murenzi, 1996, a definição de uma wavelet direcional é feita a partir de seu suporte no domínio de freqüências espaciais. Segundo a definição, uma wavelet é direcional se sua transformada de Fourier possuir suporte essencial em um cone convexo com vértice na origem, ou uma união finita desses cones, no caso de wavelets multidirecionais (Seção 3.1.4). Uma wavelet que tiver suporte direcional no domínio espacial pode não ser capaz de detectar estruturas direcionais, como o chapéu mexicano anisotrópico, apresentado na Seção 3.1.4. Segundo essa definição, tem-se que a wavelet de Gabor é direcional, tendo suporte na elipse determinada pela gaussiana (alongada) da Equação 3.22 , o que pode ser visto nos exemplos da Figura 3.1. Se a definição for levada com mais rigor, a wavelet é na verdade aproximadamente direcional, dadas as terminações da gaussiana que estão fora da elipse, mas são numericamente desprezíveis. A capacidade de detecção da wavelet de Gabor foi analisada em função de sua precisão em escala e ângulo, o que também permite definir famílias de wavelets que formem coberturas das freqüências espaciais. As condições para definir essas famílias, chamadas de frames, foram estudadas em Antoine et al., 1993; Antoine e Murenzi, 1996; Lee, 1996.

Dada a capacidade da wavelet de Gabor ser ajustada para freqüências específicas, ela pôde ser ajustada para realçar os vasos e ao mesmo tempo filtrar ruídos do fundo da retina (ver Seção 4.2). Os parâmetros foram ajustados para $\epsilon=4$, gerando uma wavelet alongada e $\mathbf{k}_{\mathbf{0}}=[0,3]$, fornecendo uma exponencial de baixa freqüência com transições na direção do menor eixo da wavelet, como nas Figuras 3.1(e) e 3.1(f). A capacidade de detectar estruturas orientadas é fundamental para a detecção dos vasos sangüíneos. Note que o formato da wavelet é localmente similar ao dos vasos sangüíneos e não se altera em escalas e orientações diferentes. Assim, produz respostas fortes quando na posição, orientação e escala correspondente a um vaso através da operação do produto escalar. 


\subsubsection{Outras wavelets 2D}

Muitas outras wavelets 2D foram apresentadas na literatura para tratar problemas específicos, das quais algumas mais conhecidas serão descritas a seguir. Para uma revisão mais completa, a referência Antoine e Murenzi, 1996] pode ser consultada.

\section{Wavelets de Cauchy}

Para obter wavelets estritamente direcionais segundo a definição dada na Seção 3.1.3, foram introduzidas as wavelets 2D de Cauchy Antoine et al., 1999]. As wavelets são definidas diretamente em freqüências espaciais de forma que tenham suporte estritamente em um cone convexo $S$ e dentro dele se comportem como um polinômio $2 \mathrm{D}$ restrito por um envelope gaussiano, isto é, $P(\mathbf{k}) \exp (-\boldsymbol{\alpha} \mathbf{k})$, com $\boldsymbol{\alpha} \in S$, em que $P$ denota o polinômio bidimensional.

\section{Wavelets multidirecionais}

Dada uma wavelet direcional $\psi$, é fácil construir uma multidirecional pela sobreposição de $n$ cópias rotacionadas da wavelet original:

$$
\psi_{n}(\mathbf{x})=\frac{1}{n} \sum_{k=0}^{n-1} \psi\left(r_{-\theta_{k}}(\mathbf{x})\right), \quad \theta_{k}=k \frac{2 \pi}{n}, \quad k=0,1, \ldots, n-1 .
$$

Por exemplo, tomando a wavelet de Gabor $\psi_{G} \operatorname{com} \epsilon=1, \mathbf{k}_{0}=\left[0, k_{0}\right]$ e $n=4$, obtém-se

$$
\psi_{4 G}(\mathbf{x})=\frac{1}{2}\left(\cos \left(k_{0} x\right)+\cos \left(k_{0} y\right)\right) \exp \left(-\frac{1}{2}|\mathbf{x}|^{2}\right)
$$

O resultado é uma wavelet real que detecta estruturas verticais e horizontais, descartando as demais. De forma análoga, constroem-se pode-se detectar simetrias com $n=6$ ou $n=10$, o que pode ter aplicações, respectivamente, em problemas biológicos ou de análise de cristais. Outras construções de wavelets multidirecionais também são possíveis, como em [Pei e Jaw, 1994]. As wavelets multidirecionais permitem a detecção de simetrias locais ou globais de imagens, como na análise de ângulos de bifurcação de fractais apresentada em Arrault e Pouligny, 1996. 


\section{Chapéu mexicano 2D}

O chapéu mexicano 2D foi primeiramente introduzido em [Marr e Hildreth, 1980] e é definido pela extensão de sua definição em 1D. A definição mais genérica da wavelet é

$$
\begin{aligned}
& \psi_{M}(\mathbf{x})=(2-\mathbf{x} A \mathbf{x}) \exp \left(-\frac{1}{2}(\mathbf{x} A \mathbf{x})\right) \\
& \hat{\psi}_{M}(\mathbf{k})=|\operatorname{det} B|(\mathbf{k} B \mathbf{k}) \exp \left(-\frac{1}{2}(\mathbf{k} B \mathbf{k})\right),
\end{aligned}
$$

em que $A$ e $B$ são definidos como na Seção 3.1 .3 . O chapéu mexicano está ilustrado na Figura 3.2 no domínio espacial e de freqüências espaciais, para $\epsilon=1$ e $\epsilon=4$. É importante observar que, mesmo com $\epsilon \neq 1$, ele funciona como um operador de segunda ordem em todas as direções. Não é adequado, portanto, para a detecção de estruturas direcionais e na grande maioria dos casos, não compensa utilizálo com $\epsilon \neq 1$. A wavelet não satisfaz a definição de wavelet direcional (Seção 3.1.3), o que fica claro na Figura 3.2. Ela não possui boa seletividade angular, mas sim espacial, sendo mais adequada a análises pontuais. Quando $\epsilon=1$, a matriz $A$ é a identidade, resultando numa wavelet isotrópica equivalente ao laplaciano de uma gaussiana, filtro extensivamente utilizado em processamento de imagens. Podese também tomar o laplaciano em ordens maiores, gerando wavelets com mais momentos nulos. A wavelet isotrópica perde a dependência em $\theta$ (por ser invariante a rotações), simplificando a análise e reconstrução.

\section{Wavelets diferença}

Uma classe importante de wavelets é daquelas formadas pela diferença entre duas funções positivas.

É comum usar a diferença entre uma função e uma versão contraída da mesma. Dada uma função não negativa $h$ integrável e quadraticamente integrável, com todos os momentos de ordem um nulos na origem, a função $\psi_{h}$ dada por

$$
\psi_{h}(\mathbf{x})=\alpha^{-2} h\left(-\alpha^{1} \mathbf{x}\right)-h(\mathbf{x}), \quad(0<\alpha<1)
$$




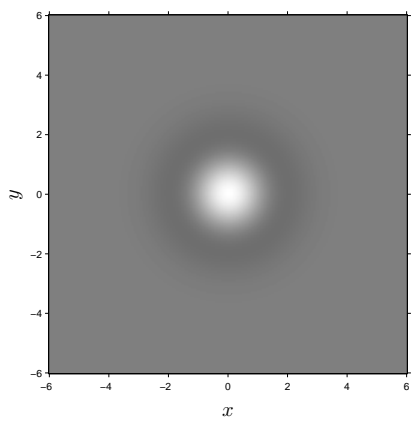

(a) $\psi_{M}, \operatorname{com} \epsilon=1$.

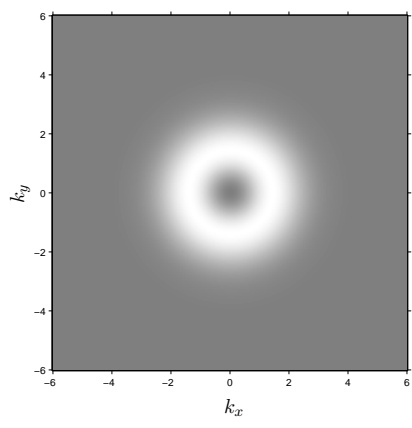

(b) $\hat{\psi}_{M}, \operatorname{com} \epsilon=1$.

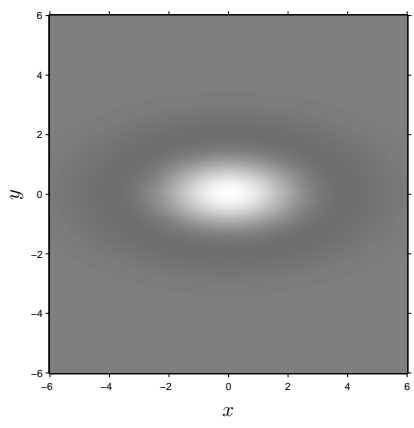

(c) $\psi_{M}, \operatorname{com} \epsilon=4$.

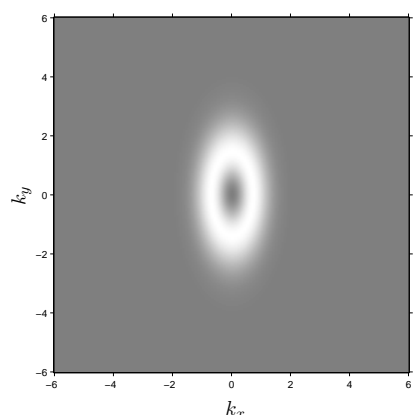

(d) $\hat{\psi}_{M}, \operatorname{com} \epsilon=4$.

Figura 3.2: O chapéu mexicano no domínio espacial $\left(\psi_{M}\right)$ e de freqüências espaciais $\left(\hat{\psi}_{M}\right)$ para $\epsilon=1$ e $\epsilon=4$. Tons claros e escuros representam, respectivamente, valores positivos e negativos.

é uma wavelet satisfazendo a condição de admissibilidade Antoine e Murenzi, 1996. Como exemplo típico, temos a diferença de gaussianas,

$$
\psi_{D}(\mathbf{x})=\alpha^{-2} \exp \left(-\frac{|\mathbf{x}|^{2}}{2 \alpha^{2}}\right)-\exp \left(-\frac{|\mathbf{x}|^{2}}{2}\right), \quad(0<\alpha<1)
$$

A diferença de gaussianas é bastante usada em estudos psicofísicos Daugman, 1980; Marr e Hildreth, 1980 e pode substituir o chapéu mexicano por ter um formato similar.

Tomando $h$ como o formato de um objeto conhecido a priori, $\psi_{h}$ será especialmente adequada para a análise do objeto, funcionando de forma similar a filtros casados [Antoine et al., 1995]. Vale ressaltar que também é possível obter wavelets direcionais usando essa construção, a partir da diferença de funções não isotrópicas.

\subsection{Classificação supervisionada}

Na abordagem de segmentação dos vasos proposta, os pixels das imagens são vistos como objetos representados por vetores de características, permitindo a aplicação de classificadores estatísticos para a geração da segmentação. No caso, cada pixel é classificado como pertencente à classe vaso ou não vaso, usando classificação supervisionada. Os conjuntos de treinamento dos classificadores são formados 
a partir das segmentações manuais das imagens de treinamento da seguinte forma: os pixels segmentados manualmente são rotulados como vaso, enquanto os restantes recebem o rótulo de não vaso. A abordagem permite o uso de diferentes respostas da transformada wavelet para caracterizar os pixels, bem como a aplicação dos métodos a diferentes modalidades de imagens, desde que acompanhadas de um conjunto de treinamento adequado. A seguir são apresentados os fundamentos e qualidades importantes dos três classificadores usados nos experimentos: o classificador bayesiano usando modelos de mistura gaussiana (Seções 3.2.1 e 3.2.2), o classificador dos $k$ vizinhos mais próximos (Seção 3.2.3) e o classificador linear de erro quadrático mínimo (Seção 3.2.4).

\subsubsection{Teoria de decisão bayesiana}

A teoria de decisão bayesiana é umas das principais abordagens adotadas em problemas de reconhecimentos de padrões. Ela é baseada em atribuir custos (ou perdas) às decisões de classificação corretas e incorretas e tomar decisões usando as distribuições de probabilidades dos objetos sendo classificados. Em geral, as distribuições são desconhecidas e precisam ser estimadas, o que pode ser feito utilizando conhecimentos a priori sobre a estrutura probabilística em conjunto com dados de treinamento. A regra de classificação de Bayes para um vetor de características observado $\mathbf{v}$ em um problema com duas classes $C_{1}$ e $C_{2}$ pode ser escrita em termos de probabilidades posteriores como:

$$
\begin{aligned}
& \text { escolha } C_{1} \text { se } P\left(C_{1} \mid \mathbf{v}\right)>P\left(C_{2} \mid \mathbf{v}\right) \text {; } \\
& \text { caso contrário, escolha } C_{2} .
\end{aligned}
$$

Essa decisão segue a intuição natural e minimiza a esperança da probabilidade de erro, como mostrado a seguir. A probabilidade de erro para dado vetor observado v é

$$
P(\text { erro } \mid \mathbf{v})=\left\{\begin{array}{l}
P\left(C_{1} \mid \mathbf{v}\right), \text { se foi escolhida } C_{2} \\
P\left(C_{2} \mid \mathbf{v}\right), \text { se foi escolhida } C_{1}
\end{array} .\right.
$$


Assim, a esperança da probabilidade de erro é

$$
P(\text { erro })=\int P(\text { erro, } \mathbf{v}) d \mathbf{v}=\int P(\operatorname{erro} \mid \mathbf{v}) p(\mathbf{v}) d \mathbf{v}
$$

e, ao minimizar $P($ erro|v) para todo $\mathbf{v}$ através da escolha da classe com maior probabilidade posterior (Equação 3.30), minimiza-se a esperança da probabilidade de erro.

A regra de Bayes é escrita como

$$
P\left(C_{i} \mid \mathbf{v}\right)=\frac{p\left(\mathbf{v} \mid C_{i}\right) P\left(C_{i}\right)}{p(\mathbf{v})}
$$

em que $p\left(\mathbf{v} \mid C_{i}\right)$ é a função densidade de probabilidade condicional à classe, também conhecida como verossimilhança, $P\left(C_{i}\right)$ é a probabilidade a priori da classe $C_{i}$ e $p(\mathbf{v})$ é a função de densidade de probabilidade de $\mathbf{v}$. Para obter uma regra de decisão baseada em estimativas do conjunto de treinamento (como será feito na Seção 3.2.2), a regra de Bayes pode ser aplicada à Equação 3.30, obtendo a regra de decisão equivalente:

escolha $C_{1}$ se $p\left(\mathbf{v} \mid C_{1}\right) P\left(C_{1}\right)>p\left(\mathbf{v} \mid C_{2}\right) p\left(C_{2}\right)$;

caso contrário, escolha $C_{2}$.

A regra de classificação de Bayes pode ser estendida para o caso em que existem perdas associadas às decisões de classificação. Sejam $\alpha_{1}$ e $\alpha_{2}$ as decisões de escolher respectivamente as classes $C_{1}$ e $C_{2}$ para dada amostra v. A perda esperada (ou risco) da decisão $\alpha_{i}$ condicionada a dada amostra pode ser escrita como

$$
R\left(\alpha_{i} \mid \mathbf{v}\right)=\lambda\left(\alpha_{i} \mid C_{1}\right) P\left(C_{1} \mid \mathbf{v}\right)+\lambda\left(\alpha_{i} \mid C_{2}\right) P\left(C_{2} \mid \mathbf{v}\right),
$$

em que a função $\lambda\left(\alpha_{i} \mid C_{j}\right)$ indica o perda associada a escolher $\alpha_{i}$ para uma amostra da classe $C_{j}$.

De forma análoga à da derivação da regra de classificação que minimiza a esperança da probabilidade de erro (Equações 3.30 3.31 e 3.32, é simples mostrar que o conjunto de decisões que minimiza a perda condicional em cada amostra minimiza também a perda esperada total Duda et al., 2001. A perda 
esperada total (ou risco total) mínima é chamada de risco de Bayes e fornece o melhor desempenho possível. Dada uma amostra v, a regra de classificação de Bayes com perdas que atinge a perda esperada mínima é dada por:

escolha $C_{1}$ se $R\left(\alpha_{1} \mid \mathbf{v}\right)<R\left(\alpha_{2} \mid \mathbf{v}\right)$;

caso contrário, escolha $C_{2}$.

Pode-se expressar a decisão em termos de probabilidades posteriores, ou ainda, aplicando a regra de Bayes (Equação 3.33) para expressá-la usando as verossimilhanças e probabilidades a priori. Deve-se escolher $C_{1}$ se $R\left(\alpha_{1} \mid \mathbf{v}\right)<R\left(\alpha_{2} \mid \mathbf{v}\right)$, que é reescrito usando a definição da Equação 3.35 como

$$
\begin{aligned}
\lambda\left(\alpha_{1} \mid C_{1}\right) P\left(C_{1} \mid \mathbf{v}\right)+\lambda\left(\alpha_{1} \mid C_{2}\right) P\left(C_{2} \mid \mathbf{v}\right) & <\lambda\left(\alpha_{2} \mid C_{1}\right) P\left(C_{1} \mid \mathbf{v}\right)+\lambda\left(\alpha_{2} \mid C_{2}\right) P\left(C_{2} \mid \mathbf{v}\right) \\
\left(\lambda\left(\alpha_{1} \mid C_{1}\right)-\lambda\left(\alpha_{2} \mid C_{1}\right)\right) P\left(C_{1} \mid \mathbf{v}\right) & <\left(\lambda\left(\alpha_{2} \mid C_{2}\right)-\lambda\left(\alpha_{1} \mid C_{2}\right)\right) P\left(C_{2} \mid \mathbf{v}\right)
\end{aligned}
$$

e aplicando a regra de Bayes, escolhe-se $C_{1}$ se

$$
\left(\lambda\left(\alpha_{1} \mid C_{1}\right)-\lambda\left(\alpha_{2} \mid C_{1}\right)\right) p\left(\mathbf{v} \mid C_{1}\right) P\left(C_{1}\right)<\left(\lambda\left(\alpha_{2} \mid C_{2}\right)-\lambda\left(\alpha_{1} \mid C_{2}\right)\right) p\left(\mathbf{v} \mid C_{2}\right) P\left(C_{2}\right)
$$

e $C_{2}$ caso contrário.

Nos experimentos realizados, a função de perda usada foi a simétrica ou zero-um, dada por

$$
\lambda\left(\alpha_{i} \mid C_{j}\right)=\left\{\begin{array}{l}
0, \text { se } i=j \\
1, \text { se } i \neq j
\end{array}\right.
$$

que resulta simplesmente na regra de classificação de Bayes das Equações 3.30 e 3.34 . Contudo, a classificação usando outras funções de perda pode ser uma alternativa interessante, principalmente na classificação dos pixels nas classes vaso e não vaso. Além disso, sua compreensão permite esclarecer os princípios da análise ROC, apresentados na Seção 4.5 . 


\subsubsection{Classificador bayesiano usando modelos de mistura gaussiana}

Nesta seção, será apresentado o classificador bayesiano em que as funções de densidade de probabilidade de cada classe (verossimilhanças) são descritas pelo modelo de mistura gaussiana (MMG), dado pela combinação linear de funções gaussianas Duda et al., 2001; Theodoridis e Koutroumbas, 1999]. Esse classificador será chamado de classificador MMG.

Seguindo a teoria de decisão bayesiana, pode-se determinar a decisão de classificação usando estimativas das verossimilhanças e probabilidades a priori. Nos experimentos realizados, as probabilidades a priori $P\left(C_{i}\right)$ são estimadas por $N_{i} / N$, a fração de amostras da classe $i$ no conjunto de treinamento. As verossimilhanças das classes, por sua vez, são descritas pelas combinações lineares de funções gaussianas do MMG. O procedimento que estima as verossimilhanças, descrito a seguir, é aplicado separadamente para a verossimilhança de cada classe. Para simplificar a notação, suponha que a classe $C_{i}$ cuja distribuição será modelada foi fixada. Com isso, a verossimilhança da classe (antes denotada $p\left(\mathbf{v} \mid C_{i}\right)$ ) será denotada $p(\mathbf{v} \mid \phi)$ e modelada por

$$
p(\mathbf{v} \mid \phi)=\sum_{j=1}^{c} P_{j} p\left(\mathbf{v} \mid \phi_{j}\right)
$$

em que são usadas $c$ gaussianas, dadas por $p\left(\mathbf{v} \mid \phi_{j}\right)$ e pesos $P_{j}$. Cada $\phi_{j}$ descreve os parâmetros da gaussiana $j$ e $\phi \equiv\left\{\phi_{1}, \ldots, \phi_{c}, P_{1}, \ldots, P_{c}\right\}$ é o conjunto completo de parâmetros que descrevem o modelo. As funções gaussianas $p\left(\mathbf{v} \mid \phi_{j}\right)$ são

$$
p\left(\mathbf{v} \mid \phi_{j}\right)=\frac{1}{\sqrt{\operatorname{det}\left(2 \pi \Sigma_{j}\right)}} \exp \left(-\frac{1}{2}\left(\mathbf{v}-\boldsymbol{\mu}_{j}\right)^{T} \Sigma_{j}^{-1}\left(\mathbf{v}-\boldsymbol{\mu}_{j}\right)\right) .
$$

em que $\phi_{j}=\left\{\boldsymbol{\mu}_{j}, \Sigma_{j}\right\}, \boldsymbol{\mu}_{j}$ é a média e $\Sigma_{j}$ a matriz de covariância que descreve a gaussiana. Para que $p(\mathbf{v} \mid \phi)$ seja uma função de densidade de probabilidade, é necessário que

$$
\sum_{j=1}^{c} P_{j}=1 \quad \text { e } \quad \int p\left(\mathbf{v} \mid \phi_{j}\right) d \mathbf{v}=1, j=1, \ldots, c .
$$

MMGs são bastante usados para agrupamento em classificação não supervisionada. Para tanto, cada 
gaussiana modela a verossimilhança de uma classe com distribuição anteriormente desconhecida em que os pesos atribuídos às gaussianas representam as probabilidades a priori. Aqui, o MMG é usado de outra forma, na descrição das verossimilhanças das classes com amostras já rotuladas. O MMG permite que as verossimilhanças sejam modeladas com precisão arbritrária, sendo um modelo flexível e aplicável a distribuições complexas e multimodais. Em ambos os usos citados do modelo, existe a necessidade de estimar os parâmetros e pesos das gaussianas a partir dos dados.

Para a estimação dos parâmetros do MMG, assume-se que a distribuição a priori dos parâmetros $\phi$ é desconhecida. Assim, eles são estimados de modo a maximizar a verossimilhança dos dados. Seja um conjunto $\mathcal{D}=\left\{\mathbf{v}_{1}, \cdots, \mathbf{v}_{M}\right\}$ de $M$ amostras (que no caso é formado pelo conjunto de treinamento da classe sendo analisada). Sua função de verossimilhança é dada por

$$
p(\mathcal{D} \mid \phi)=\prod_{k=1}^{M} p\left(\mathbf{v}_{k} \mid \phi\right)
$$

A log-verossimilhança é então dada por

$$
\log p(\mathcal{D} \mid \boldsymbol{\phi})=\log \prod_{k=1}^{M} p\left(\mathbf{v}_{k} \mid \boldsymbol{\phi}\right)=\sum_{k=1}^{M} \log \sum_{j=1}^{c} P_{j} p\left(\mathbf{v}_{k} \mid \boldsymbol{\phi}_{j}\right)
$$

Os parâmetros $\phi$ entram na verossimilhança de forma não-linear, necessitando de técnicas de otimização não-linear para maximizá-la. Aqui os parâmetros serão estimados usando o algoritmo Expectation-Maximization (EM) Dempster et al., 1977; Duda et al., 2001; Theodoridis e Koutroumbas, 1999. O EM é um algoritmo iterativo muito usado na estimação de parâmetros de modelos de mistura e em outros domínios e garante um máximo local da função sendo maximizada, podendo ser aplicado à maximização de verossimilhanças ou probabilidades posteriores. Ele é especialmente adequado a problemas em que existe um conjunto de dados incompleto, sendo que o problema em questão pode ser interpretado por essa perspectiva. O conjunto de dados $\mathcal{D}$ estaria incompleto pela ausência dos rótulos $\mathcal{J}=\left\{j_{1}, \ldots, j_{M}\right\}$ indicando a gaussiana $j_{k}$ de que cada amostra $\mathbf{v}_{k}$ teria sido gerada. No restante da discussão, $\mathcal{C}=\{\mathcal{D}, \mathcal{J}\}$ será o conjunto de dados completo e $\mathcal{D}$ será chamado de conjunto de dados 
incompletos. Nessa nova formulação, maximiza-se a verossimilhança dos dados completos

$$
\log p(\mathcal{C} \mid \phi)=\log \prod_{k=1}^{M} p\left(\mathbf{v}_{k}, j_{k} \mid \phi\right)=\sum_{k=1}^{M} \log \left(P_{j_{k}} p\left(\mathbf{v}_{k} \mid \phi_{j_{k}}\right)\right) .
$$

Os rótulos $\mathcal{J}$ são desconhecidos e podem ser vistos como variáveis aleatórias que governam a distribuição da verossimilhança. A dificuldade na estimação de $\phi$ que maximizasse a verossimilhança viria do fato desses rótulos não serem conhecidos. Se fossem, para cada gaussiana haveria um problema independente que poderia ser resolvido analiticamente. O algoritmo EM maximiza então a esperança da verossimilhança dos dados completos, condicionada nos dados observados e numa estimativa anterior dos parâmetros. A esperança é dada por

$$
Q\left(\phi, \phi^{i-1}\right) \equiv E_{\mathcal{J}}\left[\log p(\mathcal{C} \mid \phi) \mid \mathcal{D}, \phi^{i-1}\right]
$$

em que $E_{\mathcal{J}}$ é a esperança tomada sobre os dados não observados $\mathcal{J}$ e $\phi^{i-1}$ é a estimativa anterior dos parâmetros. Note que na expressão anterior, tanto os dados observados $\mathcal{D}$ como a estimativa anterior $\phi^{i-1}$ são fixados. Com isso, a esperança pode ser calculada analiticamente e maximizada, resultando numa nova estimativa

$$
\phi^{i}=\underset{\phi}{\operatorname{argmax}} Q\left(\phi, \phi^{i-1}\right)
$$

Pode-se mostrar que as estimativas sucessivas $\phi^{i}$ nunca diminuem a verossimilhança dos dados completos nem dos incompletos, convergindo para máximos locais de ambas [Dempster et al., 1977]. Existe uma variação do algoritmo, o EM generalizado, que apenas busca $\phi^{i}$ tal que haja alguma melhora no valor de $Q\left(\phi, \phi^{i-1}\right)$, isto é, tal que $Q\left(\phi^{i}, \phi^{i-1}\right)>Q\left(\phi^{i-1}, \phi^{i-1}\right)$ e também é capaz de garantir convergência. No problema em questão, é possível maximizar $Q\left(\phi^{i}, \phi^{i-1}\right)$ a cada passo, sendo utilizado o EM tradicional.

O algoritmo EM produz uma seqüência de estimativas $\left\{\phi^{i}, i=0,1,2, \ldots\right\}$ até que o critério de convergência seja satisfeito. Ele é inicializado com uma estimativa $\phi^{0}$ e alterna sucessivamente os passos de cálculo da esperança (Equação 3.47) e sua maximização (Equação 3.48). No caso do MMG, os passos do algoritmo ficam da seguinte forma: 
- Esperança: usando as Equações 3.46 e 3.47, na iteração $i$ do algoritmo tem-se

$$
\begin{aligned}
Q\left(\boldsymbol{\phi}, \boldsymbol{\phi}^{(i-1)}\right) & =E_{\mathcal{J}}\left[\log p(\mathcal{C} \mid \boldsymbol{\phi}) \mid \mathcal{D}, \boldsymbol{\phi}^{(i-1)}\right] \\
& =E_{\mathcal{J}}\left[\sum_{k=1}^{M} \log \left(P_{j_{k}} p\left(\mathbf{v}_{k} \mid \boldsymbol{\phi}_{j_{k}}\right)\right) \mid \mathcal{D}, \boldsymbol{\phi}^{(i-1)}\right] \\
& =\sum_{k=1}^{M} E_{\mathcal{J}}\left[\log \left(P_{j_{k}} p\left(\mathbf{v}_{k} \mid \boldsymbol{\phi}_{j_{k}}\right)\right) \mid \mathcal{D}, \boldsymbol{\phi}^{(i-1)}\right] \\
& =\sum_{k=1}^{M} \sum_{j_{k}=1}^{c} P\left(j_{k} \mid \mathbf{v}_{k}, \boldsymbol{\phi}^{i-1}\right) \log \left(P_{j_{k}} p\left(\mathbf{v}_{k} \mid \boldsymbol{\phi}_{j_{k}}\right)\right) .
\end{aligned}
$$

Como na equação anterior somamos todos os valores de $j_{k}$ para todo valor de $k$, no restante da discussão a notação será simplificada eliminando o índice $k$ de $j_{k}$. A distribuição acima é calculada para que seja maximizada no passo seguinte (de maximização). Assim, calculam-se os valores de $P\left(j \mid \mathbf{v}_{k}, \phi^{i-1}\right)$ usando a regra de Bayes:

$$
\begin{gathered}
P\left(j \mid \mathbf{v}_{k}, \phi^{i-1}\right)=\frac{p\left(\mathbf{v}_{k} \mid \phi_{j}^{i-1}\right) P_{j}^{i-1}}{p\left(\mathbf{v}_{k} \mid \phi^{i-1}\right)}, \\
p\left(\mathbf{v}_{k} \mid \phi^{i-1}\right)=\sum_{j=1}^{c} p\left(\mathbf{v}_{k} \mid \phi_{j}^{i-1}\right) P_{j}^{i-1},
\end{gathered}
$$

em que $\phi_{j}^{i-1}$ e $P_{j}^{i-1}$ são, respectivamente, as estimativas anteriores dos parâmetros e peso da gaussiana $j$.

- Maximização: neste passo, a esperança $Q\left(\phi, \phi^{i-1}\right)$ calculada no passo anterior é maximizada, resultando na nova estimativa dos parâmetros. A maximização é feita sob a restrição de que $\sum_{j=1}^{c} P_{j}=1$, usando o lagrangiano da esperança. Após alguma álgebra Bilmes, 1997, obtém-se

$$
P_{j}^{i}=\frac{1}{M} \sum_{k=1}^{M} P\left(j \mid \mathbf{v}_{k}, \phi^{i-1}\right),
$$




$$
\begin{gathered}
\boldsymbol{\mu}_{j}^{i}=\frac{\sum_{k=1}^{M} P\left(j \mid \mathbf{v}_{k}, \phi^{i-1}\right) \mathbf{v}_{k}}{\sum_{k=1}^{M} P\left(j \mid \mathbf{v}_{k}, \phi^{i-1}\right)}, \\
\sum_{j}^{i}=\frac{\sum_{k=1}^{M} P\left(j \mid \mathbf{v}_{k}, \phi^{i-1}\right)\left(\mathbf{v}_{k}-\boldsymbol{\mu}_{j}^{i}\right)\left(\mathbf{v}_{k}-\boldsymbol{\mu}_{j}^{i}\right)^{T}}{\sum_{k=1}^{M} P\left(j \mid \mathbf{v}_{k}, \phi^{i-1}\right)}
\end{gathered}
$$

em que $P\left(j \mid \mathbf{v}_{k}, \phi^{i-1}\right)$ foi calculada segundo as Equações 3.52 e 3.53 no passo anterior.

Na inicialização, as médias $\boldsymbol{\mu}_{j}$ correspondem a amostras observadas escolhidas aleatoriamente e as matrizes de covariância $\Sigma_{j}$ são matrizes identidade. Inicializações mais cuidadosas podem favorecer a convergência mais rápida ou para máximos locais melhores [Figueiredo e Jain, 2002]. A convergência pode ser detectada pela condição $Q\left(\phi^{i+1}, \phi^{i}\right)-Q\left(\phi^{i}, \phi^{i-1}\right) \leq T$, em que $T$ é um parâmetro que pode ser definido em função do tamanho do conjunto de dados $M$.

O algoritmo pode ser entendido intuitivamente da seguinte forma. Na iteração $i$ do algoritmo, cada amostra $\mathbf{v}_{k}$ possui uma certa participação no peso da gaussiana $j$, representada por $P\left(j \mid \mathbf{v}_{k}, \phi^{i-1}\right)$, que foi calculada usando os parâmetros anteriores das gaussianas, $\phi^{i-1}$ (Equações 3.52 e 3.53 . O cálculo dos novos pesos $\left(P_{j}^{i}\right)$, médias $\left(\boldsymbol{\mu}_{j}^{i}\right)$ e covariâncias $\left(\Sigma_{j}^{i}\right)$ pode ser visto simplesmente como o cálculo dessas estatísticas a partir dos dados, ponderadas pelas participações $P\left(j \mid \mathbf{v}_{k}, \phi^{i-1}\right)$ (Equações 3.54 . 3.55 e 3.56 . As participações são então recalculadas usando os novos parâmetros, iniciando uma nova iteração. A Figura 3.3 ilustra algumas iterações do algoritmo sobre um conjunto de amostras da classe vaso provenientes de imagens de treinamento.

As matrizes de covariância podem ser restritas de diferentes formas, levando a variações do algoritmo. Pode-se assumir que elas são diagonais ou então completas mas todas iguais, o que reduz o número de parâmetros desconhecidos, adequado para situações com um número reduzido de amostras observadas. Uma restrição maior é assumir que as matrizes são sempre algum múltiplo da identidade. Se, além disso, os pesos das gaussianas tiverem de ser iguais, o algoritmo resultante será equivalente ao conhecido fuzzy $k$-médias. Pode-se ainda restringir as probabilidades $P\left(j \mid \mathbf{v}_{k}, \phi^{i}\right)$ de forma a obter o $k$-médias tradicional Duda et al., 2001.

O algoritmo EM como descrito apresenta algumas dificuldades. Primeiramente, pode convergir 


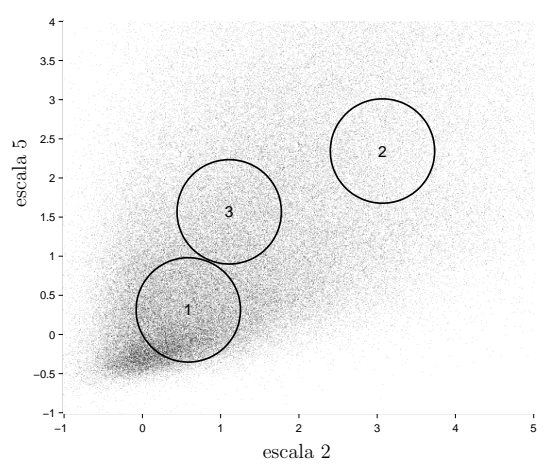

(a) Inicialização.

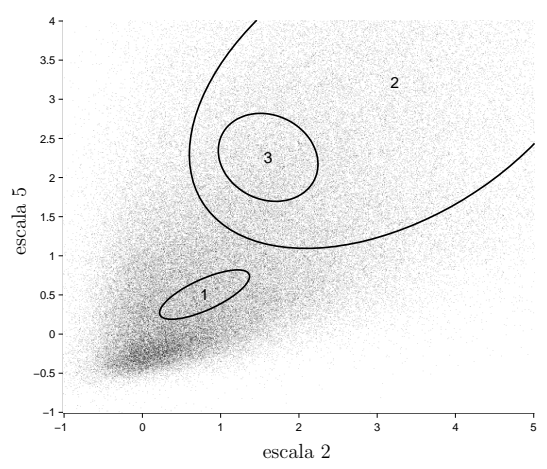

(d) Iteração 3.

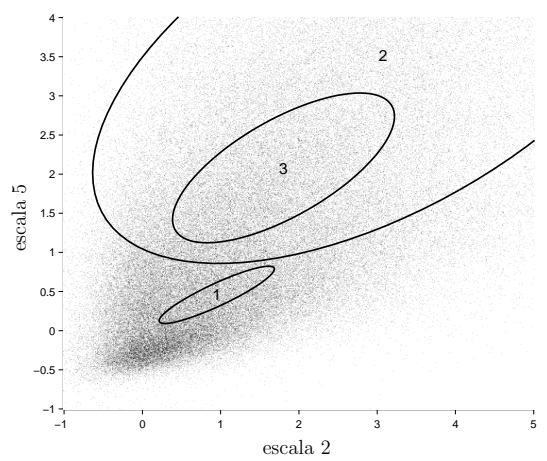

(g) Iteração 10.

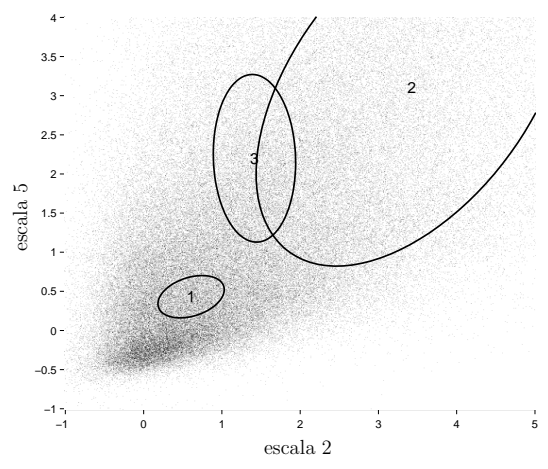

(b) Iteração 1.

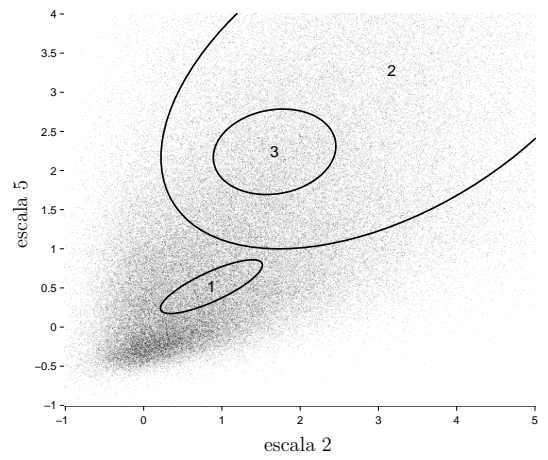

(e) Iteração 4.

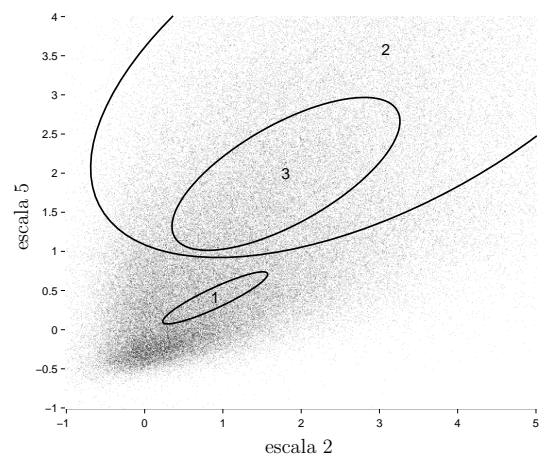

(h) Iteração 15.

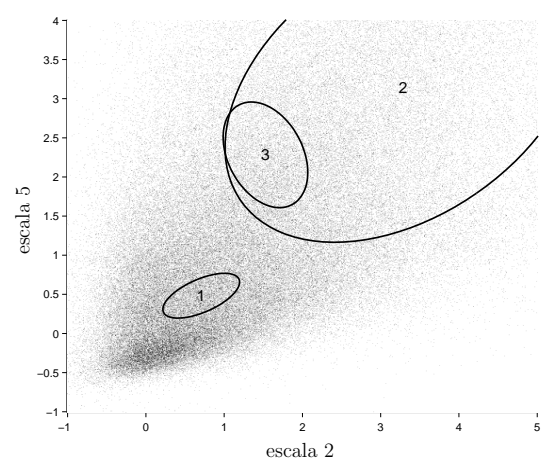

(c) Iteração 2 .

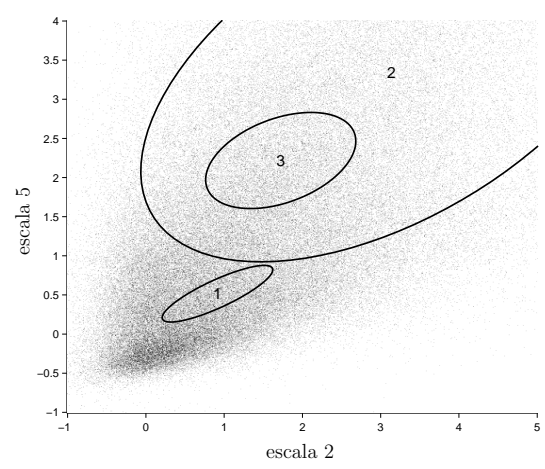

(f) Iteração 5 .

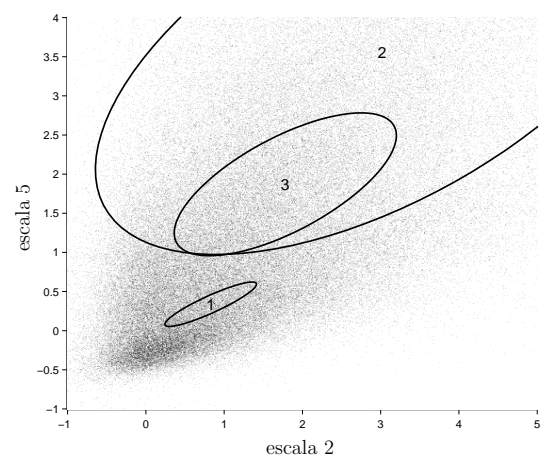

(i) Iteração 30, em que se detectou convergência.

Figura 3.3: Execução do algoritmo EM usando 3 gaussianas para modelar amostras da classe vaso. As características apresentadas nos eixos estão normalizadas e correspondem ao módulo máximo da transformada wavelet de Gabor sobre todos os ângulos (Seção 4.2), para escalas $a=2$ e $a=5$ pixels. O algoritmo foi executado em um espaço de dimensão maior, porém apenas duas estão ilustradas. 
para estimativas em fronteiras do espaço de parâmetros que não são apropriadas para descrever os dados. Por exemplo, no caso em que uma gaussiana fica com média muito próxima de uma amostra de treinamento durante as iterações, a média da gaussiana pode convergir para a amostra e a covariância para a matriz nula, situação em que a verossimilhança é infinita. Em situações em que o espaço tem alta dimensão ou há poucas amostras, esse problema pode ser significativo. Na implementação feita, gaussianas que apresentassem matrizes de covariância com números de condição muito altos durante as iterações eram simplesmente eliminadas. Contudo, essa situação apenas foi encontrada em testes com números reduzidos de amostras de treinamento. Outra dificuldade é a escolha do número de gaussianas $c$ modelando cada classe. Pode-se mostrar que o MMG pode aproximar com precisão arbitrária qualquer função contínua de densidade de probabilidade dado um número suficiente de gaussianas. Contudo, escolhendo $c$ muito grande, o modelo se ajusta excessivamente aos dados (fenômeno conhecido como overfitting), enquanto $c$ muito pequeno pode não permitir um modelo flexível o suficiente para descrever a verdadeira função de probabilidade. Foram realizados experimentos variando os valores de $c$ para cada classe, levando a diferentes resultados. Finalmente, há apenas a garantia de um máximo local da verossimilhança, com dependência na inicialização. O algoritmo EM tem recebido atenção nos últimos anos, sendo usado em uma variedade de aplicações. Foram desenvolvidos diversos métodos para contornar os problemas citados [Figueiredo e Jain, 2002], mas que não foram usados nesta dissertação.

O MMG representa um meio-termo entre modelos puramente paramétricos e não paramétricos, fornecendo uma fase rápida de classificação a custo de uma algoritmo de treinamento mais pesado. Métodos não paramétricos, (como a classificação usando os $k$ vizinhos mais próximos apresentada na Seção 3.2.3 são computacionalmente caros para números grandes de amostras de treinamento, apesar de não colocarem nenhuma restrição sobre as funções de probabilidade sendo estimadas. Por outro lado, o MMG garante uma fase rápida de classificação que apenas depende do $c$ escolhido (sendo independente do tamanho do conjunto de treinamento) ao mesmo tempo que permite funções de probabilidade complexas. 


\subsubsection{Classificador dos $k$ vizinhos mais próximos}

Uma abordagem simples e bastante popular de classificação é utilizar a regra dos $k$ vizinhos mais próximos ( $k \mathrm{NN}$, do inglês $k$ nearest neighbors). Seja $\mathcal{V}=\left\{\mathbf{v}_{1}, \cdots, \mathbf{v}_{N}\right\}$ o conjunto das $N$ amostras de treinamento rotuladas. Dado um número ímpar $k$ de vizinhos, uma medida de distância e um vetor de características $\mathbf{v}$, o algoritmo de classificação dos $k$ vizinhos mais próximos pode ser resumido da seguinte forma:

1. das $N$ amostras de treinamento, os $k$ vizinhos mais próximos de $\mathbf{v}$ são identificados usando a medida de distância determinada;

2. das $k$ amostras mais próximas identificadas, o número de amostras $k_{i}$ que pertencem a cada classe $C_{i}$ é calculado;

3. $\mathbf{v}$ é classificado como pertencente à classe $C_{i}$ com o maior número de amostras $k_{i}$.

Várias medidas de distância podem ser utilizadas, como a distância euclidiana e a de Mahalanobis, levando a diferentes resultados Duda et al., 2001]. Nos testes realizados, foi sempre utilizada a distância euclidiana.

O classificador é não paramétrico, quer dizer, independente de um modelo das distribuições de probabilidade e capaz de produzir separações não-lineares complexas entre as classes. É possível estabelecer limites superiores teóricos sobre o erro do classificador que diminuem com o aumento de $N$, sendo que, quando $k \rightarrow \infty$, o erro tende ao erro do classificador bayesiano ótimo [Duda et al., 2001.

A regra do classificador pode ser interpretada como a decisão baseada nas estimativas das probabilidades posteriores $P\left(C_{i} \mid \mathbf{v}\right)$ (simplesmente estimadas por $\left.k_{i} / k\right)$ a partir dos dados. Por essa perspectiva, à medida que $k$ aumenta, aumenta-se a confiança na estimativa, porém perde-se precisão espacial, uma vez que amostras muito longe de $\mathbf{v}$ começam a ser usadas na estimativa. Quanto maior o número de $\operatorname{amostras} N$, menor o efeito da perda de precisão espacial, permitindo maiores valores de $k$. No estudo realizado, existem muitas amostras de treinamento disponíveis, permitindo boas estimativas, mas exigindo muito processamento. Um dos problemas das técnicas que usam vizinhos mais próximos é a complexidade computacional durante a busca dos vizinhos mais próximos entre as $N$ amostras 
de treinamento. Fixando a dimensão do espaço de características, a busca exaustiva dos vizinhos mais próximos de apenas uma amostra leva tempo pelo menos $O(N)$, necessário para o cálculo das distâncias. Assim, várias estratégias têm sido estudadas para melhorar o desempenho, incluindo buscas mais eficientes e redução do número de amostras do conjunto de treinamento Duda et al., 2001; Theodoridis e Koutroumbas, 1999. Nos testes realizados, foi apenas implementada a busca exaustiva.

\subsubsection{Classificador linear de erro quadrático mínimo}

Também foi testado o classificador linear de erro quadrático mínimo Duda et al., 2001; Theodoridis e Koutroumbas, 1999, denotado LEQM. Classificadores lineares são definidos por uma função de decisão linear $g$ no espaço de características $d$-dimensional

$$
g(\mathbf{v})=\mathbf{w}^{t} \mathbf{v}+w_{0}
$$

em que v é o vetor de características, w é o vetor de pesos e $w_{0}$ é o limiar.

A regra de classificação é escolher $C_{1}$ se $g(\mathbf{v})>0$ e $C_{2}$ caso contrário. Para simplificar a formulação, o limiar $w_{0}$ é acomodado pela definição dos vetores $(d+1)$-dimensionais $\mathbf{v}^{\prime} \equiv\left[\mathbf{v}^{T}, 1\right]^{T}$ e $\mathbf{w}^{\prime} \equiv\left[\mathbf{w}^{T}, w_{0}\right]^{T}$, de forma que $g(\mathbf{v})=\mathbf{w}^{\prime T} \mathbf{v}^{\prime}$.

O classificador é determinado encontrando $\mathbf{w}^{\prime}$ que minimiza o critério da soma de erros quadráticos sobre as amostras do conjunto de treinamento,

$$
J\left(\mathbf{w}^{\prime}\right)=\sum_{i=1}^{N}\left(\mathbf{v}_{i}^{\prime T} \mathbf{w}^{\prime}-y_{i}\right)^{2},
$$

em que $N$ é o número total de amostras de treinamento, $\mathbf{v}_{i}^{\prime}$ é a $i$-ésima amostra estendida de treinamento e $y_{i}$ é a saída desejada.

O critério mede a soma dos erros quadráticos entre a saída gerada pelo classificador $\left(\mathbf{v}_{i}^{\prime T} \mathbf{w}^{\prime}\right)$ e a saída desejada $y_{i}$. Os valores para as saídas desejadas foram arbitrariamente escolhidos como $y_{i}=1$ para $\mathbf{v}_{i} \in C_{1}$ e $y_{i}=-1$ para $\mathbf{v}_{i} \in C_{2}$. 
Definindo

$$
V=\left[\begin{array}{c}
\mathbf{v}_{1}^{\prime T} \\
\mathbf{v}_{2}^{\prime T} \\
\vdots \\
\mathbf{v}_{N}^{\prime T}
\end{array}\right], \quad \mathbf{y}=\left[\begin{array}{c}
y_{1} \\
y_{2} \\
\vdots \\
y_{N}
\end{array}\right]
$$

o gradiente da função critério pode ser escrito como

$$
\begin{aligned}
\nabla J\left(\mathbf{w}^{\prime}\right) & =\sum_{i=1}^{N} 2\left(\mathbf{v}_{i}^{\prime T} \mathbf{w}^{\prime}-y_{i}\right) \mathbf{v}_{i}^{\prime} \\
& =2 V^{T}\left(V \mathbf{w}^{\prime}-\mathbf{y}\right) .
\end{aligned}
$$

A função critério pode ser minimizada calculando $\hat{\mathbf{w}}^{\prime}$ tal que seu gradiente possua valor nulo, resultando em

$$
\left(V^{T} V\right) \hat{\mathbf{w}}^{\prime}=V^{T} \mathbf{y} \Rightarrow \hat{\mathbf{w}}^{\prime}=\left(V^{T} V\right)^{-1} V^{T} \mathbf{y}
$$

A matriz $\left(V^{T} V\right)^{-1} V^{T}$ é conhecida como a pseudo-inversa de $V$ e existe apenas se $V^{T} V$ possuir inversa. $V^{T} V$ é a matriz de correlação das amostras e terá inversa se $V$ tiver posto $d+1$. Dado o grande número de amostras de treinamento utilizadas nos testes realizados, isso sempre ocorreu.

Em comparação com os classificadores $k \mathrm{NN}$ e MMG apresentados, o LEQM possui fases de treinamento e classificação mais rápidas, mas é restrito por ser linear, enquanto os outros são capazes de modelar superfícies de decisão complexas. Apesar disso, resultados obtidos usando o classificador LEQM são comparáveis aos dos outros dois (ver Capítulo 5), fornecendo uma alternativa interessante. 


\section{Capítulo 4}

\section{Segmentação usando wavelets e}

\section{classificadores estatísticos}

Anteriormente, foram mostrados resultados preliminares promissores da segmentação dos vasos em imagens de retina usando a transformada wavelet contínua Cesar-Jr. e Jelinek, 2003, Leandro et al., 2001. Esta dissertação apresenta uma evolução do método anterior com o uso de informação de diferentes escalas através da classificação supervisionada dos pixels, incluindo novos testes e uma avaliação de resultados mais completa Cornforth et al., 2005; Leandro et al., 2003; Soares et al., 2005; Soares et al., 2006]. Na abordagem criada, cada pixel é representado por um vetor de características que inclui diferentes respostas da transformada wavelet 2D de Gabor. O espaço de características resultante é usado para classificar cada pixel como vaso ou não vaso. A classificação utilizada é supervisionada e necessita de pixels rotulados para a fase de treinamento, que são obtidos pela segmentação manual de partes de imagens ou imagens completas. Um esquema do treinamento de um classificador é apresentado na Figura 4.1(a), Após o treinamento, o classificador é aplicado aos pixels de novas imagens, como esquematizado na Figura 4.1(b)] As fases apresentadas nos esquemas estão descritas em detalhe no restante deste capítulo. A incorporação da informação de diferentes escalas e a abordagem de aprendizado supervisionado facilita o uso do método, minimizando a necessidade de interação e configuração de parâmetros. 


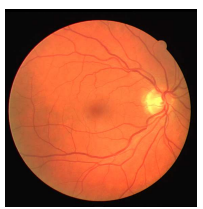

Imagem de treinamento

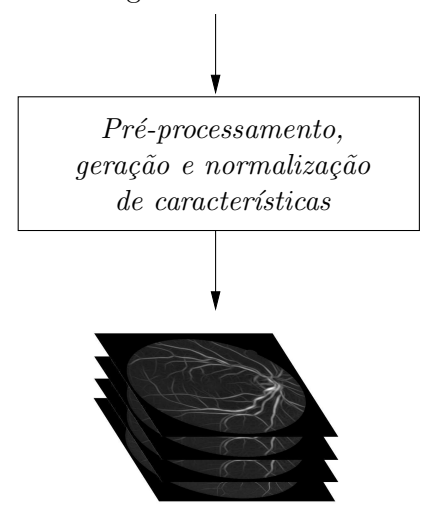

Características dos pixels
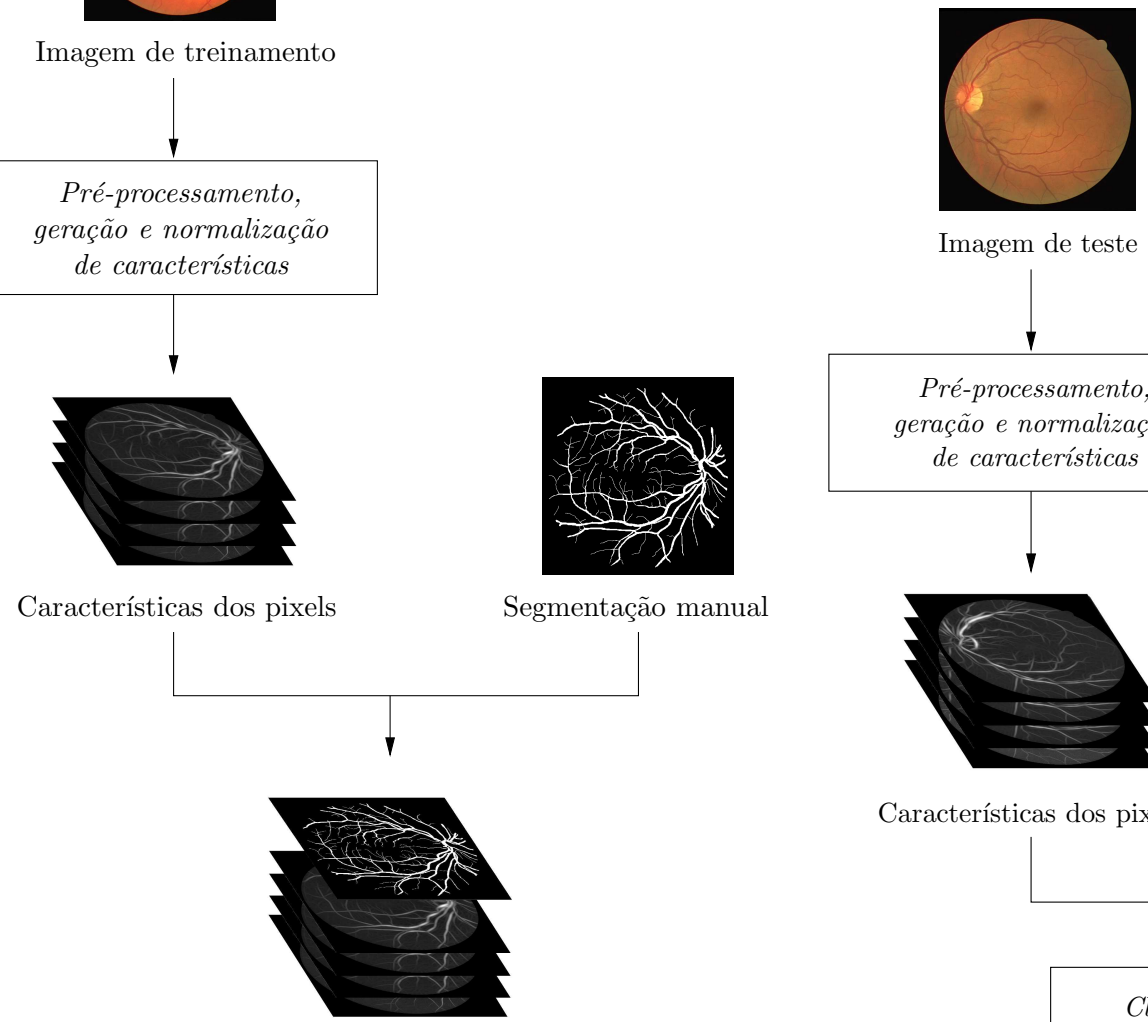

Imagem de teste
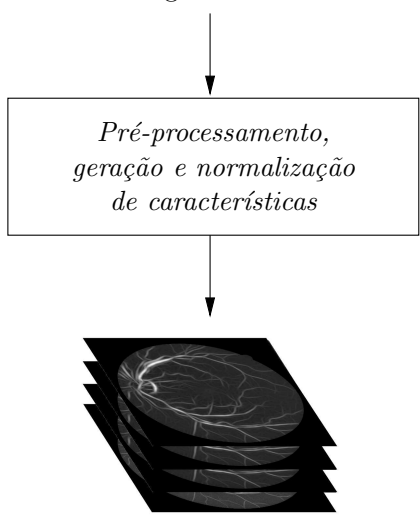

Características dos pixels

Classificador

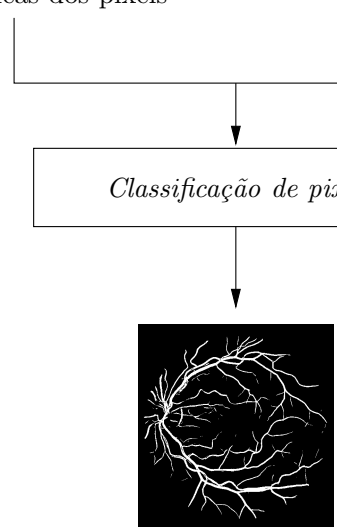

Classificador

Segmentação

(a) Treinamento supervisionado de um classificador.

(b) Segmentação de uma imagem de teste.

Figura 4.1: Esquema geral da abordagem adotada. 
Este capítulo apresenta os métodos desenvolvidos e a forma de avaliação experimental. Foram realizados testes com um classificador bayesiano em que a verossimilhança de cada classe é modelada por uma mistura gaussiana, fornecendo bons resultados e uma classificação rápida. Para comparação, no lugar do classificador bayesiano foram testados os classificadores dos $k$ vizinhos mais próximos e linear de erro quadrático mínimo (ver Seção 3.2). O desempenho da wavelet 2D de Gabor é demonstrado pela comparação da detecção usando apenas uma escala da wavelet com a detecção usando um filtro casado gaussiano 2D (ver Seção 2.2.3 Chaudhuri et al., 1989]. Os métodos são avaliados quantitativamente usando análise ROC. A análise ROC vem sendo usada para a avaliação e comparação de métodos de segmentação de vasos retínicos em bancos públicos de imagens Hoover et al., 2000 Jiang e Mojon, 2003 : Staal et al., 2004]. Essa análise quantitativa, bem como a análise visual, mostra que há espaço para melhorias: observadores humanos são mais precisos que os métodos, que apresentam falhas ao redor do disco óptico e não detectam os vasos mais finos Cree et al., 2005b; Niemeijer et al., 2004.

\subsection{Pré-processamento}

Quando os canais RGB das imagens coloridas são visualizados separadamente, percebe-se que o maior contraste entre os vasos e o fundo da retina é apresentado pelo canal verde, enquanto os canais vermelho e azul apresentam pouca qualidade e pouco contraste dos vasos (Figura 4.2). Assim, toda a extração de características é realizada sobre o canal verde das imagens coloridas. Antes da aplicação da transformada wavelet às imagens coloridas, o canal verde da imagem é invertido, para que os vasos apareçam como mais claros que o fundo. Da mesma forma, imagens aneritras são invertidas. Para angiografias fluoresceínicas, a inversão não é necessária (ver Seção 1.1).

A wavelet de Gabor gera fortes respostas em regiões com bordas de alto contraste. Isso faz com que as bordas da abertura da câmera apareçam como falsos positivos nos resultados. Para reduzir esse efeito, um algoritmo iterativo foi desenvolvido. O objetivo do algoritmo é remover o forte contraste entre o fundo da retina e a região que está fora do campo de vista da câmera (Figura 4.3).

O algoritmo de pré-processamento se inicia com a região determinada pela abertura da câmera e expande iterativamente essa região. Cada passo do algoritmo é formado pelas seguintes operações: 


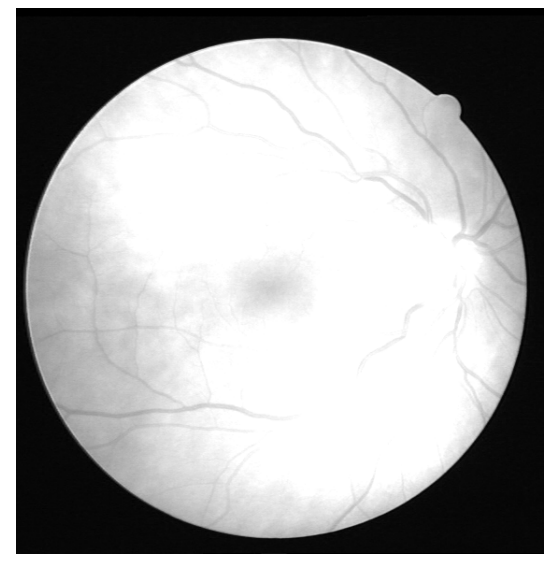

(a) Canal vermelho.

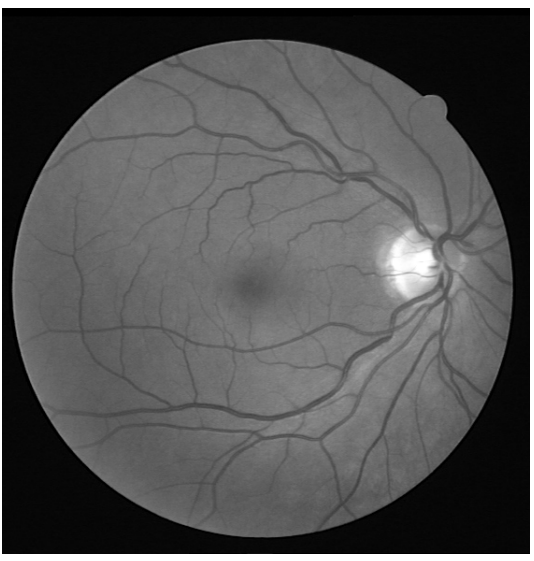

(b) Canal verde.

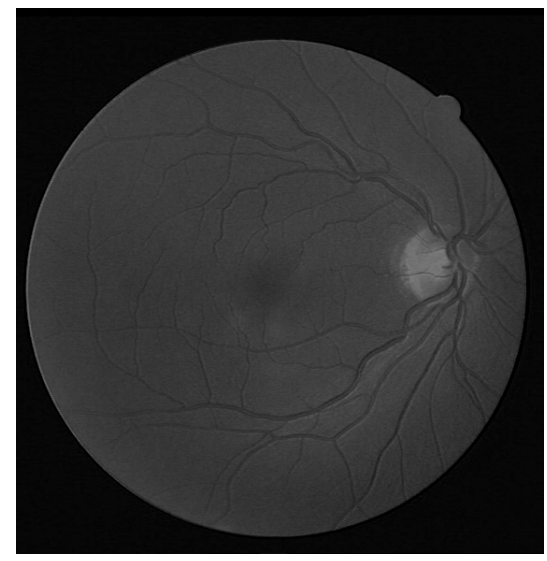

(c) Canal azul.

Figura 4.2: Canais vermelho, verde e azul da imagem colorida apresentada na Figura 4.7(a).

primeiramente, determina-se o conjunto de pixels da borda exterior da região, isto é, pixels que estejam fora da região e que sejam vizinhos (usando 4-vizinhança) de pixels internos; em seguida, substitui-se o valor de cada pixel desse conjunto pela média dos valores de seus vizinhos (dessa vez, usando 8vizinhança) que estão dentro da região; finalmente, o novo conjunto de pixels é agregado à região sendo processada. Esse processo é repetido e pode ser visto como uma extensão artificial da região dentro do campo de vista da câmera, como ilustrado na Figura 4.3(b).

\subsection{Detecção usando a wavelet 2D de Gabor}

Das diferentes wavelets 2D analisadoras úteis em processamento de imagens, a wavelet de Gabor tem a capacidade de detectar estruturas direcionais e de ser ajustada para freqüências específicas (ver Seção 3.1.3), especialmente importante para filtrar o ruído de fundo das imagens de retina. Além disso, demonstrou desempenho superior ao de outros detectores lineares de estruturas orientadas Ayres e Rangayyan, 2005. Essas qualidades motivaram a adoção da wavelet de Gabor para a detecção de vasos sangüíneos em Leandro et al., 2001 e no presente trabalho.

A wavelet de Gabor pode ser ajustada para detectar diferentes estruturas através da configuração de seus parâmetros. Nos experimentos realizados, os parâmetros foram $\epsilon=4$, gerando uma wavelet 


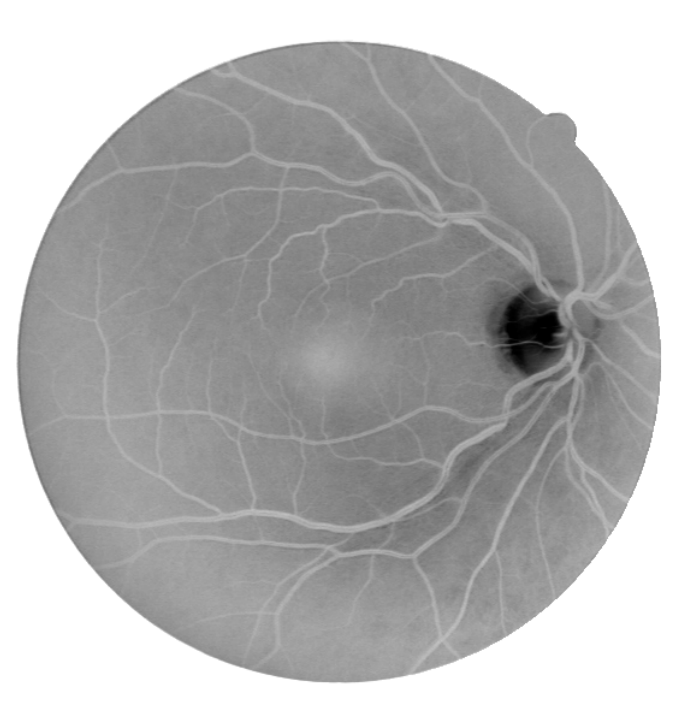

(a) Canal verde invertido da imagem colorida apresentada na Figura $4.7(\mathrm{a})$

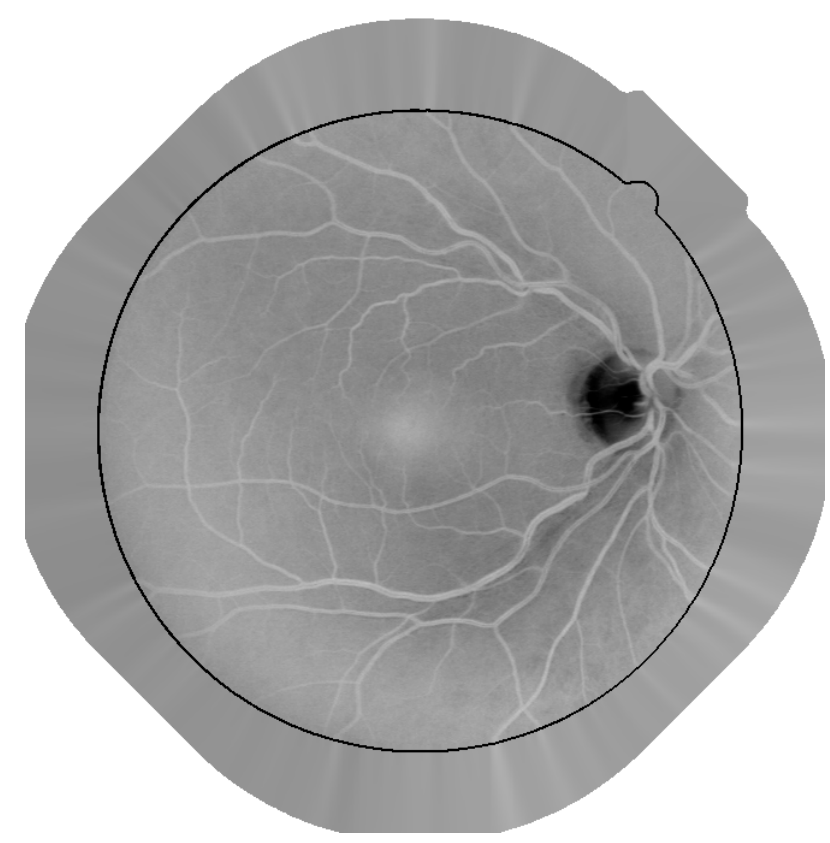

(b) Canal verde invertido com fundo estendido. A linha delimita a imagem original.

Figura 4.3: Pré-processamento das imagens para remoção de efeitos de borda indesejados. 


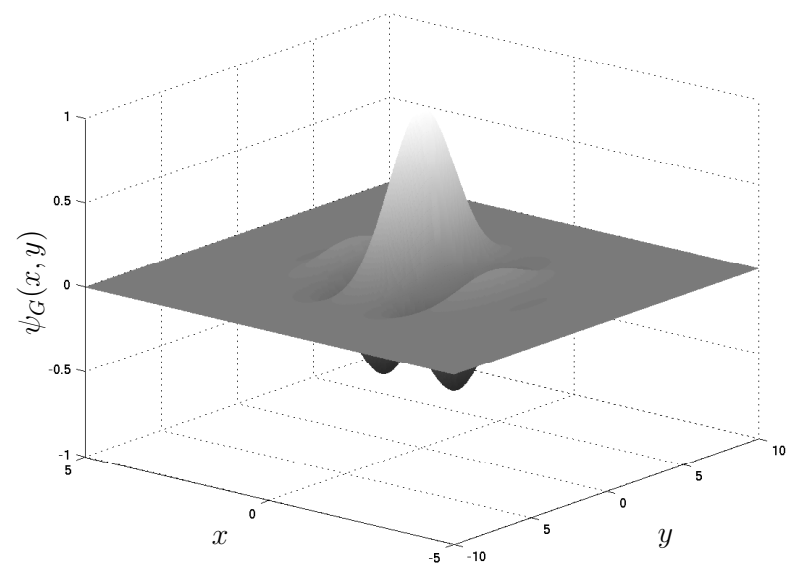

(a) Representação em superfície da parte real.

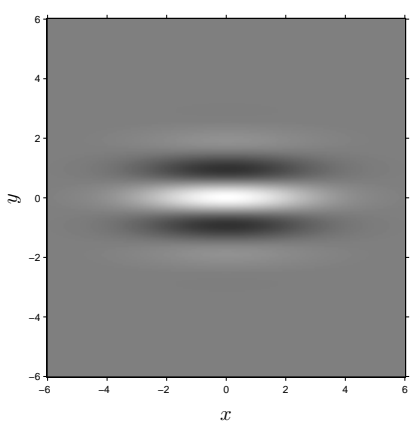

(b) Parte real.

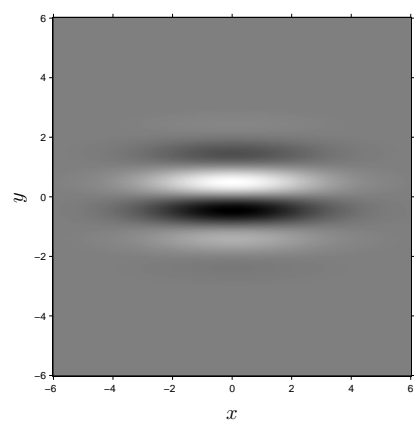

(c) Parte imaginária.

Figura 4.4: Diferentes representações para a wavelet 2D de Gabor $\left(\psi_{G}\right)$ com parâmetros $\mathbf{k}_{\mathbf{0}}=[0,3]$ e $\epsilon=4$. Tons claros e escuros representam, respectivamente, valores positivos e negativos.

alongada e $\mathbf{k}_{\mathbf{0}}=[0,3]$, fornecendo uma exponencial de baixa freqüência com transições na direção do menor eixo da wavelet, como na Figura 4.4. Essas duas características são especialmente apropriadas para a deteç̧ão de estruturas direcionais e foram escolhidas para que a transformada apresentasse respostas mais fortes para os pixels associados com vasos. Note que o formato da wavelet é localmente similar ao dos vasos sangüíneos, produzindo então respostas fortes quando na posição, orientação e escala correspondente a um vaso através da operação do produto escalar em $L^{2}\left(\mathbb{R}^{2}\right)$ (ver Seção 3.1.2).

Para detectar vasos em qualquer orientação, para cada posição e valor de escala considerado, toma-se a resposta da transformada de maior módulo sobre todas as orientações, isto é,

$$
M_{\psi}(\mathbf{b}, a)=\max _{\theta}\left|T_{\psi}(\mathbf{b}, \theta, a)\right|
$$

Assim, para cada posição e valor de escala, a transformada wavelet de Gabor é calculada para $\theta$ de 0 a 170 graus a passos de 10 graus e toma-se a resposta de módulo máximo (isso é possível porque $\left.\left|T_{\psi}(\mathbf{b}, \theta, a)\right|=\left|T_{\psi}\left(\mathbf{b}, \theta+180^{\circ}, a\right)\right|\right)$. Os módulos máximos da transformada sobre todos os ângulos para diferentes escalas serão tomados como características dos pixels. $M_{\psi}(\mathbf{b}, a)$ é mostrado na Figura 4.5 para $a=2$ e $a=5$ pixels. 


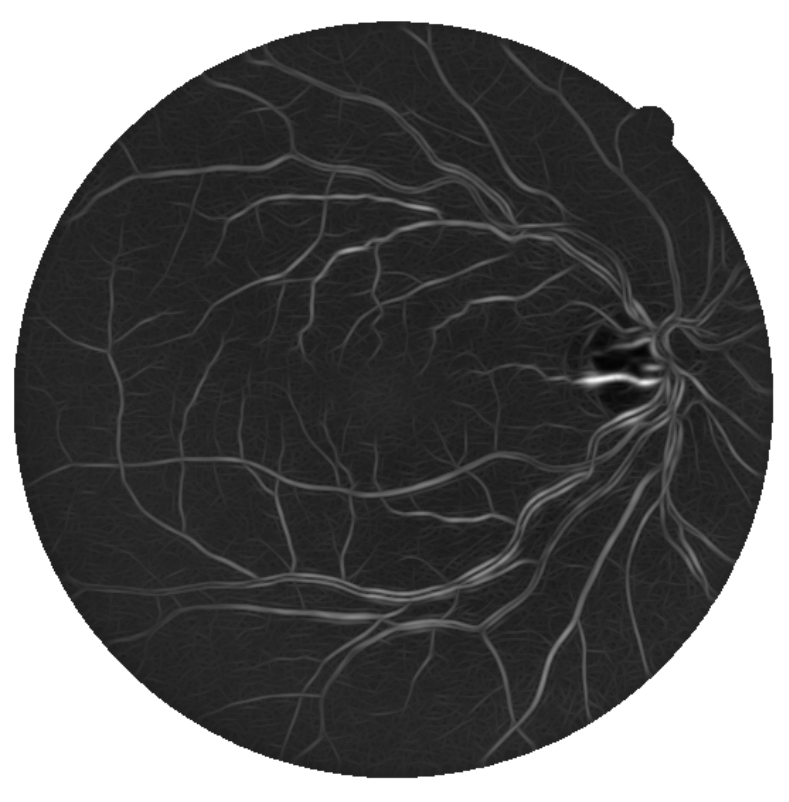

(a) $M_{\psi}(\mathbf{b}, 2)$.

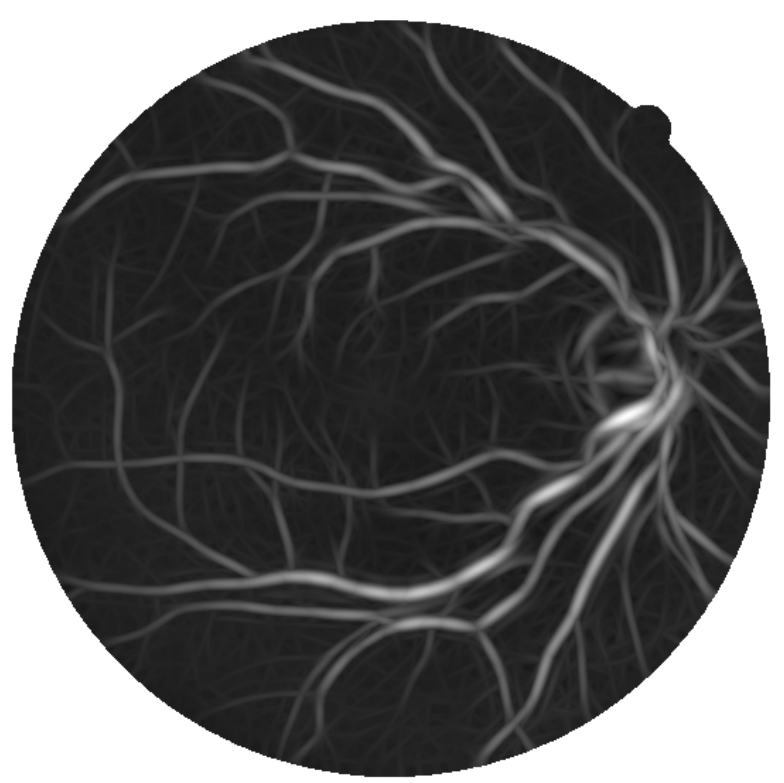

(b) $M_{\psi}(\mathbf{b}, 5)$.

Figura 4.5: Módulo máximo da transformada wavelet de Gabor sobre todos os ângulos, $M_{\psi}(\mathbf{b}, a)$ (Equação 4.1), para valores de escala $a=2$ e $a=5$ pixels. Os demais parâmetros estão fixos em $\epsilon=4$ $\mathrm{e} \mathbf{k}_{\mathbf{0}}=[0,3]$. 


\subsection{Normalização de características}

Cada medida usada como característica pode assumir valores de diferentes ordens de magnitude, o que pode gerar erros no processo de classificação por causa da diferença entre a influência de cada característica no cálculo de distâncias.

Considerando os elementos do espaço de características como variáveis aleatórias, pode-se aplicar uma transformação aos elementos para obter um novo tipo de variável aleatória mais apropriada para o processo de classificação. Um modo de obter uma nova variável aleatória de média zero e desvio padrão unitário, compensando as possíveis diferenças nas ordens de magnitude, é aplicar a transformação normal ao espaço de características, definida como Costa e Cesar-Jr., 2001

$$
\hat{v}_{i}=\frac{v_{i}-\mu_{i}}{\sigma_{i}}
$$

em que $v_{i}$ é a $i$-ésima característica assumida por cada pixel, $\mu_{i}$ é a média dos valores dessa característica e $\sigma_{i}$, seu desvio padrão.

A transformação normal é aplicada separadamente às características de cada imagem, isto é, o espaço de características de cada imagem é normalizado pelas próprias médias e desvios padrão, ajudando a compensar pela variação intrínseca entre imagens, como diferenças de iluminação.

\subsection{Classificação supervisionada de pixels}

As segmentações são geradas pela aplicação de classificação supervisionada aos pixels da região de interesse das imagens de teste, com classes definidas como $C_{1}=\{$ pixels pertencentes a vasos $\}$ e $C_{2}=\{$ pixels não pertencentes a vasos $\}$. A classificação supervisionada utiliza amostras de treinamento rotuladas, isto é, com classes conhecidas, como base para a classificação de novas amostras. Para a criação do conjunto de treinamento, são utilizadas segmentações manuais de imagens (ver Seção 4.5.1) e extraídas características de seus pixels, permitindo a criação de conjuntos de treinamento com elementos rotulados como pertencentes a $C_{1}$ ou $C_{2}$ (Figura 4.6 ).

Os conjuntos de treinamento são gerados da seguinte forma. Primeiramente, algumas imagens de 


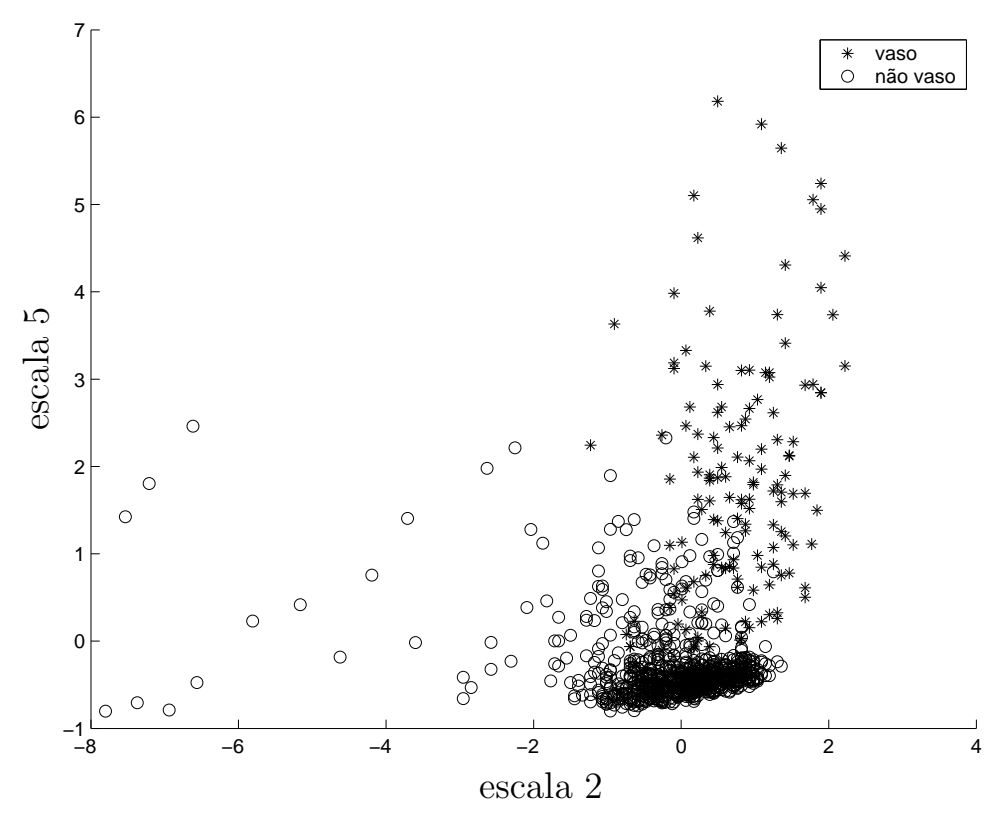

Figura 4.6: Espaço de características com amostras rotuladas. As características apresentadas nos eixos estão normalizadas e são o módulo máximo da transformada wavelet de Gabor sobre todos os ângulos, $M_{\psi}(\mathbf{b}, a)$ (Equação 4.1), para escalas $a=2$ e $a=5$ pixels.

retina são segmentadas manualmente para a geração de rótulos. Um subconjunto dos pixels rotulados é escolhido aleatoriamente para compor o conjunto de treinamento. O conjunto de treinamento é então fornecido a um classificador para que seja capaz de classificar pixels de outras imagens, gerando assim suas segmentações (ver Figura 4.1).

Outro modo de utilizar classificadores para a geração das segmentações, que também foi testado, produzindo resultados promissores, é usar amostras rotuladas de uma fração da imagem a ser segmentada como conjunto de treinamento Cornforth et al., 2005]. Os pixels rotulados são utilizados para treinar o classificador, que deverá ser aplicado à mesma imagem para a obtenção da segmentação final. Esse método poderia ser utilizado em um software semi-automatizado, em que o usuário define alguns pixels pertencentes a vasos e obtém a segmentação da imagem sem a necessidade da configuração de parâmetros. A vantagem dessa abordagem é que peculiaridades da imagem podem ser incorporadas pelo classificador em troca de um pequeno esforço por parte do usuário. 


\subsection{Avaliação experimental}

\subsubsection{Bancos de imagens}

Existem diferentes formas de obter imagens de retina, como através de câmeras digitais coloridas ou angiografias usando corantes fluorescentes (ver Seção 1.1). A abordagem utilizada pode ser aplicada aos diferentes tipos de imagens, desde que segmentações manuais estejam disponíveis para a fase de treinamento. Para comparação com outros métodos, serão apresentados testes realizados em dois bancos públicos de imagens, contendo imagens coloridas acompanhadas de segmentações manuais: os bancos DRIVE [Staal et al., 2004] e STARE [Hoover et al., 2000].

O banco DRIVE é formado por 40 imagens (7 das quais apresentam patologia), acompanhadas de segmentações manuais dos vasos. As imagens foram escolhidas aleatoriamente de um programa de triagem para detecção de retinopatia diabética na Holanda. Foram capturadas em formato digital por uma câmera não midriática Canon CR5 3CCD com um campo de vista de $45^{\circ}$. O tamanho das imagens é de $768 \times 584$ pixels, 8 bits por canal de cor e o campo de vista abrange aproximadamente 540 pixels de diâmetro. As imagens estão no formato comprimido JPEG, que pode ser prejudicial para o processamento, porém é muito usado na prática.

Nos testes realizados com esse banco em Niemeijer et al., 2004; Staal et al., 2004, as 40 imagens foram divididas em conjuntos fixos de treinamento e teste, cada um contendo 20 imagens (o conjunto de treinamento contendo 3 imagens com patologia e o de teste, 4). Elas foram manualmente segmentadas por três observadores treinados por um oftalmologista. As imagens do conjunto de treinamento foram segmentadas uma única vez, enquanto as do conjunto de teste foram segmentadas duas vezes, resultando nos conjuntos de segmentações manuais A e B. Os observadores dos conjuntos A e B produziram segmentações similares. No conjunto A, $12.7 \%$ dos pixels foram marcados como vaso, contra $12.3 \%$ de vasos para o conjunto B. Uma imagem do conjunto de teste acompanhada de suas segmentações manuais está ilustrada na Figura 4.7. O desempenho dos métodos é calculado sobre as imagens de teste, utilizando as segmentações do conjunto A como resultado ideal. As segmentações do conjunto B são testadas contra as do conjunto A, fornecendo uma medida de variação entre observadores humanos.

O banco STARE consiste de 20 eslaides digitalizados, capturados por uma câmera TopCon TRV- 
50 com um campo de vista de $35^{\circ}$. Os eslaides foram digitalizados para uma resolução de $700 \times 605$ pixels e 8 bits para cada canal de cor. O campo de vista das imagens abrange aproximadamente $650 \times 550$ pixels em diâmetro. As imagens foram selecionadas de forma que dez delas apresentassem patologias, dificultando a detecção dos vasos. A escolha foi feita para que os métodos pudessem ser avaliados em imagens com patologia e para que pudesse ser avaliada a diferença entre o desempenho em imagens normais e patológicas. Dois observadores segmentaram manualmente todas as 20 imagens. Em média, o primeiro observador marcou 32200 pixels como vaso em cada imagem contra 46100 do segundo observador. As segmentações dos dois observadores são razoavelmente diferentes, sendo que o segundo observador consistentemente segmentou bem mais dos vasos finos que o primeiro. A Figura 4.7 mostra uma imagem do banco acompanhada de suas segmentações manuais. Nos testes realizados com esse banco [Cree et al., 2005b; Hoover et al., 2000; Jiang e Mojon, 2003; Staal et al., 2004], o desempenho dos métodos é calculado usando as segmentações do primeiro observador como resultado ideal, enquanto as segmentações do segundo observador são testadas contra as do primeiro. Não existe uma separação das imagens em conjunto de teste e treinamento, portanto se utiliza validação cruzada para o cálculo do desempenho de métodos supervisionados.

\subsubsection{Experimentos e configurações}

Os métodos descritos foram testados nos bancos de imagens DRIVE e STARE com as seguintes configurações. As características dos pixels usadas para classificação foram o canal verde invertido e suas respostas de módulo máximo sobre ângulos da transformada wavelet de Gabor $M_{\psi}(\mathbf{b}, a)$ (Equação 4.1) para valores de escala $a=2,3,4,5$ pixels (veja a Seção 4.2 ). Os valores de escala foram escolhidos para abranger todas as possíveis larguras dos vasos nas imagens, para que todos os vasos pudessem ser detectados.

Para o banco DRIVE, o conjunto de treinamento foi formado por amostras das 20 imagens de treinamento. Para o banco STARE, foi realizada uma validação cruzada, em que cada imagem foi segmentada usando amostras das outras 19 para o conjunto de treinamento (ver Seção 4.5.1). Foram testados os três classificadores apresentados na Seção 3.2. Para verificar a dependência do método 

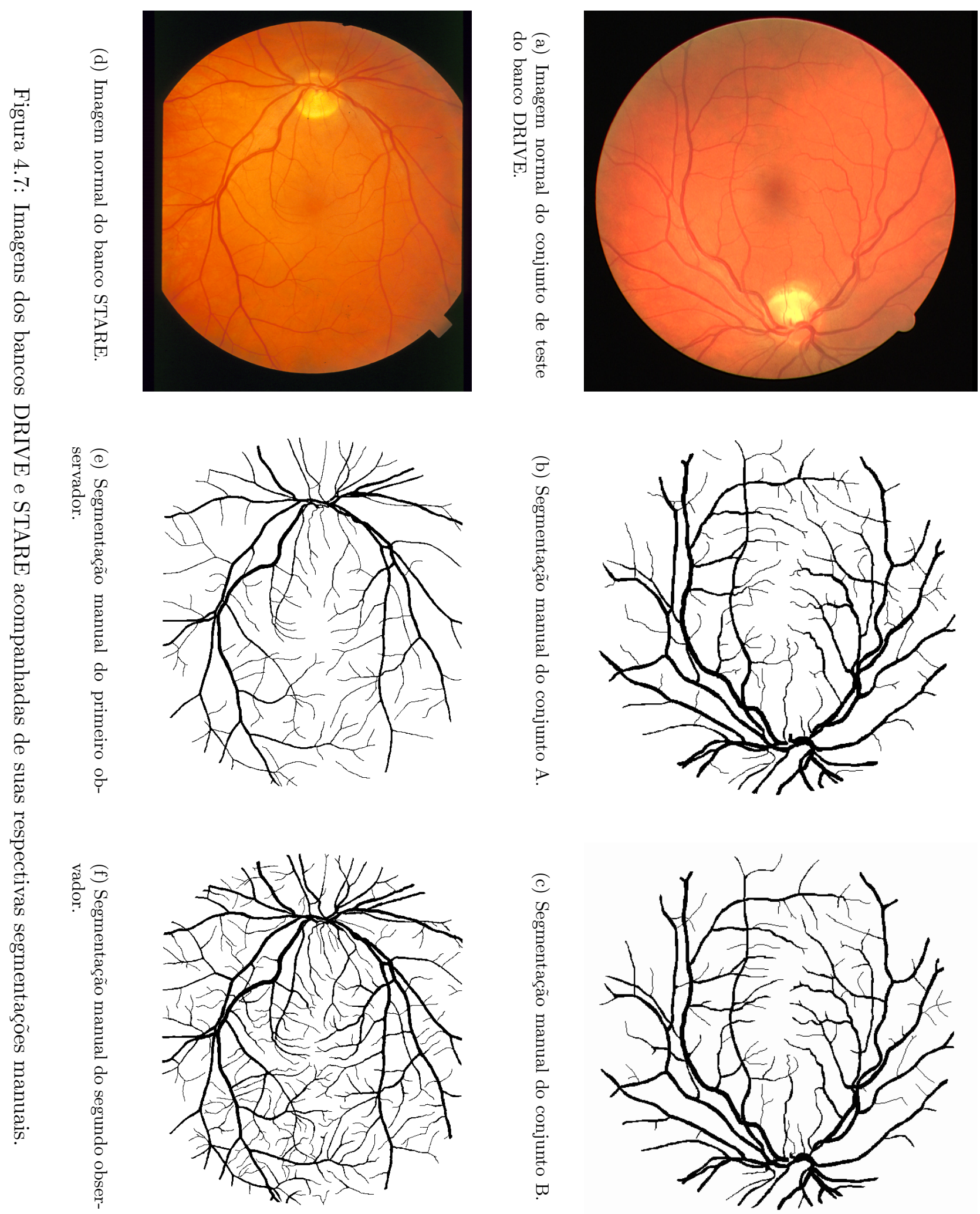
no conjunto de treinamento, também foi realizado um teste com o classificador MMG sendo treinado em cada um dos bancos DRIVE e STARE e avaliado no outro. Dado o grande número de pixels, em todos os experimentos, amostras foram aleatoriamente escolhidas para treinar os classificadores. Os três classificadores foram comparados usando cem mil amostras $\left(N=10^{5}\right)$ por causa da demanda computacional do classificador $k \mathrm{NN}$. Contudo, para comparação com outros métodos, foi utilizado o classificador MMG com um milhão de amostras $\left(N=10^{6}\right)$. Com o classificador MMG, variou-se o número $c$ de gaussianas modelando a verossimilhança de cada classe (Equação 3.41), enquanto que para o $k \mathrm{NN}$, variou-se o número $k$ de vizinhos.

Para demonstrar o desempenho da wavelet 2D de Gabor em realçar os vasos, são comparados resultados da filtragem usando apenas uma escala da wavelet com os da detecção usando um filtro casado gaussiano 2D (ver Seção 2.2.3 Chaudhuri et al., 1989]. Os parâmetros dos filtros foram escolhidos de modo a produzirem os melhores resultados: $a=4$ pixels para filtragem com a wavelet e $\sigma=1$ pixel para o filtro casado gaussiano.

\subsubsection{Análise ROC}

O desempenho dos métodos é medido usando curvas em gráficos ROC (do inglês, receiver operating characteristic, ou característica de operação do receptor). Gráficos ROC são bastante utilizados na teoria de detecção de sinais e recentemente em reconhecimento de padrões e auxílio em sistemas de diagnóstico médico Fawcett, 2006. Eles permitem visualizar o desempenho de classificadores ou testes diagnósticos, expressando a relação de compromisso entre o aumento da capacidade de detecção e da taxa de alarmes falsos.

As curvas ROC são formadas por pares ordenados compostos de taxas de verdadeiros positivos e falsos positivos. Diferentes taxas são obtidas ao variar os parâmetros dos métodos, como em Hoover et al., 2000; Jiang e Mojon, 2003, Mendonça e Campilho, 2006, ou os limiares aplicados sobre as probabilidades posteriores, como em Staal et al., 2004. Um par formado por uma taxa de verdadeiros positivos e uma de falsos positivos é marcado no gráfico para cada configuração dos parâmetros ou valor do limiar, produzindo uma curva como na Figura 4.8. Verdadeiros positivos são pixels marcados 
Tabela 4.1: Matriz de confusão.

\begin{tabular}{|c|c|c|c|}
\cline { 3 - 4 } \multicolumn{2}{c|}{} & \multicolumn{2}{c|}{ Referência } \\
\cline { 3 - 4 } \multicolumn{2}{c|}{} & Positivo $(p)$ & Negativo $(n)$ \\
\hline $\begin{array}{c}\text { Resultado do } \\
\text { método }\end{array}$ & Positivo & Verdadeiro positivo $(v p)$ & Falso positivo $(f p)$ \\
\cline { 2 - 4 } & Negativo & Falso negativo $(f n)$ & Verdadeiro negativo $(v n)$ \\
\hline
\end{tabular}

como vaso (positivo) tanto na segmentação manual usada como referência, quanto na segmentação produzida por dado método, enquanto os falsos positivos são aqueles marcados como vaso pelo método, mas marcados como não vaso (negativo) na referência. As medidas podem ser resumidas na matriz de confusão (também chamada matriz de erro), ilustrada na Tabela 4.1. O total de positivos e negativos da referência será denotado por $p$ e $n$; os verdadeiros e falsos positivos por $v p$ e $f p$ e os verdadeiros e falsos negativos por $v n$ e $f n$, como na matriz de confusão. A partir dos elementos da matriz, pode-se desenvolver as medidas usadas na avaliação dos métodos. As taxas de verdadeiros e falsos positivos, denotadas tvp e tfp, são dadas por

$$
t v p=\frac{v p}{p}, \quad t f p=\frac{f p}{n} .
$$

Também é medida a acurácia (fração de pixels corretamente classificados) dos resultados produzidos pelos métodos e por observadores humanos nas segmentações manuais. A acurácia é dada por $\frac{v p+v n}{p+n}$ e mede a taxa de acertos nas segmentações. Ao contrário da análise ROC, a acurácia não tem como expressar a relação entre a quantidade de verdadeiros positivos e a de falsos positivos.

Alguns pontos do gráfico ROC ajudam a fornecer uma idéia intuitiva da representação. O ponto $(0,0)$ corresponde a um método extremamente conservador, que designa não vaso (negativo) a todos os pixels. Assim, ele não é capaz de gerar verdadeiros positivos, mas também não gera falsos positivos. O método oposto, que apenas designa a classe vaso (positiva) aos pixels corresponde ao ponto $(1,1)$. Quanto mais uma curva ROC se aproxima do canto superior esquerdo, melhor o desempenho, sendo que o ponto $(0,1)$ representa uma concordância perfeita. Assim, dizemos que uma curva domina outra quando está totalmente acima e a esquerda dela. A linha diagonal em que $t v p=t f p$ representa a estratégia de 
classificação aleatória, em que diferentes pontos representam diferentes taxas de atribuição de positivos e negativos pelo método aleatório.

Uma propriedade importante do gráfico ROC é que ele é invariante a mudanças na distribuição a priori das classes, representada pela proporção entre amostras positivas e negativas. Isso ocorre porque as taxas são relativas ao total de amostras em cada classe analisada. O mesmo não vale para outras medidas, como a acurácia. De forma similar, o gráfico é invariante a mudanças nas perdas associadas às decisões de classificação. Dada uma função de perda e a distribuição a priori das classes (ver Seção 3.2.1), é possível determinar linhas de mesmo erro esperado no gráfico. Fixando-se que não há perda associada a decisões corretas $\left(\lambda\left(\alpha_{1} \mid C_{1}\right)=\lambda\left(\alpha_{2} \mid C_{2}\right)=0\right)$, a perda esperada da aplicação de um classificador correspondente ao ponto $(t f p, t v p)$ é

$$
P\left(C_{1}\right)(1-t v p) \lambda\left(\alpha_{2} \mid C_{1}\right)+P\left(C_{2}\right) \operatorname{tfp} \lambda\left(\alpha_{1} \mid C_{2}\right),
$$

em que a função $\lambda\left(\alpha_{i} \mid C_{j}\right)$ indica o custo do erro de escolher $\alpha_{i}$ para uma amostra da classe $C_{j}$ e $P\left(C_{i}\right)$ é a probabilidade a priori da classe $C_{i}$.

Assim, dois pontos do gráfico ROC $\left(t f p_{a}, t v p_{a}\right)$ e $\left(t f p_{b}, t v p_{b}\right)$ terão o mesmo erro esperado se

$$
m=\frac{t v p_{b}-t v p_{a}}{t f p_{b}-t f p_{a}}=\frac{\lambda\left(\alpha_{1} \mid C_{2}\right) P\left(C_{2}\right)}{\lambda\left(\alpha_{2} \mid C_{1}\right) P\left(C_{1}\right)}
$$

Cada conjunto de custos e distribuições a priori fornece a inclinação de retas de mesmo desempenho. Como exemplo, considere as curvas produzidas por dois métodos $A$ e $B$ mostradas na Figura 4.8(a). No caso em que os erros possuem o mesmo custo e existem 3 vezes mais amostras negativas do que positivas, pela Equação 4.5, temos $m=3$. Linhas de mesmo desempenho terão alta inclinação, como a reta $r$, que passa tangente à curva do método $A$ no ponto de melhor desempenho, levando à preferência por esse método. O exemplo é similar ao dos classificadores MMG e $k$ NN na segmentação dos vasos: os classificadores buscam minimizar o erro usando custos iguais para ambas as classes, sendo que existem muito mais amostras não vaso (negativa) do que vaso (positiva). Por outro lado, se tivéssemos erros de mesmo custo e 3 vezes mais amostras positivas do que negativas, teríamos $m=1 / 3$. Assim, a curva 


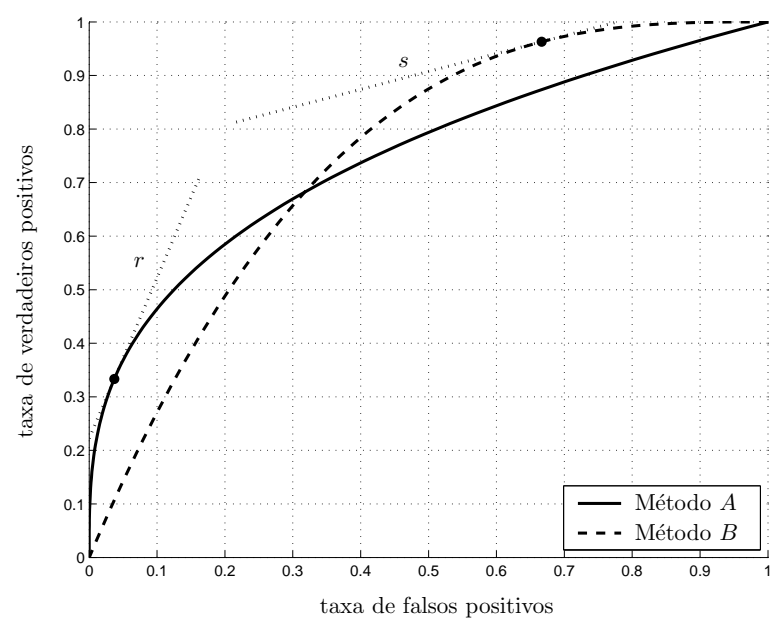

(a) Dependendo dos custos e distribuição de probabilidades a priori, linhas de mesmo desempenho possuem diferentes inclinações, levando à preferência por diferentes métodos.

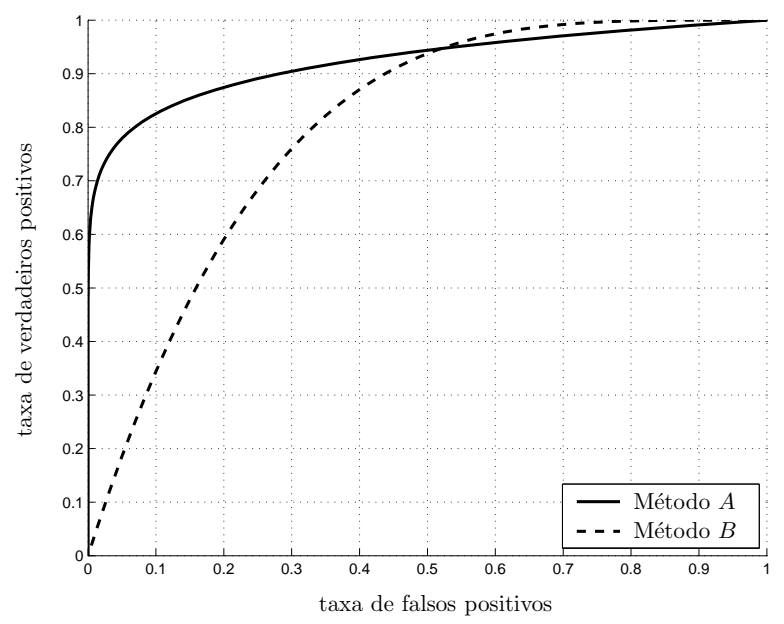

(b) A área da curva ROC produzida pelo método $A$ é maior do que a produzida pelo método $B$, porém para taxas de falsos positivos maiores que aproximadamente 0.55 , o método $B$ mostra-se melhor.

Figura 4.8: Exemplos de gráficos ROC ilustrando algumas de suas propriedades.

gerada pelo método $B$ teria melhor desempenho, ilustrado pela reta $s$, que passa tangente à curva $B$ no ponto de melhor desempenho.

A área sob a curva ROC $\left(A_{z}\right)$ é usada como medida escalar do desempenho de cada método. As áreas, por serem frações de um quadrado unitário, possuem valor entre 0 e 1 . Entretanto, como um classificador aleatório produziria uma curva diagonal ligando os pontos $(0,0)$ e $(1,1)$ com $A_{z}=0.5$, na prática, os métodos devem sempre ter $A_{z} \geq 0.5$. Uma classificação que concordasse completamente com as segmentações usadas como referência teria uma área sob a curva ROC de $A_{z}=1$. Uma propriedade importante das áreas sob as curvas é que elas são equivalentes à estatística de Wilcoxon Hanley e McNeil, 1982, isto é, a probabilidade de que um classificador atribua chance maior a uma amostra positiva escolhida aleatoriamente do que a uma amostra negativa também escolhida aleatoriamente. É possível que um método de maior área sob a curva tenha desempenho pior do que um de menor área em alguma região do gráfico, como ilustrado na Figura 4.8(b), porém a área é uma boa estimativa do desempenho médio.

Para comparar métodos, não basta que a curva ROC de um método, calculada sobre dado conjunto 
de teste, domine a de outro, uma vez que a variância das curvas deve ser levada em consideração. Essa variância pode ser estimada por abordagens como validação cruzada ou bootstrapping Fawcett, 2006. O mesmo vale para poder comparar medidas de acurácia e $A_{z}$. Em Mendonça e Campilho, 2006: Staal et al., 2004], essas medidas foram geradas para diferentes métodos e comparadas em testes pareados, em que as medidas de acurácia e $A_{z}$ para cada imagem de teste representaram a amostragem. A análise realizada não incluiu o cálculo das variâncias das curvas ou testes de hipóteses, o que daria maior confiabilidade à comparação entre métodos.

Nos experimentos realizados, as medidas são calculadas sobre todas as imagens de teste, considerando apenas os pixels dentro da região de interesse definida pela abertura da câmera. Para os classificadores MMG e $k \mathrm{NN}$, as curvas ROC são produzidas variando o limiar sobre as estimativas das probabilidades posteriores dos pixels serem da classe vaso. A curva ROC do classificador LEQM é produzida variando o limiar $w_{0}$ sobre o produto interno entre os vetores de características e o vetor de pesos (Equação 3.57). Para o banco DRIVE, o desempenho é calculado usando as segmentações do conjunto A como resultado ideal e o desempenho humano é calculado usando as segmentações manuais do conjunto B, que fornecem apenas um par de taxas de verdadeiros e falsos positivos, aparecendo como um ponto no gráfico ROC (Figura 5.4). Para o banco STARE, as segmentações manuais do primeiro observador são usadas como resultado ideal, enquanto as taxas de verdadeiros e falsos positivos do segundo observador são apresentadas no gráfico ROC (Figura 5.5. É importante notar que os conjuntos de segmentações manuais avaliados não apresentam taxas perfeitas de verdadeiros e falsos positivos, pois diferem em alguns dos pixels com as segmentações usadas como referência. Assim, a variância entre observadores pode ser estimada, ajudando a fixar uma meta para o desempenho dos métodos.

\subsection{Implementação e protótipo de interface gráfica}

A implementação foi realizada na forma de scripts do MATLAB [MATLAB, 2006] e foi disponibilizada em código aberto (licença GPL [Free Software Foundation, 1991]) no ambiente de desenvolvimento da Incubadora Virtual de Conteúdos Digitais da Fapesp, em http://retina.iv.fapesp.br. No ambiente também estão disponíveis alguns de nossos resultados, permitindo que pesquisadores os avaliem 
de diferentes formas.

Para facilitar a execução dos testes, foi usada uma arquitetura pipeline em que resultados intermediários podem ser armazenados em disco para reutilização. Assim, características dos pixels de imagens, conjuntos de treinamento e classificadores puderam ser aproveitados em diferentes testes, economizando o tempo de computação necessário para gerá-los. Componentes do pipeline, como o gerador do classificador ou do conjunto de treinamento (ver Figura 4.1), podem ser substituídos para testes comparativos. Os testes são executados através da chamada de funções, com a especificação de opções e parâmetros em arquivos de configuração. Resultados são então apresentados como imagens, tabelas e gráficos organizados em páginas em HTML, como ilustrado nas Figura 4.9 e 4.10.

Uma interface gráfica foi implementada para servir de protótipo em testes junto a usuários. A interface está ilustrada na Figura 4.11 e atualmente permite:

- visualizar e salvar características dos pixels de imagens;

- treinar e salvar classificadores, especificando as características a serem utilizadas, tipo do classificador (LEQM, MMG ou $k \mathrm{NN}$ ), número de amostras de treinamento e as imagens de treinamento acompanhadas de imagens de segmentações manuais;

- abrir e visualizar classificadores e aplicá-los à segmentação das imagens.

A interface foi desenvolvida para o MATLAB complementando a implementação dos testes. O MATLAB é um software bastante usado para processamento de imagens e possui um ambiente que facilita o desenvolvimento rápido de programas. Contudo, é um programa comercial e seu uso requer uma licença normalmente paga. Uma nova implementação está sendo projetada e desenvolvida, que deverá ser mais rápida, possuir maior usabilidade e ser independente do MATLAB, permitindo maior alcance. 


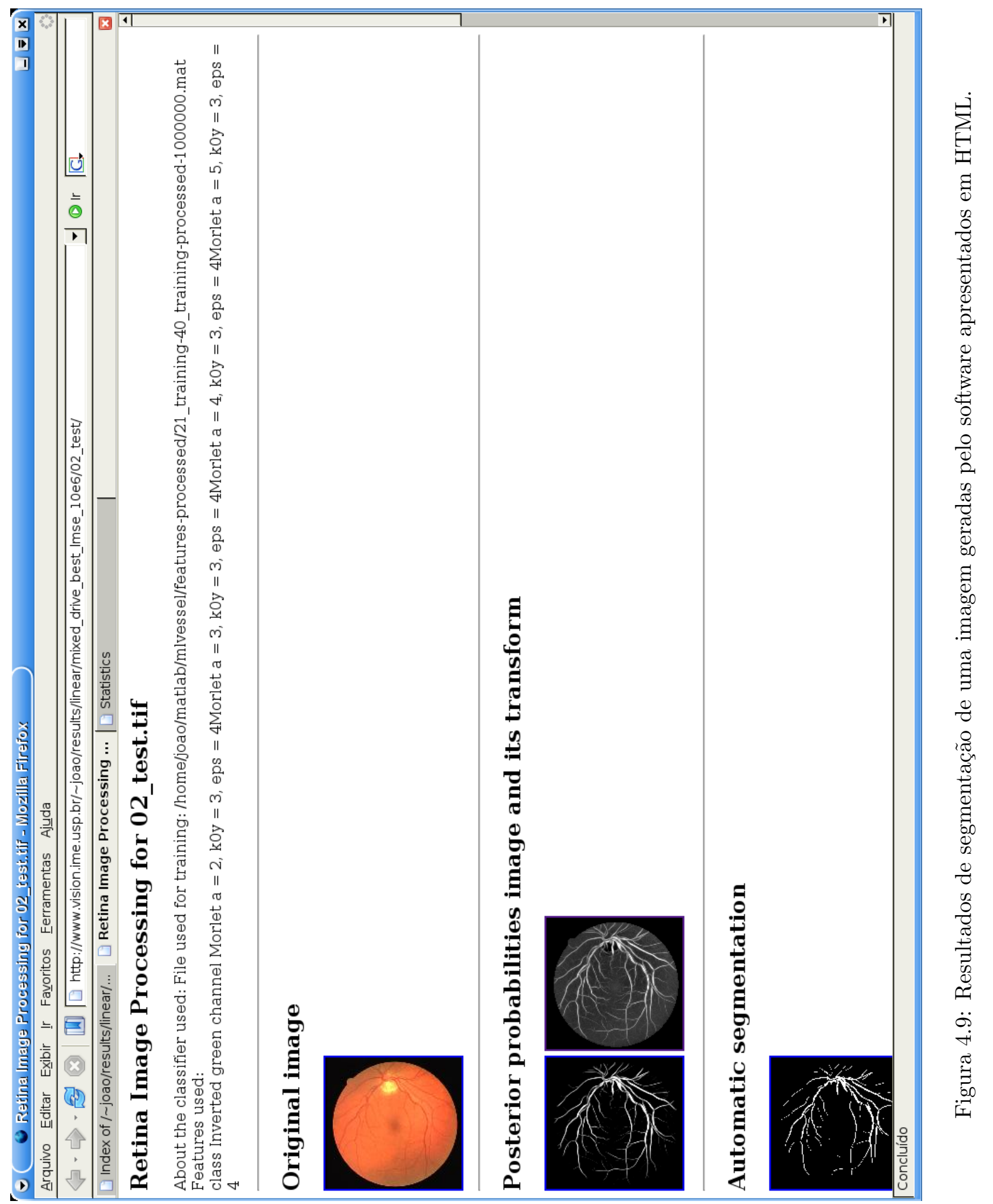




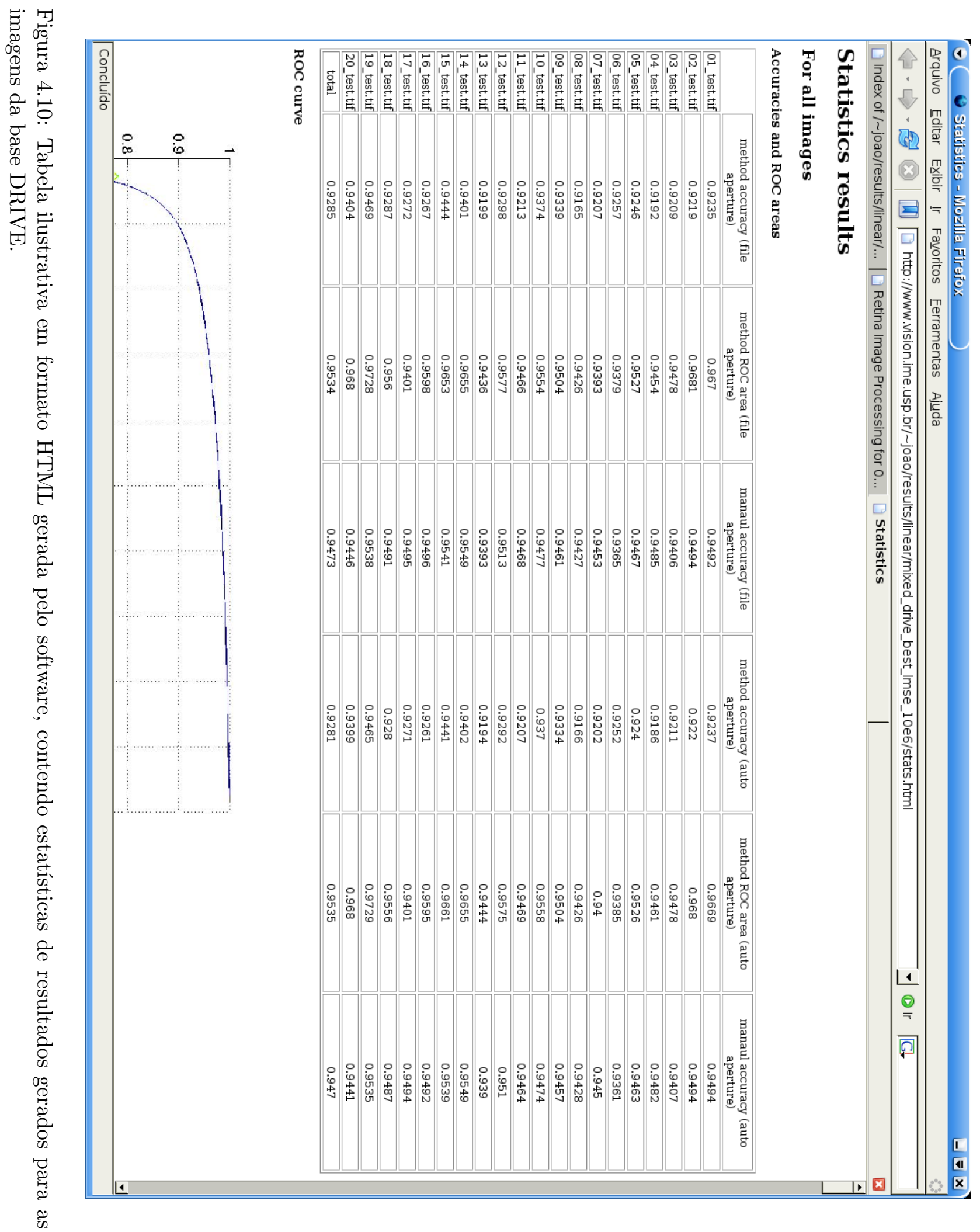




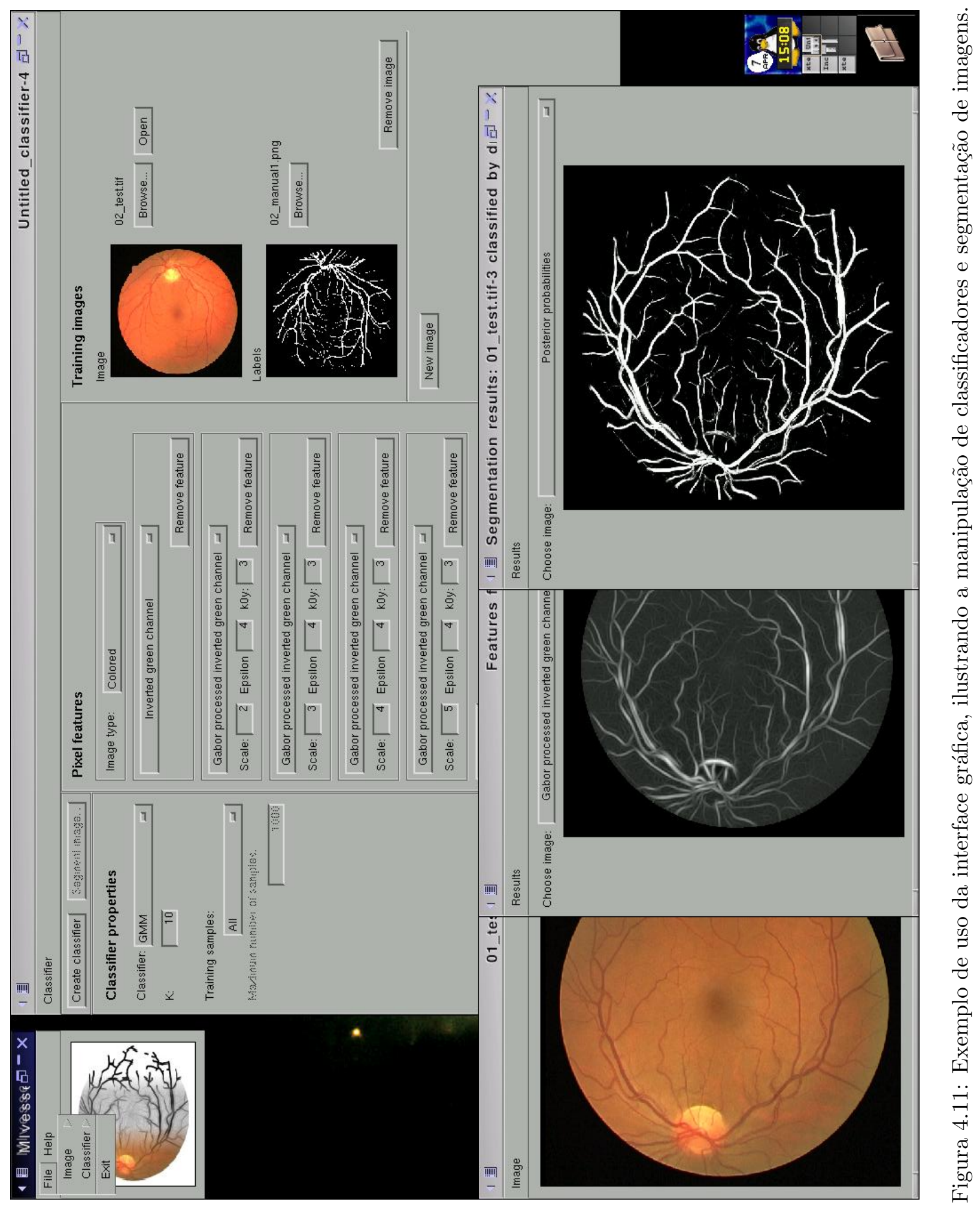




\section{Capítulo 5}

\section{Resultados Experimentais}

Resultados ilustrativos de segmentação para um par de imagens de cada banco (produzidos usando o classificador MMG com $c=20$ e $N=10^{6}$ ), acompanhados das segmentações manuais correspondentes, estão nas Figuras 5.1 e 5.2 . A Figura 5.3 apresenta resultados para as mesmas imagens e configuração de parâmetros, porém com o classificador MMG sendo treinado em cada uma das bases DRIVE e STARE e testado na outra. Os resultados são imagens formadas pelas probabilidades posteriores de cada pixel ser da classe vaso, bem como a segmentação final, produzida limiarizando as probabilidades posteriores em $p\left(C_{1} \mid \mathbf{v}\right)>0.5$.

A Tabela 5.1 apresenta resultados comparativos para os diferentes classificadores testados. As áreas sob as curvas ROC $\left(A_{z}\right)$ e acurácias são apresentadas para o classificador MMG com diferentes valores de $c$; classificador $k \mathrm{NN}$ com diferentes valores de $k$ e o classificador LEQM, sendo que todos os classificadores foram treinados com cem mil amostras $\left(N=10^{5}\right)$. Diferentes métodos de segmentação são comparados na Tabela 5.2, que apresenta as áreas sob as curvas ROC e acurácias para classificação usando o MMG com $c=20$ e $N=10^{6}$; o mesmo classificador sendo treinado em cada um dos bancos DRIVE e STARE e testado no outro (teste cruzado); detecção usando apenas uma escala da wavelet de Gabor; detecção com o filtro casado gaussiano 2D (ver Seção 2.2.3 Chaudhuri et al., 1989] e os algoritmos de [Jiang e Mojon, 2003] e [Staal et al., 2004], como publicados em [Staal et al., 2004]. Também são apresentadas as acurácias das segmentações produzidas por observadores humanos. Curvas ROC para os bancos DRIVE 

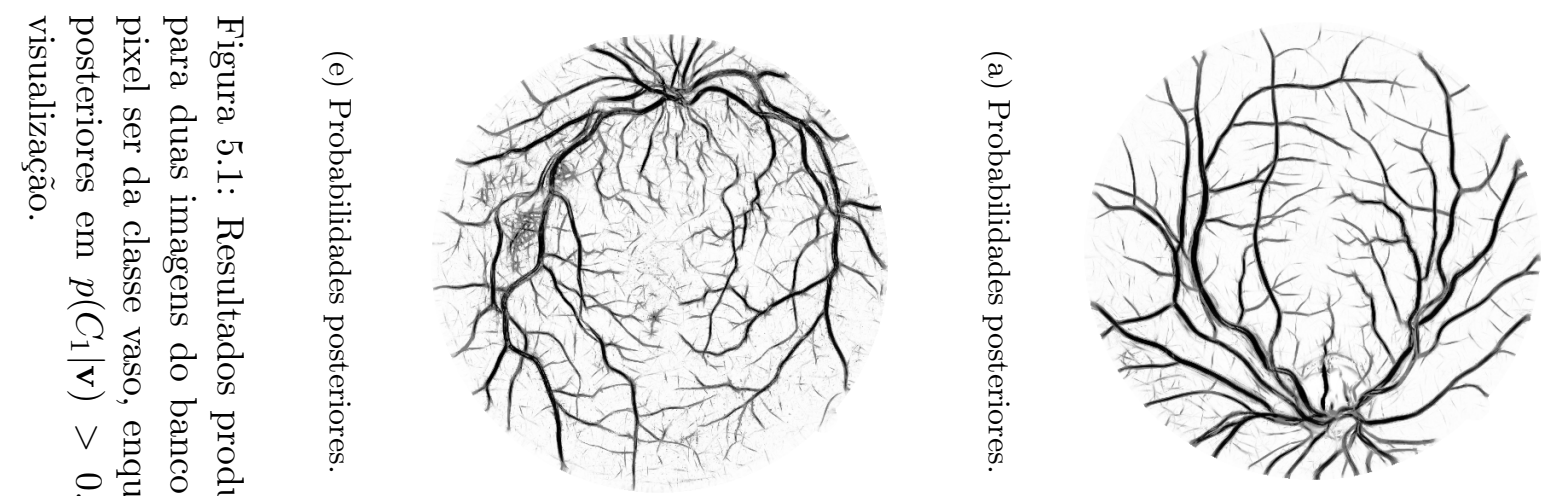

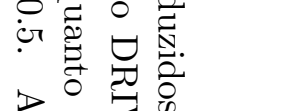

क ल स

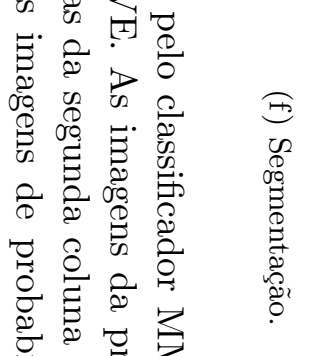
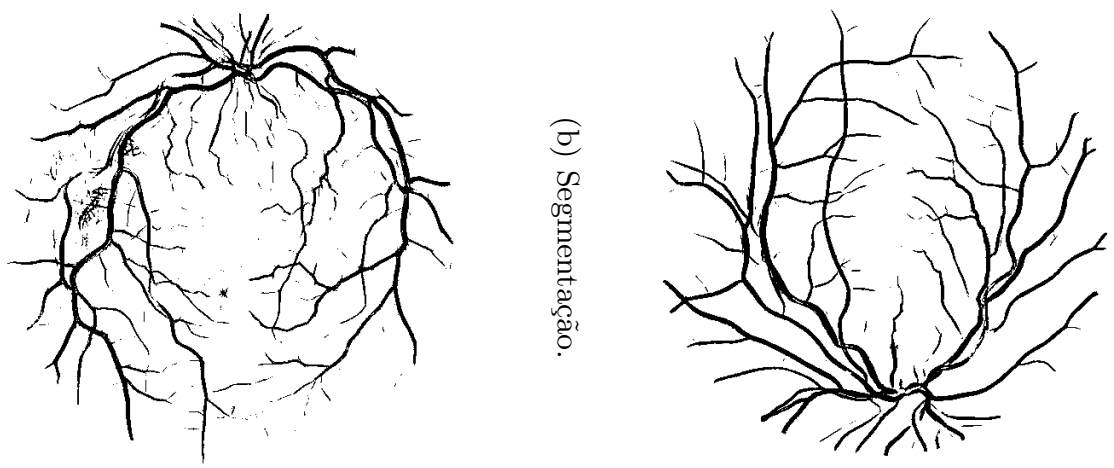

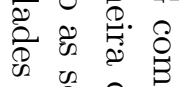

용

焉.

ज.

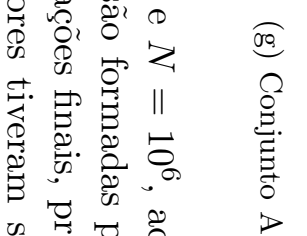

की

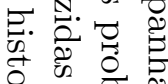

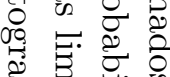

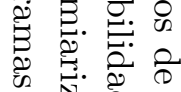

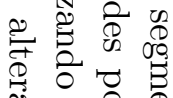

ڤँ ॠ

\&

¿ृ:

ป.

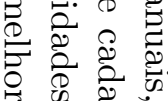
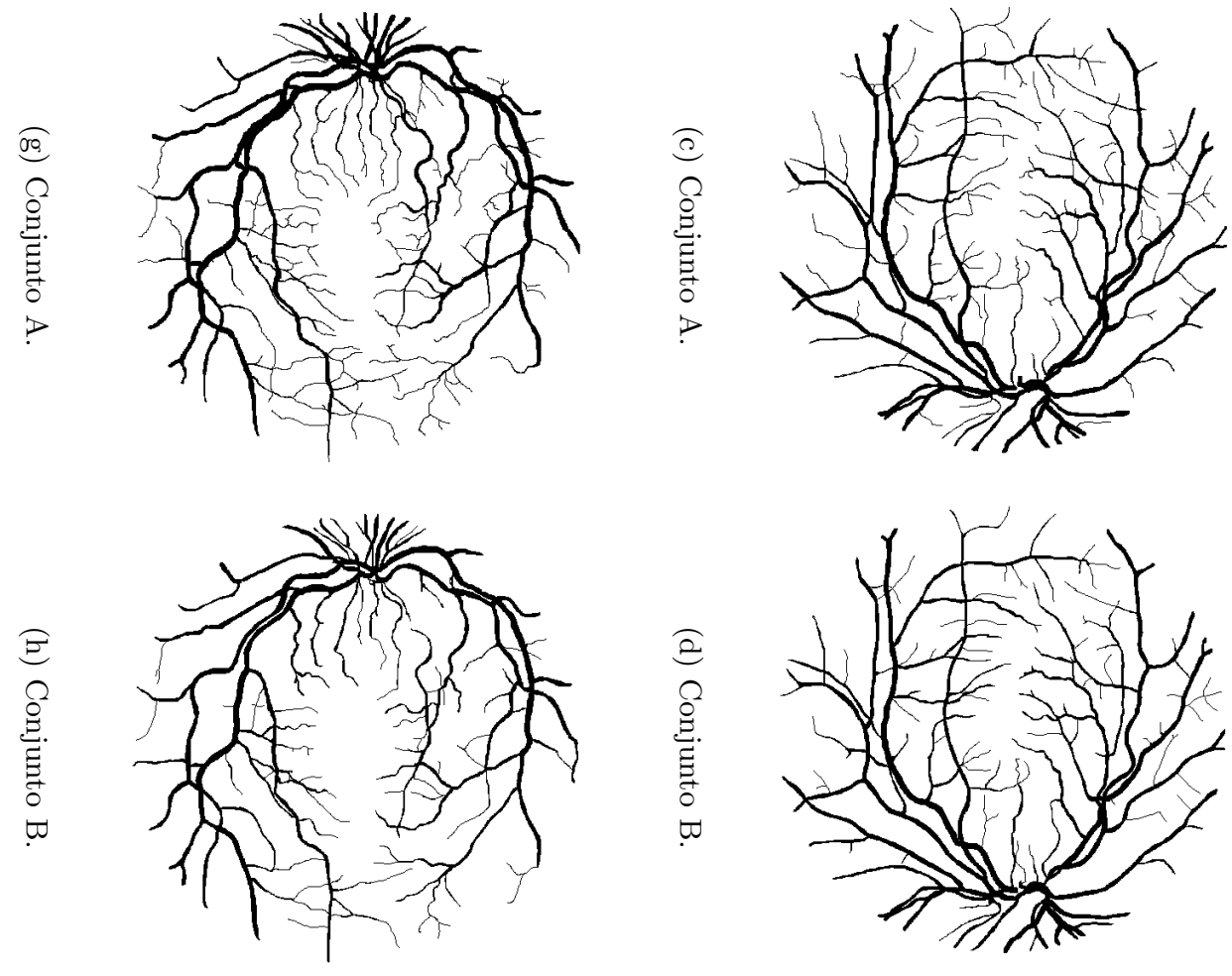

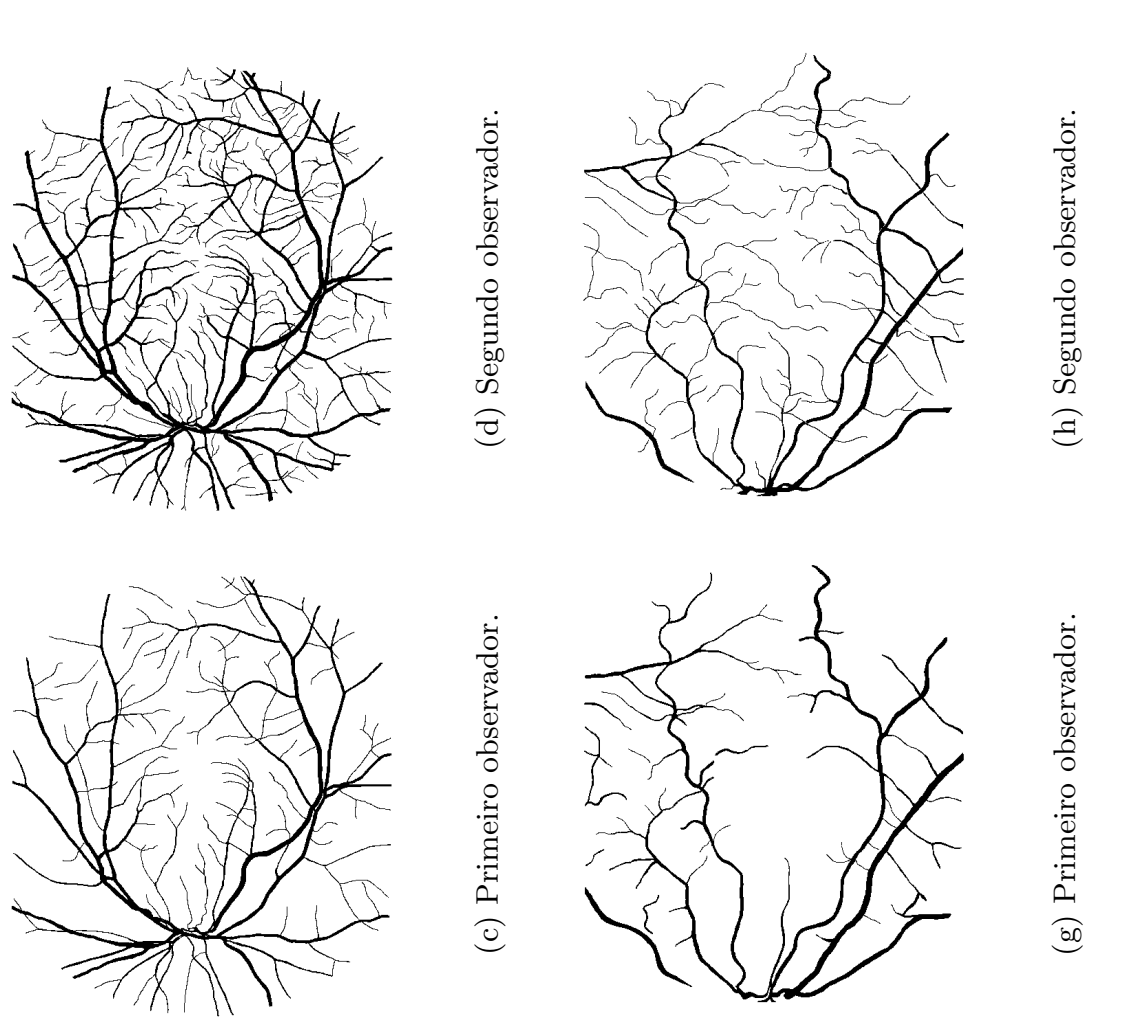

苗 త్ 娄 㻤.

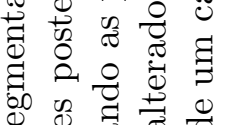
कृ ช 告 萠

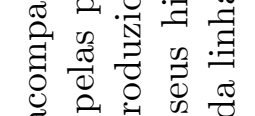

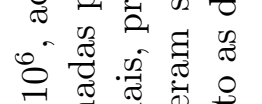

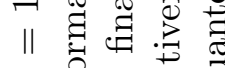
z 0 1. จ ॥
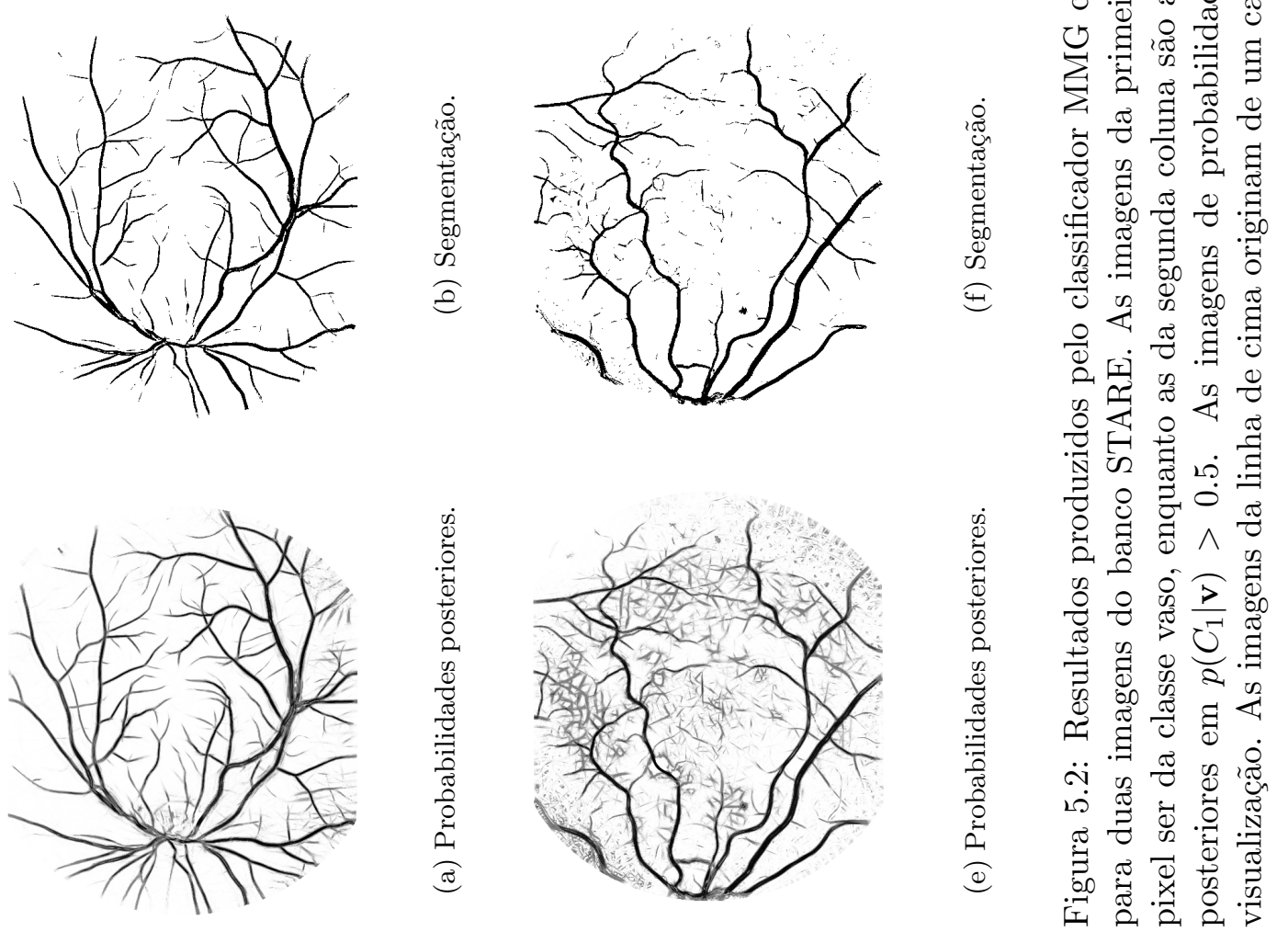

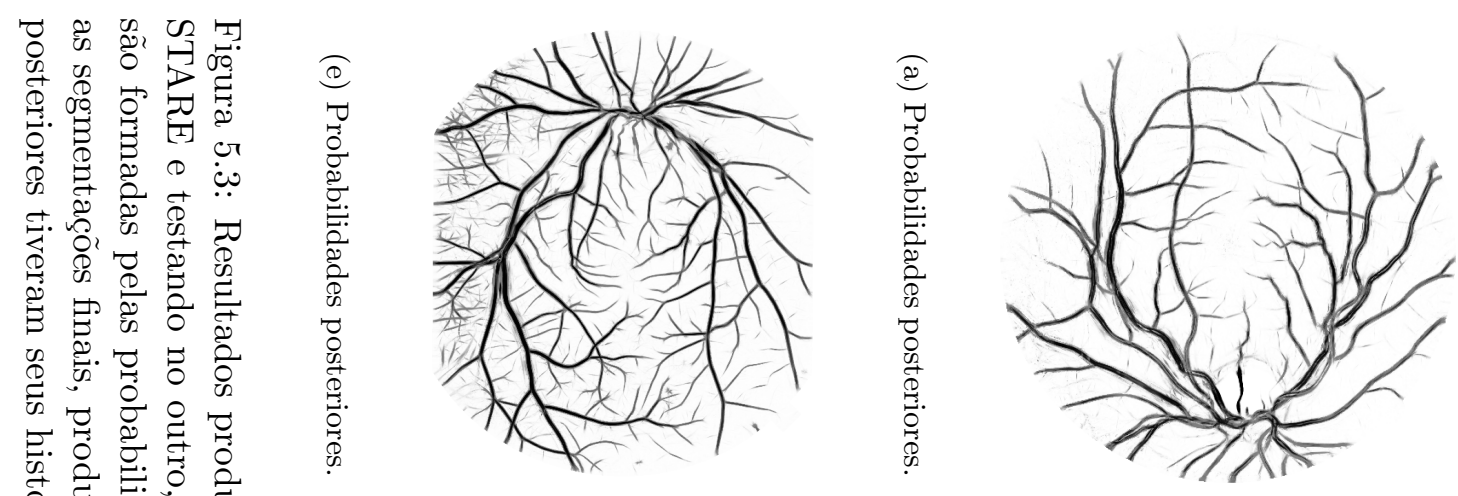

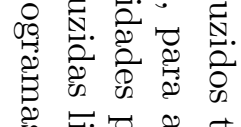

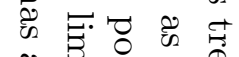

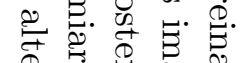
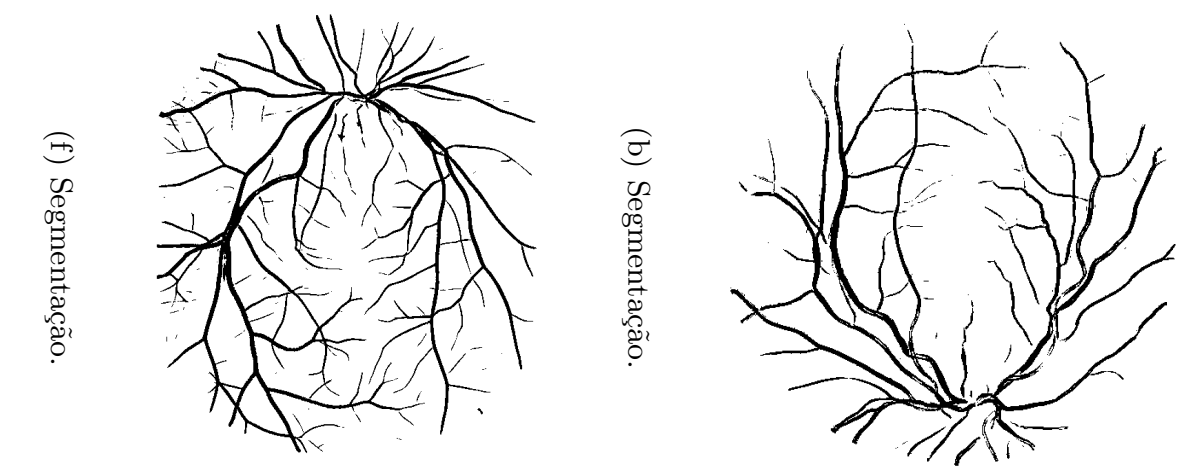

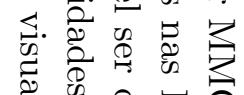

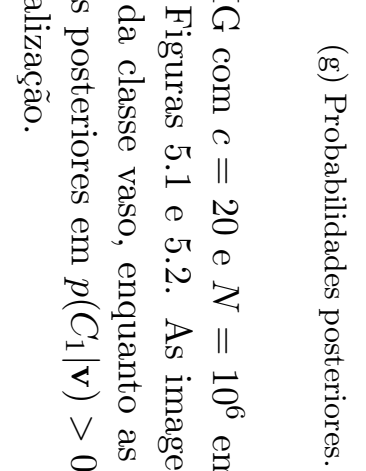
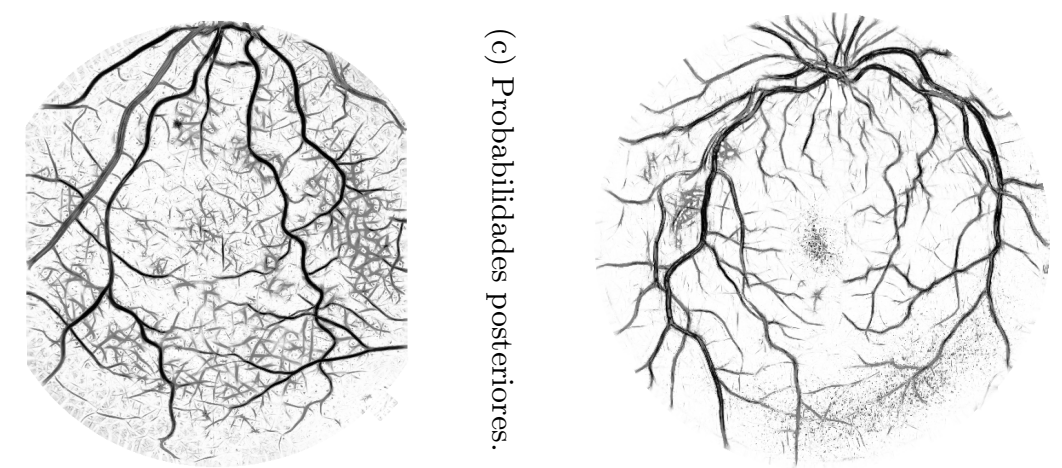

نे

is की की

范泀泀.

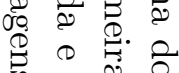

की

ग के है

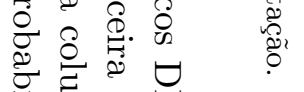
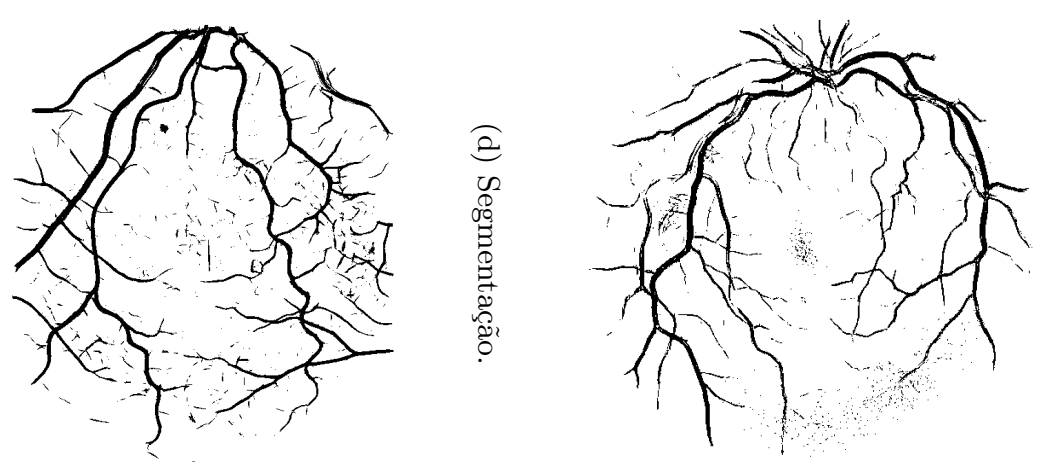
Tabela 5.1: $A_{z}$ e acurácia para resultados de classificação usando diferentes classificadores. $A_{z}$ indica a área sob a curva ROC e a acurácia é a fração de pixels corretamente classificados. Todos os classificadores foram treinados com cem mil amostras $\left(N=10^{5}\right)$.

\begin{tabular}{|c||c|c|c|c|}
\hline \multicolumn{1}{|c||}{\multirow{2}{*}{\multicolumn{1}{c||}{ Método de segmentação }}} & \multicolumn{4}{c|}{ DRIVE } & \multicolumn{2}{c|}{ STARE } \\
\cline { 2 - 5 } & $A_{z}$ & Acurácia & $A_{z}$ & Acurácia \\
\hline LEQM & 0.9532 & 0.9284 & 0.9602 & 0.9365 \\
$k \mathrm{NN}, k=1$ & 0.8220 & 0.9201 & 0.8166 & 0.9273 \\
$k \mathrm{NN}, k=8$ & 0.9339 & 0.9446 & 0.9336 & 0.9460 \\
$k \mathrm{NN}, k=32$ & 0.9529 & 0.9473 & 0.9558 & 0.9480 \\
$k \mathrm{NN}, k=64$ & 0.9568 & 0.9475 & 0.9612 & 0.9482 \\
$k \mathrm{NN}, k=128$ & 0.9591 & 0.9479 & 0.9636 & 0.9480 \\
$k \mathrm{NN}, k=256$ & 0.9605 & 0.9478 & 0.9653 & 0.9478 \\
$k \mathrm{NN}, k=512$ & 0.9609 & 0.9476 & 0.9658 & 0.9472 \\
$\mathrm{MMG}, c=1$ & 0.9287 & 0.9227 & 0.9409 & 0.9244 \\
$\mathrm{MMG}, c=5$ & 0.9549 & 0.9419 & 0.9616 & 0.9437 \\
$\mathrm{MMG}, c=10$ & 0.9582 & 0.9446 & 0.9657 & 0.9474 \\
$\mathrm{MMG}, c=15$ & 0.9592 & 0.9454 & 0.9657 & 0.9469 \\
$\mathrm{MMG}, c=20$ & 0.9600 & 0.9468 & 0.9666 & 0.9478 \\
$\mathrm{MMG}, c=30$ & 0.9609 & 0.9468 & 0.9661 & 0.9476 \\
$\mathrm{MMG}, c=40$ & 0.9610 & 0.9473 & 0.9665 & 0.9479 \\
\hline
\end{tabular}

e STARE produzidas usando o classificador MMG com $c=20$ e $N=10^{6}$, filtragem com apenas uma escala da wavelet de Gabor e detecção com o filtro casado gaussiano 2D, bem como pontos representando o desempenho de observadores humanos, são apresentados nas Figuras 5.4 e 5.5 .

É importante ressaltar que o algoritmo EM de treinamento do classificador MMG fica computacionalmente mais caro ao aumentar o valor de $c$, porém garante uma fase de classificação rápida. O classificador $k \mathrm{NN}$ implementado de forma exaustiva não possui fase de treinamento, mas tem uma fase de classificação muito custosa. Por outro lado, o classificador LEQM é rápido tanto para treinamento quanto para classificação, mas fornece resultados piores, como visto na Tabela 5.1. Fixando a dimensão do espaço de características, a classificação dos pixels de uma imagem usando o classificador MMG é 
Tabela 5.2: $A_{z}$ e acurácia para diferentes métodos de segmentação e também observadores humanos. $A_{z}$ indica a área sob a curva ROC e a acurácia é a fração de pixels corretamente classificados.

\begin{tabular}{|c||c|c|c|c|}
\hline \multicolumn{1}{|c||}{} & \multicolumn{4}{c|}{ Banco } \\
\cline { 2 - 5 } \multicolumn{1}{|c||}{ Método de segmentação } & \multicolumn{2}{c|}{ DRIVE } & \multicolumn{2}{c|}{ STARE } \\
\cline { 2 - 5 } & $A_{z}$ & Acurácia & $A_{z}$ & Acurácia \\
\hline MMG, $c=20, N=10^{6}$ & 0.9614 & 0.9466 & 0.9671 & 0.9480 \\
Teste cruzado, MMG, $c=20, N=10^{6}$ & 0.9522 & 0.9404 & 0.9601 & 0.9328 \\
$M_{\psi}(\mathbf{b}, 4)$ & 0.9312 & & 0.9351 & \\
\hline Chaudhuri et al., 1989 & 0.9103 & & 0.8987 & \\
Jiang e Mojon, 2003 & 0.9327 & 0.8911 & 0.9298 & 0.9009 \\
Segundo observador & 0.9520 & 0.9441 & 0.9614 & 0.9516 \\
\hline Staal et al., 2004 & & 0.9473 & & 0.9349 \\
\hline
\end{tabular}

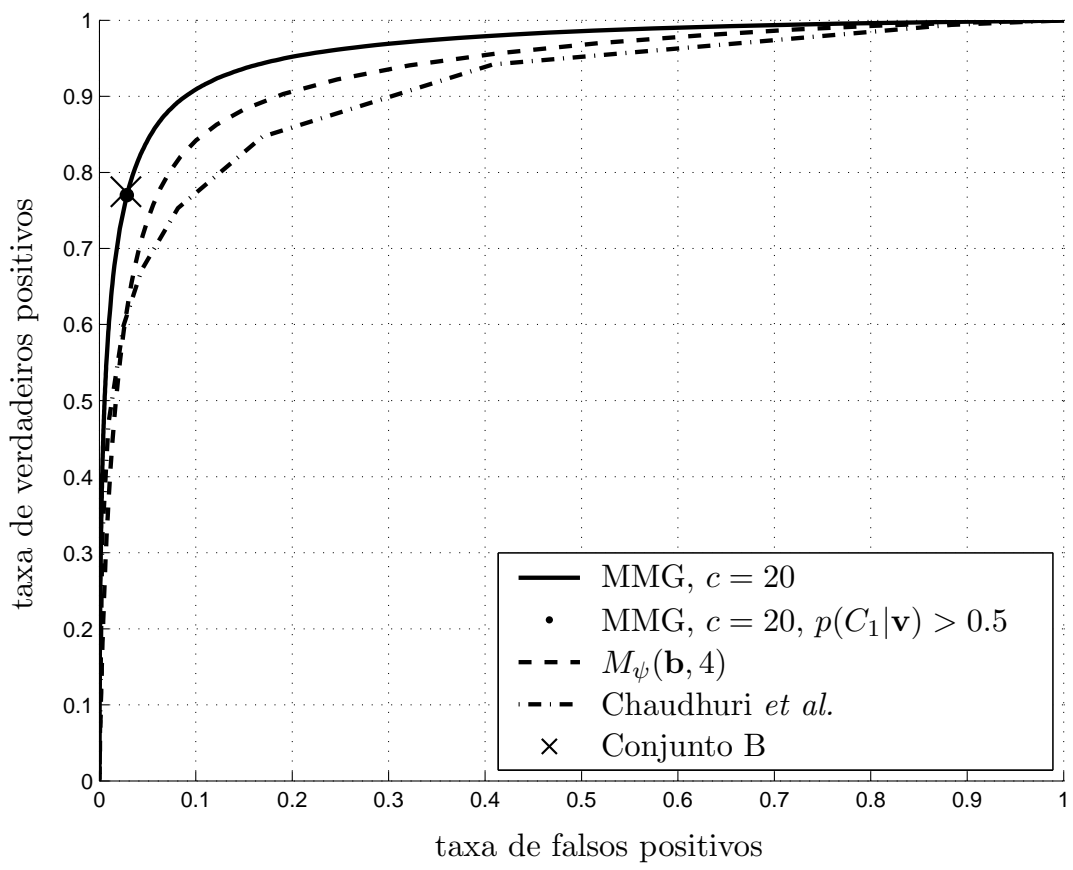

Figura 5.4: Curvas ROC para classificação no banco DRIVE usando o classificador MMG com $c=20$ e $N=10^{6}$, filtragem usando apenas uma escala da wavelet de Gabor $\left(M_{\psi}(\mathbf{b}, 4)\right)$ e o filtro casado $2 \mathrm{D}$ de Chaudhuri et al., 1989. O ponto marcado como $\bullet$ corresponde às classificações produzidas aplicando o limiar $p\left(C_{1} \mid \mathbf{v}\right)>0.5$, enquanto aquele marcado por $\times$ corresponde ao conjunto $\mathrm{B}$ de segmentações manuais. O classificador MMG possui $A_{z}=0.9614$. 


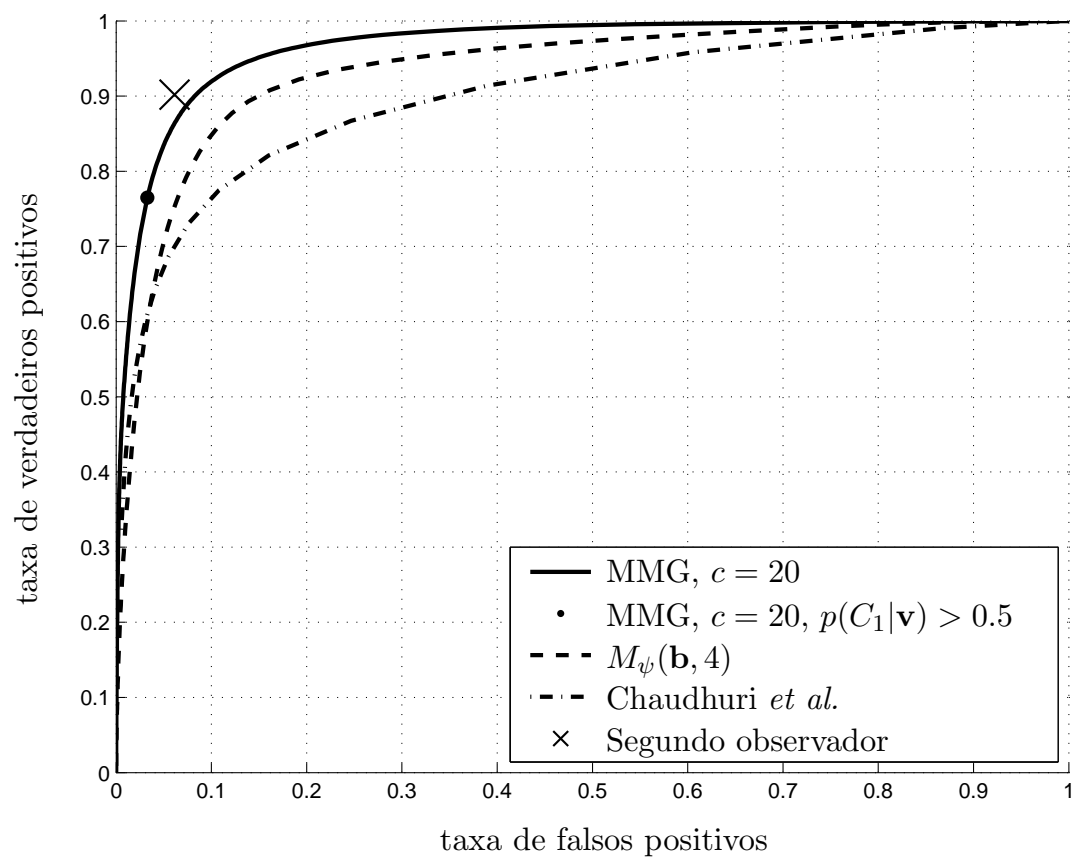

Figura 5.5: Curvas ROC para classificação no banco STARE usando o classificador MMG com $c=20$ e $N=10^{6}$, filtragem usando apenas uma escala da wavelet de Gabor $\left(M_{\psi}(\mathbf{b}, 4)\right)$ e o filtro casado 2D de Chaudhuri et al., 1989. O ponto marcado como $\bullet$ corresponde às classificações produzidas aplicando o limiar $p\left(C_{1} \mid \mathbf{v}\right)>0.5$, enquanto aquele marcado por $\times$ corresponde às segmentações manuais do segundo observador. O classificador MMG possui $A_{z}=0.9671$. 
rápida, levando tempo $O(c P)$, em que $P$ é o total de pixels de uma imagem. Comparativamente, o classificador $k \mathrm{NN}$ leva tempo $O(N P)$ apenas para o cálculo das distâncias utilizadas, em que $N$ é o número de amostras de treinamento. A geração das características é feita pelo cálculo dos coeficientes da transformada wavelet através de uma série de correlações. Usando a transformada rápida de Fourier e a definição da transformada wavelet no domínio das freqüências, (Equação 3.22), elas são feitas em $O\left(P \log _{2} P\right)$ Gonzalez e Woods, 2002. Foi usada uma implementação não otimizada em MATLAB para testes. Em um AMD Athlon XP 2700+ PC (relógio de $2167 \mathrm{MHz}$ ) com 1 GB de memória, a geração de características para uma imagem típica das bases DRIVE e STARE leva aproximadamente 3 minutos. A estimativa dos parâmetros dos MMGs usando $c=20$ e $N=10^{5}$ leva até 2 horas (o que poderia melhorar consideravelmente usando uma implementação eficiente que inclua otimizações), enquanto a classificação dos pixels de uma imagem típica com o classificador MMG com $c=20$ leva menos de 10 segundos. Por outro lado, a classificação dos pixels de uma imagem usando o classificador $k \mathrm{NN}$ usando o mesmo número de amostras de treinamento, leva aproximadamente 4 horas.

Observe que os valores de $A_{z}$ e acurácia do classificador MMG aumentaram com o valor de $c$. Esperase que a partir de certo valor de $c$ o desempenho piore, uma vez que o modelo se ajustaria excessivamente aos dados de treinamento (ver Seção 3.2.2). De forma similar, o valor $A_{z}$ do classificador $k \mathrm{NN}$ melhorou com o aumento de $k$, mas a partir de certo valor espera-se perda na precisão espacial das estimativas, levando a queda no desempenho (ver Seção 3.2.3). Esse tipo de comportamento pode ser observado pela queda na acurácia do classificador $k \mathrm{NN}$ após o valor de $k=128$. A queda se deve ao pouco número de amostras da classe vaso e altos valores de $k$, fazendo com que a maioria das amostras seja atribuída à classe não vaso. Como a análise ROC é invariante à distribuição a priori das classes, os valores de $A_{z}$ ainda não foram afetados por essa perda de precisão, mas espera-se que diminuam com valores mais altos de $k$.

As segmentações manuais dão uma idéia da variância entre observadores humanos. No banco DRIVE, a curva ROC do classificador MMG fica muito próxima do ponto representando o segundo conjunto de segmentações manuais (Figura 5.4). O método apresenta um bom desempenho em imagens normais e bem comportadas, porém imagens anormais com patologias ou má iluminação (como 
discutido abaixo) pioram o desempenho médio. É interessante notar que, no banco STARE, a acurácia de alguns métodos atinge valores maiores do que os do segundo observador humano (Tabela 5.2). Isso ocorre porque as segmentações manuais do segundo observador possuem bem mais vasos finos do que as do primeiro (diminuindo sua acurácia), enquanto o método, sendo treinado pelo primeiro observador, é capaz de segmentar os vasos de maneira semelhante a ele. No gráfico ROC, pode-se observar que o segundo observador apresenta uma alta taxa de falsos positivos (Figura 5.5 ) em comparação com aquela apresentada pelo conjunto B da base DRIVE (Figura 5.4). Ainda assim, a alta taxa de verdadeiros positivos reflete a maior precisão do segundo observador em relação aos métodos na base STARE.

A inspeção visual dos resultados mostra dificuldades típicas que devem ser trabalhadas. Os maiores erros estão na falsa detecção de ruídos e outras estruturas. A falsa detecção ocorre em algumas imagens na borda do disco óptico, em hemorragias, microaneurismas, bordas de exsudatos ou outras patologias que apresentem forte contraste. Outra dificuldade é a detecção dos vasos mais finos, algumas vezes marcados pelos observadores humanos. Além disso, o método não respondeu bem a fortes variações de iluminação dentro da mesma imagem, mas isso ocorreu em apenas uma região de uma imagem entre todas as testadas.

O teste cruzado, em que cada banco foi segmentado usando um classificador treinado no outro, apresentou um desempenho ligeiramente pior do que os experimentos normais (Tabela 5.2 e Figura 5.3 ). Apesar das imagens dos bancos serem parecidas, existe uma diferença na largura típica dos vasos nas imagens de cada banco, que contribuiu para a queda no desempenho. Nos resultados do banco DRIVE, os vasos finos são detectados com menos qualidade e existe um aumento na quantidade de ruído detectado como falso positivo. Os resultados do banco STARE, por sua vez, apresentam muito mais ruído e patologias detectados como falsos positivos. Isso mostra que o método pode ajustar-se a condições específicas de aquisição de um banco e não é capaz de generalização perfeita para outros. 


\section{Capítulo 6}

\section{Conclusão}

\subsection{Comentários finais}

A transformada wavelet de Gabor mostra-se uma ferramenta eficaz para realçar os vasos ao mesmo tempo que filtra ruídos, apresentando melhor desempenho que o filtro casado 2D de Chaudhuri et al., 1989. A informação proveniente da wavelet de Gabor em diferentes escalas pode ser integrada através dos classificadores apresentados. Dos três classificadores testados, o LEQM apresenta o pior desempenho, porém com fases rápidas de treinamento e classificação. O kNN apresenta um bom desempenho, mas com uma fase de classificação muito lenta, o que dificulta seu uso em uma aplicação prática. Por fim, o classificador MMG possui uma fase de treinamento custosa, mas garante uma fase rápida de classificação e um bom desempenho, similar ao do $k \mathrm{NN}$. A geração das características de uma imagem consiste no cálculo dos diversos coeficientes da wavelet e, assim como a classificação com o MMG, pode ser implementada de maneira eficiente, resultando numa abordagem aplicável em uma ferramenta interativa.

A abordagem usando treinamento supervisionado exige segmentações manuais, porém permite que classificadores sejam treinados para diferentes modalidades de imagens ou condições específicas definidas por exemplo pela câmera ou iluminação, sem depender de ajuste de parâmetros ou outro tipo de interação com um usuário. Nos experimentos em que o classificador MMG foi treinado em cada um dos bancos DRIVE e STARE e testado no outro, mostrou-se a dependência do método no conjunto 
de treinamento. Como alternativa para treinamento, é possível usar amostras rotuladas da própria imagem a ser segmentada, incorporando assim as peculiaridades da imagem [Cornforth et al., 2005]. A classificação supervisionada pode evitar que regras complexas precisem ser formuladas para lidar com situações específicas, uma vez que a complexidade seria incorporada pelos classificadores. Os métodos recentes de classificação supervisionada de pixels mostraram bons resultados quanto à análise ROC [Niemeijer et al., 2004; Staal et al., 2004; Soares et al., 2006], mesmo restringindo-se à detecção local dos vasos. Em comparação com o trabalho de [Staal et al., 2004, a abordagem desenvolvida baseiase no uso da transformada wavelet e não utiliza a representação da imagem em partições lineares. Além disso, apresenta resultados mais rápidos com o uso do classificador MMG e maiores áreas sob as curvas ROC. Finalmente, é importante ressaltar que, dada a simplicidade conceitual da abordagem, ela poderia ser facilmente aplicada à segmentação de outras estruturas direcionais, como neurônios ou estradas em imagens aéreas, apesar de nenhum teste ter sido realizado nesse sentido.

\subsection{Trabalhos futuros}

Analisando o método e a avaliação experimental apresentados, bem como a revisão da literatura, pode-se observar alguns pontos a serem melhor estudados e trabalhados. Em particular, a inspeção visual de problemas nos resultados sugere idéias para a evolução dos métodos.

O método não respondeu bem a fortes variações de iluminação dentro de uma mesma imagem. Essas variações poderiam ser compensadas na fase de pré-processamento (como discutido na Seção 2.1) ou incorporadas de alguma forma nos vetores de características dos pixels. A wavelet de Gabor apresentada na Equação 3.21, quando ajustada para baixas freqüências, não possui média nula. Assim, na implementação realizada, ela não é totalmente invariante a variações do fundo. Isso pode ser corrigido introduzindo o termo de compensação da wavelet Antoine et al., 1993. A introdução desse termo leva a perda da localização espacial em freqüências muito baixas, sendo prejudicial quando se analisa o módulo do resultado. Como alternativas, restariam então analisar separadamente as partes real e complexa dos coeficientes (de forma equivalente, pode-se analisar o módulo e fase dos coeficientes) ou modificar a wavelet de Gabor apropriadamente, como em Harrop et al., 2002. 
Para diferenciar bordas e outros artefatos dos vasos, o método poderia incorporar explicitamente informações sobre bordas, possivelmente pela inclusão de novos coeficientes da transformada wavelet no vetor de características. A transformada wavelet é capaz de fornecer uma representação local da imagem de forma a evidenciar bordas e outras transições direcionais, como os vasos sangüíneos neste estudo. A representação usando a wavelet de Gabor é feita calculando frames, levando a uma representação redundante Antoine et al., 1993; Lee, 1996. O uso de um número maior de coeficientes poderia ser viabilizado através de algum esquema de seleção de características, permitindo escolher e visualizar as mais importantes para classificação. Vale também ressaltar que existem algoritmos rápidos para o uso de frames da TWC 2D, o que permitiria acelerar consideravelmente a aplicação do método Vandergheynst e Gobbers, 2002].

A normalização das características foi realizada aplicando a transformação normal separadamente ao espaço de características de cada imagem (Seção 4.3). A normalização por imagem ajuda a compensar algumas variações entre imagens, como iluminação ou contraste globais diferentes. Se essas variações fossem compensadas de uma forma mais apropriada, como discutido acima, a mesma normalização poderia ser aplicada aos pixels de todas as imagens, resultando numa comparação mais precisa de valores. A aplicação da transformação normal não leva em conta a covariância entre diferentes características. As características utilizadas são altamente correlacionadas, por serem coeficientes da wavelet correspondentes a orientações e escalas similares. Assim, poderia ser mais adequado utilizar a matriz de covariância estimada dos dados para normalização, resultando em características não correlacionadas Fukunaga, 1990].

A abordagem de treinamento em que são utilizadas amostras da própria imagem a ser segmentada fornecidas por um usuário pode apresentar resultados melhores, uma vez que peculiaridades da imagem são incorporadas. Pode ser difícil ou trabalhoso obter uma amostragem representativa apenas pela interação do usuário. Assim, seria interessante estudar uma estratégia para aproveitar tanto amostras de outras imagens quanto da imagem a ser segmentada. Com isso, o esforço do usuário seria menor e seriam aproveitadas tanto a informação sobre condições específicas da imagem quanto o grande conjunto de exemplos proveniente de outras. 
O número de gaussianas usadas para modelar cada classe no classificador MMG é um importante parâmetro que poderia ser calculado automaticamente de forma a maximizar o desempenho Figueiredo e Jain, 2002. Em particular, seria mais adequado que cada classe fosse modelada por um número diferente de gaussianas, o que não foi feito nos experimentos realizados.

Uma desvantagem da abordagem proposta é que ela apenas leva em consideração a informação local a cada pixel através da transformada wavelet, ignorando informações importante sobre formas e estruturas presentes nas imagens. Os resultados atuais podem ser melhorados através de um pós-processamento simples das segmentações para a remoção de ruídos e inclusão de pixels de vasos, como em Leandro et al., 2003. As imagens de probabilidades posteriores são um resultado intermediário do método, que poderiam fornecer segmentações mais precisas se aplicada alguma forma de detecção global, como apresentado na Seção 2.3. Um algoritmo de detecção global poderia também incorporar informações como iluminação e presença de bordas, atenuando os problemas da variação entre imagens. Dada a abordagem de estimar as distribuições de probabilidades das classes vaso e não vaso, abordagens probabilísticas poderiam também ser aplicadas para a determinação da estrutura global. Assim, distribuições poderiam ser estimadas a partir das segmentações manuais disponíveis, possivelmente incorporando conhecimentos a priori e evitando a necessidade de interação ou ajuste de parâmetros. Por exemplo, como colocado na Seção 2.3.4. uma formulação bayesiana pode ser usada para inferir um conjunto de árvores vasculares Thönnes et al., 2002]. Outra alternativa interessante são modelos deformáveis probabilísticos, capazes de incorporar conhecimentos a priori e quantificar a incerteza a respeito da segmentação gerada McInerney e Terzopoulos, 1996. De forma muito similar, campos de Markov podem ser usados para definir e estimar probabilidades posteriores das segmentações. O estudo de campos de Markov para segmentação de imagens tem recebido atenção com o desenvolvimento de algoritmos rápidos para a maximização da probabilidade posterior baseados em cortes em grafos Boykov e Jolly, 2001; Greig et al., 1989.

Dependendo da aplicação, diferentes formas de avaliação se tornam mais apropriadas Bowyer e Phillips, 1998. Por exemplo, a avaliação dos esqueletos não levaria em consideração a largura dos vasos, mas poderia medir outras qualidades, como a presença de falhas e capacidade de detectar pontos 
de bifurcação e cruzamento. A informação sobre as larguras dos vasos pode ser importante ou não dependendo da aplicação. Na deteç̧ão de mudanças e patologias, ela é fundamental, porém para o registro entre imagens ou análise fractal da vasculatura pode ser desprezada. Em Lowell et al., 2004, verdadeiros e falsos positivos são determinados usando os esqueletos da seguinte forma: se um pixel do esqueleto gerado por dado método está a uma distância de até 3 pixels de um pixel pertencente à segmentação manual, ele é contado como verdadeiro positivo; caso contrário, é um falso positivo. Em [Fritzsche et al., 2003], sugere-se uma abordagem similar, definindo também a contagem de verdadeiros e falsos negativos. A análise ROC usando as segmentações completas, por outro lado, leva em conta a largura dos vasos, de forma que vasos grossos têm peso bem maior do que os finos, o que não ocorre nas abordagens usando os esqueletos. Outra forma interessante de avaliação seria diretamente através de uma aplicação, como na detecção de neovascularização através da análise e classificação da estrutura vascular [Cesar-Jr. e Jelinek, 2003. A avaliação visual qualitativa ainda é muito importante na comparação, permitindo identificar vantagens e desvantagens de cada método e regiões das imagens em que os resultados da segmentação são melhores ou piores. Por outro lado, é uma análise trabalhosa e que envolve subjetividade. Apesar de bons resultados ROC da abordagem apresentada, a análise visual (discutida no Capítulo 5) é capaz de mostrar dificuldades a serem superadas.

Uma grande dificuldade em avaliar os métodos é o estabelecimento de um resultado ideal confiável a partir de segmentações manuais. Observadores humanos são subjetivos e estão sujeitos a erros, gerando uma grande variabilidade nas suas segmentações. Assim, é desejável que sejam usadas diversas segmentações manuais para o estabelecimento do resultado a ser usado como referência Fritzsche et al., 2003, que não foi o caso na avaliação experimental apresentada. Além disso, seria ideal que as segmentações fossem realizadas por oftalmologistas, o que também não ocorreu (ver Seção 4.5.1). Uma alternativa à geração de segmentações manuais seria o uso de imagens sintéticas, que teriam então segmentações conhecidas. Contudo, seria praticamente impossível reproduzir fielmente a complexidade de formação de verdadeiras imagens de retina, tornando essa abordagem inadequada para uma avaliação completa. Mesmo assim, ela poderia ser aplicada em testes parciais, como de adequação de modelos de vasos ou robustez de detecção sob algum tipo de ruído. 
O material utilizado poderia ser enriquecido através da inclusão de imagens que apresentassem maior variedade de patologias, em particular sintomas específicos da retinopatia diabética, permitindo melhor avaliar a robustez e precisão dos algoritmos nessas condições. O banco DRIVE é composto por imagens escolhidas aleatoriamente provenientes de um programa de triagem de retinopatia diabética, mas não há uma anotação das causas de patologias. O STARE, por sua vez, possui imagens anotadas de acordo com os sinais patológicos apresentados, sendo que das 20 imagens, existe um par que apresenta sintomas decorrentes de retinopatia diabética não proliferativa. As imagens desse banco foram selecionadas de modo a privilegiar imagens apresentando patologias e dificuldades para a segmentação. Assim, é necessário um cuidado maior para avaliar a significância estatísticas de testes realizados. Também seria interessante a avaliação usando outras modalidades de imagens. Em trabalhos futuros, seria interessante calcular as variâncias das curvas ROC e incluir testes de hipótese na comparação de métodos, como em Mendonça e Campilho, 2006; Staal et al., 2004].

A análise das imagens da retina para a detecção da retinopatia diabética requer atenção para uma variedade de estruturas, com destaque para a vasculatura. Existem vários esforços para a detecção das diferentes estruturas, de forma que poderiam ser coletadas informações que em conjunto fornecessem indicadores a respeito da presença de retinopatia diabética. As propriedades dos vasos sangüíneos podem ser quantificadas pela análise de sua morfologia. A análise fractal Cesar-Jr. e Jelinek, 2003 e multifractal McQuellin et al., 2002 pode fornecer indicadores numéricos a respeito de neovascularização. Por outro lado, a curvatura [Hart et al., 1999], comprimentos e larguras dos vasos Pedersen et al., 2000 foram identificadas como características importantes para a detecção da retinopatia. Uma tarefa difícil e importante, que ainda é pouco estudada, é a separação das redes de veias e artérias, o que permitiria analisá-las separadamente. O método de segmentação automática dos vasos apresentado mostrou bons resultados e possui potencial para melhorias, tendo como base teórica wavelets e classificadores estatísticos. Ele é capaz de fornecer resultados em tempo hábil e diminui a necessidade de interação com o usuário, representando um esforço para que a análise automatizada de imagens de retina possa ser realizada por trabalhadores comunitários não especializados. Uma nova implementação dos métodos está sendo projetada e desenvolvida, que deverá ser mais rápida, possuir maior usabilidade 
e ser independente do MATLAB, evitando a necessidade de licenças e permitindo maior alcance. 


\section{Apêndice A}

\section{Publicações}

A.1 Comparison of various methods to delineate blood vessels in retinal images

Segue o trabalho "Comparison of various methods to delineate blood vessels in retinal images", apresentado no 16th National Congress of the Australian Institute of Physics [Cree et al., 2005b. O trabalho usa análise ROC para comparar implementações de diferentes abordagens de segmentação que focam na detecção local dos vasos, entre as quais uma versão anterior dos métodos apresentados nesta dissertação. 
This material is presented to ensure timely dissemination of scholarly and technical work. Copyright and all rights therein are retained by authors or by other copyright holders. All persons copying this information are expected to adhere to the terms and constraints invoked by each author's copyright. In most cases, these works may not be reposted without the explicit permission of the copyright holder.

(c) 2005 16th Australian Institute of Physics Congress Organising Committee. All rights reserved. No part of this material may be reproduced or transmitted in any form, by any means, electronic or mechanical, including photocopying, recording, or by any informational retrieval system, without permission in writing from the Congress Organising Committee. The opinions expressed in this publication are those of the authors and do not necessarily represent those of the Organising Committee. 


\title{
Comparison of Various Methods to Delineate Blood Vessels in Retinal Images
}

\author{
M. J. Cree ${ }^{1}$, J. J. G. Leandro ${ }^{2}$, J. V. B. Soares ${ }^{2}$, R. M. Cesar, Jr. ${ }^{2}$, G. Tang ${ }^{1}$, H. F. Jelinek ${ }^{3}$ and \\ D. J. Cornforth ${ }^{4}$
}

\author{
${ }^{1}$ Department of Physics \& Electronic Engineering, University of Waikato, Hamilton, New \\ Zealand \\ ${ }^{2}$ Department of Computer Science, University of Sao Paulo, Brazil \\ ${ }^{3}$ School of Community Health, Charles Sturt University, Albury \\ ${ }^{4}$ School of Environmental and Information Sciences, Charles Sturt University, Albury
}

e-mail of corresponding author: m.cree@ ieee.org

\section{Introduction}

The blood vessels in the human retina are easily visualisable via digital fundus photography and provide an excellent window to the health of a patient affected by diseases of blood circulation such as diabetes. Diabetic retinopathy is identifiable through lesions of the vessels such as narrowing of the arteriole walls, beading of venules into sausage like structures and new vessel growth as an attempt to reperfuse ischaemic regions. Automated quantification of these lesions would be beneficial to diabetes research and to clinical practice, particularly for eye-screening programmes for the detection of eye-disease amongst diabetic persons.

We compare a number of methods to detect and delineate blood vessels in retinal images including an approach using Wavelets developed by ourselves [5], and a number of other approaches reported in the literature $[2,4,6,8]$. Previous studies have tended to work with fluorescein angiographic images in which blood vessels are well highlighted, however this procedure carries health risks which limits its usability. We are therefore particularly interested in analysis of non-mydriatic colour retinal images as obtained by standard eye-screening programmes. The vessel detection methods are tested on the publicly available STARE database of retinal images [3], which comprises 20 retinal images, and gold-standard images consisting of the delineated blood vessels as determined by two ophthalmologists. A testing methodology, inspired by the free-response receiver operator characteristic (FROC) analysis [1], is employed to evaluate the efficacy of the vessel detection methods.

In the following we give a brief description of each vessel detection method and our implementation of it. The testing methodology is outlined and the results presented.

\section{Theory}

Blood vessels in retinal images are well distinguished in the green field of a RGB image, and we use that for processing. The vessels are continuous, with little curvature branching out in a tree-like structure. Their cross-sectional intensity profile can be usefully modelled as a Gaussian function. The diameter of the vessels changes only slowly as one traverses along the vessels and is in the range of 4-20 pixels for images of the resolution of the STARE database $\left(705 \times 600\right.$ pixels for a $50^{\circ}$ field-of-view of the retina). The methods we describe for detecting 
blood vessels are based upon, at least in part, on the above observations. The description of the methods follows.

\section{Wavelet Transform}

The 2D continuous wavelet transform (CWT) is used to detect vessels with the Morlet as the mother wavelet [5] by varying parameters of scale and rotation angle. The Morlet wavelet is chosen because it is directional (in the sense of being effective in selecting orientations) and capable of fine tuning specific frequencies. This latter capability is especially important in filtering out the background noise. These characteristics of the Morlet wavelet represent its advantages with respect to other standard filters such as the Gaussian and its derivatives. Its parameters are chosen to make the filter elongated and a low frequency with few significant oscillations is set for the wavelet's complex exponential. The transform maximum response (in modulus) calculated from a set of orientations for each position is then taken, emphasising the blood vessels in all directions and filtering out most of the noise.

The segmentation is produced by classifying each pixel as belonging to the class of vessel or non-vessel pixels, based on each their features. The classification is supervised and the training set is obtained from a hand-drawn labelling of a region of the image to be segmented. The pixels' feature space was formed by maximum modulus Morlet wavelet responses (taken at different scales and elongations), gaussian gradient responses at different scales, mean filter responses and also colour information (namely, the red, green and blue channels). A feature extraction process was used to obtain a lower dimensional feature space, whilst preserving the structure important for classification.

\section{Matched-filtering}

One of the earliest described approaches to detecting blood vessels used matched-filtering to isolate long linear structures in the image with a cross-section of a Gaussian [2]. A kernel, of size $11 \times 11$ pixels, with a Gaussian profile in one direction and a constant profile in the orthogonal direction, is correlated with the image at each point to give an estimate of likeness of a local region to a vessel. The kernel is rotated at $15^{\circ}$ increments and correlated with the image thereby picking out vessels at various orientations. The maximal response over all orientations is retained at each pixel and the results is thresholded with a global threshold to give a vessel pattern. We apply a final morphological filtering, not described in the inital paper, to remove noise pixels.

\section{Morphological Tophat and Curvature Estimation}

As Vincent described [7] the vessels in a retinal image can be segmented by applying a morphological opening with a long linear structure of 1 pixel width at various orientations. The result can be improved by following up the opening with a morphological reconstruction which reduces the smoothing effect of the opening. This approach is not specific enough in that any bright structure in the image that the structuring element can fit into is segmented. Large objects in addition to vessels can satisfy this condition. Zana and Klein [8] describe further filtering with morphological operators to refine the process to be more specific to 


\section{Topic area: BMP}

vessels. This produces an image where the intensity of the pixel relates to the likelihood of that pixel being vessel. We threshold this image to obtain a vessel detection result. In addition, we threshold the reconstructed opened image (at the mid stage of processing) to obtain an alternative vessel detection. As reported in Results below, it is the threshold of the mid-stage of processing that we find to have the better result!

\section{Curvature Estimation by the Hessian Matrix}

Martinez-Perez [6] point out that if the second partial derivatives are calculated on the mathematical model of the vessel intensity profile (Gaussian in one direction, constant linear in the other) then the derivative in the direction of the vessel cross-section will have a low negative value in the central region of the vessel. They therefore calculate the second-partial derivatives $\left(f_{x x}, f_{x y}=f_{y x}, f_{y y}\right)$ at each pixel in the image, form the Hessian matrix, and find the smallest eigenvalue. This in effect is a rotation of the calculation of the partial derivatives to give the derivative in the direction across the vessel profile. The smallest eigenvalue is the estimate of this derivative and should be smaller than other parts of the image based on the Gaussian profile model of the vessel. By thresholding the image formed by the smallest eigenvalue at each point an vessel pattern image is arrived at. Martinez-Perez et al. describe a further region growing procedure to inforce connectivity constraints on the detected vessels. We have not implemented that further refinement of the algorithm.

\section{Multi-threshold Probing}

A very different approach is described by Jiang and Mohon [4]. They threshold the original retinal image at a fixed threshold. This provides an image that has part of the vessel network reasonably well detected, with a lot of other extraneous noise detected in other parts of the image. They apply a series of tests to each pixel. Each pixel must be within a small distance of the background (because vessel pixels are never far away from the edge of the vessel) and have suitable contrast compared to nearby background pixels. Objects that are left after this are then tested for size: objects too small are eliminated. This procedure provides a part of the vessel network. To obtain the full vessel network, the original retinal image is thresholded at a number of other thresholds and the pruning operations are applied to retain only vessel pixels. Combining the results of these operations provides the full network.

\section{Testing Methodology}

Three of the vessel detection methods terminate with a global threshold. The value of the threshold can be adjusted to make the detection more sensitive or more specific. The vessel detection results are compared to the gold-standard images of one ophthalmologist. Detected pixels corresponding to a pixel in the gold-standard marked as vessel are counted as true-positives, and detected pixels corresponding to unmarked pixels in the gold-standard are counted as false-positives. The counting of pixels in this manner is only carried out within a region of the image comprising the camera aperture. The true-positive fraction is the number of true-positives detected divided by the number of pixels marked as vessel in the gold-standard. The false-positive fraction is the number of false-positives divided by the number of pixels in the gold-standard not marked as vessel. Results are averaged over the twenty images of the Stare database. The Wavelet method incurs some edge effects that result 


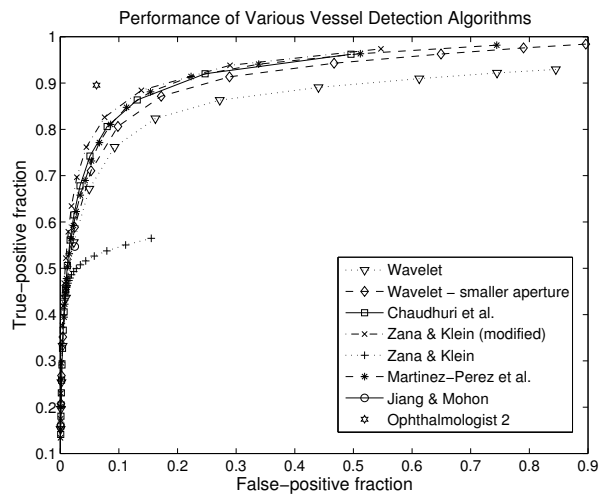

Figure 1: Results of the vessel detection of five methods

in degraded detection ability at the edges of the processed area. We also present results for the Wavelet transform that used a slightly reduced aperture to eliminate these edge effects.

\section{Results}

The results of the five methods for detecting blood vessels in non-mydriatic colour fundus images of the Stare database are shown in figure 1. The sensitivity of four methods are able to be adjusted and these appear in the graph as curves tracing out an arc of true-positive fraction versus false-positive fraction. The method due to Jiang and Mohon was not easily able to be adjusted to different sensitivity and was only operated for one set of parameters. It appears as a point in the graph. The second set of gold-standard images as determined by a second ophthalmologist was tested against the first gold-standard. This also appears as a point in the graph.

\section{Discussion}

Unfortunately this multi-detection problem violates the Poisson assumption linking FROC analysis to ROC analysis (see [1]). The statistical model of FROC analysis cannot be usefully applied and there is no known method to estimate the confidence intervals of the result curves. We can only conclude that the majority of methods detect vessels to a similar ability, despite their disparate approaches to segmentation, to the level which this study can distinguish detection characteristics. There is one exception, and that is the morphological and curvature estimation of Zana and Klein [8], which in our implementation performed poorly compared to stopping the process at an earlier stage.

[1] D. P. Chakraborty, Med. Phys., 16, 561 (1989)

[2] S. Chaudhuri, et al., IEEE Trans. Med. Im., 8, 263 (1989)

[3] A. Hoover et al., IEEE Trans. Med. Im., 19, 203 (2000)

[4] X. Jiang and D. Mohon, IEEE Trans. Patt. Anal. Mach. Int, 25131 (2003)

[5] J. J. G. Leandro et al., Image Processing and Vision (Sibgrapi03), 262 (2003)

[6] M. Martínez-Pérez et al., IEEE Int. Conf. Im. Proc., 173, (1999)

[7] L. Vincent, IEEE Trans. Im. Proc., 2176 (1993)

[8] F. Zana and J.-C. Klein, IEEE Trans. Med. Im., 10, 1010 (2001) 


\section{A.2 Development of retinal blood vessel segmentation methodology using wavelet transforms for assessment of diabetic retinopathy}

Segue o trabalho "Development of retinal blood vessel segmentation methodology using wavelet transforms for assessment of diabetic retinopathy", apresentado no 8th Asia Pacific Symposium on Intelligent and Evolutionary Systems e posteriormente publicado na Complexity International Cornforth et al., 2005. O trabalho apresenta a evolução dos métodos de segmentação usando a wavelet 2D de Gabor, desde a implementação preliminar em que se utilizava a transformada wavelet combinada com morfologia matemática até o método apresentado nesta dissertação. O artigo inclui resultados preliminares, entre os quais testes em que foi utilizada uma fração da própria imagem sendo segmentada para treinamento do classificador. 
This material is presented to ensure timely dissemination of scholarly and technical work. Copyright and all rights therein are retained by authors or by other copyright holders. All persons copying this information are expected to adhere to the terms and constraints invoked by each author's copyright. In most cases, these works may not be reposted without the explicit permission of the copyright holder.

(c) 2005 Complexity International. Personal use of this material is permitted. Permission from Complexity International must be obtained for all other uses, including reprinting/republishing this material for advertising or promotional purposes, creating new collective works for resale or redistribution to servers or lists, or reuse of any copyrighted component of this work in other works. 


\title{
Development of retinal blood vessel segmentation methodology using wavelet transforms for assessment of diabetic retinopathy
}

\author{
D. J. Cornforth ${ }^{1}$, H. J. Jelinek ${ }^{1}$, J. J. G. Leandro ${ }^{2}$, J. V. B. Soares ${ }^{2}$, R. M .Cesar, Jr. ${ }^{2}$, M. J. \\ Cree $^{3}$, P. Mitchell ${ }^{4}$, and T. Bossomaier ${ }^{1}$. \\ ${ }^{1}$ Charles Sturt University, Australia \\ Email: \{dcornforth, hjelinek, tbossomaier \}@csu.edu.au \\ ${ }^{2}$ Computer Science, University of Sao Paulo, Brazil \\ Email: $\{j$ leandro, joao, cesar\}@vision.ime.usp.br \\ ${ }^{3}$ Physics and Electronic Engineering, University of Waikato, New Zealand \\ Email: creeephys.waikato.ac.nz \\ ${ }^{4}$ University of Sydney Department of Ophthalmology, Westmead Hospital, Australia \\ Email: paul_mitchellewmi.usyd.edu.au
}

\begin{abstract}
Ab stract
Automated image processing has the potential to assist in the early detection of diabetes, by detecting changes in blood vessel diameter and patterns in the retina. This paper describes the development of segmentation methodology in the processing of retinal blood vessel images obtained using non-mydriatic colour photography. The methods used include wavelet analysis, supervised classifier probabilities and adaptive threshold procedures, as well as morphology-based techniques. We show highly accurate identification of blood vessels for the purpose of studying changes in the vessel network that can be utilized for detecting blood vessel diameter changes associated with the pathophysiology of diabetes. In conjunction with suitable feature extraction and automated classification methods, our segmentation method could form the basis of a quick and accurate test for diabetic retinopathy, which would have huge benefits in terms of improved access to screening people for risk or presence of diabetes.
\end{abstract}

\section{Introduction}

Diabetes affects almost one million Australians, and has associated complications such as vision loss, heart failure and stroke. Any improvement in early diagnosis would therefore represent a significant gain with respect to reducing the morbidity and mortality of the Australian population. This work describes one step along the path to providing automated 
diagnostic support tools for the early detection of diabetes associated retinal pathology. We focus on the blood vessel network in the retina that is affected by diabetes. Currently, the correct assessment of these images using fluorescein requires a specialist, which presents difficulties in remote or rural areas and is also a relatively invasive and dangerous procedure. The alternative is to use non-mydriatic colour images that although more difficult to interpret, are more desirable for use in remote or rural areas as they can be obtained by trained rural health professionals.

Non-mydriatic camera images were analysed in an attempt to fine tune and improve the quality of retinal blood vessel detection in medical imaging. For this purpose we used the Morlet wavelet as a tool for segmenting retinal blood vessels in combination with adaptive thresholding, supervised classification and supervised classifier probabilities combined with adaptive thresholding. The advantage of wavelet analysis is its multiscale analysing capability in tuning to specific frequencies, allowing noise filtering and blood vessel enhancement in a single step. Twenty non-mydriatic camera images of the retinal fundus were analysed, from the Stare database (http://www.parl.clemson.edu/stare). The results were compared against the corresponding gold-standard images indicating the true location of vessels as determined by two ophthalmologists and presented in the manner of free-response receiver operator characteristic (FROC) curves.

\section{Image processing for medical diagnosis}

Identification of vascular anomalies associated with diabetes health care represents a large portion of the assessment carried out by ophthalmologists, which is time consuming and in many cases does not show any anomalies at the initial visit. Utilizing non-specialist health workers in identifying diabetic eye disease is an alternative but trials have shown that correct identification of retinal pathology may be poor (i.e. only $50 \%$ of the cases). This success rate decreases for early proliferative retinopathy stages. Telemedicine is an attractive approach. However, this procedure is not time effective and does not lessen the burden on a comparatively small number of ophthalmologists in rural areas that need to assess the images. In addition significant technical problems lessen the availability of telemedicine (Yogesan et al., 2000).

Automated assessment of blood vessel patterns that can be used by rural health professionals is now being extended from fluorescein-labelled to non-mydriatic camera images (Cesar \& Jelinek 2003; McQuellin et al., 2002). This work presents the evolution of retinal blood vessel segmentation as a function of the effectiveness of the wavelet transform. We outline the use of the wavelet transform combined with mathematical morphology, supervised training algorithms and adaptive thresholding.

Several methods for segmenting blood vessels using either rule-based or supervised methods have recently been reported for both fluorescein and non-mydriatic colour retinal images (Leandro et al., 2003; Sinthanayothin et al., 1999; Staal et al., 2004). Mathematical morphology, which is a rule-based method, has previously revealed itself as a very useful digital image processing technique for detecting and counting microaneurysms in fluorescein and non-mydriatic camera images (Cree et al., 2004; Spencer et al., 1996). Wavelet transform theory has grown rapidly since the seminal work by Morlet and Grossman, finding applications in several realms (Goupillaud et al., 1984). The wavelets space-scale analysis capability can be used to "decompose" vessel structures into differently scaled Morlet 
wavelets, so as to segment them from the retinal fundus. Supervised classification, which requires manually labelled images for training vessel pixel candidates, can then be added to the pattern recognition process (Gardner et al., 1996; Leandro et al., 2003; Sinthanayothin et al., 1999; Staal et al., 2004).

\section{Methods}

The purpose of these experiments was to assess the relative merits of several techniques for segmentation of blood vessels from retinal images. Twenty digital images were used from the Stare database. This database also includes the opinions of two experts who had indicated the position of the vessels from colour images to establish two "gold standards" as separate images.

Our strategy was to use three methods for segmenting retinal blood vessels from directly digitized colour retinal images. The experimental procedure followed was to pre-process the images first to optimise the use of the wavelet transforms. The methods tested were:

1. Wavelet transform plus adaptive thresholding,

2. Wavelet transform plus supervised classifiers,

3. Wavelet transform plus pixel probabilities combined with adaptive thresholding.

In addition, we compared two training techniques: training on one or more complete images, then classifying the remaining images, and training on a window of the image then classifying the remainder of the same image.

Initially the methods were compared qualitatively, but the best of these methods were selected and compared numerically by plotting on a graph of true positive against false positive results from the classification. This graph resembles a free receiver operator curve (FROC) to aid the reader in its interpretation. True positives occur when the classifier labels a pixel as belonging to a vessel and the "gold standard" segmentation also labels the pixel as vessel.

\subsection{Pre-processing}

In order to reduce the noise effects associated with the processing, the input image was preprocessed by a mean filter of size $5 \times 5$ pixels. Due to the circular shape of the non-mydriatic image boundary, neither the pixels outside the region-of-interest nor its boundary were considered, in order to avoid boundary effects. For our wavelet analysis we used the green channel of the RGB components of the colour image as it displayed the best vessels/background contrast.

\subsection{Continuous wavelet transform plus adaptive thresholding}

Applying the continuous wavelet transform approach provides several benefits but resulted in some loss of detail as the scale parameter was fixed. We therefore adopted a pixel thresholding approach that represented each pixel by a feature vector including colour information, measurements at different scales taken from the continuous wavelet (Morlet) transform and the Gaussian Gradient, as well as from mean filtering applied to the green channel. The 
resulting feature space was used to provide an adaptive local threshold to assign each pixel as either a vessel-pixel or a non-vessel pixel.

The real plane $R \times R$ is denoted as $R^{2}$, and vectors are represented as bold letters, e.g. $\mathbf{x}, \mathbf{b} \in R^{2}$. Let $f \in L^{2}$ be an image represented as a square integrable (i.e. finite energy) function defined over $R^{2}$ (Arnéodo et al., 2000). The continuous wavelet transform (CWT) is defined as:

$$
T_{\psi}(\mathbf{b}, \theta, a)(\mathbf{x})=C_{\psi}^{-1 / 2} \frac{1}{a} \int \psi^{*}\left(a^{-1} r_{-\theta}(\mathbf{x}-\mathbf{b})\right) f(\mathbf{x}) d
$$

where $C_{\psi}, \psi, \mathbf{b}, r_{-\theta}, \theta$ and $a$ denote the normalizing constant, the analysing wavelet, the displacement vector, the rotation operator, the rotation angle and the dilation parameter, respectively ( $\psi^{*}$ denotes the complex conjugate). The double integral is taken over $R^{2}$ with respect to vector variable $\mathbf{x}$, being denoted by $d^{2} \mathbf{x}$. The Morlet wavelet is directional (in the sense of being effective in selecting orientations) and capable of fine tuning specific frequencies. These latter capabilities are especially important in filtering out the background noise, and comprise the advantages of the Morlet wavelet with respect to other standard filters such as the Gaussian and its derivatives. The 2D Morlet wavelet is defined as:

$$
\psi_{M}(\mathbf{x})=\exp \left(j \mathbf{k}_{0} \cdot \mathbf{x}\right) \exp \left(-\frac{1}{2}|A \mathbf{x}|\right.
$$

where $j=\sqrt{-1}$ and $A=\operatorname{diag}\left[\varepsilon^{-1 / 2}, 1\right] \varepsilon \geq 1$ is a $2 \times 2$ array that defines the anisotropy of the filter, i.e. its elongation in some direction. In the Morlet equation (2), which is a complex exponential multiplying a $2 \mathrm{D}$ Gaussian, $\mathbf{k}_{0}$ is a vector that defines the frequency of the complex exponential. Using the Morlet transform to segment the blood vessels, the scale parameter is held constant and the transform is calculated for a set of orientations $\theta=0,10$, $20,30, \ldots, 180$. The $\varepsilon$ parameter has been set as 4 in order to make the filter elongated and $\mathbf{k}_{0}=[0,2]$, i.e. a low frequency complex exponential with few significant oscillations. The transform maximum response (in modulus) from all orientations for each position, $\mathbf{b}$, is then taken, emphasizing the blood vessels and filtering out most of the noise. The blood vessels can then be detected from this representation.

\subsection{Feature extraction}

The pixel feature space was formed by Morlet wavelet responses (taken at different scales and elongations), Gaussian Gradient responses (taken at different scales) and colour information, which determine each pixel's colour. This resulted in a computationally demanding high dimensional feature space. At the same time, Morlet responses taken at close scales are highly correlated, as are the Gaussian Gradient responses for similar scales. Therefore we used a feature extraction approach to obtain a lower dimensional feature space, while trying to 
preserve structure important for discrimination. Feature extraction was performed by a linear mapping provided by nonparametric discriminant analysis (Fukunaga, 1990). Nonparametric discriminant analysis consists of building two matrices. The first is a nonparametric betweenclass scatter matrix, constructed using k-nearest neighbour techniques, which defines the directions of class separability. The second is the within-class scatter matrix, which shows the scatter of samples around their mean class vectors. These matrices were built based on the labelled training samples. The two matrices are then used to find a projection (given by a linear mapping) that maximizes class separability while minimizing the within-class scatter in the projected feature space.

During the adaptive thresholding process, the dimensional nature of the features forming the feature space might give rise to errors. Since the feature space elements may be considered as random variables, we applied a normal transformation in order to obtain a new relative random variable, redefined in a dimensionless manner. The normal transformation is defined as:

$$
\hat{X}_{j}=\frac{X_{j}-1}{\sigma_{j}}
$$

where $X_{j}$ is the $j$ th feature assumed by each pixel, $\mu_{j}$ is the average value of the $j$ th feature and $\sigma_{j}$ is the associated standard deviation.

\subsection{Supervised classification}

In methods 2 and 3, supervised classification was applied to obtain the final segmentation, with the pixel classes defined as $\mathrm{C} 1=$ vessel-pixels and $\mathrm{C} 2=$ non-vessel pixels using the Bayesian classifier consisting of a mixture of Gaussians (Theodoridis, 1999). In order to obtain the training set, retinal fundus images have been manually segmented, thus allowing the creation of a labelled training set into 2 classes $\mathrm{C} 1$ and $\mathrm{C} 2$ (i.e. vessels and non-vessels). In this work, the hand-drawn vascular tree provided by the ophthalmologist has been used - our training pattern - so that we obtained its feature space. Two different strategies for deriving the training set were applied:

1. Some images were completely segmented by an expert and a random sub-set of their pixels was used to train the classifier.

2. Only a small portion (window) of a sample image was manually segmented. The labelled pixels are then used to train the classifier, which is applied to the same image in order to conclude its segmentation.

This $2^{\text {nd }}$ strategy has been devised so that a semi-automated fundus segmentation software can be developed, in which the operator only has to draw a small portion of the vessels over the input image or simply click on several pixels associated with the vessels. The remaining image is then segmented based on this partial training set without the need of tuning any additional parameters. This approach requires a small effort from the operator, which is compensated for by the fact that image peculiarities (e.g. due to camera model and settings) are directly incorporated by the classifier. Note that this method should be repeated for every new image. 


\subsection{Post-processing}

The output produced by the classifier leads to a binary image where each pixel is labelled as vessel or non-vessel. Some misclassified pixels appeared as undesirable noise in the classified image. In addition, for some vessels, only their boundaries were classified, so that it was necessary to perform post-processing by using morphological tools to obtain the final desired segmentation. Finally, to optimize the vessel contours, morphological operations have been applied, beginning by area open to eliminate small noisy components. The vessels were completely filled by morphological dilation and area close (Cesar \& Jelinek, 2003).

\subsection{Comparison}

The results were obtained in the form of segmented images and compared by the experts. Here we present the results in the manner of FROC curves to assess the trade off between truepositive fraction and false-positive fraction of our methods in detecting the pixels associated with the vessel patterns.

\section{Results}

Before we present the results of the experiments comparing the different applications of the segmentation procedures, we provide for comparison an example of the application of the wavelet transform to fluorescein images (Leandro et al., 2001). Figure 1(a) shows a typical image of the retinal fundus with the optic disk on the right hand side and the protruding blood vessels that course throughout the image. Figure 1 (b) shows the result of image segmentation using the Morlet wavelet transform. The latter shows the difficulty in obtaining a clear segmentation. Background noise and variable grey levels across the image introduce artefacts. In particular, this method did not remove the optic disc located on the right hand side of the image and was very susceptible to hue variation that resulted in the large grey area to the left of the image.

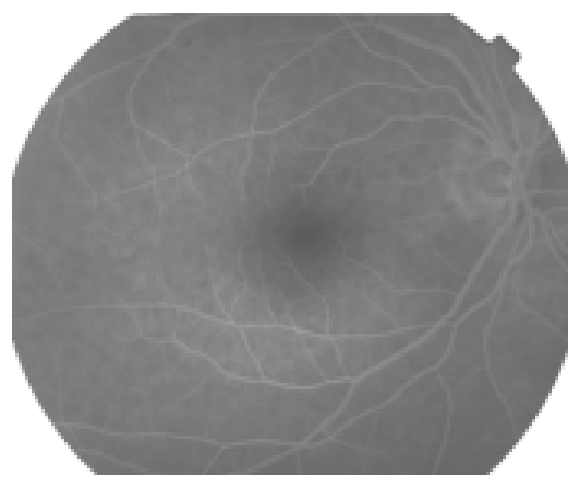

(a)

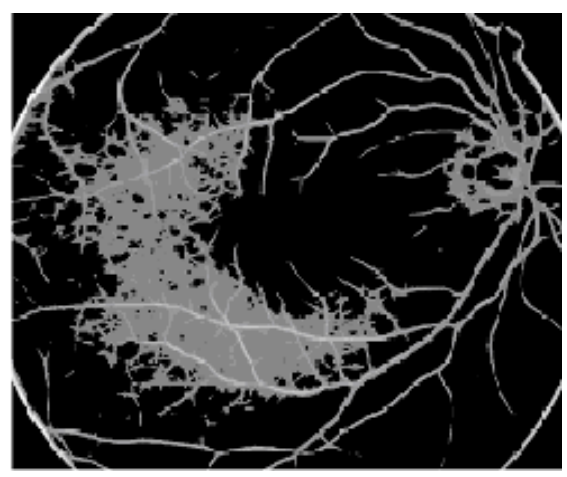

(b)

Figure 1. Wavelet transform in blood vessel segmentation: a) original fluorescein retinal image; b) and example of segmentation of blood vessels from a fluorescein image using the Morlet wavelet transform only. 
In method 1 we applied the wavelet transform plus adaptive thresholding to colour nonmydriatic camera images. Figure 2 (a) shows a typical grey scale representation of a colour image obtained from the digital camera. The optic disk is noticeable as a light grey area on the left hand side with blood vessels emanating from it. Notice the variable brightness across the image, and especially the presence of the optic disc, which can introduce artefacts during the image processing. Figure 2 (b) shows the same image after application of the Morlet wavelet transform and thresholding. This is much more successful than using the fluorescein monochrome image (Figure 1). The optic disc has been successfully removed, but artefacts remain. In particular, notice the extra "vessels" apparent at the bottom of Figure 2 (b) at approximately 5 o'clock. Many disconnected segments also remain, and some smaller vessels clearly visible in (a) have not been detected in (b).

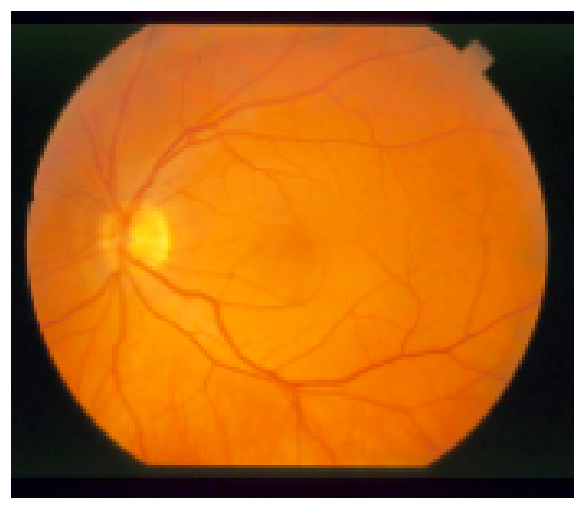

(a)

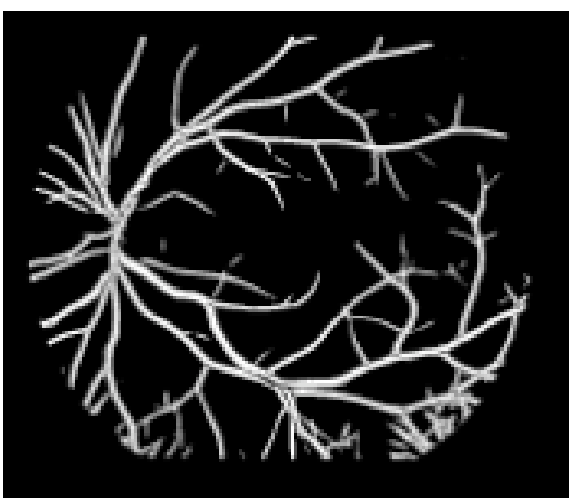

(b)

Figure 2. Segmentation of non-mydriatic colour images for method 1: a) grey-scale image of original retinal fundus; b) segmentation of retinal blood vessels using wavelet transform and adaptive thresholding.

For a more sophisticated approach to dealing with the image variations in hue of background and blood vessels, we applied a supervised learning algorithm. The classifier was first trained using all pixels from entire images. All pixels were labelled by the experts, as shown in Figure 3(a). The trained classifier was then used to segment other images. In Figure 3 (b) we show the result of supervised classification, where the classifier has been trained on four other images, and then used to segment the image of Figure 2 (a). Comparing this with Figure 2 (b) the improvement is obvious. Many of the artefacts at the bottom (5 o'clock) of that image have now disappeared. However, many of the smaller vessels towards the centre of the image have not been detected, and there are still many disconnected vessel segments. 


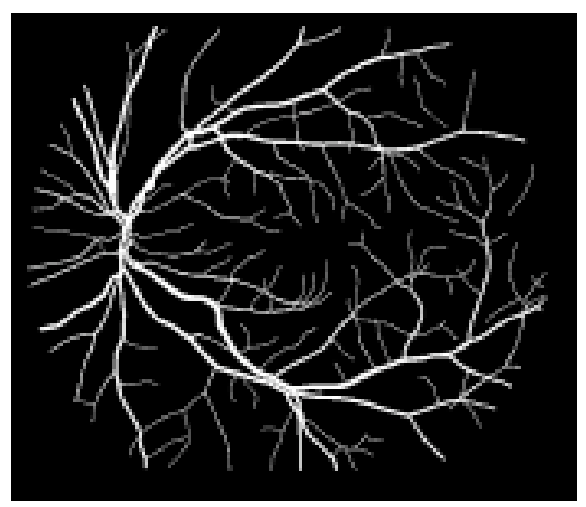

(a)

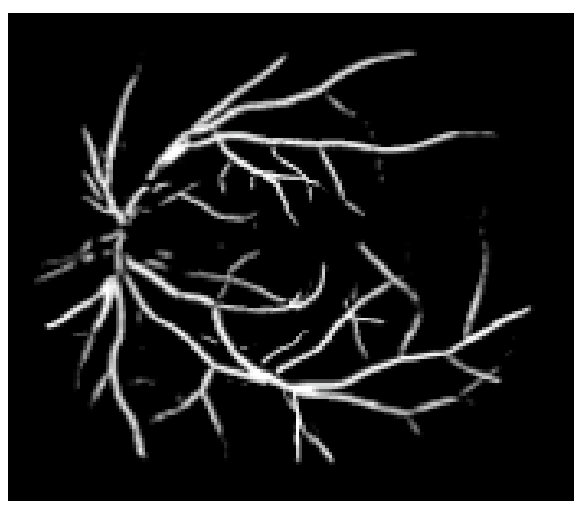

(b)

Figure 3. Results from method 2, wavelet transform plus pixel classification: (a) an example of the training set provided by the experts; (b) an example of a segmented image obtained using the total vessel pattern as a training set.

For method 3, we combined the wavelet transform with the supervised classification and mixed adaptive thresholding. In this case, instead of using the simplified approach of Leandro et al. the thresholding procedure was applied to the pixel probability of being vessel as estimated by the supervised classifier approach (Leandro et al., 2001). This led to the results shown in Figure 4. Here many of the smaller vessels are now visible, and the number of disconnected vessel segments is much less.

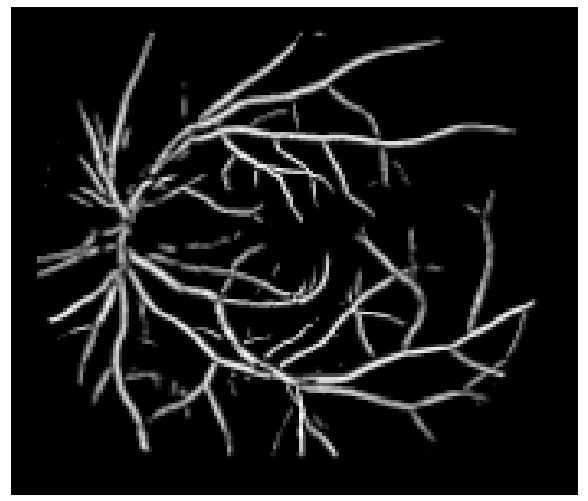

Figure 4. The same image after adaptive thresholding on the probability of each pixel being part of a vessel.

A variation of the pixel classification is to train the classifier with a window of the image, then use it to segment the remainder of the image. This should provide more accurate classification, as it corrects for different image parameters. Figure 5 (a) shows the window containing the training data for method 2. This represents a portion of the retinal vessels as identified by the expert. Figure 5 (b) shows the result of the segmentation when only using a part of the figure as a training set. The number of small vessels detected has increased, and the segmentation is of superior quality. Compare this with figure 3. 


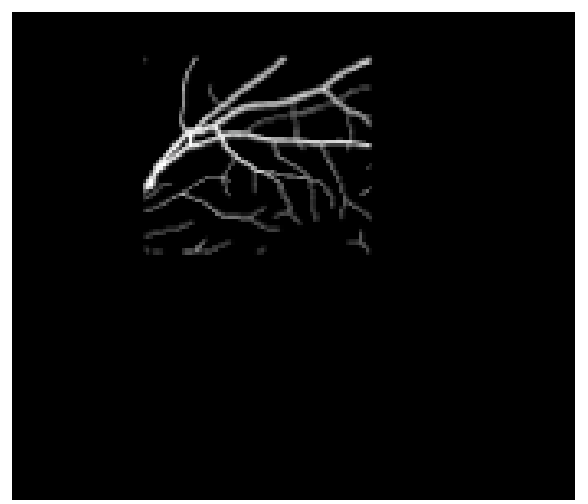

(a)

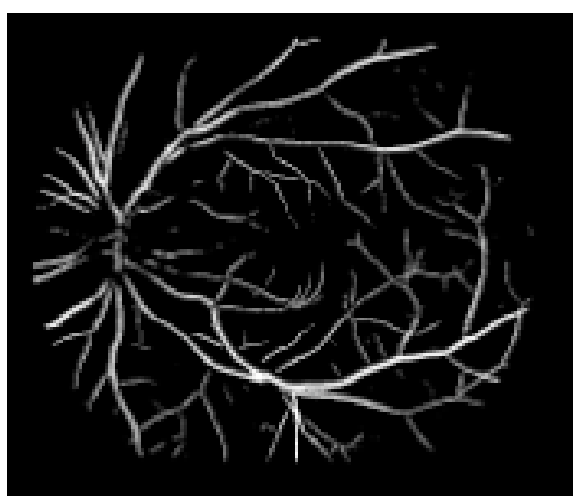

(b)

Figure 5. Segmented image (b) obtained using only a portion of the vessel pattern as a training set (a).

Finally, we applied the adaptive thresholding (method 3) to the vessel probability of each pixel of the window based classification. A typical result is shown in Figure 6. This represents the best result obtained so far, where most of the smaller vessels have been detected. The main problem with this approach is that it does not take the probability of being background into account. We hope to address this problem in our future work.

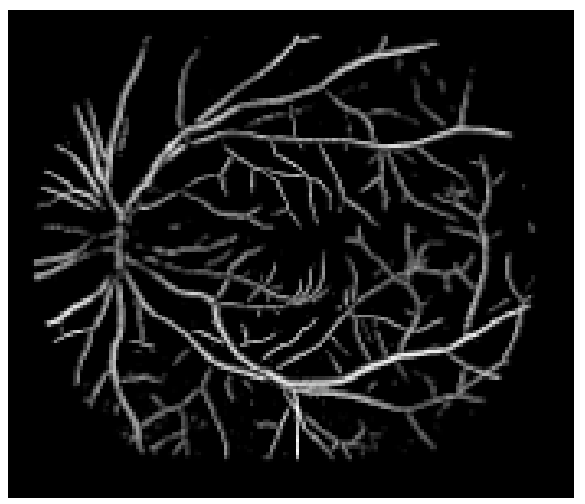

Figure 6. Typical result of using the window method to train the classifier, followed by an adaptive thresholding process.

It is clear from these results that methods 2 and 3, each using the supervised classifier approach, provide the best results. We now present quantitative results from these two methods in Figure 7. For method 2, (wavelet transform and supervised classifier) each source image resulted in a single binary output image with pixels either marked as 'true' (a vessel pixel) or marked 'false' (not a vessel pixel). Each output image produced the single point on the graph in figure 7 . The average from the 20 images processed is shown as a circle marked "Adaptive threshold" in the legend. 


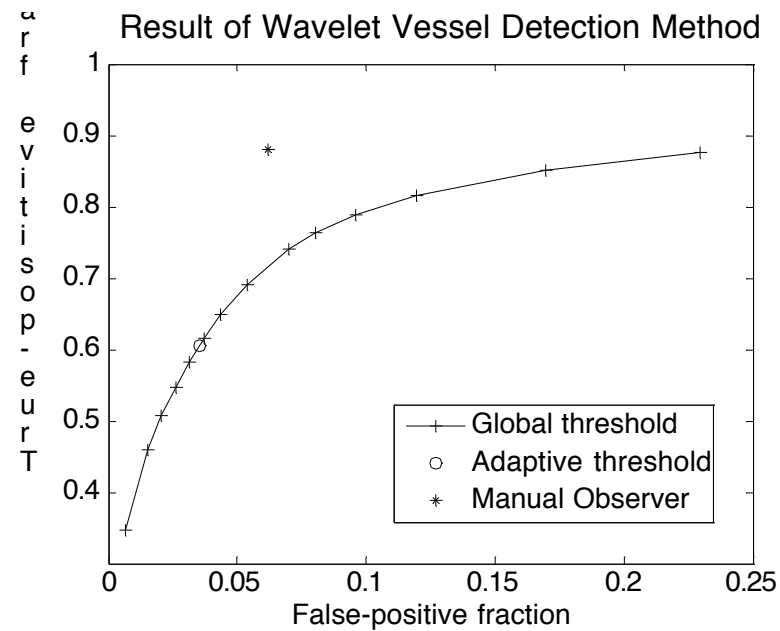

Figure 7: Numerical results from methods 2 and 3, shown in the same form as an ROC graph. Method 2 uses an adaptive threshold, so a single point was obtained, being the average of the values obtained from the 20 images. Method 3 uses a global threshold, so many points were generated as the threshold was varied. Each point is the average of the results from the 20 images. The grey cross indicates the evaluation of one ophthalmologist.

Method 3 (wavelet transform and adaptive threshold) resulted in 20 grey-scale images, where the brighter the pixel the more likely it landed in the vessel class. A global threshold was applied to each image to generate a point on the graph. The threshold was varied from high (poor sensitivity) to low (good sensitivity but too many false positives). The average values taken from the 20 images produced a number of points tracing out the curve (appearing in the legend as "Global threshold".

\section{Discussion}

We have demonstrated some new techniques for the automated processing of non-mydriatic images in the study of diabetic retinopathy that can certainly be extended to other contexts in pattern recognition. The results we have obtained so far suggest that pixel classification, in conjunction with wavelet transform and adaptive thresholding, can provide noise-robust vessel segmentation. The approach reported here improved on previous results by reducing the level of interaction required with the segmentation program, providing a useful tool for nonspecialists such as community health workers in assessing fundus complications associated with diabetes (Antoine et al., 1997; Cesar \& Jelinek, 2003; da Costa, 2001; Grossmann, 1988; Zana \& Klein, 2000).

Wavelets are especially suitable for detecting singularities (e.g. edges) in signals, extracting instantaneous frequencies, and performing fractal and multifractal analysis (Antoine et al., 1997; Grossmann, 1988). Applying the wavelet transform allows noise filtering and blood vessel enhancement in a single step. Our results indicate that for the same false-positive fraction, the supervised learning with adaptive thresholding obtained a greater than $75 \%$ sensitivity compared to the ophthalmologist with approximately $90 \%$. Future research is now focused on fine tuning our algorithms on a larger data set. 
Although these methods are targeted at segmentation in retinal blood vessels, there is no reason why they may not be applied in other areas, especially in medical imaging, where it is necessary to extract intricate branching patterns from images with a noisy background.

\section{Acknowledgements}

RMC and JS are grateful to FAPESP (Research Support Foundation of the State of São Paulo, Brazil) and to CNPq (Brazil's National Council for Scientific and Technological Development). HJ was in receipt of grants from CSU and Australian Diabetes Association. The authors also wish to acknowledge the contribution of Alan Luckie and Tien Wong for their expert advice on diabetic retinopathy and arteriolar narrowing.

\section{References}

Antoine J. P., Barache D., Cesar Jr. R. M. \& da Costa L. (1997), Shape characterization with the wavelet transform, Signal Processing 62(3): 265-290.

Arnéodo, A., Decoster, N. \& Roux S. G. (2000), A wavelet-based method for multifractal image analysis. I. Methodology and test applications on isotropic and anisotropic random rough surfaces, The European Physical Journal B 15: 567-600.

Cesar Jr. R. M. \& Jelinek H. F. (2003), Segmentation of retinal fundus vasculature in nonmydriatic camera images using wavelets, In Suri J. S. \& Laxminarayan S., (Eds.), Angiography and plaque imaging, CRC Press, London: 193-224.

Cree M., Luckie M., Jelinek H. F., Cesar R., Leandro J., McQuellin C. \& Mitchell P. (2004), Identification and follow-up of diabetic retinopathy in rural health in Australia: an automated screening model, In AVRO, Fort Lauderdale, USA 5245/B5569.

da Costa L. F. (2001), On neural shape and function, In World Congress on Neuroinformatics: ARGESIM / ASIM - Verlag Vienna: 397-411.

Fukunaga K. (1990), Introduction to statistical pattern recognition, 2nd ed., Academic Press, Boston.

Gardner G. G., Keating D, Williamson T. H., \& Elliot A.T. (1996), Automatic detection of diabetic retinopathy using an artificial neural network: a screening tool, British Journal of Ophthalmology 80: 940-944.

Goupillaud P., Grossmann, A. \& Morlet J. (1984), Cycle-octave and related transform in seismic signal analysis, Geoexploration 23: 85-102.

Grossmann A. (1988), Wavelet Transforms and Edge Detection, In Albeverio, S., et al., (Eds.), Stochastic Processes in Physics and Engineering, Reidel Publishing Company, Dordrecht.

Leandro J. J. G., Cesar R. M. Jr., Jelinek H. F. (2001), Blood vessels segmentation in retina: preliminary assessment of the mathematical morphology and of the wavelet transform techniques, In SIBGRAPI-01, Florianópolis - SC, IEEE Computer Society Press: 84-90.

Leandro J. J. G., Soares J. V. B., Cesar R. M. Jr., \& Jelinek H. F. (2003), Blood vessel segmentation of nonmydriatic images using wavelets and statistical classifiers, In Proceedings of the Brazilian Conference on Computer Graphics, Image Processing and Vision (Sibgrapi03), Sao Paulo, Brazil, IEEE Computer Society Press: 262-269.

McQuellin C. P., Jelinek H. F. \& Joss G. (2002), Characterisation of fluorescein angiograms of retinal fundus using mathematical morphology: a pilot study, In 5th International Conference on Ophthalmic Photography, Adelaide: 83 .

Sinthanayothin C., Boyce J. \& Williamson C. T. (1999), Automated localisation of the optic disc, fovea and retinal blood vessels from digital colour fundus images, British Journal of Ophthalmology 83(8): 902-912.

Spencer T., Olson J. A., McHardy K., Sharp P. F. \& Forrester J. V. (1996), An Image-Processing Strategy for the Segmentation and Quantification of Microaneurysms in Fluorescein Angiograms of the Ocular Fundus, Comput. Biomed. Res. 29: 284-302. 
Staal J. J., Abramoff M. D., Niemeijer M., Viergever M. A. \& van Ginneken B. (2004), Ridge-based vessel segmentation in color images of the retina, IEEE Trans Med Imag 23(4): 501-509.

Theodoridis S. (1999), Pattern Recognition, Academic Press, Baltimore.

Yogesan K., Constable I. J., Barry C. J., Eikelboom R. H. \& Tay-Kearney M. L. (2000), Telemedicine screening of diabetic retinopathy using a hand-held fundus camera, Telemedicine Journal 6(2): 219-223.

Zana F. \& Klein J. C. (2000), Segmentation of vessel-like patterns using mathematical morphology and curvature evaluation, IEEE Transactions on Image Processing 10(7): 1010-1019. 


\section{A.3 Using the 2-D Morlet wavelet with supervised classification for retinal ves- sel segmentation}

Segue uma cópia do trabalho "Using the 2-D Morlet wavelet with supervised classification for retinal vessel segmentation", apresentado no IV Workshop de Teses e Dissertações em Computação Gráfica e Processamento de Imagens do XVIII Simpósio Brasileiro de Computação Gráfica e Processamento de Imagens - SIBGRAPI [Soares et al., 2005]. O artigo apesenta resumidamente os métodos desta dissertação, incluindo alguns dos resultados nos bancos públicos DRIVE e STARE. 


\title{
Using the 2-D Morlet Wavelet with Supervised Classification for Retinal Vessel Segmentation
}

\author{
João V. B. Soares, Jorge J. G. Leandro, Roberto M. Cesar-Jr. (advisor) \\ Department of Computer Science \\ Institute of Mathematics and Statistics - University of São Paulo \\ Rua do Matão, 1010, São Paulo, SP, Brazil \\ \{joao, jleandro, cesar\}@ vision.ime.usp.br \\ Herbert F. Jelinek \\ School of Community Health \\ Charles Sturt University, Albury, Australia \\ hjelinek@csu.edu.au \\ Michael J. Cree \\ Department of Physics and Electronic Engineering \\ University of Waikato, Hamilton, New Zealand \\ cree@waikato.ac.nz
}

\begin{abstract}
We present a method for automated segmentation of the vasculature in retinal images. The method produces segmentations by classifying each image pixel as vessel or nonvessel, based on the pixel's feature vector. Feature vectors are composed of the pixel's intensity and continuous twodimensional Morlet wavelet transform responses taken at multiple scales. The Morlet wavelet is capable of tuning to specific frequencies, thus allowing noise filtering and vessel enhancement in a single step. We use a Bayesian classifier with class-conditional probability density functions (likelihoods) described as gaussian mixtures, yielding a fast classification, while being able to model complex decision surfaces. The probability distributions are estimated based on a training set of labeled pixels obtained from manual segmentations. The method's performance is evaluated on publicly available DRIVE [34] and STARE [16] databases of manually labeled non-mydriatic images. On the DRIVE database, it achieves an area under the receiver operating characteristic (ROC) curve of 0.9598 and an accuracy of 0.9467 versus 0.9473 for a second human observer.
\end{abstract}

\section{Introduction}

Optic fundus (Figure 1(a)) assessment has been widely used by the medical community for diagnosing vascular and non-vascular pathology. Inspection of the retinal vasculature may reveal hypertension, diabetes, arteriosclerosis, cardiovascular disease and stroke [19]. Diabetic retinopathy is a major cause of adult blindness and requires laborious

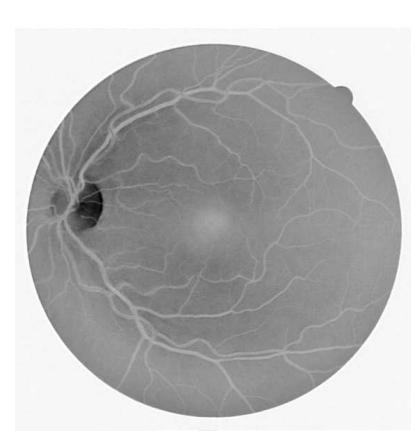

(a) Inverted green channel of non-mydriatic fundus image.

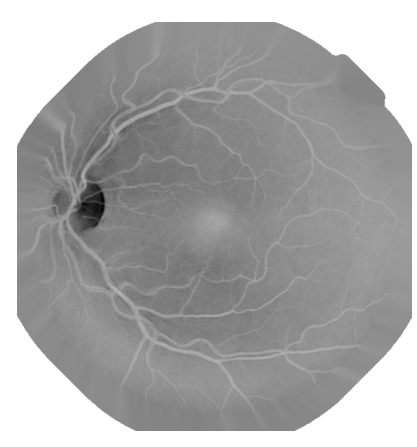
extended border. (b) Pre-processed image with

\section{Figure 1. Fundus image pre-processing for re- moving undesired border effects.}

analysis from a specialist [35]. Endeavoring to reduce the effect of proliferative diabetic retinopathy includes obtaining and analyzing images of the optic fundus at regular intervals such as every six months to a year. Early recognition of changes to the blood vessel patterns can prevent major vision loss as early intervention becomes possible [23, 36].

To provide the opportunity for initial assessment to be carried out by community health workers, computer based analysis has been introduced, which includes assessment of the presence of microaneurysms and changes in the blood flow/vessel distribution due to either vessel narrowing, complete occlusions or new vessel growth. 
An automatic assessment for blood vessel anomalies of the optic fundus initially requires the segmentation of the vessels from the background, so that suitable feature extraction and processing may be performed. Several methods have been developed for vessel segmentation, but visual inspection and evaluation by receiver operating characteristic (ROC) analysis shows that there is still room for improvement $[7,31]$. In addition, it is important to have segmentation algorithms that do not critically depend on configuring many parameters so that untrained community health workers may utilize this technology. These limitations of the state-of-the-art algorithms have motivated the development of the framework described here, which only depends on manually segmented images.

Many different approaches for automated vessel segmentation have been reported. The papers $[4,6,14,20,24$, $39,42]$ present vessel tracking methods to obtain the vasculature structure, along with vessel diameters and branching points. Tracking consists of following vessel center lines guided by local information, usually trying to find the path which best matches a vessel profile model. The use of deformable models also shows promising results in $[27,29,38,40]$. In $[5,13,16]$, matched filters are used to emphasize blood vessels. An improvement is obtained in [16] by a region-based threshold probing of the matched filter response. Multithreshold probing is directly applied to the images in [18]. A non-linear filter that enhances vessels by exploiting properties of the vessel profiles is introduced in [25]. Along this line is the use of mathematical morphology filtering in $[10,41]$, coupled with curvature evaluation. In [26], multi-scale curvature and border detection are used to drive a region growing algorithm.

Supervised methods for pixel classification have been shown in [30, 33, 34]. In [30], feature vectors are formed by gray-scale values from a window centered on the pixel being classified. A window of values is also used in [33], but the features used are a principal component transformation of RGB values and edge strength. In [34], ridge detection is used to form line elements and partition the image into patches belonging to each line element. Pixel features are then generated based on this representation. Many features are presented and a feature selection scheme is used to select those which provide the best class separability.

Previously, we have shown promising preliminary results using the continuous wavelet transform (CWT) [17, 21] and integration of multi-scale information through supervised classification [22]. Here we improve on those methods using a Bayesian classifier with gaussian mixture models as class likelihoods and evaluate performances with ROC analysis. ROC analysis has been used for evaluation of segmentation methods in $[16,18,34]$ and comparison of some of the cited methods in [7, 31].

In our approach, each pixel is represented by a fea- ture vector including measurements at different scales taken from the continuous two-dimensional Morlet wavelet transform. The resulting feature space is used to classify each pixel as either a vessel or non-vessel pixel. We use a Bayesian classifier with class-conditional probability density functions (likelihoods) described as gaussian mixtures, yielding a fast classification, while being able to model complex decision surfaces.

Originally devised for suitably analyzing non-stationary and inhomogeneous signals, the time-scale analysis took place to accomplish unsolvable problems within the Fourier framework, based on the continuous wavelet transform (CWT). The CWT is a powerful and versatile tool that has been applied to many different image processing problems, from image coding [32] to shape analysis [8]. This success is largely due to the fact that wavelets are especially suitable for detecting singularities (e.g. edges and other visual features) in images [15], extracting instantaneous frequencies [1], and performing fractal and multi-fractal analysis. Furthermore, the wavelet transform using the Morlet wavelet, also often referred to as Gabor wavelet, has played a central role in increasing our understanding of visual processing in different contexts from feature detection to face tracking [11]. The Morlet wavelet is directional and capable of tuning to specific frequencies, allowing it to be adjusted for vessel enhancement and noise filtering in a single step.

This work is organized as follows. The databases used for tests are described in Subsection 2.1. Subsection 2.2 presents our segmentation framework based on supervised pixel classification. In Subsection 2.3 the feature generation process is described, including the 2-D CWT and Morlet wavelet. Our use of supervised classification and the classifiers tested are presented in Subsection 2.4. ROC analysis for performance evaluation is described in Subsection 2.5 and results are presented in Section 3. Discussion and conclusion are in Section 4.

\section{Materials and Methods}

\subsection{Materials}

There are different ways of obtaining ocular fundus images, such as with non-mydriatic cameras, which do not require the dilation of the eyes through drops, or through angiograms [23]. We have tested our methods on angiogram gray-level images and colored non-mydriatic images [21, 22]. Here, our methods are tested and evaluated on two publicly available databases of non-mydriatic images and corresponding manual segmentations: the DRIVE [34] and STARE [16] databases.

The DRIVE database consists of 40 images (7 of which present pathology), along with manual segmentations of the vessels. The images are captured in digital form from a 
Canon CR5 non-mydriatic 3CCD camera at $45^{\circ}$ field of view (FOV). The images are of size $768 \times 584$ pixels, 8 bits per color channel and have a FOV of approximately 540 pixels in diameter. The images are in compressed JPEG format, which is unfortunate for image processing but is commonly used in screening practice.

The 40 images have been divided into a training and test set, each containing 20 images (the training set has 3 images with pathology). They have been manually segmented by three observers trained by an ophthalmologist. The images in the training set were segmented once, while images in the test set were segmented twice, resulting in sets $\mathrm{A}$ and $\mathrm{B}$. The observers of sets A and B produced similar segmentations. In set $\mathrm{A}, 12.7 \%$ of pixels where marked as vessel, against $12.3 \%$ vessel for set $\mathrm{B}$. Performance is measured on the test set using the segmentations of set $\mathrm{A}$ as ground truth. The segmentations of set B are tested against those of A, serving as a human observer reference for performance comparison.

The STARE database consists of 20 digitized slides captured by a TopCon TRV-50 fundus camera at $35^{\circ}$ FOV. The slides were digitized to $700 \times 605$ pixels, 8 bits per color channel. The FOV in the images are approximately $650 \times 550$ pixels in diameter. Ten of the images contain pathology. Two observers manually segmented all images. The first observer segmented $10.4 \%$ of pixels as vessel, against $14.9 \%$ vessels for the second observer. The segmentations of the two observers are fairly different in that the second observer segmented much more of the thinner vessels than the first one. Performance is computed with the segmentations of the first observer as ground truth.

\subsection{General framework}

The image pixels of a fundus image are viewed as objects represented by feature vectors, so that we may apply statistical classifiers in order to segment the image. In this case, two classes are considered, i.e. vessel $\times$ non-vessel pixels. The training set for the classifier is derived by manual segmentations of training images, i.e. pixels segmented by hand are labeled as vessel while the remaining pixels are labeled as non-vessel. This approach allows us to integrate information from wavelet responses at multiple scales in order to distinguish pixels from each class.

\subsection{Pixel features}

When the RGB components of the non-mydriatic images are visualized separately, the green channel shows the best vessel/background contrast (Figure 1(a)), whereas, the red and blue channels show low contrast and are very noisy. Therefore, the green channel was selected to be processed by the wavelet, as well as to compose the feature vector itself, i.e. the green channel intensity of each pixel is taken as one of its features. For angiograms, the wavelet is applied directly to the gray-level values, which are also used to compose the feature vectors.

2.3.1. Pre-processing. In order to reduce false detection of the border of the camera's aperture by the wavelet transform, an iterative algorithm has been developed. Our intent is to remove the strong contrast between the retinal fundus and the region outside the aperture (see Figure 1).

The pre-processing algorithm consists of determining the pixels outside the aperture that are neighbors to pixels inside the aperture and replacing each of their values with the mean value of their neighbors inside the aperture. This process is repeated and can be seen as artificially increasing the area inside the aperture, as shown in Figure 1(b).

Before the application of the wavelet transform to nonmydriatic images, we invert the green channel of the image, so that the vessels appear brighter than the background.

2.3.2. Wavelet transform features. The notation and definitions in this section follow [2]. The real plane $\mathbb{R} \times \mathbb{R}$ is denoted as $\mathbb{R}^{2}$, and the vectors are represented as bold letters, e.g. $\mathbf{x}, \mathbf{b} \in \mathbb{R}^{2}$. Let $f \in L^{2}$ be an image represented as a square integrable (i.e. finite energy) function defined over $\mathbb{R}^{2}$. The continuous wavelet transform $T_{\psi}(\mathbf{b}, \theta, a)$ is defined as:

$$
T_{\psi}(\mathbf{b}, \theta, a)=C_{\psi}^{-1 / 2} \frac{1}{a} \int \psi^{*}\left(a^{-1} r_{-\theta}(\mathbf{x}-\mathbf{b})\right) f(\mathbf{x}) d^{2} \mathbf{x}
$$

where $C_{\psi}, \psi, \mathbf{b}, \theta$ and $a$ denote the normalizing constant, analyzing wavelet, the displacement vector, the rotation angle and the dilation parameter (also known as scale), respectively. $\psi^{*}$ denotes the complex conjugate.

Combining the conditions for both the analyzing wavelet and its Fourier transform of being well localized in the time and frequency domain plus the requirement of having zero mean, one realizes that the wavelet transform provides a local filtering at a constant rate $\frac{\Delta \omega}{\omega}$, indicating its great efficiency as the frequency increases, i.e. as the scale decreases. This property is what makes the wavelet effective for detection and analysis of localized properties and singularities [1], such as the blood vessels in the present case.

Among several available analyzing wavelets, for instance, the 2-D Mexican hat and the optical wavelet, we chose the 2-D Morlet wavelet for the purposes of this work, due to its directional selectiveness capability in detecting oriented features and fine tuning to specific frequencies $[1,2]$. This latter property is especially important in filtering out the background noise of the fundus images. The 2-D Morlet wavelet is defined as:

$$
\psi_{M}(\mathbf{x})=\exp \left(j \mathbf{k}_{\mathbf{0}} \mathbf{x}\right) \exp \left(-\frac{1}{2}|A \mathbf{x}|^{2}\right)
$$




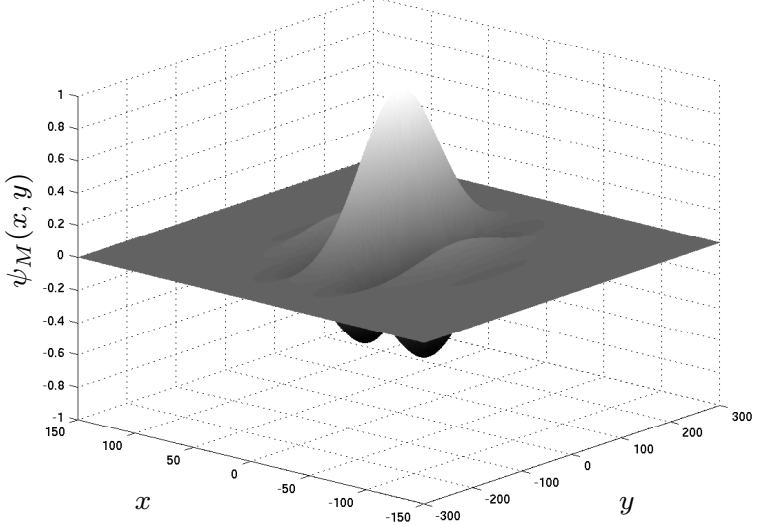

(a) Surface representation of the real part.

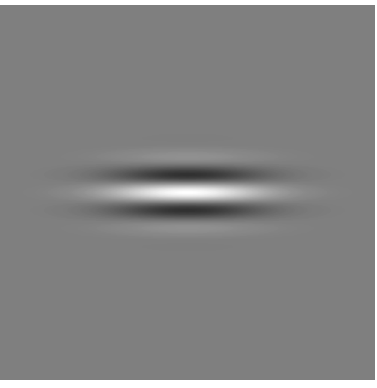

(b) Real part.

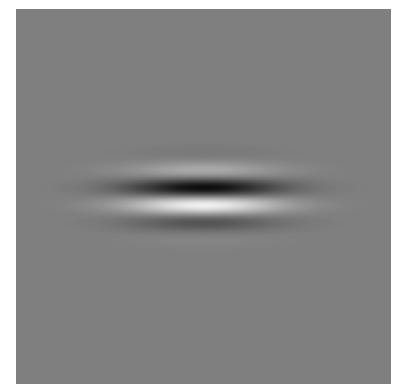

(c) Imaginary part.
Figure 2. Different representations for the 2D Morlet wavelet $\left(\psi_{M}\right)$ with parameters $\epsilon=8$ and $\mathbf{k}_{0}=[0,3]$.

where $j=\sqrt{-1}$ and $A=\operatorname{diag}\left[\epsilon^{-1 / 2}, 1\right], \epsilon \geq 1$ is a $2 \times 2$ diagonal matrix that defines the anisotropy of the filter, i.e. its elongation in any desired direction [1]. The Morlet wavelet is actually a complex exponential modulated gaussian, where $\mathbf{k}_{0}$ is a vector that defines the frequency of the complex exponential.

We have set the $\epsilon$ parameter to 8 , making the filter elongated and $\mathbf{k}_{0}=[0,3]$, i.e. a low frequency complex exponential with few significant oscillations, as shown in Figure 2. These two characteristics have been chosen in order to enable the transform to present stronger responses for pixels associated with the blood vessels.

For each considered scale value, we are interested in the response with maximum modulus over all possible orientations, i.e.:

$$
M_{\psi}(\mathbf{b}, a)=\max _{\theta}\left|T_{\psi}(\mathbf{b}, \theta, a)\right|
$$

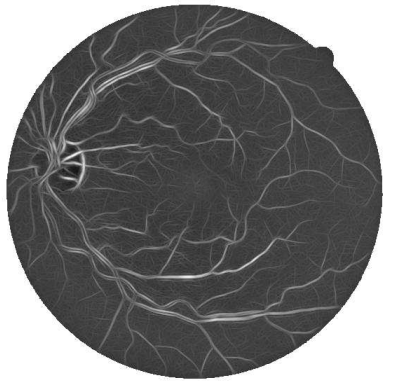

(a) $M_{\psi}(\mathbf{b}, 2)$.

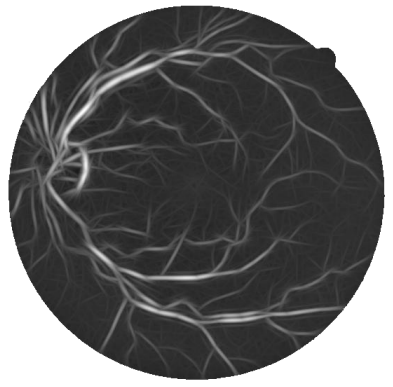

(b) $M_{\psi}(\mathbf{b}, 4)$.

Figure 3. Maximum modulus of Morlet wavelet transform over angles, $M_{\psi}(\mathbf{b}, a)$ (Equation $\left.\mathbf{3}\right)$, for scale values of $a=2$ and $a=4$ pixels. The remaining parameters are fixed at $\epsilon=8$ and $\mathbf{k}_{0}=[0,3]$.

Thus, the Morlet wavelet transform is computed for $\theta$ spanning from 0 up to 170 degrees at steps of $10 \mathrm{de}-$ grees and the maximum is taken (this is possible because $\left.\left|T_{\psi}(\mathbf{b}, \theta, a)\right|=\left|T_{\psi}(\mathbf{b}, \theta+180, a)\right|\right)$. The maximum modulus of the wavelet transform over all angles for multiple scales are then taken as pixel features. $M_{\psi}(\mathbf{b}, a)$ is shown in Figure 3 for $a=2$ and $a=4$ pixels.

2.3.3. Feature normalization. Given the dimensional nature of the features forming the feature space, one must bear in mind that this might give rise to errors in the classification process, as the units chosen might affect the distance in the feature space.

A strategy to obtain a new random variable with zero mean and unit standard deviations, yielding, in addition, dimensionless features, is to apply the normal transformation to the feature space. The normal transformation is defined as [8]:

$$
\hat{v}_{i}=\frac{v_{i}-\mu_{i}}{\sigma_{i}}
$$

where $v_{i}$ is the $i^{\text {th }}$ feature assumed by each pixel, $\mu_{i}$ is the average value of the $i^{t h}$ feature and $\sigma_{j}$ is the associated standard deviation.

We have applied the normal transformation separately to each image's feature space, i.e., every image's feature space is normalized by its own means and standard deviations, helping to compensate for intrinsic variation between images (e.g. illumination). 


\subsection{Supervised classification for segmentation}

Supervised classification has been applied to obtain the final segmentation, with the pixel classes defined as $C_{1}=$ $\{$ vessel pixels $\}$ and $C_{2}=\{$ non-vessel pixels $\}$. In order to obtain the training set, several fundus image have been manually segmented, allowing the creation of a labeled training set into classes $C_{1}$ and $C_{2}$ (see Subsection 2.1). Due to the computational cost of training the classifiers and the large number of samples, we randomly select a subset of the available samples to use for actually training the classifiers. We will present results for two different classifiers, described in the following.

2.4.1. Gaussian mixture model Bayesian classifier. We have achieved very good results using a Bayesian classifier in which each class-conditional probability density function (likelihood) is described as a linear combination of gaussian functions $[9,37]$. We will call this the gaussian mixture model (GMM) classifier.

The Bayes classification rule for a feature vector $\mathbf{v}$ can be stated in terms of posterior probabilities as

$$
\text { Decide } C_{1} \text { if } P\left(C_{1} \mid \mathbf{v}\right)>P\left(C_{2} \mid \mathbf{v}\right) \text {; }
$$$$
\text { otherwise, decide } C_{2}
$$

We recall Bayes rule:

$$
P\left(C_{i} \mid \mathbf{v}\right)=\frac{p\left(\mathbf{v} \mid C_{i}\right) P\left(C_{i}\right)}{p(\mathbf{v})}
$$

where $p\left(\mathbf{v} \mid C_{i}\right)$ is the class-conditional probability density function, also known as likelihood, $P\left(C_{i}\right)$ is the prior probability of class $C_{i}$, and $p(\mathbf{v})$ is the probability density function of $\mathbf{v}$ (sometimes called evidence).

To obtain a decision rule based on estimates from our training set, we apply Bayes rule to Equation 5, obtaining the equivalent decision rule:

$$
\begin{aligned}
& \text { Decide } C_{1} \text { if } p\left(\mathbf{v} \mid C_{1}\right) P\left(C_{1}\right)>p\left(\mathbf{v} \mid C_{2}\right) p\left(C_{2}\right) ; \\
& \text { otherwise, decide } C_{2}
\end{aligned}
$$

We estimate $P\left(C_{i}\right)$ as $N_{i} / N$, the ratio of class $i$ samples in the training set. The class likelihoods are described as linear combinations of gaussian functions:

$$
p\left(\mathbf{v} \mid C_{i}\right)=\sum_{j=1}^{k_{i}} p\left(\mathbf{v} \mid j, C_{i}\right) P_{j}
$$

where $k_{i}$ is the number of gaussians modeling likelihood $i, P_{j}$ is the weight of gaussian $j$ and each $p\left(\mathbf{v} \mid j, C_{i}\right)$ is a $d$-dimensional gaussian distribution.

For each class $i$, we estimate the $k_{i}$ gaussian parameters and weights with the Expectation-Maximization (EM) algorithm [37]. The EM algorithm is an iterative scheme that guarantees a local maximum of the likelihood of the training data.

GMMs represent a halfway between purely nonparametric and parametric models, providing a relatively fast classification process at the cost of a more expensive training algorithm.

2.4.2. Minimum squared error linear classifier. We have also tested the linear minimum squared error classifier [9, 37], denoted LMSE. Linear classifiers are defined by a linear decision function $g$ in the $d$-dimensional feature space:

$$
g(\mathbf{v})=\mathbf{w}^{t} \mathbf{v}+w_{0}
$$

where $\mathbf{v}$ is a feature vector, $\mathbf{w}$ is the weight vector and $w_{0}$ the threshold.

The classification rule is to decide $C_{1}$ if $g(\mathbf{v})>0$ and $C_{2}$ otherwise. To simplify the formulation, the threshold $w_{0}$ is accommodated by defining the extended $(d+1)$ dimensional vectors $\mathbf{v}^{\prime} \equiv\left[\mathbf{v}^{T}, 1\right]^{T}$ and $\mathbf{w}^{\prime} \equiv\left[\mathbf{w}^{T}, w_{0}\right]^{T}$, so that $g(\mathbf{v})=\mathbf{w}^{\prime T} \mathbf{v}^{\prime}$.

The classifier is determined by finding $\mathbf{w}^{\prime}$ that minimizes the sum of error squares criterion:

$$
J\left(\mathbf{w}^{\prime}\right)=\sum_{i=1}^{N}\left(y_{i}-\mathbf{v}_{i}^{\prime T} \mathbf{w}^{\prime}\right)^{2}
$$

where $N$ is the total number of training samples, $\mathbf{v}_{i}^{\prime}$ is the extended $i^{t h}$ training sample, and $y_{i}$ its desired output.

The criterion measures the sum of squared errors between the true output of the classifier $\left(\mathbf{v}_{i}^{\prime T} \mathbf{w}^{\prime}\right)$ and the desired output $\left(y_{i}\right)$. We have arbitrarily set $y_{i}=1$ for $\mathbf{v}_{i} \in C_{1}$ and $y_{i}=-1$ for $\mathbf{v}_{i} \in C_{2}$.

Let us define

$$
V=\left[\begin{array}{c}
\mathbf{v}_{1}^{\prime T} \\
\mathbf{v}_{2}^{\prime T} \\
\vdots \\
\mathbf{v}_{N}^{\prime T}
\end{array}\right], \quad \mathbf{y}=\left[\begin{array}{c}
y_{1} \\
y_{2} \\
\vdots \\
y_{N}
\end{array}\right]
$$

Minimizing the criterion with respect to $\mathrm{w}^{\prime}$ results in:

$$
\left(V^{T} V\right) \hat{\mathbf{w}}^{\prime}=V^{T} \mathbf{y} \Rightarrow \hat{\mathbf{w}}^{\prime}=\left(V^{T} V\right)^{-1} V^{T} \mathbf{y}
$$

In comparison to the GMM classifier, the LMSE classifier has a much faster training process, but is restricted in the sense that it is linear, while GMMs allow for complex decision boundaries. However, as we will show, the results obtained using LMSE are comparable to those using GMMs, representing a reasonable trade-off. 


\subsection{Experimental Evaluation}

The performances are measured using receiver operating characteristic (ROC) curves. ROC curves are plots of true positive fractions versus false positive fractions for varying thresholds on the posterior probabilities. A pair formed by a true positive fraction and a false positive fraction is plotted on the graph for each threshold value (as explained below), producing a curve. The true positive fraction is determined by dividing the number of true positives by the total number of vessel pixels in the ground truth segmentations, while the false positive fraction is the number of false positives divided by the total number of non-vessel pixels in the ground truth. In our experiments, these fractions are calculated over all test images, considering only pixels inside the FOV.

For the GMM classifier, the ROC curve is produced by varying the threshold on the posterior pixel probabilities (see Equation 6), while the LMSE ROC curve is produced varying the threshold $w_{0}$ on the projection of the feature vectors on the discriminant vector (see Equation 9).

We have tested our methods on the DRIVE and STARE databases with the following settings. The pixel features used for classification where the inverted green channel and its maximum Morlet transform response over angles $M_{\psi}(\mathbf{b}, a)$ (Equation 3) for scales $a=2,3,4,6$ pixels (see Subsection 2.3).

For the DRIVE database, the training set was formed by pixel samples from the 20 labeled training images. For the STARE database, leave-one-out tests where performed, i.e., every image is segmented using samples from the other 19 images for the training set. Due to the large number of pixels, in all experiments, one million pixel samples where randomly chosen to train the classifiers. Tests were performed with the LMSE and GMM classifiers. For the GMM classifier, we vary the number $k=k_{1}=k_{2}$ of vessel and nonvessel gaussians modeling each class likelihood.

\section{Results}

Illustrative segmentation results for a pair of images from each database (produced by the GMM classifier with $k=20$ ), along with the manual segmentations, are shown in Figures 4 and 5.

For the DRIVE database, the manual segmentations from set $\mathrm{A}$ are used as ground truth and the human observer performance is measured using the manual segmentations from set $\mathrm{B}$, which provide only one true/false positive fraction pair, appearing as a point in the ROC graph (Figure 6). For the STARE database, the first observer's manual segmentations are used as ground truth, and the second observer's true/false positive fraction pair is plotted on the ROC graph (Figure 7). The closer a ROC curve approaches the top left corner, the better the performance of the method. A system
Table 1. Results for different classification methods and human observer. $A_{z}$ indicates the area under the ROC curve, while the accuracy is the fraction of pixels correctly classified.

\begin{tabular}{|c|c|c|c|c|}
\hline \multirow{3}{*}{$\begin{array}{c}\text { Classification } \\
\text { Method }\end{array}$} & \multicolumn{4}{|c|}{ Database } \\
\hline & \multicolumn{2}{|c|}{ DRIVE } & \multicolumn{2}{|c|}{ STARE } \\
\hline & $A_{z}$ & Accuracy & $A_{z}$ & Accuracy \\
\hline LMSE & 0.9520 & 0.9280 & 0.9584 & 0.9362 \\
\hline $\mathrm{GMM}, k=1$ & 0.9250 & 0.9217 & 0.9394 & 0.9239 \\
\hline $\mathrm{GMM}, k=5$ & 0.9537 & 0.9431 & 0.9609 & 0.9430 \\
\hline $\mathrm{GMM}, k=10$ & 0.9570 & 0.9454 & 0.9627 & 0.9450 \\
\hline $\mathrm{GMM}, k=15$ & 0.9588 & 0.9459 & 0.9648 & 0.9470 \\
\hline $\mathrm{GMM}, k=20$ & 0.9598 & 0.9467 & 0.9651 & 0.9474 \\
\hline 2nd. observer & & 0.9473 & & 0.9349 \\
\hline
\end{tabular}

that agreed completely with the ground truth segmentations would yield $A_{z}=1$. However, note that the second sets of manual segmentations do not produce perfect true/false positive fractions, for the manual segmentations evaluated disagree on some of the pixels with the manual segmentations used as ground truth. Thus, the variance between observers can be estimated, helping set a goal for the method's performance.

The areas under the ROC curves $\left(A_{z}\right)$ are used as a single measure of the performance of each method and are shown in Table 1 for GMM classifiers of varying $k$ and for the LMSE classifier. For comparison with the manual segmentations, we also measure the accuracies (fraction of correctly classified pixels) of the automatic and manual segmentations. Note that the accuracy and $A_{z}$ values for the GMM classifier increase with $k$. The ROC curves for the DRIVE and STARE databases produced using the GMM classifier with $k=20$, as well as performances for human observers are shown in Figures 6 and 7.

We note that the EM training process for the GMMs is computationally more expensive as $k$ increases, while the classification phase is fast. On the other hand, LMSE is very fast both for training and classification, but produces poorer results, as seen in Table 1.

\section{Discussion and conclusion}

The Morlet transform shows itself efficient in enhancing vessel contrast, while filtering out noise. Information from Morlet transforms at different scales are integrated through the use of the statistical classifiers presented. The LMSE classifier shows a reasonable performance with a fast classification and training phase, while the GMM classifier has a 


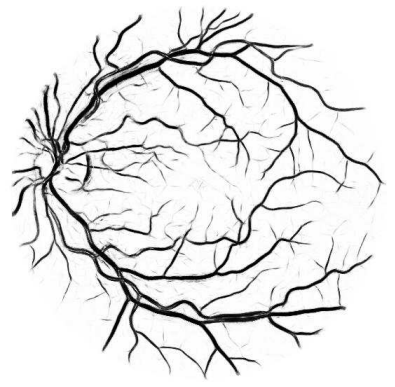

(a) Posterior probabilities.

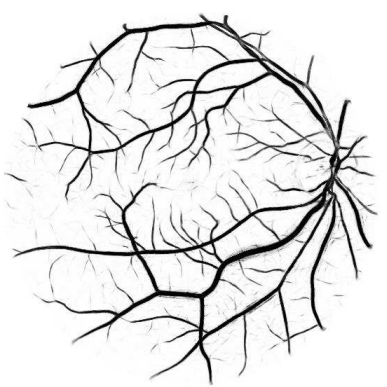

(e) Posterior probabilities.

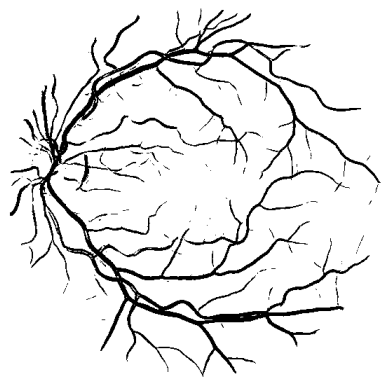

(b) Segmentation.

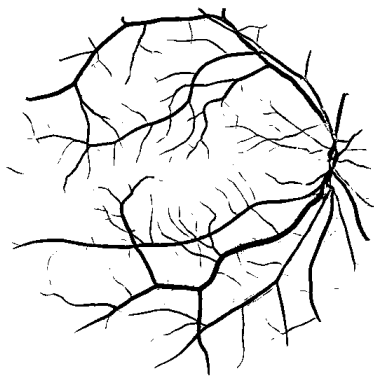

(f) Segmentation.

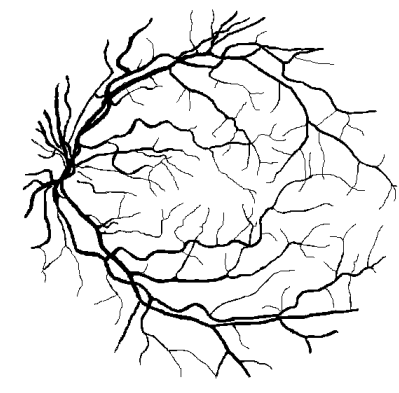

(c) Set A.

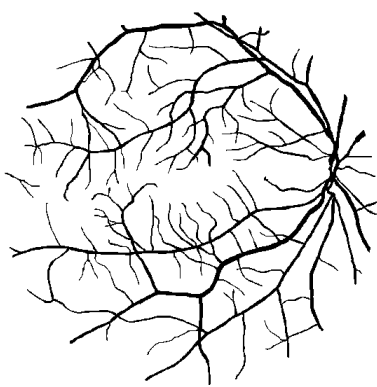

(g) Set A.

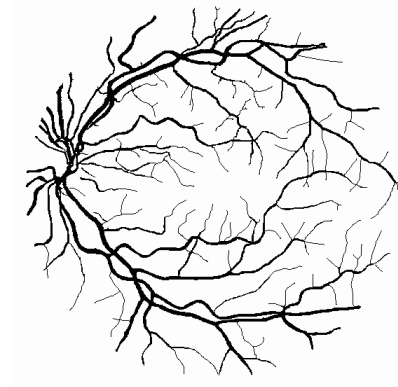

(d) Set B.

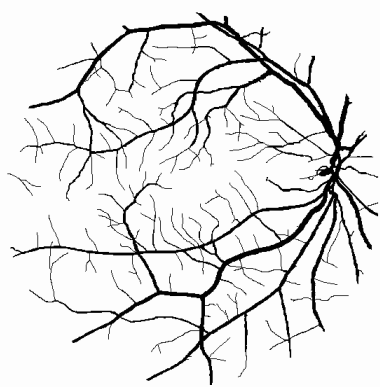

(h) Set B.

Figure 4. Results produced by the GMM classifier with $k=20$ and manual segmentations for two images from the DRIVE database. The top row results are for the image shown in Figure 1(a).

computationally demanding training phase, but guarantees a fast classification phase and better performance.

It is curious to note that, on the STARE database, the accuracy of the method is higher than that of the second observer (Table 1). The second observer's manual segmentations contain much more of the thinnest vessels than the first observer (lowering his accuracy), while the method, trained by the first observer, is able to segment the vessels at a similar rate. However, the ROC graph (Figure 7) still reflects the higher precision of the second observer.

The classification framework demands the use of manual labelings, but allows the methods to be trained for different types of images (provided the corresponding manual segmentations), possibly adjusted to specific camera or lighting conditions and are otherwise automatic, i.e., adjustment of parameters or user interaction is not necessary. We are studying the use of training sets composed of a small portion of the image to be segmented. Using this approach, a semi-automated fundus segmentation software may be developed, in which the operator only has to draw a small portion of the vessels over the input image or simply click on several pixels associated with the vessels. The remaining image would then be segmented based on the partial training set. This approach is interesting since it requires a small effort from the operator, which is compensated by the fact that image peculiarities are directly incorporated by the classifier.

It is possible to use only the skeleton of the segmentations for the extraction of features from the vasculature. Depending on the application, different evaluation methods become more appropriate [3]. For example, the evaluation of the skeleton would not take into account the width of the vessels, but could measure other qualities such as the presence of gaps and detection of branching points. Another interesting form of evaluation would be directly through an application, such as in detection of neovascularization by means of analysis and classification of the vessel structure [17]. A major difficulty in evaluating the results is the establishment of a reliable ground truth [12]. Human observers are subjective and prone to errors, resulting in large variability between observations. Thus, it is desirable that multiple human-generated segmentations be combined to 


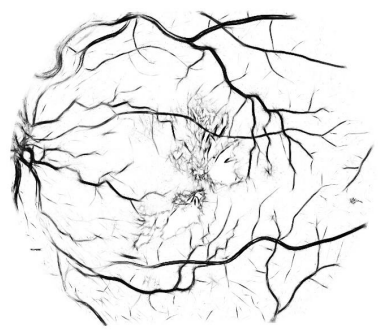

(a) Posterior probabilities.

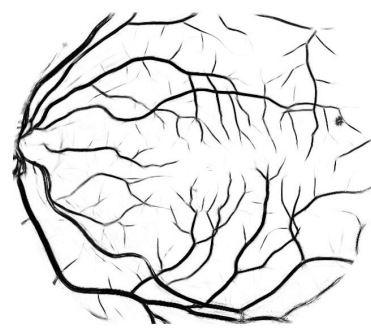

(e) Posterior probabilities.

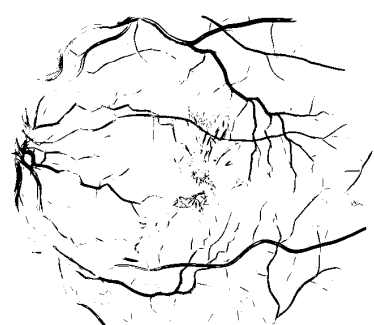

(b) Segmentation.

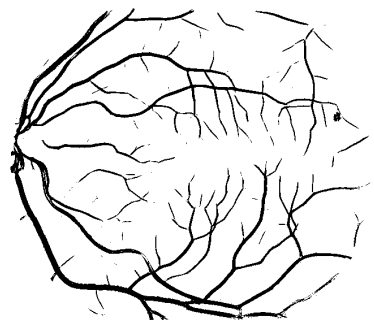

(f) Segmentation.

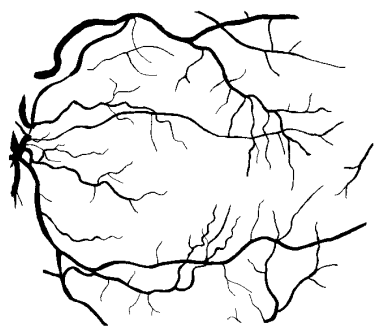

(c) First observer.

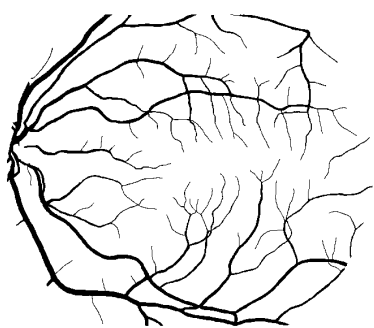

(g) First observer.

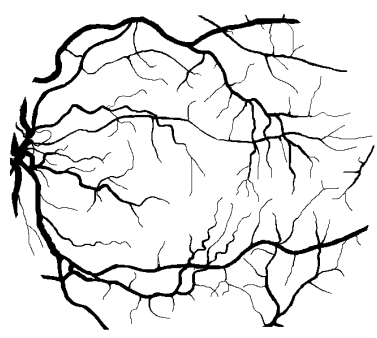

(d) Second observer.

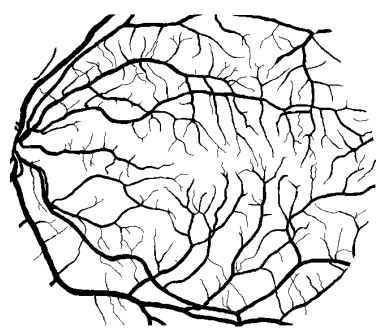

(h) Second observer.

Figure 5. Results produced by the GMM classifier with $k=20$ and manual segmentations for two images from the STARE database. The top row images originate from a pathological case, while the bottom ones originate from a normal case.

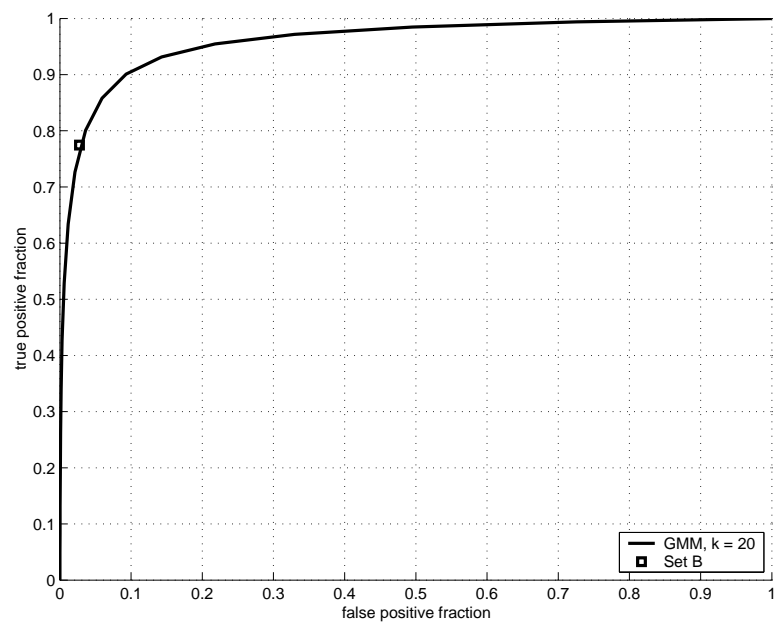

Figure 6. ROC curve for classification on the DRIVE database using the GMM classifier with $k=20$. The point marked as $\square$ corresponds to set $B$, the second set of manual segmentations. The method has $A_{z}=0.9598$.

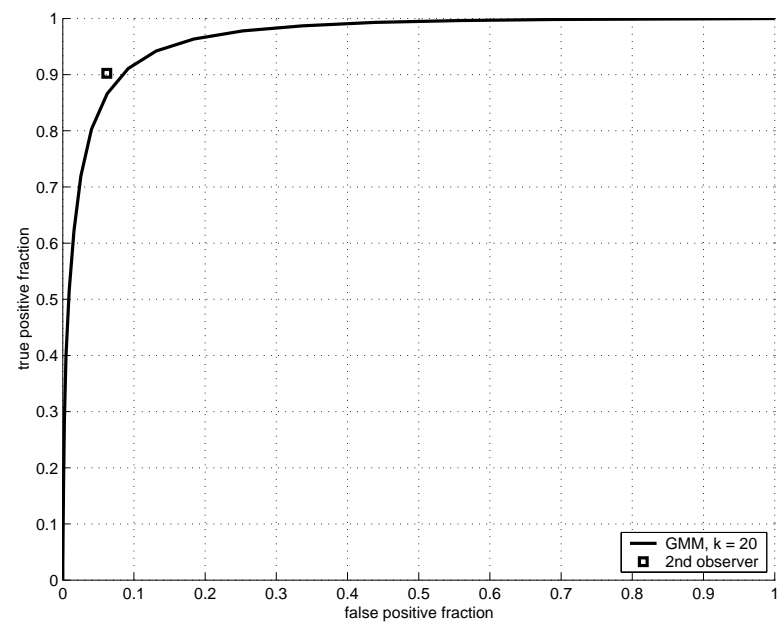

Figure 7. ROC curve for classification on the STARE database using the GMM classifier with $k=20$. The point marked as $\mathbf{c}$ corresponds to the second observer's manual segmentations. The method has $A_{z}=0.9651$. 
establish a ground truth, which was not the case in the analysis presented.

Though very good ROC results are presented, visual inspection shows some typical difficulties of the method that must be solved by future work. The major errors are in false detection of noise and other artifacts. False detection occurs in some images for the border of the optic disc, haemorrhages and other types of pathologies that present strong contrast. Also, the method does not perform well for very large variations in lighting throughout an image, but this occurred for only one image out of the 40 tested from both databases. Another difficulty is the inability to capture some of the thinnest vessels that are barely perceived by the human observers.

One drawback of our approach is that it only takes into account information local to each pixel through image filters, ignoring useful information from shapes and structures present in the image. We intend to work on methods addressing this drawback in the near future. The results can be slightly improved through a post-processing of the segmentations for removal of noise and inclusion of missing vessel pixels as in [22]. An intermediate result of our method is the intensity image of posterior probabilities, which could possibly benefit from a threshold probing as in [16] or region growing schemes.

Automated segmentation of non-mydriatic images provides the basis for automated assessment by community health workers. Skeletonized images of the vessel pattern of the ocular fundus can be analyzed mathematically using nonlinear methods such as global fractal [17] and local fractal [28] analysis based on the wavelet transform thus providing a numeric indicator of the extent of neovascularization. Our ongoing work aims at applying the shape analysis and classification strategies described in [17] to the segmented vessels produced by method described in this work.

\section{Acknowledgements}

The authors thank J. J. Staal et al. [34] and A. Hoover et al. [16] for making their databases publicly available and Dr. Alan Luckie and Chris McQuellin from the Albury Eye Clinic for providing fluorescein images used during our research. J. Soares is grateful to CNPq (131403/2004-4). R. Cesar-Jr. is grateful to FAPESP (99/12765-2) and to CNPq (300722/98-2 and 474596/2004-4). H. Jelinek was in receipt of a Australian Diabetes Association Grant and a CSU CoS grant.

\section{References}

[1] J.-P. Antoine, P. Carette, R. Murenzi, and B. Piette. Image analysis with two-dimensional continuous wavelet transform. Signal Processing, 31:241-272, 1993.
[2] A. Arnéodo, N. Decoster, and S. G. Roux. A wavelet-based method for multifractal image analysis. i. methodology and test applications on isotropic and anisotropic random rough surfaces. The European Physical Journal B, 15:567-600, 2000.

[3] K. W. Bowyer and P. J. Phillips, editors. Empirical Evaluation Techniques in Computer Vision. IEEE Computer Society, 1998.

[4] A. Can, H. Shen, J. N. Turner, H. L. Tanenbaum, and B. Roysam. Rapid automated tracing and feature extraction from retinal fundus images using direct exploratory algorithms. IEEE Transactions on Information Technology in Biomedicine, 3(2):125-138, 1999.

[5] S. Chaudhuri, S. Chatterjee, N. Katz, M. Nelson, and M. Goldbaum. Detection of blood vessels in retinal images using two-dimensional matched filters. IEEE Transactions on Medical Imaging, pages 263-269, 1989.

[6] O. Chutatape, L. Zheng, and S. M. Krishnan. Retinal blood vessel detection and tracking by matched gaussian and kalman filters. In Proc. of the 20th Annual International Conference of the IEEE Engineering in Medicine and Biology Society, (EMBS'98), volume 20, pages 3144-3149, 1998.

[7] M. J. Cree, J. J. G. Leandro, J. V. B. Soares, R. M. Cesar-Jr., G. Tang, H. F. Jelinek, and D. J. Cornforth. Comparison of various methods to delineate blood vessels in retinal images. In Proc. of the 16th National Congress of the Australian Institute of Physics, Canberra, Australia, 2005.

[8] L. da F. Costa and R. M. Cesar-Jr. Shape analysis and classification: theory and practice. CRC Press, 2001.

[9] R. O. Duda, P. E. Hart, and D. G. Stork. Pattern Classification. John Wiley and Sons, 2001.

[10] B. Fang, W. Hsu, and M. Lee. Reconstruction of vascular structures in retinal images. In ICIP03, pages II: 157-160, 2003.

[11] R. S. Feris, V. Krueger, and R. M. Cesar-Jr. A wavelet subspace method for real-time face tracking. Real-Time Imaging, 10:339-350, 2004.

[12] K. H. Fritzsche, A. Can, H. Shen, C.-L. Tsai, J. N. Turner, H. L. Tanenbaum, C. V. Stewart, and B. Roysam. Automated model-based segmentation, tracing, and analysis of retinal vasculature fom digital fundus images. In J. Suri and S. Laxminarayan, editors, Angiography and Plaque Imaging: Advanced Segmentation Techniques, pages 225-297. CRC Press, 2003.

[13] L. Gang, O. Chutatape, and S. M. Krishnan. Detection and measurement of retinal vessels in fundus images using amplitude modified second-order gaussian filter. IEEE Transactions on Biomedical Engineering, 49(2):168-172, 2002.

[14] X. Gao, A. Bharath, A. Stanton, A. Hughes, N. Chapman, and S. Thom. A method of vessel tracking for vessel diameter measurement on retinal images. In ICIP01, pages II: 881-884, 2001.

[15] A. Grossmann. Wavelet transforms and edge detection. In S. A. et al., editor, Stochastic Processes in Physics and Engineering, pages 149-157. D. Reidel Publishing Company, 1988.

[16] A. Hoover, V. Kouznetsova, and M. Goldbaum. Locating blood vessels in retinal images by piece-wise threshold 
probing of a matched filter response. IEEE Transactions on Medical Imaging, 19:203-210, March 2000.

[17] H. F. Jelinek and R. M. Cesar-Jr. Segmentation of retinal fundus vasculature in non-mydriatic camera images using wavelets. In J. Suri and T. Laxminarayan, editors, Angiography and Plaque Imaging: Advanced Segmentation Techniques, pages 193-224. CRC Press, 2003.

[18] X. Jiang and D. Mojon. Adaptive local thresholding by verification-based multithreshold probing with application to vessel detection in retinal images. IEEE Transactions on Pattern Analysis and Machine Intelligence, 25(1):131-137, 2003.

[19] J. J. Kanski. Clinical Ophthalmology: A systematic approach. Butterworth-Heinemann, London, 1989.

[20] M. Lalonde, L. Gagnon, and M.-C. Boucher. Non-recursive paired tracking for vessel extraction from retinal images. In Proc. of the Conference Vision Interface 2000, pages 61-68, 2000.

[21] J. J. G. Leandro, R. M. Cesar-Jr., and H. Jelinek. Blood vessels segmentation in retina: Preliminary assessment of the mathematical morphology and of the wavelet transform techniques. In Proc. of the 14th Brazilian Symposium on Computer Graphics and Image Processing, pages 84-90. IEEE Computer Society, 2001.

[22] J. J. G. Leandro, J. V. B. Soares, R. M. Cesar-Jr., and H. F. Jelinek. Blood vessels segmentation in non-mydriatic images using wavelets and statistical classifiers. In Proc. of the 16th Brazilian Symposium on Computer Graphics and Image Processing, pages 262-269. IEEE Computer Society Press, 2003.

[23] S. J. Lee, C. A. McCarty, H. R. Taylor, and J. E. Keeffe. Costs of mobile screening for diabetic retinopathy: A practical framework for rural populations. Aust J Rural Health, 8:186-192, 2001.

[24] I. Liu and Y. Sun. Recursive tracking of vascular networks in angiograms based on the detection-deletion scheme. IEEE Transactions on Medical Imaging, 12(2):334-341, 1993.

[25] J. Lowell, A. Hunter, D. Steel, A. Basu, R. Ryder, and R. Kennedy. Measurement of retinal vessel widths from fundus images based on 2-D modeling. IEEE Transactions on Medical Imaging, 23(10):1196-1204, October 2004.

[26] M. E. Martínez-Pérez, A. D. Hughes, A. V. Stanton, S. A. Thom, A. A. Bharath, and K. H. Parker. Retinal blood vessel segmentation by means of scale-space analysis and region growing. In Medical Image Computing and Comptuerassisted Intervention - MICCAI, pages 90-97, 1999.

[27] T. McInerney and D. Terzopoulos. T-snakes: Topology adaptive snakes. Medical Image Analysis , 4:73-91, 2000.

[28] C. P. McQuellin, H. F. Jelinek, and G. Joss. Characterisation of fluorescein angiograms of retinal fundus using mathematical morphology: a pilot study. In 5th International Conference on Ophthalmic Photography, page 152, 2002.

[29] D. Nain, A. Yezzi, and G. Turk. Vessel segmentation using a shape driven flow. In Medical Image Computing and Comptuer-assisted Intervention - MICCAI, pages 5159, 2004.

[30] R. Nekovei and Y. Sun. Back-propagation network and its configuration for blood vessel detection in angiograms. IEEE Transactions on Neural Networks, 6(1):64-72, 1995.
[31] M. Niemeijer, J. J. Staal, B. van Ginneken, M. Loog, and M. D. Abràmoff. Comparative study of retinal vessel segmentation methods on a new publicly available database. In J. M. Fitzpatrick and M. Sonka, editors, SPIE Medical Imaging, volume 5370, pages 648-656, 2004.

[32] O. Rioul and M. Vetterli. Wavelets and signal processing. IEEE Signal Processing Magazine, pages 14-38, Oct. 1991.

[33] C. Sinthanayothin, J. Boyce, and C. T. Williamson. Automated localisation of the optic disc, fovea, and retinal blood vessels from digital colour fundus images. British Journal of Ophthalmology, 83:902-910, 1999.

[34] J. J. Staal, M. D. Abràmoff, M. Niemeijer, M. A. Viergever, and B. van Ginneken. Ridge based vessel segmentation in color images of the retina. IEEE Transactions on Medical Imaging, 23(4):501-509, 2004.

[35] E. J. Sussman, W. G. Tsiaras, and K. A. Soper. Diagnosis of diabetic eye disease. JAMA, 247:3231-3234, 1982.

[36] H. R. Taylor and J. E. Keeffe. World blindness: a 21st century perspective. British Journal of Ophthalmology, 85:261266, 2001.

[37] S. Theodoridis and K. Koutroumbas. Pattern Recognition. Academic Press, USA, first edition, 1999.

[38] R. Toledo, X. Orriols, X. Binefa, P. Radeva, J. Vitria, and J. Villanueva. Tracking of elongated structures using statistical snakes. In IEEE Computer Society Conference on Computer Vision and Pattern Recognition (CVPR), volume 1, page 1157, 2000.

[39] Y. A. Tolias and S. M. Panas. A fuzzy vessel tracking algorithm for retinal images based on fuzzy clustering. IEEE Transactions on Medical Imaging, 17:263-273, April 1998.

[40] A. Vasilevskiy and K. Siddiqi. Flux maximizing geometric flows. IEEE Transactions on Pattern Analysis and Machine Intelligence, pages 1565-1578, 2002.

[41] F. Zana and J.-C. Klein. Segmentation of vessel-like patterns using mathematical morphology and curvature evaluation. IEEE Transactions on Image Processing, 10:1010 1019, 2001.

[42] L. Zhou, M. S. Rzeszotarski, L. J. Singerman, and J. M. Chokreff. The detection and quantification of retinopathy using digital angiograms. IEEE Transactions on Medical Imaging, 13(4):619-626, 1994. 


\section{A.4 Retinal vessel segmentation using the 2-D Gabor wavelet and supervised classification}

Segue uma cópia do trabalho "Retinal vessel segmentation using the 2-D Gabor wavelet and supervised classification", publicado na revista IEEE Transactions on Medical Imaging Soares et al., 2006]. O artigo apesenta resumidamente os métodos desta dissertação e a avaliação ROC dos métodos, incluindo a comparação do desempenho da wavelet de Gabor com o do filtro casado 2D de Chaudhuri et al., 1989 . 
This material is presented to ensure timely dissemination of scholarly and technical work. Copyright and all rights therein are retained by authors or by other copyright holders. All persons copying this information are expected to adhere to the terms and constraints invoked by each author's copyright. In most cases, these works may not be reposted without the explicit permission of the copyright holder.

(C) 2006 IEEE. Personal use of this material is permitted. Permission from IEEE must be obtained for all other uses, including reprinting/republishing this material for advertising or promotional purposes, creating new collective works for resale or redistribution to servers or lists, or reuse of any copyrighted component of this work in other works. 


\title{
Retinal Vessel Segmentation Using the 2-D Gabor Wavelet and Supervised Classification
}

\author{
João V. B. Soares*, Jorge J. G. Leandro, Roberto M. Cesar Jr., Herbert F. Jelinek, and \\ Michael J. Cree, Senior Member, IEEE
}

\begin{abstract}
We present a method for automated segmentation of the vasculature in retinal images. The method produces segmentations by classifying each image pixel as vessel or nonvessel, based on the pixel's feature vector. Feature vectors are composed of the pixel's intensity and two-dimensional Gabor wavelet transform responses taken at multiple scales. The Gabor wavelet is capable of tuning to specific frequencies, thus allowing noise filtering and vessel enhancement in a single step. We use a Bayesian classifier with class-conditional probability density functions (likelihoods) described as Gaussian mixtures, yielding a fast classification, while being able to model complex decision surfaces. The probability distributions are estimated based on a training set of labeled pixels obtained from manual segmentations. The method's performance is evaluated on publicly available DRIVE (Staal et al., 2004) and STARE (Hoover et al., 2000) databases of manually labeled images. On the DRIVE database, it achieves an area under the receiver operating characteristic curve of 0.9614 , being slightly superior than that presented by state-of-the-art approaches. We are making our implementation available as open source MATLAB scripts for researchers interested in implementation details, evaluation, or development of methods.
\end{abstract}

Index Terms-Fundus, Gabor, pattern classification, retina, vessel segmentation, wavelet.

\section{INTRODUCTION}

O PTIC fundus [Fig. 1(a)] assessment has been widely used by the medical community for diagnosing vascular and nonvascular pathology. Inspection of the retinal vasculature may reveal hypertension, diabetes, arteriosclerosis, cardiovascular disease, and stroke [3]. Diabetic retinopathy is a major cause of adult blindness due to changes in blood vessel structure and distribution such as new vessel growth (proliferative diabetic retinopathy) and requires laborious analysis from a specialist [4]. Endeavoring to reduce the effect of proliferative diabetic retinopathy includes obtaining and analyzing images of the optic fundus at regular intervals such as every six months

Manuscript received February 2, 2006; revised May 22, 2006. This work was supported in part by the National Council for Scientific and Technological Development (CNPq) under Grant 131403/2004-4, Grant 300722/98-2, Grant 474596/2004-4, and Grant 491323/2005-0, in part by the The State of São Paulo Research Foundation (FAPESP) under Grant 2005/00587-5, in part by the Australian Diabetes Association, and in part by the Charles Sturt University Community of Science (CSU CoS). Asterisk indicates corresponding author.

*J. Soares is with the Institute of Mathematics and Statistics, University of São Paulo, 05508-090 Brazil (e-mail: joao@ vision.ime.usp.br).

J. Leandro and R. Cesar, Jr. are with the Institute of Mathematics and Statistics, University of São Paulo, 05508-090 Brazil (e-mail: jleandro@ vision.ime. usp.br; cesar@vision.ime.usp.br).

H. Jelinek is with the School of Community Health, Charles Sturt University, Albury 2640, Australia (e-mail: hjelinek@csu.edu.au).

M. Cree is with the Department of Physics and Electronic Engineering, University of Waikato, Hamilton 3240, New Zealand (e-mail: cree@ waikato.ac.nz).

Digital Object Identifier 10.1109/TMI.2006.879967

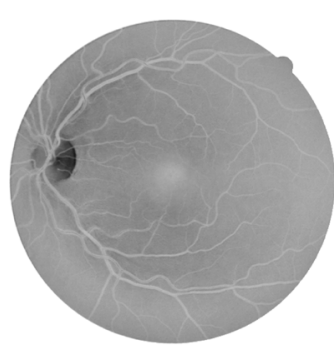

(a)

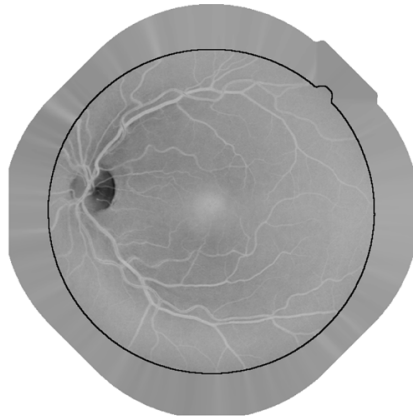

(b)
Fig. 1. Fundus image preprocessing for removing undesired border effects. (a) Inverted green channel of colored fundus image. (b) Preprocessed image with extended border. Original image limit is indicated for illustration.

to a year. Early recognition of changes to the blood vessel patterns can prevent major vision loss as early intervention becomes possible [5], [6].

To provide the opportunity for initial assessment to be carried out by community health workers, computer based analysis has been introduced, which includes assessment of the presence of microaneurysms and changes in the blood flow/vessel distribution due to either vessel narrowing, complete occlusions or new vessel growth [7]-[9].

An automatic assessment for blood vessel anomalies of the optic fundus initially requires the segmentation of the vessels from the background, so that suitable feature extraction and processing may be performed. Several methods have been developed for vessel segmentation, but visual inspection and evaluation by receiver operating characteristic (ROC) analysis show that there is still room for improvement: human observers are significantly more accurate than the methods, which show flaws around the optic disk and in detection of the smallest vessels [10], [11]. In addition, it is important to have segmentation algorithms that are fast and do not critically depend on configuring several parameters, so that untrained community health workers may utilize this technology. This has motivated the use of the supervised classification framework described here, which only depends on manually segmented images and can be implemented efficiently.

Many different approaches for automated vessel segmentation have been reported. The papers [12]-[18] present vessel tracking methods to obtain the vasculature structure, along with vessel diameters and branching points. Tracking consists of following vessel center lines guided by local information, usually trying to find the path which best matches a vessel profile model. The use of deformable models also shows promising results in 
[19]-[22]. In [2], [23], and [24], matched filters are used to emphasize blood vessels. An improvement is obtained in [2] by a region-based threshold probing of the matched filter response. Multithreshold probing is directly applied to the images in [25]. A nonlinear filter that enhances vessels by exploiting properties of the vessel profiles is introduced in [26]. Along this line is the use of mathematical morphology filtering in [27] and [28], coupled with curvature evaluation. In [29], multiscale curvature and border detection are used to drive a region growing algorithm.

Supervised methods for pixel classification have been shown in [1], [30], and [31]. In [30], feature vectors are formed by gray-scale values from a window centered on the pixel being classified. A window of values is also used in [31], but the features used are a principal component transformation of RGB values and edge strength. In [1], ridge detection is used to form line elements and partition the image into patches belonging to each line element. Pixel features are then generated based on this representation. Many features are presented and a feature selection scheme is used to select those which provide the best class separability.

Previously, we have shown promising preliminary results using the wavelet transform [32], [33] and integration of multiscale information through supervised classification [32]-[36]. ${ }^{1}$ Here, we improve on those methods using a Bayesian classifier with Gaussian mixture models as class likelihoods and evaluate performances with ROC analysis. ROC analysis has been used for evaluation of segmentation methods in [1], [2], [25], and comparison of some of the cited methods in [10] and [11].

In our approach, each pixel is represented by a feature vector including measurements at different scales taken from the two-dimensional (2-D) Gabor wavelet transform. The resulting feature space is used to classify each pixel as either a vessel or nonvessel pixel. This is done using a Bayesian classifier with class-conditional probability density functions (likelihoods) described as Gaussian mixtures, yielding a fast classification, while being able to model complex decision surfaces. The original contributions of this work are the following:

- the use of Gabor wavelets applied to the detection of retinal blood vessels, using responses from different scales as features, in order to account for vessels of different widths;

- the use of the Bayesian classifier with Gaussian mixtures as class likelihoods to perform vessel segmentation;

- results and ROC analysis of our methods on two public databases of retinal images, thus corroborating its performance.

Originally devised for suitably analyzing nonstationary and inhomogeneous signals, the time-scale analysis took place to accomplish unsolvable problems within the Fourier framework, based on the wavelet transform. The wavelet transform is a powerful and versatile tool that has been applied to many different image processing problems, such as image coding [37], [38], texture analysis [39], shape analysis [40], and functional magnetic resonance imaging (fMRI) brain activity detection [41]. This success is largely due to the fact that wavelets are especially suitable for detecting singularities (e.g., edges and other visual features) in images [42], extracting instantaneous frequencies

\footnotetext{
${ }^{1}$ Previous partial descriptions of the developed research have appeared as conference papers.
}

[43], and performing fractal and multifractal analysis. Furthermore, the wavelet transform using the Gabor wavelet, also often referred to as Morlet wavelet, has played a central role in increasing our understanding of visual processing in different contexts from feature detection to face tracking [44]. The Gabor wavelet is directional and capable of tuning to specific frequencies, thus allowing it to be adjusted for vessel enhancement and noise filtering in a single step, having been shown to outperform other oriented feature detectors [45]. These nice characteristics motivate the adoption of the Gabor wavelet in our proposed framework.

This work is organized as follows. The databases used for tests are described in Section II-A. Section II-B presents our segmentation framework based on supervised pixel classification. In Section II-C, the feature generation process is described, including the 2-D wavelet transform and Gabor wavelet. Our use of supervised classification and the classifier tested are presented in Section II-D. ROC analysis for performance evaluation is described in Section II-E and results are presented in Section III. Discussion and conclusion are in Section IV.

\section{MATERIALS AND MethodS}

\section{A. Materials}

There are different ways of obtaining ocular fundus images, such as with color cameras, or through angiograms using fluorescein as a tracer [5]. We have tested our methods on angiogram gray-level images and colored images [32], [34]. Here, our methods are tested and evaluated on two publicly available databases of colored images and corresponding manual segmentations: the DRIVE [1] and STARE [2] databases.

The DRIVE database consists of 40 images (seven of which present pathology), along with manual segmentations of the vessels. The images are captured in digital form from a Canon CR5 nonmydriatic $3 \mathrm{CCD}$ camera at $45^{\circ}$ field of view (FOV). The images are of size $768 \times 584$ pixels, eight bits per color channel and have a FOV of approximately 540 pixels in diameter. The images are in compressed JPEG format, which is unfortunate for image processing but is commonly used in screening practice.

The 40 images have been divided into a training and test set, each containing 20 images (the training set has three images with pathology). They have been manually segmented by three observers trained by an ophthalmologist. The images in the training set were segmented once, while images in the test set were segmented twice, resulting in sets A and $\mathrm{B}$. The observers of sets A and B produced similar segmentations. In set A, 12.7\% of pixels where marked as vessel, against $12.3 \%$ vessel for set B. Performance is measured on the test set using the segmentations of set $\mathrm{A}$ as ground truth. The segmentations of set $\mathrm{B}$ are tested against those of $\mathrm{A}$, serving as a human observer reference for performance comparison.

The STARE database consists of 20 digitized slides captured by a TopCon TRV-50 fundus camera at $35^{\circ} \mathrm{FOV}$. The slides were digitized to $700 \times 605$ pixels, eight bits per color channel. The FOV in the images are approximately $650 \times 550$ pixels in diameter. Ten of the images contain pathology. Two observers manually segmented all images. The first observer segmented $10.4 \%$ of pixels as vessel, against $14.9 \%$ vessels for the second 
observer. The segmentations of the two observers are fairly different in that the second observer segmented much more of the thinner vessels than the first one. Performance is computed with the segmentations of the first observer as ground truth.

\section{B. General Framework}

The image pixels of a fundus image are viewed as objects represented by feature vectors, so that we may apply statistical classifiers in order to segment the image. In this case, two classes are considered, i.e., vessel and nonvessel pixels. The training set for the classifier is derived using manual segmentations of training images, i.e., pixels segmented by hand are labeled as vessel while the remaining pixels are labeled as nonvessel. This approach allows us to integrate information from wavelet responses at multiple scales, accounting for vessels of different widths, in order to distinguish pixels from each class.

\section{Pixel Features}

When the RGB components of the colored images are visualized separately, the green channel shows the best vessel/background contrast [Fig. 1(a)], whereas the red and blue channels show low contrast and are very noisy [27]. Therefore, the green channel was selected to be processed by the wavelet, as well as to compose the feature vector itself, i.e., the green channel intensity of each pixel is taken as one of its features.

1) Preprocessing: In order to reduce false detection of the border of the camera's aperture by the wavelet transform, an iterative algorithm has been developed. Our intent is to remove the strong contrast between the retinal fundus and the region outside the aperture (see Fig. 1).

The preprocessing algorithm starts with a region of interest (ROI) determined by the camera's aperture and iteratively grows this ROI. Each step of the algorithm consists in the following. First, the set of pixels of the exterior border of the ROI is determined, i.e., pixels that are outside the ROI and are neighbors (using four-neighborhood) to pixels inside it. Then, each pixel value of this set is replaced with the mean value of its neighbors (this time using eight-neighborhood) inside the ROI. Finally, the ROI is expanded by inclusion of this altered set of pixels. This process is repeated and can be seen as artificially increasing the ROI, as shown in Fig. 1(b).

The green channel is inverted before the application of the wavelet transform to it, so that the vessels appear brighter than the background.

2) Wavelet Transform Features: The notation and definitions in this section follow [46]. The real plane $\mathbb{R} \times \mathbb{R}$ is denoted as $\mathbb{R}^{2}$, and the vectors are represented as bold letters, e.g., $\mathbf{x}, \mathbf{b} \in$ $\mathbb{R}^{2}$. Let $f \in L^{2}$ be an image represented as a square integrable (i.e., finite energy) function defined over $\mathbb{R}^{2}$ and $\psi \in L^{2}$ be the analyzing (or mother) wavelet. A family of wavelets $\left\{\psi_{\mathbf{b}, \theta, \mathbf{a}}\right\}$ can be defined by translations, rotations and dilations (by $\mathbf{b}, \theta$ and $a$, respectively) of the analyzing wavelet. The continuous wavelet transform $T_{\psi}(\mathbf{b}, \theta, a)$ is defined in terms of the scalar product of $f$ with the transformed wavelet $\psi_{\mathbf{b}, \theta, \mathbf{a}}$

$$
\begin{aligned}
T_{\psi}(\mathbf{b}, \theta, a) & =C_{\psi}^{-1 / 2}\left\langle\psi_{\mathbf{b}, \theta, a} \mid f\right\rangle \\
& =C_{\psi}^{-1 / 2} a^{-1} \int \psi^{*}\left(a^{-1} r_{-\theta}(\mathbf{x}-\mathbf{b})\right) f(\mathbf{x}) d^{2} \mathbf{x}
\end{aligned}
$$

where $C_{\psi}, \psi, \mathbf{b}, \theta$, and $a$ denote the normalizing constant, analyzing wavelet, the displacement vector, the rotation angle, and the dilation parameter (also known as scale), respectively. $\psi^{*}$ denotes the complex conjugate of $\psi$. The wavelet transform can be easily implemented using the fast Fourier transform algorithm and the equivalent Fourier definition of the wavelet transform [43]

$T_{\psi}(\mathbf{b}, \theta, a)=C_{\psi}^{-1 / 2} a \int \exp (j \mathbf{k b}) \hat{\psi}^{*}\left(a r_{-\theta} \mathbf{k}\right) \hat{f}(\mathbf{k}) d^{2} \mathbf{k}$

where $j=\sqrt{-1}$, and the hat (i.e., $\hat{\psi}^{*}$ and $\hat{f}$ ) denotes a Fourier transform.

The transform conserves energy and provides a linear decomposition of $f$ in terms of the family of analyzing wavelets $\left\{\psi_{\mathbf{b}, \theta, \mathbf{a}}\right\}$, with coefficients $T_{\psi}(\mathbf{b}, \theta, a)$. Combining the conditions for both the analyzing wavelet and its Fourier transform of being well localized in the time and frequency domains plus the requirement of having zero mean, one realizes that the wavelet transform provides a local filtering at a constant rate $\Delta k / k$, indicating its great efficiency as the frequency increases, i.e., as the scale decreases. This property is what makes the wavelet effective for detection and analysis of localized properties and singularities [43], such as the blood vessels in the present case.

Among several available analyzing wavelets, for instance, the 2-D Mexican hat and the optical wavelet, we chose the 2-D Gabor wavelet for the purposes of this work, due to its directional selectiveness capability of detecting oriented features and fine tuning to specific frequencies [43], [46]. This latter property is especially important in filtering out the background noise of the fundus images. The 2-D Gabor wavelet is defined as

$$
\psi_{G}(\mathbf{x})=\exp \left(j \mathbf{k}_{\mathbf{0}} \mathbf{x}\right) \exp \left(-\frac{1}{2}|A \mathbf{x}|^{2}\right)
$$

where $A=\operatorname{diag}\left[\epsilon^{-1 / 2}, 1\right], \epsilon \geq 1$ is a $2 \times 2$ diagonal matrix that defines the anisotropy of the filter, i.e., its elongation in any desired direction. The Gabor wavelet is actually a complex exponential modulated Gaussian, where $\mathbf{k}_{0}$ is a vector that defines the frequency of the complex exponential.

We have set the $\epsilon$ parameter to 4, making the filter elongated and $\mathbf{k}_{\mathbf{0}}=[0,3]$, i.e., a low-frequency complex exponential with few significant oscillations perpendicular to the large axis of the wavelet, as shown in Fig. 2. These two characteristics are specially suited for the detection of directional features and have been chosen in order to enable the transform to present stronger responses for pixels associated with the blood vessels.

For each pixel position and considered scale value, we are interested in the response with maximum modulus over all possible orientations, i.e.,

$$
M_{\psi}(\mathbf{b}, a)=\max _{\theta}\left|T_{\psi}(\mathbf{b}, \theta, a)\right| .
$$

Thus, the Gabor wavelet transform is computed for $\theta$ spanning from 0 up to $170^{\circ}$ at steps of $10^{\circ}$ and the maximum is taken (this is possible because $\left.\left|T_{\psi}(\mathbf{b}, \theta, a)\right|=\left|T_{\psi}(\mathbf{b}, \theta+180, a)\right|\right)$. The maximum modulus of the wavelet transform over all angles 


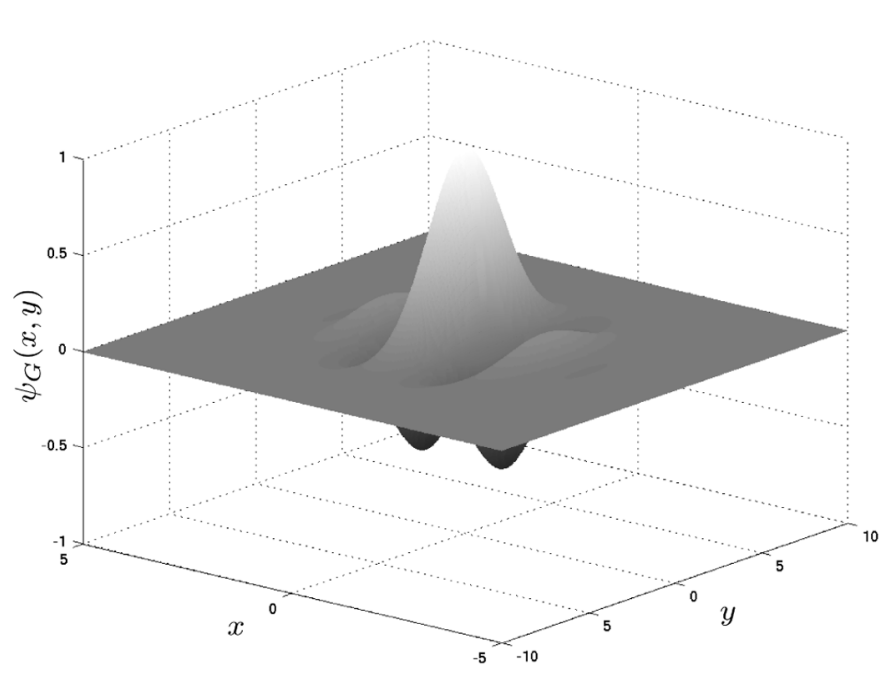

(a)

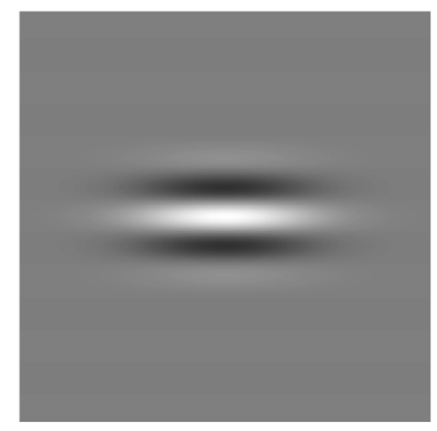

(b)

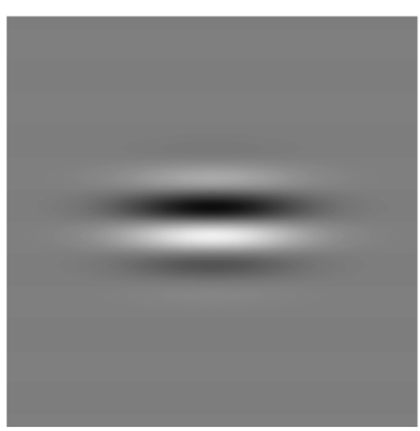

(c)
Fig. 2. Different representations for the 2-D Gabor wavelet $\left(\psi_{G}\right)$ with parameters $\epsilon=4$ and $\mathbf{k}_{0}=[0,3]$. (a) Surface representation of the real part. (b) Real part. (c) Imaginary part.

for multiple scales are then taken as pixel features. $M_{\psi}(\mathbf{b}, a)$ is shown in Fig. 3 for $a=2$ and $a=4$ pixels.

3) Feature Normalization: Given the dimensional nature of the features forming the feature space, one must bear in mind that this might give rise to errors in the classification process, as the units chosen might affect the distance in the feature space.

A strategy to obtain a new random variable with zero mean and unit standard deviations, leading to dimensionless features, is to apply the normal transformation to the feature space. The normal transformation is defined as [40]

$$
\hat{v}_{i}=\frac{v_{i}-\mu_{i}}{\sigma_{i}}
$$

where $v_{i}$ is the $i$ th feature assumed by each pixel, $\mu_{i}$ is the average value of the $i$ th feature, and $\sigma_{i}$ is the associated standard deviation.

We have applied the normal transformation separately to each image's feature space, i.e., every image's feature space is normalized by its own means and standard deviations,

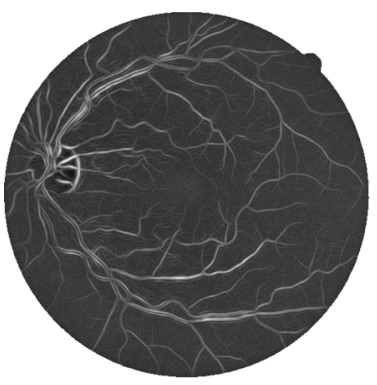

(a)

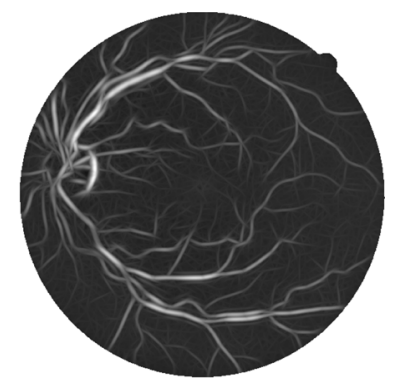

(b)
Fig. 3. Maximum modulus of Gabor wavelet transform over angles, $M_{\psi}(\mathbf{b}, a)$ (3), for scale values of $a=2$ and $a=4$ pixels. Remaining parameters are fixed at $\epsilon=4$ and $\mathbf{k}_{0}=[0,3]$. (a) $M_{\phi}(\mathbf{b}, 2)$. (b) $M_{\phi}(\mathbf{b}, 4)$.

helping to compensate for intrinsic variation between images (e.g., illumination).

\section{Supervised Classification for Segmentation}

Supervised classification has been applied to obtain the final segmentation, with the pixel classes defined as $C_{1}=\{$ vessel pixels $\}$ and $C_{2}=$ \{nonvessel pixels $\}$. Several fundus images have been manually segmented, allowing the creation of a labeled training set into classes $C_{1}$ and $C_{2}$ (see Subsection II-A). Due to the computational cost of training the classifier and the large number of samples, we randomly select a subset of the available samples to actually use for training.

We have achieved very good results using a Bayesian classifier in which each class-conditional probability density function (likelihood) is described as a linear combination of Gaussian functions [47], [48]. We will call this the Gaussian mixture model (GMM) classifier.

To obtain a decision rule based on estimates from our training set, we use Bayes decision rule, which can be stated as

$$
\begin{aligned}
& \text { Decide } C_{1} \text { if } p\left(\mathbf{v} \mid C_{1}\right) P\left(C_{1}\right)>p\left(\mathbf{v} \mid C_{2}\right) P\left(C_{2}\right) ; \\
& \text { otherwise, decide } C_{2}
\end{aligned}
$$

where $p\left(\mathbf{v} \mid C_{i}\right)$ is the class-conditional probability density function, also known as likelihood, and $P\left(C_{i}\right)$ is the prior probability of class $C_{i}$.

We estimate $P\left(C_{i}\right)$ as $N_{i} / N$, the ratio of class $C_{i}$ samples in the training set. The class likelihoods are described as linear combinations of Gaussian functions

$$
p\left(\mathbf{v} \mid C_{i}\right)=\sum_{j=1}^{k_{i}} p\left(\mathbf{v} \mid j, C_{i}\right) P_{i j}
$$

where $k_{i}$ is the number of Gaussians modeling $p\left(\mathbf{v} \mid C_{i}\right)$ and each $p\left(\mathbf{v} \mid j, C_{i}\right)$ is a $d$-dimensional Gaussian distribution of weight $P_{i j}$, with $d$ being the dimension of the feature space.

For each class $C_{i}$, given the number $k_{i}$ of Gaussians, we can estimate the $k_{i}$ Gaussian parameters and weights with the expectation-maximization (EM) algorithm [47]. The EM algorithm is an iterative scheme that guarantees a local maximum of the likelihood of the training data.

GMMs represent a halfway between purely nonparametric and parametric models, providing a fast classification phase at 
the cost of a more expensive training algorithm. Nonparametric methods are computationally demanding for large numbers of training samples, though they do not impose restrictions on the underlying probability distributions. On the other hand, GMMs guarantee a fast classification phase that depends only on the chosen $k_{i}$ (i.e., independent of the number of training samples), while still allowing for modeling complex probability distributions.

\section{E. Experimental Evaluation}

We have tested our methods on the DRIVE and STARE databases with the following settings. The pixel features used for classification were the inverted green channel and its maximum Gabor transform response over angles $M_{\psi}(\mathbf{b}, a)(3)$ for scales $a=2,3,4,5$ pixels (see Section II-C). These scales were chosen as to span the possible widths of vessels throughout the images, so that all vessels could be detected.

For the DRIVE database, the training set was formed by pixel samples from the 20 labeled training images. For the STARE database, leave-one-out tests where performed, i.e., every image is segmented using samples from the other 19 images for the training set. Due to the large number of pixels, in all experiments, one million pixel samples where randomly chosen to train the classifier. Tests were performed varying the number $k=k_{1}=k_{2}$ of vessel and nonvessel Gaussians modeling each class likelihood of the GMM classifier.

To demonstrate the performance of the Gabor wavelet in enhancing blood vessels, we also present results of filtering using a single wavelet scale and compare them with results of the matched filter of Chaudhuri et al. [23]. The parameters of both filters were chosen as to produce the best results: $a=4$ pixels for wavelet filtering and $\sigma=1$ pixel for the matched filter of Chaudhuri et al.

The performances are measured using ROC curves. ROC curves are plots of true positive fractions versus false positive fractions for varying thresholds on the posterior probabilities. A pair formed by a true positive fraction and a false positive fraction is plotted on the graph for each threshold value (as explained below), producing a curve as in Figs. 4 and 5. The true positive fraction is determined by dividing the number of true positives by the total number of vessel pixels in the ground truth segmentations, while the false positive fraction is the number of false positives divided by the total number of nonvessel pixels in the ground truth. In our experiments, these fractions are calculated over all test images, considering only pixels inside the FOV. For the GMM classifier, the ROC curve is produced by varying the threshold on the posterior pixel probabilities, while the curves for filtering using a single wavelet scale and the matched filter of Chaudhuri et al. are produced varying the threshold on the filters' responses.

We also present the values of the areas under the ROC curves and accuracies of the methods of Jiang et al. [25] and Staal et al. [1], though we did not perform hypothesis tests to state which methods are better, because we do not have enough data from previous results to analyze the variances.

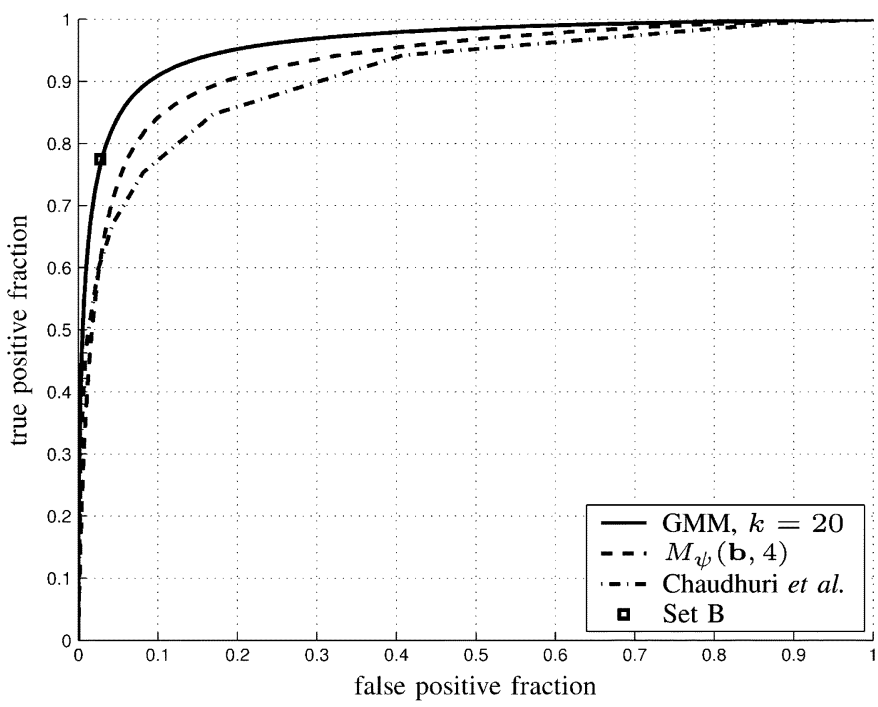

Fig. 4. ROC curve for classification on the DRIVE database using the GMM classifier with $k=20$, filtering using a single Gabor wavelet scale $\left(M_{\psi}(\mathbf{b}, 4)\right)$, and the matched filter of Chaudhuri et al. Point marked as $\square$ corresponds to set $\mathrm{B}$, the second set of manual segmentations. GMM classifier has $A_{z}=0.9614$.

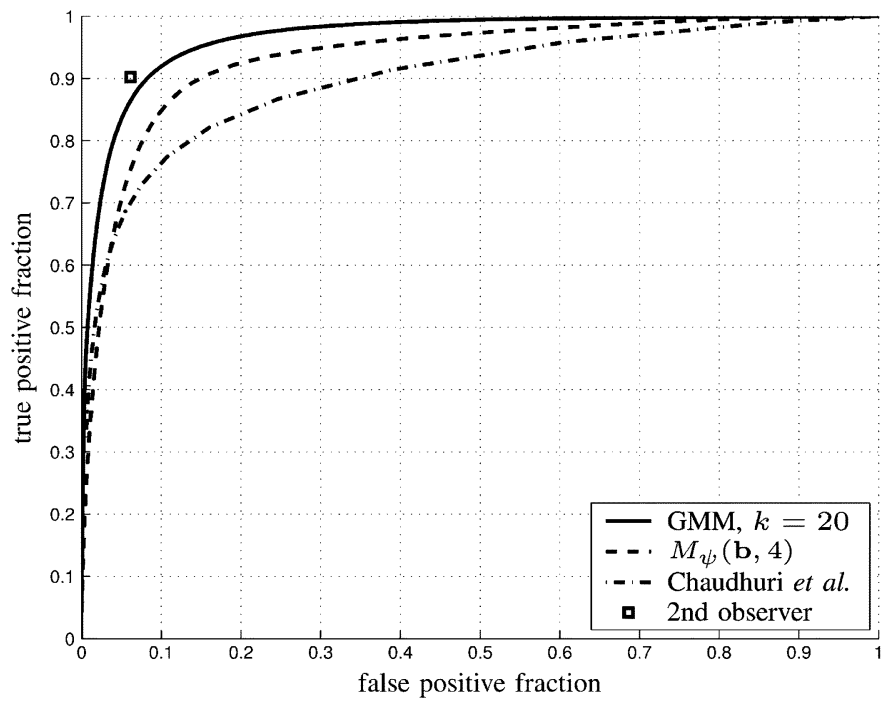

Fig. 5. ROC curve for classification on the STARE database using the GMM classifier with $k=20$, filtering using a single Gabor wavelet scale $\left(M_{\psi}(\mathbf{b}, 4)\right)$, and the matched filter of Chaudhuri et al. Point marked as $\square$ corresponds to the second observer's manual segmentations. GMM classifier has $A_{z}=0.9671$.

\section{RESULTS}

Illustrative segmentation results for a pair of images from each database (produced by the GMM classifier with $k=20$ ), along with the manual segmentations, are shown in Figs. 6 and 7.

For the DRIVE database, the manual segmentations from set $\mathrm{A}$ are used as ground truth and the human observer performance is measured using the manual segmentations from set $\mathrm{B}$, which provide only one true/false positive fraction pair, appearing as a point in the ROC graph (Fig. 4). For the STARE database, the first observer's manual segmentations are used as ground truth, and the second observer's true/false positive 

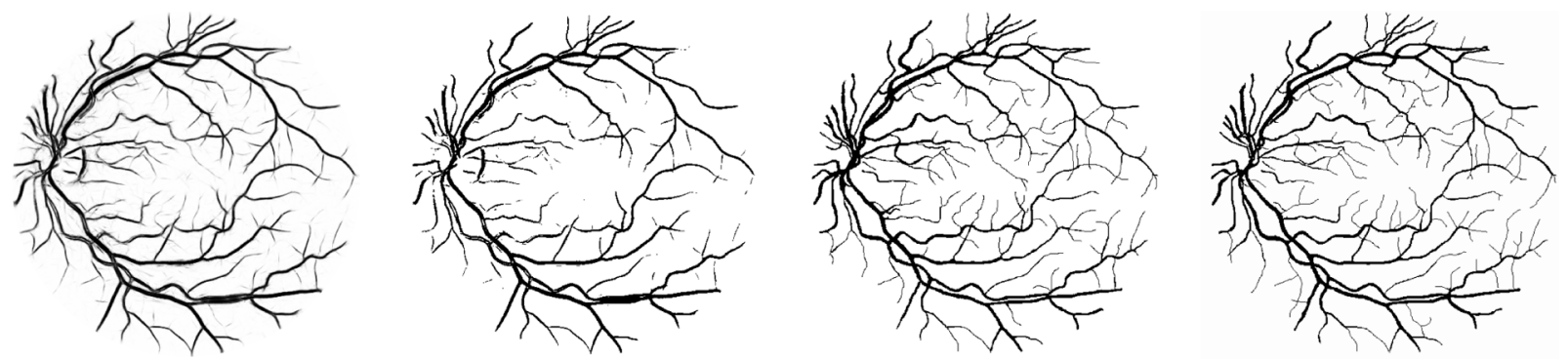

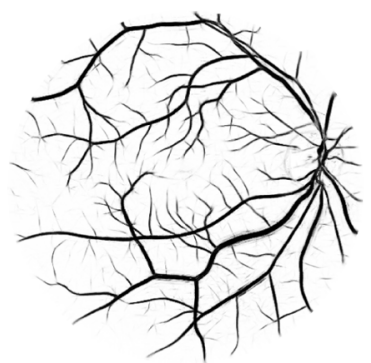

(a)

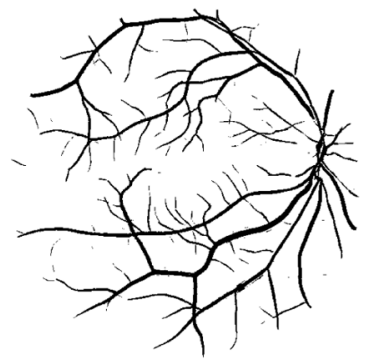

(b)

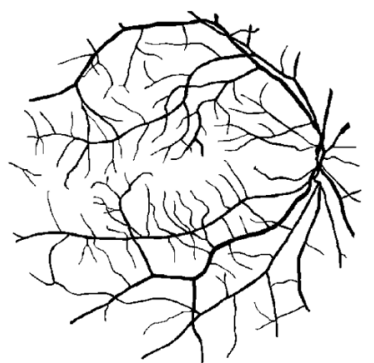

(c)

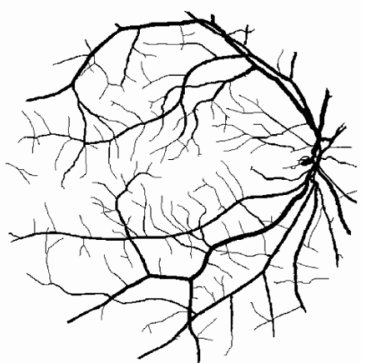

(d)

Fig. 6. Results produced by the GMM classifier with $k=20$ and manual segmentations (sets A and B) for two images from the DRIVE database. Top row results are for the image shown in Fig. 1(a). (a) Posterior probabilities. (b) Segmentation. (c) Set A. (d) Set B.
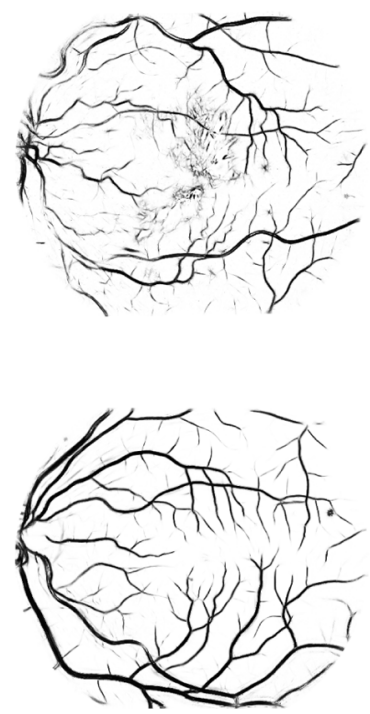

(a)
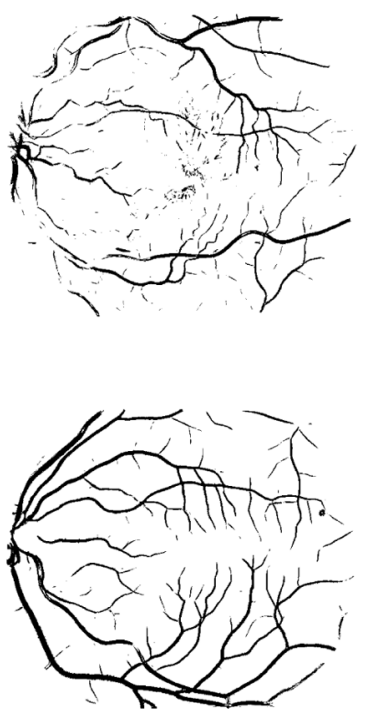

(b)
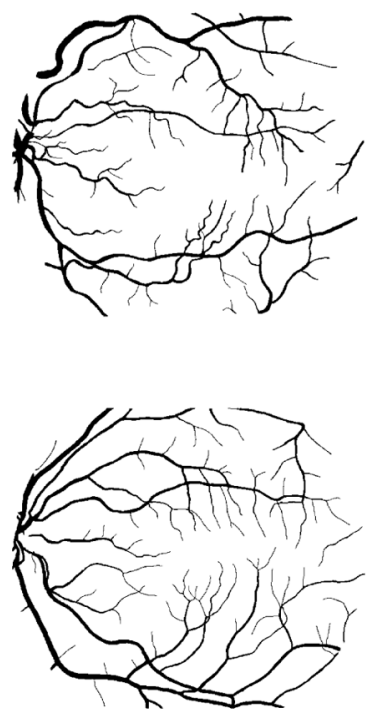

(c)
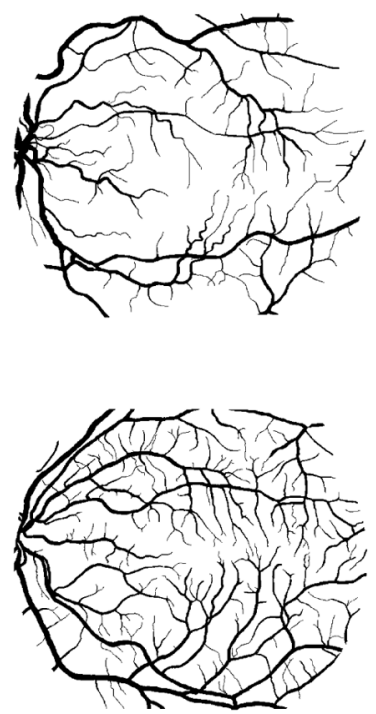

(d)

Fig. 7. Results produced by the GMM classifier with $k=20$ and manual segmentations for two images from the STARE database. Top row images originate from a pathological case, while the bottom ones originate from a normal case. (a) Posterior probabilities. (b) Segmentation. (c) First observer. (d) Second observer.

fraction pair is plotted on the ROC graph (Fig. 5). The closer an ROC curve approaches the top left corner, the better the performance of the method. A system that agreed completely with the ground truth segmentations would yield an area under the ROC curve $A_{z}=1$. However, note that the manual segmentations evaluated do not produce perfect true/false positive fractions, for they disagree on some of the pixels with the manual segmentations used as ground truth. Thus, the variance between observers can be estimated, helping to set a goal for the method's performance.

The areas under the ROC curves $\left(A_{z}\right)$ are used as a single measure of the performance of each method and are shown in
Table I for the following methods: GMM classifiers of varying $k$; filtering using a single Gabor wavelet scale; our implementation of the matched filter of Chaudhuri et al. and the methods of Jiang et al. and Staal et al., as published in [1]. For comparison with the manual segmentations, we also measure the accuracies (fraction of correctly classified pixels) of the automatic and manual segmentations. Note that the accuracy and $A_{z}$ values for the GMM classifier increase with $k$. The ROC curves for the DRIVE and STARE databases produced using the GMM classifier with $k=20$, filtering using a single Gabor wavelet scale, the matched filter of Chaudhuri et al., as well as performances for human observers, are shown in Figs. 4 and 5. 
TABLE I

RESUlts For DifFERENT Segmentation Methods AND A SECOND Human OBSERVER. $A_{z}$ Indicates the AREa Under the ROC CURVE, WHILE THE ACCURACY IS THE FRACTION OF PIXELS CORRECTLY CLASSIFIED

\begin{tabular}{|c|c|c|c|c|}
\hline \multirow{3}{*}{ Segmentation Method } & \multicolumn{4}{|c|}{ Database } \\
\hline & \multicolumn{2}{|c|}{ DRIVE } & \multicolumn{2}{|c|}{ STARE } \\
\hline & $A_{z}$ & Accuracy & $\overline{A_{z}}$ & Accuracy \\
\hline GMM, $k=1$ & 0.9283 & 0.9218 & 0.9409 & 0.9243 \\
\hline GMM, $k=5$ & 0.9546 & 0.9413 & 0.9618 & 0.9431 \\
\hline GMM, $k=10$ & 0.9588 & 0.9447 & 0.9651 & 0.9467 \\
\hline GMM, $k=15$ & 0.9605 & 0.9460 & 0.9666 & 0.9476 \\
\hline GMM, $\mathrm{k}=\mathbf{2 0}$ & 0.9614 & 0.9466 & 0.9671 & 0.9480 \\
\hline$M_{\psi}(\mathbf{b}, 4)$ & 0.9312 & & 0.9351 & \\
\hline Chaudhuri et al. & 0.9103 & & 0.8987 & \\
\hline Jiang et al. & 0.9327 & 0.8911 & 0.9298 & 0.9009 \\
\hline Staal et al. & 0.9520 & 0.9441 & 0.9614 & 0.9516 \\
\hline 2nd. observer & & 0.9473 & & 0.9349 \\
\hline
\end{tabular}

We note that the EM training process for the GMMs is computationally more expensive as $k$ increases, but can be done offline, while the classification phase is fast. The process of feature generation is basically the calculation of the wavelet coefficients, which is done by a series of correlations. By using the fast Fourier transform and the Fourier definition of the wavelet transform (1), these are done in $O\left(N \log _{2} N\right)$, where $N$ is the total number of image pixels [49]. Since the dimension of the feature space and the number of Gaussians modeling each class likelihood are fixed, classification of an image's pixel feature vectors is also fast, taking time $O(N)$. We have used a straightforward MATLAB implementation for tests. On an AMD Athlon XP $2700+$ PC (2167 MHz clock) with 1-GB memory, estimation of the GMM parameters for one million training samples and $k=20$ (using a nonoptimized EM algorithm) takes up to $9 \mathrm{~h}$, though this would speed up considerably with an efficient implementation. Feature generation for an image from the DRIVE or STARE database takes about $3 \mathrm{~min}$, while the classification of its pixels with $k=20$ takes less than $10 \mathrm{~s}$. We are making all our results and implementation code (in the form of open source MATLAB scripts) publicly available to researchers interested in implementation details, evaluation or development of methods. ${ }^{2}$

\section{DISCUSSION AND CONCLUSION}

The Gabor transform shows itself efficient in enhancing vessel contrast, while filtering out noise. Information from Gabor transforms at different scales, which allows the segmentation of vessels of different diameters, are integrated through the use of the statistical classifier presented. The GMM classifier has a computationally demanding training phase, but guarantees a fast classification phase and good performance. Furthermore, the methods presented are conceptually simple and can be implemented efficiently.

The classification framework demands the use of manual labelings, but allows the methods to be trained for different types of images (such as gray-level angiograms or colored images, provided the corresponding manual segmentations are available), possibly adjusted to specific camera or lighting conditions and are otherwise automatic, i.e., adjustment of

\footnotetext{
${ }^{2}$ Available online at http://retina.iv.fapesp.br.
}
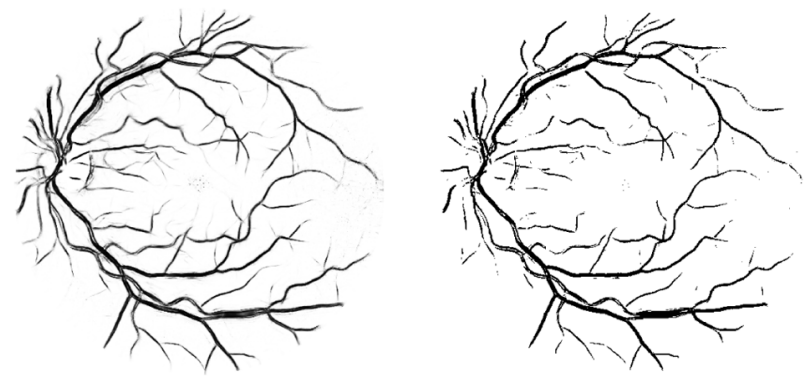

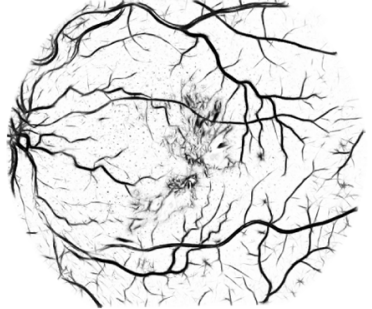

(a)

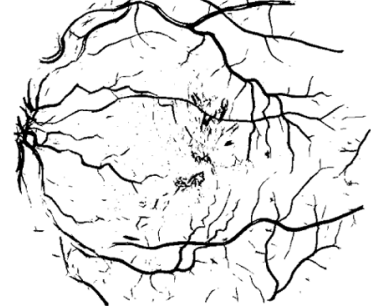

(b)
Fig. 8. Results produced by training the GMM classifier with $k=20$ on each of the STARE and DRIVE databases while testing it on the other. Top row results are from the image shown in Fig. 1(a) and Fig. 6 and the bottom ones originate from the pathological case that is also shown in Fig. 7. Note that the thinnest vessels of the top row image are poorly detected, whereas the bottom results present increased false positives on noise and pathological features. (a) Posterior probabilities. (b) Segmentation.

parameters or user interaction is not necessary. To verify the dependence of the method on the training set, we have performed experiments training the classifier with each of the STARE and DRIVE databases while testing it on the other. The results obtained are slightly worse visually and with respect to ROC analysis, as illustrated in Fig. 8. Though the databases are similar, there is a difference in the typical vessel widths found in each database's images, which contributed significantly to the performance loss. While the performance difference is not large, this shows that even for the simple vessel structures there is a certain dependence of the method on the training set. We are studying the use of training sets composed of a small portion of the image to be segmented. Using this approach, a semi-automated fundus segmentation software may be developed, in which the operator only has to draw a small portion of the vessels over the input image or simply click on several pixels associated with the vessels. The remaining image would then be segmented based on the partial training set. This approach is interesting since it requires a small effort from the operator, which is compensated by the fact that image peculiarities are directly incorporated by the classifier.

It is curious to note that, on the STARE database, the accuracy of the method is higher than that of the second observer (Table I). The second observer's manual segmentations contain much more of the thinnest vessels than the first observer (lowering their accuracy), while the method, trained by the first observer, is able to segment the vessels at a similar rate. However, the ROC graph (Fig. 5) still reflects the higher precision of the second observer, due to some difficulties found by the method, as discussed below. 
It is possible to use only the skeleton of the segmentations for the extraction of shape features from the vasculature. Depending on the application, different evaluation methods become more appropriate [50]. For example, the evaluation of the skeleton would not take into account the width of the vessels, but could measure other qualities such as the presence of gaps and detection of branching points. Another interesting form of evaluation would be directly through an application, such as in detection of neovascularization by means of analysis and classification of the vessel structure [33]. A major difficulty in evaluating the results is the establishment of a reliable ground truth [51]. Human observers are subjective and prone to errors, resulting in large variability between observations. Thus, it is desirable that multiple human-generated segmentations be combined to establish a ground truth, which was not the case in the analysis presented.

Though very good ROC results are presented, visual inspection shows some typical difficulties of the method that must be solved by future work. The major errors are in false detection of noise and other artifacts. False detection occurs in some images for the border of the optic disc, haemorrhages and other types of pathologies that present strong contrast. Also, the method did not perform well for very large variations in lighting throughout an image, but this occurred for only one image out of the 40 tested from both databases. This could possibly be solved by including intraimage normalization in the preprocessing phase [52]. Another difficulty is the inability to capture some of the thinnest vessels that are barely perceived by the human observers.

Another drawback of our approach is that it only takes into account information local to each pixel through image filters, ignoring useful information from shapes and structures present in the image. We intend to work on methods addressing this drawback in the near future. The results can be slightly improved through a postprocessing of the segmentations for removal of noise and inclusion of missing vessel pixels as in [34]. An intermediate result of our method is the intensity image of posterior probabilities, which could possibly benefit from a threshold probing as in [2] or region growing schemes.

Automated segmentation of fundus images provides the basis for automated assessment by community health workers. Skeletonized images of the vessel pattern of the ocular fundus can be analyzed mathematically using nonlinear methods such as global fractal [33] and local fractal [7] analysis based on the wavelet transform thus providing a numeric indicator of the extent of neovascularization. Our ongoing work aims at applying the shape analysis and classification strategies described in [33] to the segmented vessels produced by method described in this work.

\section{ACKNOWLEDGMENT}

The authors would like to thank J. J. Staal and colleagues and A. Hoover for making their databases publicly available, Dr. A. Luckie and C. McQuellin from the Albury Eye Clinic for providing fluorescein images used during our research, and P. Mani for running the tests of the Chaudhuri method as part of her B.E. degree final year project. The suggestions and comments of anonymous reviewers, which have helped in improving the paper, are also gratefully acknowledged.

\section{REFERENCES}

[1] J. J. Staal, M. D. Abràmoff, M. Niemeijer, M. A. Viergever, and B. van Ginneken, "Ridge based vessel segmentation in color images of the retina," IEEE Trans. Med. Imag., vol. 23, no. 4, pp. 501-509, Apr. 2004.

[2] A. Hoover, V. Kouznetsova, and M. Goldbaum, "Locating blood vessels in retinal images by piecewise threshold probing of a matched filter response," IEEE Trans. Med. Imag., vol. 19, no. 3, pp. 203-210, Mar. 2000.

[3] J. J. Kanski, Clinical Ophthalmology: A Systematic Approach. London, U.K.: Butterworth-Heinemann, 1989.

[4] E. J. Sussman, W. G. Tsiaras, and K. A. Soper, "Diagnosis of diabetic eye disease," J. Am. Med. Assoc., vol. 247, pp. 3231-3234, 1982.

[5] S. J. Lee, C. A. McCarty, H. R. Taylor, and J. E. Keeffe, "Costs of mobile screening for diabetic retinopathy: A practical framework for rural populations," Aust. J. Rural Health, vol. 8, pp. 186-192, 2001.

[6] H. R. Taylor and J. E. Keeffe, "World blindness: A 21st century perspective," Brit. J. Ophthalmol., vol. 85, pp. 261-266, 2001.

[7] C. P. McQuellin, H. F. Jelinek, and G. Joss, "Characterisation of fluorescein angiograms of retinal fundus using mathematical morphology: A pilot study," in Int. Conf. Ophthalmic Photogr., Adelaide, Australia, 2002 , p. 152.

[8] L. Streeter and M. J. Cree, "Microaneurysm detection in colour fundus images," in Image Vision Comput. New Zealand, Palmerston North, New Zealand, Nov. 2003, pp. 280-284.

[9] T. Y. Wong, W. Rosamond, P. P. Chang, D. J. Couper, A. R. Sharrett, L. D. Hubbard, A. R. Folsom, and R. Klein, "Retinopathy and risk of congestive heart failure," J. Amer. Med. Assoc., vol. 293, no. 1, pp. 63-69, 2005.

[10] M. Niemeijer, J. J. Staal, B. van Ginneken, M. Loog, and M. D. Abràmoff, "Comparative study of retinal vessel segmentation methods on a new publicly available database," in Proc. SPIE Med. Imag., J. M. Fitzpatrick and M. Sonka, Eds., 2004, vol. 5370, pp. 648-656.

[11] M. J. Cree, J. J. G. Leandro, J. V. B. Soares, R. M. Cesar-Jr, G. Tang, H. F. Jelinek, and D. J. Cornforth, "Comparison of various methods to delineate blood vessels in retinal images," presented at the 16th Nat. Cong. Austral. Inst. Phys., Canberra, Australia, 2005.

[12] I. Liu and Y. Sun, "Recursive tracking of vascular networks in angiograms based on the detection-deletion scheme," IEEE Trans. Med. Imag., vol. 12, no. 2, pp. 334-341, Jun. 1993.

[13] L. Zhou, M. S. Rzeszotarski, L. J. Singerman, and J. M. Chokreff, "The detection and quantification of retinopathy using digital angiograms," IEEE Trans. Med. Imag., vol. 13, no. 4, pp. 619-626, Dec. 1994.

[14] O. Chutatape, L. Zheng, and S. M. Krishnan, "Retinal blood vessel detection and tracking by matched Gaussian and Kalman filters," in Proc. 20th Annu. Int. Conf. IEEE Eng. Med. Biol. Soc. (EMBS'98), 1998, vol. 20, pp. 3144-3149.

[15] Y. A. Tolias and S. M. Panas, "A fuzzy vessel tracking algorithm for retinal images based on fuzzy clustering," IEEE Trans. Med. Imag., vol. 17, no. 2, pp. 263-273, Apr. 1998.

[16] A. Can, H. Shen, J. N. Turner, H. L. Tanenbaum, and B. Roysam, "Rapid automated tracing and feature extraction from retinal fundus images using direct exploratory algorithms," IEEE Trans. Inf. Technol. Biomed., vol. 3, no. 2, pp. 125-138, Jun. 1999.

[17] M. Lalonde, L. Gagnon, and M.-C. Boucher, "Non-recursive paired tracking for vessel extraction from retinal images," Vision Interface, pp. 61-68, 2000.

[18] X. Gao, A. Bharath, A. Stanton, A. Hughes, N. Chapman, and S. Thom, "A method of vessel tracking for vessel diameter measurement on retinal images," in Proc. ICIP'01, 2001, pp. II: 881-884.

[19] T. McInerney and D. Terzopoulos, "T-snakes: Topology adaptive snakes," Med. Image Anal., vol. 4, pp. 73-91, 2000.

[20] R. Toledo, X. Orriols, X. Binefa, P. Radeva, J. Vitrià, and J. Villanueva, "Tracking of elongated structures using statistical snakes," in IEEE Comput. Soc. Conf. Comput. Vision Pattern Recog. (CVPR), 2000, vol. 1, p. 1157.

[21] A. Vasilevskiy and K. Siddiqi, "Flux maximizing geometric flows," IEEE Trans. Pattern Anal. Mach. Intell., vol. 24, no. 12, pp. 1565-1578, Dec. 2002.

[22] D. Nain, A. Yezzi, and G. Turk, "Vessel segmentation using a shape driven flow," in Med. Image Comput. Comput.-Assist. Intervention-MICCAI, 2004, pp. 51-59.

[23] S. Chaudhuri, S. Chatterjee, N. Katz, M. Nelson, and M. Goldbaum, "Detection of blood vessels in retinal images using two-dimensional matched filters," IEEE Trans. Med. Imag., pp. 263-269, 1989. 
[24] L. Gang, O. Chutatape, and S. M. Krishnan, "Detection and measurement of retinal vessels in fundus images using amplitude modified second-order Gaussian filter," IEEE Trans. Biomed. Eng., vol. 49, no. 2, pp. 168-172, Feb. 2002.

[25] X. Jiang and D. Mojon, "Adaptive local thresholding by verificationbased multithreshold probing with application to vessel detection in retinal images," IEEE Trans. Pattern Anal. Mach. Intell., vol. 25, no. 1, pp. 131-137, Jan. 2003.

[26] J. Lowell, A. Hunter, D. Steel, A. Basu, R. Ryder, and R. Kennedy, "Measurement of retinal vessel widths from fundus images based on 2-D modeling," IEEE Trans. Med. Imag., vol. 23, no. 10, pp. 1196-1204, Oct. 2004.

[27] F. Zana and J.-C. Klein, "Segmentation of vessel-like patterns using mathematical morphology and curvature evaluation," IEEE Trans. Image Process., vol. 10, no. 7, pp. 1010-1019, Jul. 2001.

[28] B. Fang, W. Hsu, and M. Lee, "Reconstruction of vascular structures in retinal images," in Proc. ICIP'03, 2003, pp. II: 157-160.

[29] M. E. Martínez-Pérez, A. D. Hughes, A. V. Stanton, S. A. Thom, A. A. Bharath, and K. H. Parker, "Retinal blood vessel segmentation by means of scale-space analysis and region growing," in Med. Image Comput. Computer-Assist. Intervention - Proc. PMICCAI, 1999, pp. 90-97.

[30] R. Nekovei and Y. Sun, "Back-propagation network and its configuration for blood vessel detection in angiograms," IEEE Trans. Neural Netw., vol. 6, no. 1, pp. 64-72, Jan. 1995.

[31] C. Sinthanayothin, J. Boyce, and C. T. Williamson, "Automated localisation of the optic disc, fovea, and retinal blood vessels from digital colour fundus images," Br. J. Ophthalmol., vol. 83, pp. 902-910, 1999.

[32] J. J. G. Leandro, R. M. Cesar, Jr., and H. Jelinek, "Blood vessels segmentation in retina: Preliminary assessment of the mathematical morphology and of the wavelet transform techniques," in Proc. 14th IEEE Comput. Soc. Brazil. Symp. Comput. Graph. Image Process. (SIBGRAPI), 2001, pp. 84-90.

[33] H. F. Jelinek and R. M. Cesar, Jr., "Segmentation of retinal fundus vasculature in non-mydriatic camera images using wavelets," in Angiography and Plaque Imaging: Advanced Segmentation Techniques, J. Suri and T. Laxminarayan, Eds. Boca Raton, FL: CRC, 2003, pp. 193-224.

[34] J. J. G. Leandro, J. V. B. Soares, R. M. Cesar Jr., and H. F. Jelinek, "Blood vessels segmentation in non-mydriatic images using wavelets and statistical classifiers," in Proc. 16th Brazil. Symp. Comput. Graphics Image Process. (ISIBGRAPI), 2003, pp. 262-269.

[35] D. J. Cornforth, H. F. Jelinek, J. J. G. Leandro, J. V. B. Soares, R. M. Cesar-Jr, M. J. Cree, P. Mitchell, and T. Bossamaier, "Development of retinal blood vessel segmentation methodology using wavelet transforms for assessment of diabetic retinopathy," in Proc. 8th Asia Pacific Symp. Intell. Evolution. Syst., Cairns, Australia, 2004, pp. 50-60.

[36] J. V. B. Soares, J. J. G. Leandro, R. M. Cesar-Jr, H. F. Jelinek, and M. J. Cree, "Using the 2-D morlet wavelet with supervised classification for retinal vessel segmentation," presented at the 18th Brazil. Symp. Comput. Graphics Image Process. (SIBGRAPI), Oct. 9-12, 2005.
[37] O. Rioul and M. Vetterli, "Wavelets and signal processing," IEEE Signal Process. Mag., pp. 14-38, Oct. 1991.

[38] T. S. Lee, "Image representation using 2D Gabor wavelets," IEEE Trans. Pattern Anal. Mach. Intell., vol. 18, no. 10, pp. 959-971, Oct. 1996.

[39] B. S. Manjunath and W. Y. Ma, "Texture features for browsing and retrieval of image data," IEEE Trans. Pattern Anal. Mach. Intell., vol. 18, no. 8, pp. 837-842, Aug. 1996.

[40] L. F. Costa and R. M. Cesar-Jr, Shape Analysis and Classification: Theory and Practice. Boca Raton, FL: CRC, 2001.

[41] D. Van De Ville, T. Blu, and M. Unser, "Integrated wavelet processing and spatial statistical testing of fMRI data," NeuroImage, vol. 23, no. 4, pp. 1472-1485, Dec. 2004.

[42] A. Grossmann, "Wavelet transforms and edge detection," in Stochastic Processes Phys. Eng., S. Albeverio, P. Blanchard, M. Hazewinkel, and L. Streit, Eds. Dordrecht, The Netherlands: D. Reidel, 1988, pp. 149-157.

[43] J.-P. Antoine, P. Carette, R. Murenzi, and B. Piette, "Image analysis with two-dimensional continuous wavelet transform," Signal Process., vol. 31, pp. 241-272, 1993.

[44] R. S. Feris, V. Krueger, and R. M. Cesar-Jr, "A wavelet subspace method for real-time face tracking," Real-Time Imag., vol. 10, pp. 339-350, 2004.

[45] F. J. Ayres and R. M. Rangayyan, "Performance analysis of oriented feature detectors,", presented at the IEEE 18th Comput. Soc. Brazil. Symp. Comput. Graph. Image Process. (SIBGRAPI), Oct. 9-12, 2005

[46] A. Arnéodo, N. Decoster, and S. G. Roux, "A wavelet-based method for multifractal image analysis. I. Methodology and test applications on isotropic and anisotropic random rough surfaces," Eur. Phys. J. A, vol. 15, pp. 567-600, 2000.

[47] S. Theodoridis and K. Koutroumbas, Pattern Recognition, 1st ed. Burlington,, MA: Academic, 1999.

[48] R. O. Duda, P. E. Hart, and D. G. Stork, Pattern Classification. New York: Wiley, 2001.

[49] R. C. Gonzalez and R. E. Woods, Digital Image Processing, 2nd ed. Reading, MA: Addison-Wesley, 2002.

[50] K. W. Bowyer and P. J. Phillips, Empirical Evaluation Techniques in Computer Vision. Piscataway, NJ: IEEE Press, 1998.

[51] K. H. Fritzsche, A. Can, H. Shen, C.-L. Tsai, J. N. Turner, H. L. Tanenbaum, C. V. Stewart, and B. Roysam, "Automated model-based segmentation, tracing, and analysis of retinal vasculature from digital fundus images," in Angiography and Plaque Imaging: Advanced Segmentation Techniques, J. Suri and S. Laxminarayan, Eds. Boca Raton: CRC, 2003, pp. 225-297.

[52] M. J. Cree, E. Gamble, and D. Cornforth, "Colour normalisation to reduce inter-patient and intra-patient variability in microaneurysm detection in colour retinal images," in Proc. WDIC2005 ARPS Workshop Digital Image Comput., Brisbane, Australia, Feb. 2005, pp. 163-168. 


\section{Referências Bibliográficas}

Abdul-Karim, M.-A., Roysam, B., Dowell-Mesfin, N. M., Jeromin, A., Yuksel, M. e Kalyanaraman, S. (2005). Automatic selection of parameters for vessel/neurite segmentation algorithms. IEEE Transactions on Image Processing, 14(9):1338-1350.

American Academy of Ophthalmology (2000). Information statement: Eye care for people with diabetes mellitus. Disponível em http://www.medem.com. Acesso em: maio de 2006.

American Diabetes Association (2006). All about diabetes. Disponível em http://www.diabetes.org/ about-diabetes.jsp. Acesso em: maio de 2006.

Antoine, J.-P., Carette, P., Murenzi, R. e Piette, B. (1993). Image analysis with two-dimensional continuous wavelet transform. Signal Processing, 31:241-272.

Antoine, J.-P. e Murenzi, R. (1996). Two-dimensional directional wavelets and the scale-angle representation. Signal Processing, 52:259-281.

Antoine, J.-P., Murenzi, R. e Vandergheynst, P. (1999). Directional wavelets revisited: Cauchy wavelets and symmetry detection in patterns. Applied and Computational Harmonic Analysis, 6:314-345.

Antoine, J.-P., Vandergheynst, P., Bouyoucef, K. e Murenzi, R. (1995). Target detection and recognition using two-dimensional isotropic and anisotropic wavelets. In Proceedings of SPIE Conference Automatic Object Recognition V, volume 2485, páginas 20-31.

Argoul, F., Arnéodo, A., Elezgaray, J., Grasseau, G. e Murenzi, R. (1990). Wavelet analysis of the 
self-similarity of diffusion-limited aggregates and electrodeposition clusters. Physical Review A, 41(10):5537-5560.

Arnéodo, A., Decoster, N. e Roux, S. G. (2000). A wavelet-based method for multifractal image analysis. I. Methodology and test applications on isotropic and anisotropic random rough surfaces. The European Physical Journal B, 15:567-600.

Arrault, J. e Pouligny, B. (1996). Objective determination of branching angles in fractals. Journal de Physique I, 6:431-441.

Ayres, F. J. e Rangayyan, R. M. (2005). Performance analysis of oriented feature detectors. In Proc. of the 18th Brazilian Symposium on Computer Graphics and Image Processing - SIBGRAPI, páginas 147- 154. IEEE Computer Society.

Bilmes, J. (1997). A gentle tutorial on the EM algorithm and its application to parameter estimation for Gaussian Mixture and Hidden Markov Models. Technical Report TR-97-021, International Computer Science Institute, Berkeley, Califórnia.

Boelter, M. C., de Azevedo, M. J., Gross, J. L. e Lavinsky, J. (2003). Fatores de risco para retinopatia diabética. Arquivos Brasileiros de Oftalmologia, 66:239-247.

Bowyer, K. W. e Phillips, P. J., editores (1998). Empirical Evaluation Techniques in Computer Vision. IEEE Computer Society.

Boykov, Y. Y. e Jolly, M.-P. (2001). Interactive graph cuts for optimal boundary \& region segmentation of objects in N-D images. In International Conference on Computer Vision (ICCV), volume 1, páginas 105-112, Vancouver, Canadá.

Can, A., Shen, H., Turner, J. N., Tanenbaum, H. L. e Roysam, B. (1999). Rapid automated tracing and feature extraction from retinal fundus images using direct exploratory algorithms. IEEE Transactions on Information Technology in Biomedicine, 3(2):125-138. 
Cesar-Jr., R. M. e Jelinek, H. F. (2003). Segmentation of retinal fundus vasculature in non-mydriatic camera images using wavelets. In Suri, J. e Laxminarayan, T., editores, Angiography and Plaque Imaging: Advanced Segmentation Techniques, páginas 193-224. CRC Press.

Chaudhuri, S., Chatterjee, S., Katz, N., Nelson, M. e Goldbaum, M. (1989). Detection of blood vessels in retinal images using two-dimensional matched filters. IEEE Transactions on Medical Imaging, $8: 263-269$.

Chen, J., Sato, Y. e Tamura, S. (2000). Orientation space filtering for multiple orientation line segmentation. IEEE Transactions on Pattern Analysis and Machine Intelligence, 22:417-429.

Chutatape, O., Zheng, L. e Krishnan, S. M. (1998). Retinal blood vessel detection and tracking by matched Gaussian and Kalman filters. In Proc. of the 20th Annual International Conference of the IEEE Engineering in Medicine and Biology Society, (EMBS'98), volume 20, páginas 3144-3149.

Chwialkowski, M., Ibrahim, Y., Hong, F. e Peshock, R. (1996). A method for fully automated quantitative analysis of arterial flow using flow-sensitized MR images. Computerized Medical Imaging and Graphics, 20:365-378.

Cornforth, D. J., Jelinek, H. F., Leandro, J. J. G., Soares, J. V. B., Cesar-Jr., R. M., Cree, M. J., Mitchell, P. e Bossomaier, T. R. J. (2005). Development of retinal blood vessel segmentation methodology using wavelet transforms for assessment of diabetic retinopathy. Complexity International, 11. Disponível em http://www.complexity.org.au/ci/vol11/. Acesso em: maio de 2006.

Corrêa, Z. M. S. e Eagle, R. C. J. (2005). Aspectos patológicos da retinopatia diabética. Arquivos Brasileiros de Oftalmologia, 68:410-414.

Costa, L. F. e Cesar-Jr., R. M. (2001). Shape analysis and classification: theory and practice. CRC Press.

Cree, M. J., Gamble, E. e Cornforth, D. (2005a). Colour normalisation to reduce inter-patient and 
intra-patient variability in microaneurysm detection in colour retinal images. In WDIC2005 ARPS Workshop on Digital Image Computing, páginas 163-168, Brisbane, Austrália.

Cree, M. J., Leandro, J. J. G., Soares, J. V. B., Cesar-Jr., R. M., Tang, G., Jelinek, H. F. e Cornforth, D. J. (2005b). Comparison of various methods to delineate blood vessels in retinal images. In Proc. of the 16th National Congress of the Australian Institute of Physics, Canberra, Austrália. Disponível em http://aipcongress2005.anu.edu.au/index.php?req=CongressProceedings. Acesso em: maio de 2006.

Cree, M. J., Olson, J. A., McHardy, K. C., Sharp, P. F. e Forrester, J. V. (1999). The preprocessing of retinal images for the detection of fluorescein leakage. Physics in Medicine and Biology, 44:293-308.

Daubechies, I. (1992). Ten lectures on wavelets. Society for Industrial and Applied Mathematics, Filadélfia, PA, EUA.

Daugman, J. G. (1980). Two-dimensional spectral analysis of cortical receptive field profiles. Vision Research, 20:847-856.

Daugman, J. G. (1988). Complete discrete 2-D Gabor transforms by neural networks for image analysis and compression. IEEE Transactions on Acoustics, Speech, and Signal Processing, 36(7):1169-1179.

Dempster, A. P., Laird, N. M. e Rubin, D. B. (1977). Maximum likelihood from incomplete data via the EM algorithm. Journal of the Royal Statistical Society, Series B, 39(1):1-38.

Duda, R. O., Hart, P. E. e Stork, D. G. (2001). Pattern Classification. John Wiley and Sons.

Fang, B., Hsu, W. e Lee, M. (2003). Reconstruction of vascular structures in retinal images. In ICIP03, volume 2, páginas 157-160.

Farge, M. (1992). Wavelet transforms and their applications to turbulence. Annual Review of Fluid Mechanics, 24:395-457.

Fawcett, T. (2006). An introduction to ROC analysis. Pattern Recognition Letters, 27:861-874. 
Feris, R. S., Krueger, V. e Cesar-Jr., R. M. (2004). A wavelet subspace method for real-time face tracking. Real-Time Imaging, 10:339-350.

Ferrari, R. J., Rangayyan, R. M., Desautels, J. E. L. e Frere, A. F. (2001). Analysis of asymmetry in mammograms via directional filtering with Gabor wavelets. IEEE Transactions on Medical Imaging, 20:953-964.

Figueiredo, M. A. T. e Jain, A. K. (2002). Unsupervised learning of finite mixture models. IEEE Transactions on Pattern Analysis and Machine Intelligence, 24:381-396.

Frangi, A. F., Niessen, W. J., Vincken, K. L. e Viergever, M. A. (1998). Multiscale vessel enhancement filtering. In Medical Image Computing and Computer-assisted Intervention - MICCAI, volume 1496, páginas 130-137.

Free Software Foundation (1991). Gnu general public license. Disponível em http://www.gnu.org/ copyleft/gpl.html. Acesso em: julho de 2006.

Fritzsche, K. H., Can, A., Shen, H., Tsai, C.-L., Turner, J. N., Tanenbaum, H. L., Stewart, C. V. e Roysam, B. (2003). Automated model-based segmentation, tracing, and analysis of retinal vasculature from digital fundus images. In Suri, J. e Laxminarayan, S., editores, Angiography and Plaque Imaging: Advanced Segmentation Techniques, páginas 225-297. CRC Press.

Fukunaga, K. (1990). Introduction to Statistical Pattern Recognition. Academic Press, segunda edição.

Gabor, D. (1946). Theory of communication. Journal of the IEE, 93:429-457.

Gang, L., Chutatape, O. e Krishnan, S. M. (2002). Detection and measurement of retinal vessels in fundus images using amplitude modified second-order Gaussian filter. IEEE Transactions on Biomedical Engineering, 49(2):168-172.

Gao, X., Bharath, A., Stanton, A., Hughes, A., Chapman, N. e Thom, S. (2001). A method of vessel tracking for vessel diameter measurement on retinal images. In ICIP01, volume 2, páginas 881-884. 
Goatman, K. A., Whitwam, A. D., Manivannan, A., Olson, J. A. e Sharp, P. F. (2003). Colour normalisation of retinal images. In Proceedings of Medical Image Understanding and Analysis, páginas $49-52$.

Gonzalez, R. C. e Woods, R. E. (2002). Digital Image Processing. Addison-Wesley, segunda edição.

Goupillaud, P., Grossmann, A. e Morlet, J. (1984). Cycle-Octave and related transforms in seismic signal analysis. Geoexploration, 23:85-102.

Gray, H. (1918). Anatomy of the human body. Lea \& Febiger, Filadélfia, EUA. Bartleby.com, 2000. www. bartleby.com/107/, Acesso em: maio de 2006.

Greig, D., Porteous, B. e Seheult, A. (1989). Exact maximum a posteriori estimation for binary images. Journal of the Royal Statistical Society, Series B, 51(2):271-279.

Grossmann, A. (1988). Wavelet transforms and edge detection. In Albeverio, S., Blanchard, P., Hazewinkel, M. e Streit, L., editores, Stochastic Processes in Physics and Engineering, páginas 149-157. D. Reidel Publishing Company.

Grossmann, A. e Morlet, J. (1984). Decomposition of hardy functions into square integrable wavelets of constant shape. SIAM Journal on mathematical analysis, 15:723-736.

Hanley, J. A. e McNeil, B. J. (1982). The meaning and use of the area under a receiver operating characteristic (ROC) curve. Radiology, 143:29-36.

Harrop, J. D., Taraskin, S. N. e Elliott, S. R. (2002). Instantaneous frequency and amplitude identification using wavelets: Application to glass structure. Phys. Rev. E, 66(2):026703.

Hart, W. E., Goldbaum, M., Côté, B., Kube, P. e Nelson, M. R. (1999). Measurement and classification of retinal vascular tortuosity. International Journal of Medical Informatics, 53:239-252.

Hill, R. (1998). Retina identification. In Jain, A. K., Bolle, R. e Pankanti, S., editores, Biometrics: Personal Identification in Networked Society, páginas 123-141. Kluwer Academic Publishers. 
Hoover, A., Kouznetsova, V. e Goldbaum, M. (2000). Locating blood vessels in retinal images by piecewise threshold probing of a matched filter response. IEEE Transactions on Medical Imaging, 19:203-210.

Jelinek, H. F., Leandro, J. J. G., Cesar-Jr., R. M. e Cree, M. J. (2005). Classification of pathology in diabetic eye disease. In WDIC2005 ARPS Workshop on Digital Image Computing, páginas 9-13, Brisbane, Austrália.

Jiang, X. e Mojon, D. (2003). Adaptive local thresholding by verification-based multithreshold probing with application to vessel detection in retinal images. IEEE Transactions on Pattern Analysis and Machine Intelligence, 25(1):131-137.

Kanski, J. J. (1989). Clinical Ophthalmology: A systematic approach. Butterworth-Heinemann, Londres.

Kirbas, C. e Quek, F. (2004). A review of vessel extraction techniques and algorithms. ACM Comput. Surv., 36(2):81-121.

Klein, A., Lee, F. e Amini, A. A. (1997). Quantitative coronary angiography with deformable spline models. IEEE Transactions on Medical Imaging, 16:468-482.

Krueger, V. e Sommer, G. (2002). Gabor wavelet networks for face processing. Journal of the Optical Society of America, 19:1112-1119.

Lalonde, M., Gagnon, L. e Boucher, M.-C. (2000). Non-recursive paired tracking for vessel extraction from retinal images. In Proc. of the Conference Vision Interface 2000, páginas 61-68.

Leandro, J. J. G., M. Cesar-Jr., R. e Jelinek, H. F. (2001). Blood vessels segmentation in retina: Preliminary assessment of the mathematical morphology and of the wavelet transform techniques. In Proc. of the 14th Brazilian Symposium on Computer Graphics and Image Processing - SIBGRAPI, páginas 84-90. IEEE Computer Society.

Leandro, J. J. G., Soares, J. V. B., M. Cesar-Jr., R. e Jelinek, H. F. (2003). Blood vessels segmentation in non-mydriatic images using wavelets and statistical classifiers. In Proc. of the 16th Brazilian 
Symposium on Computer Graphics and Image Processing - SIBGRAPI, páginas 262-269. IEEE Computer Society Press.

Lee, S. J., McCarty, C. A., Taylor, H. R. e Keeffe, J. E. (2001). Costs of mobile screening for diabetic retinopathy: A practical framework for rural populations. Aust J Rural Health, 8:186-192.

Lee, T. S. (1996). Image representation using 2D Gabor wavelets. IEEE Transactions on Pattern Analysis and Machine Intelligence, 18(10):959-971.

Li, H., Hsu, W., Lee, M. L. e Wang, H. (2003). A piecewise Gaussian model for profiling and differentiating retinal vessels. In ICIP03, volume 1, páginas 1069-1072.

Liu, I. e Sun, Y. (1993). Recursive tracking of vascular networks in angiograms based on the detectiondeletion scheme. IEEE Transactions on Medical Imaging, 12(2):334-341.

Lowell, J., Hunter, A., Steel, D., Basu, A., Ryder, R. e Kennedy, R. (2004). Measurement of retinal vessel widths from fundus images based on 2-D modeling. IEEE Transactions on Medical Imaging, 23(10):1196-1204.

Malerbi, D. A. e Franco, L. J. (1992). Multicenter study of the prevalence of diabetes mellitus and impaired glucose tolerance in the urban brazilian population aged 30-69 yr. Diabetes Care, 15(11):15091516.

Malladi, R., Sethian, J. A. e Vemuri, B. C. (1995). Shape modeling with front propagation: A level set approach. IEEE Transactions on Pattern Analysis and Machine Intelligence, 17(2):158-175.

Mallat, S. e Hwang, W. L. (1992). Singularity detection and processing with wavelets. IEEE Transactions on Information Theory, 38(2):617-643.

Mallat, S. e Zhong, S. (1992). Characterization of signals from multiscale edges. IEEE Transactions on Pattern Analysis and Machine Intelligence, 14(7):710-732.

Manjunath, B. S. e Ma, W. Y. (1996). Texture features for browsing and retrieval of image data. IEEE Transactions on Pattern Analysis and Machine Intelligence, 18(8):837-842. 
Marr, D. e Hildreth, E. (1980). Theory of edge detection. Proceedings of the Royal Society of London. Series B, Biological Sciences, 207:187-217.

Martínez-Pérez, M. E., Hughes, A. D., Stanton, A. V., Thom, S. A., Bharath, A. A. e Parker, K. H. (1999). Retinal blood vessel segmentation by means of scale-space analysis and region growing. In Medical Image Computing and Computer-assisted Intervention - MICCAI, páginas 90-97.

Marčelja, S. (1980). Mathematical description of the responses of simple cortical cells. Journal of the Optical Society of America, 70(11):1297-1300.

MATLAB (2006). Página do MATLAB na MathWorks. Disponível em http://www.mathworks.com/ products/matlab. Acesso em: maio de 2006.

McInerney, T. e Terzopoulos, D. (1996). Deformable models in medical images analysis: a survey. Medical Image Analysis, 1(2):91-108.

McInerney, T. e Terzopoulos, D. (2000). T-snakes: Topology adaptive snakes. Medical Image Analysis, $4: 73-91$.

McQuellin, C. P., Jelinek, H. F. e Joss, G. (2002). Characterisation of fluorescein angiograms of retinal fundus using mathematical morphology: a pilot study. In 5th International Conference on Ophthalmic Photography, página 152, Adelaide.

Mendonça, A. M. e Campilho, A. (2006). Segmentation of retinal blood vessels by combining the detection of centerlines and morphological reconstruction. IEEE Transactions on Medical Imaging, $25: 1200-1213$.

Ministério da Saúde (2000). Estatísticas. Disponível em http://portal.saude.gov.br/portal/ aplicacoes/noticias/noticias_detalhe.cfm?co_seq_noticia=132. Acesso em: maio de 2006.

Murenzi, R. (1990). Ondelettes multidimensionelles et application à l'analyse d'images. Tese de doutorado, Université Catholique de Louvain. 
Nain, D., Yezzi, A. e Turk, G. (2004). Vessel segmentation using a shape driven flow. In Medical Image Computing and Computer-assisted Intervention - MICCAI, páginas 51-59.

Nekovei, R. e Sun, Y. (1995). Back-propagation network and its configuration for blood vessel detection in angiograms. IEEE Transactions on Neural Networks, 6(1):64-72.

Niemeijer, M., Staal, J. J., van Ginneken, B., Loog, M. e Abràmoff, M. D. (2004). Comparative study of retinal vessel segmentation methods on a new publicly available database. In Fitzpatrick, J. M. e Sonka, M., editores, SPIE Medical Imaging, volume 5370, páginas 648-656.

Niemeijer, M., van Ginneken, B., Staal, J. J., Suttorp-Schulten, M. S. A. e Abràmoff, M. D. (2005). Automatic detection of red lesions in digital color fundus photographs. IEEE Transactions on Medical Imaging, 24(5):584-592.

Osareh, A., Mirmehdi, M., Thomas, B. e Markham, R. (2003). Automated identification of diabetic retinal exudates in digital colour images. British Journal of Ophthalmology, 87:1220-1223.

Osareh, A., Mirmehdi, M., Thomas, B. T. e Markham, R. (2002). Classification and localisation of diabetic-related eye disease. In $E C C V$ (4), páginas 502-516.

Pedersen, L., Ersbøll, B., Madsen, K., Grunkin, M., Skands, U., Larsen, M. e Christoffersen, N. (2000). Quantitative measurement of changes in retinal vessel diameter in ocular fundus images. Pattern Recognition Letters, 21(13-14):1215-1223.

Pei, S. C. e Jaw, S. B. (1994). Two-dimensional general fan-type FIR digital filter design. Signal Processing, 37:265-274.

Pinz, A., Bernogger, S., Datlinger, P. e Kruger, A. (1998). Mapping the human retina. IEEE Transactions on Medical Imaging, 17:606-619.

Rioul, O. e Vetterli, M. (1991). Wavelets and signal processing. IEEE Signal Processing Magazine, $8: 14-38$. 
Sagiv, C., Sochen, N. A. e Zeevi, Y. Y. (2002). Gabor features diffusion via the minimal weighted area method. In Energy Minimization Methods in Computer Vision and Pattern Recognition.

Sato, Y., Nakajima, S., Shiraga, N., Atsumi, H., Yoshida, S., Koller, T., Gerig, G. e Kikinis, R. (1998). Three-dimensional multi-scale line filter for segmentation and visualization of curvilinear structures in medical images. Medical Image Analysis, 2(2):143-168.

Schellini, S. A., Silva, M. R. B. M. e Silva, M. A. M. (1994). Diabetes, retinopatia diabética e cegueira. Jornal Brasileiro de Medicina, 67:171-174.

Sinthanayothin, C., Boyce, J. e Williamson, C. T. (1999). Automated localisation of the optic disc, fovea, and retinal blood vessels from digital colour fundus images. British Journal of Ophthalmology, 83:902-910.

Soares, J. V. B., Leandro, J. J. G., Cesar-Jr., R. M., Jelinek, H. F. e Cree, M. J. (2005). Using the 2-D Morlet wavelet with supervised classification for retinal vessel segmentation. In $I V$ Workshop de Teses e Dissertações em Computação Gráfica e Processamento de Imagens, CD-ROM - 18th Brazilian Symposium on Computer Graphics and Image Processing - SIBGRAPI, Natal, RN.

Soares, J. V. B., Leandro, J. J. G., Cesar-Jr., R. M., Jelinek, H. F. e Cree, M. J. (2006). Retinal vessel segmentation using the 2-D Gabor wavelet and supervised classification. IEEE Transactions on Medical Imaging, 25:1214-1222.

Spencer, T., Olson, J. A., McHardy, K. C., Sharp, P. F. e Forrester, J. V. (1996). An image-processing strategy for the segmentation and quantification of microaneurysms in fluorescein angiograms of the ocular fundus. Comput. Biomed. Res., 29(4):284-302.

Staal, J. J., Abràmoff, M. D., Niemeijer, M., Viergever, M. A. e van Ginneken, B. (2004). Ridge based vessel segmentation in color images of the retina. IEEE Transactions on Medical Imaging, 23(4):501-509.

Streeter, L. e Cree, M. J. (2003). Microaneurysm detection in colour fundus images. In Image and Vision Computing New Zealand, páginas 280-284, Palmerston North, Nova Zelândia. 
Sussman, E. J., Tsiaras, W. G. e Soper, K. A. (1982). Diagnosis of diabetic eye disease. Journal of the American Medical Association, 247:3231-3234.

Taylor, H. R. e Keeffe, J. E. (2001). World blindness: a 21st century perspective. British Journal of Ophthalmology, 85:261-266.

Theodoridis, S. e Koutroumbas, K. (1999). Pattern Recognition. Academic Press, EUA, primeira edição.

Thönnes, E., Bhalerao, A., Kendall, W. e Wilson, R. (2002). A Bayesian approach to inferring vascular tree structure from 2D imagery. In Proc. of IEEE International Conference on Image Processing (ICIP), volume 2, páginas 937-940, Rochester, EUA.

Toledo, R., Orriols, X., Binefa, X., Radeva, P., Vitrià, J. e Villanueva, J. (2000). Tracking of elongated structures using statistical snakes. In IEEE Computer Society Conference on Computer Vision and Pattern Recognition (CVPR), volume 1, página 1157.

Tolias, Y. A. e Panas, S. M. (1998). A fuzzy vessel tracking algorithm for retinal images based on fuzzy clustering. IEEE Transactions on Medical Imaging, 17:263-273.

Unser, M. e Aldroubi, A. (1996). A review of wavelets in biomedical applications. Proceedings of the IEEE, 84:626-638.

U.S. National Eye Institute (2006). Photos, Images, and Video. Disponível em http://www.nei.nih . gov/photo/, Acesso em: maio de 2006.

Van De Ville, D., Blu, T. e Unser, M. (2004). Integrated wavelet processing and spatial statistical testing of fMRI data. NeuroImage, 23(4):1472-1485.

Vandergheynst, P. e Gobbers, J.-F. (2002). Directional dyadic wavelet transforms: design and algorithms. IEEE Transactions on Image Processing, 11(4):363-372.

Vasilevskiy, A. e Siddiqi, K. (2002). Flux maximizing geometric flows. IEEE Transactions on Pattern Analysis and Machine Intelligence, páginas 1565-1578. 
Wang, L. e Bhalerao, A. (2003). Model based segmentation for retinal fundus images. In Proc. of Scandinavian Conference on Image Analysis (SCIA), páginas 422-429, Gotemburgo, Suécia.

Wang, Y. e Lee, S. C. (1997). A fast method for automated detection of blood vessels in retinal images. In Conf. Record of the Thirty-First Asilomar Conference on Signals, Systems 85 Computers, volume 2, páginas 1700-1704.

Wild, S., Roglic, G., Green, A., Sicree, R. e King, H. (2004). Global prevalence of diabetes: estimates for the year 2000 and projections for 2030. Diabetes Care, 27(5):1047-1053.

Wong, T. Y., Rosamond, W., Chang, P. P., Couper, D. J., Sharrett, A. R., Hubbard, L. D., Folsom, A. R. e Klein, R. (2005). Retinopathy and risk of congestive heart failure. Journal of the American Medical Association, 293(1):63-69.

Wood, S. L., Qu, G. e Roloff, L. W. (1995). Detection and labeling of retinal vessels for longitudinal studies. In Proc. of IEEE International Conference on Image Processing (ICIP), volume 3, Washington, DC, EUA.

Yang, G. e Stewart, C. V. (2004). Covariance-driven mosaic formation from sparsely-overlapping image sets with application to retinal image mosaicing. In CVPR04, volume 1, páginas 804-810.

Zana, F. e Klein, J.-C. (1999). A multimodal registration algorithm of eye fundus images using vessels detection and hough transform. IEEE Transactions on Medical Imaging, 18:419-428.

Zana, F. e Klein, J.-C. (2001). Segmentation of vessel-like patterns using mathematical morphology and curvature evaluation. IEEE Transactions on Image Processing, 10:1010-1019.

Zhou, L., Rzeszotarski, M. S., Singerman, L. J. e Chokreff, J. M. (1994). The detection and quantification of retinopathy using digital angiograms. IEEE Transactions on Medical Imaging, 13(4):619-626. 